Felipe de Souza Dias dos Santos Vilhena

\title{
ESTUDO DA FORMAÇÃO DE COMPLEXOS BINÁRIOS E TERNÁRIOS DO ÍON Cu(II) COM ALGUNS DIPEPTÍDEOS E AMINOÁCIDOS
}

Tese apresentada como requisito parcial para obtenção do grau de Doutor pelo Programa de PósGraduação em Química do Departamento de Química da PUC-Rio.

Orientador: Prof. Nicolás Adrián Rey Co-orientador: Prof. Fabio da Silva Miranda 
Felipe de Souza Dias dos Santos Vilhena

\section{ESTUDO DA FORMAÇÃO DE COMPLEXOS BINÁRIOS E TERNÁRIOS DO ÍON Cu(II) COM ALGUNS DIPEPTÍDEOS E AMINOÁCIDOS}

Tese apresentada como requisito parcial para obtenção do grau de Doutor pelo Programa de PósGraduação em Química do Departamento de Química da PUC-Rio. Aprovada pela Comissão Examinadora abaixo assinada.

Prof. Nicolás Adrián Rey

Orientador

Departamento de Química - PUC-Rio

Prof. Fabio da Silva Miranda

Co-orientador Instituto de Química - UFF

Prof. Odivaldo Cambraia Alves Instituto de Química - UFF

Prof. Otávio Versiane Cabral IFRJ

Dra. Luciana Dornelas Pinto Sem vínculo

Prof. José Eugenio Leal Coordenador Setorial de Pós-Graduação do Centro Técnico Científico - PUC-Rio 
Todos os direitos reservados. É proibida a reprodução total ou parcial do trabalho sem autorização da universidade, do autor e dos orientadores.

\section{Felipe de Souza Dias dos Santos}

\section{Vilhena}

Graduou-se em Química na UFF em 2005. Concluiu o mestrado em Química pela PUC-Rio em 2008. Recebeu o prêmio de Bolsa Nota 10 da FAPERJ para Doutorado. Atua na área de Química, com ênfase em Bioinorgânica e cálculos de constantes de estabilidade e especiação via DFT.

Ficha Catalográfica

\footnotetext{
Vilhena, Felipe de Souza Dias dos Santos

Estudo da formação de complexos binários e ternários do íon $\mathrm{Cu}$ (II) com alguns dipeptídeos e aminoácidos/ Felipe de Souza Dias dos Santos Vilhena; orientador: Nicolás Adrián Rey; co-orientador: Fabio da Silva Miranda. - Rio de Janeiro PUC, Departamento de Química, 2012.

165 f. : il. ; $30 \mathrm{~cm}$

Tese (doutorado) - Pontifícia Universidade Católica do Rio de Janeiro, Departamento de Química.

Inclui referências bibliográficas.

1. Química - Teses. 2. Bioinorgânica. 3. Alzheimer. 4. Complexos de cobre. 5. Dipeptídeos. 6. Aminoácidos. 7. DFT. I. Rey, Nicolás Adián. II. Miranda, Fabio da Silva. III. Pontifícia Universidade Católica do Rio de Janeiro. Departamento de Química. IV. Título.
} 
Dedico a minha mãe Berta e ao meu falecido pai João. 


\section{Agradecimentos}

A minha falecida orientadora professora Judith Felcman, por ter me aceito como aluno de Doutorado. Agradecimento especial:

"Não tenho como retribuir a orientação que você me deu. Aprendi que ser um profissional vai além do conhecimento inerente de cada profissão. Você sempre fará parte fundamental da minha carreira profissional. Sua postura, seu profissionalismo e sua sabedoria sempre farão parte da minha formação."

À FAPERJ e à PUC-Rio, pelos auxílios concedidos, sem os quais este trabalho não poderia ter sido realizado.

Ao professor Cambraia pelas medidas de RPE e pelas simulações dos espectros.

Aos professores do Departamento de Química: Isabel Moreira, André, Pércio e Nicolás.

Ao professor Fabio da Silva Miranda pela amizade e pelo treinamento em Química Computacional.

Ao professor Bruno Szpoganicz pelo treinamento no programa de cálculos de constantes de equilíbrio. 


\section{Resumo}

Vilhena, Felipe de Souza Dias dos Santos; Rey, Nicolás Adrián. Estudo da formação de complexos binários e ternários do íon $\mathbf{C u}(\mathrm{II}) \mathrm{com}$ alguns dipeptídeos e aminoácidos. Rio de Janeiro, 2012. 165p. Tese de Doutorado - Departamento de Química, Pontifícia Universidade Católica do Rio de Janeiro.

Um grande número de complexos de cobre(II) tendo como ligantes compostos biológicos têm sido utilizados como modelos para o entendimento das diversas reações que ocorrem in vivo. Diversas desordens neurodegenerativas são caracterizadas pela presença anormal de proteínas no sistema nervoso central que possuem uma alta afinidade pelo íon cobre(II). Essa coordenação do metal à proteínas favorece o processo de deposição e associado ocorre a produção em excesso de espécies reativas de oxigênio ( $\mathrm{ROS}$ - reactive oxygen species). A metionina é um antioxidante presente no meio biológico que pode se ligar ao cobre e prevenir os danos oxidativos. No presente trabalho, estudamos em solução aquosa, os complexos binários $\mathrm{Cu}(\mathrm{II}): \mathrm{L}_{1}$ e $\mathrm{Cu}(\mathrm{II}): \mathrm{L}_{2}$ e o complexo ternário $\mathrm{Cu}(\mathrm{II}): \mathrm{L}_{1}: \mathrm{L}_{2}\left(\mathrm{~L}_{1}=\right.$ GlyGly e $\left.\mathrm{L}_{2}=\mathrm{Met}\right)$ a $25{ }^{\circ} \mathrm{C}$ e $\mu=0,1 \mathrm{~mol} \mathrm{~L}^{-1}$. As constantes de formação dos complexos foram calculadas utilizando o programa BEST7. Os modos de coordenação dos ligantes nos complexos de $\mathrm{Cu}$ (II) foram investigados por cálculos DFT utilizando o programa TURBOMOLE 6.1. Foi utilizado o funcional PBE empregando a aproximação da resolução da identidade (RI-J) e com o conjunto de bases def2-SVP. Os efeitos do solvente foram incluídos através do modelo de solvatação COSMO. Os resultados DFT mostraram comportamento bidentado da glicilglicina na espécie $\mathrm{Cu}\left(\mathrm{H}_{-1}\right.$ GlyGly), sem a participação do oxigênio do grupo carboxílico na esfera de coordenação do metal. O modelo de cluster-contínuo foi utilizado para obter, para os complexos mais estáveis, as energias livres em fase gasosa e em solução aquosa através dos métodos DFT: B3LYP/def2/TZVP e PBE0/def2-TZVP. Para os complexos mais estáveis foi incluída a segunda camada de solvatação (36 moléculas de água) para verificar a interferência de moléculas explícitas do solvente nos cálculos. Os resultados mostraram comportamento monodentado do ligante glicilglicina no complexo $\left[\mathrm{Cu}(\mathrm{GlyGly})\left(\mathrm{H}_{2} \mathrm{O}\right)_{36}\right]^{+}$, sem a participação do oxigênio peptídico na esfera de coordenação do centro metálico. Observou-se que os clusters assumem diferentes geometrias: octaédrica $\left(\left[\mathrm{Cu}(\mathrm{Met})\left(\mathrm{H}_{2} \mathrm{O}\right)_{36}\right]^{+}\right)$, pirâmide de base quadrada 
$\left(\left[\mathrm{Cu}(\mathrm{GlyGly})\left(\mathrm{H}_{2} \mathrm{O}\right)_{36}\right]^{+}, \quad\left[\mathrm{Cu}\left(\mathrm{H}_{-1} \mathrm{GlyGly}\right)\left(\mathrm{H}_{2} \mathrm{O}\right)_{36}\right], \quad\left[\mathrm{Cu}(\mathrm{Met})(\mathrm{OH})\left(\mathrm{H}_{2} \mathrm{O}\right)_{36}\right]\right.$, $\left[\mathrm{Cu}(\mathrm{Met})(\mathrm{OH})_{2}\left(\mathrm{H}_{2} \mathrm{O}\right)_{36}\right]^{-}, \quad\left[\mathrm{Cu}(\mathrm{HGlyGly})(\mathrm{Met})\left(\mathrm{H}_{2} \mathrm{O}\right)_{36}\right]$, $\left[\mathrm{Cu}(\mathrm{GlyGly})(\mathrm{Met})\left(\mathrm{H}_{2} \mathrm{O}\right)_{36}\right]^{-}$e $\left.\left[\mathrm{Cu}(\mathrm{GlyGly})(\mathrm{Met})(\mathrm{OH})\left(\mathrm{H}_{2} \mathrm{O}\right)_{35}\right]^{2-}\right)$ e quadrado distorcido $\left(\left[\mathrm{Cu}(\mathrm{GlyGly})(\mathrm{OH})\left(\mathrm{H}_{2} \mathrm{O}\right)_{35}\right]^{-}\right)$. Todos os clusters apresentaram uma configuração eletrônica do estado fundamental $t_{2 g}^{6} d_{z^{2}}^{2} d_{x^{2}-y^{2}}^{1}$ o que concorda com a distorção Jahn-Teller. Nas doenças neurodegenerativas o pH fisiológico é levemente acidificado. Na espécie ternária $\left[\mathrm{Cu}(\mathrm{GlyGly})(\mathrm{Met})\left(\mathrm{H}_{2} \mathrm{O}\right)_{36}\right]^{-}$, que é formada em pH 7, o enxofre não faz parte da esfera de coordenação do cobre, indicando que ele pode exercer uma ação antioxidante em sistemas biológicos sob condições de estresse oxidativo.

\section{Palavras-chave}

Bioinorgânica; Alzheimer; DFT; constantes de equilíbrio; complexos de cobre(II); dipeptídeos; aminoácidos. 


\section{Abstract}

Vilhena, Felipe de Souza Dias dos Santos; Rey, Nicolás Adrián. Study of the formation of binary and ternary complexes of $\mathbf{C u}$ (II) ion with some dipeptides and amino acids. Rio de Janeiro, 2012. 165p. DSc. Thesis Departamento de Química, Pontifícia Universidade Católica do Rio de Janeiro.

A great number of copper(II) complexes that have as ligands biological compounds have been used as models for the understanding of several reactions that occur in vivo. Several neurodegenerative disorders are characterized by the abnormal presence of proteins in the central nervous system that have a high affinity for the copper(II) ion. This coordination of metal to proteins favor the deposition process and associated the production in excess of reactive oxygen species (ROS) occurs. The methionine is an antioxidant present in the biological medium that could bind to copper and prevent the oxidative damages. In the present work we studied in aqueous solution the binary complexes $\mathrm{Cu}(\mathrm{II}): \mathrm{L}_{1}$ and $\mathrm{Cu}(\mathrm{II}): \mathrm{L}_{2}$ and the ternary complex $\mathrm{Cu}(\mathrm{II}): \mathrm{L}_{1}: \mathrm{L}_{2}\left(\mathrm{~L}_{1}=\right.$ GlyGly and $\left.\mathrm{L}_{2}=\mathrm{Met}\right)$ at 25 ${ }^{\circ} \mathrm{C}$ and $\mu=0.1 \mathrm{~mol} \mathrm{~L}^{-1}$. The binding constants of the complexes were determined using the BEST7 program. The coordination modes of the ligands in the $\mathrm{Cu}(\mathrm{II})$ complexes were investigated by DFT calculation using the TURBOMOLE 6.1 program. The PBE functional was used employing the resolution of identity approximation (RI-J) and with the def2-SVP basis set. The solvent effects were included through the COSMO solvation model. The DFT results showed bidentate behavior of the glycylglycine in the $\mathrm{Cu}\left(\mathrm{H}_{-1}\right.$ GlyGly) species without the participation of the oxygen from the carboxylic group in the metal coordination sphere. The cluster-continuum model was used to obtain for the more stable complexes the free energies in gas phase and in the aqueous solution through DFT methods: B3LYP/def2/TZVP and PBE0/def2-TZVP. The second solvation shell (36 water molecules) was included in the more stable complexes to verify the interference of solvent explicit molecules in the calculation. The results showed monodentate behavior of the glycylglycine ligand in the complex $\left[\mathrm{Cu}(\mathrm{GlyGly})\left(\mathrm{H}_{2} \mathrm{O}\right)_{36}\right]^{+}$, without the participation of the peptidic oxygen in coordination sphere of metallic centre. It was observed that the clusters assume different geometries: octahedral $\left(\left[\mathrm{Cu}(\mathrm{Met})\left(\mathrm{H}_{2} \mathrm{O}\right)_{36}\right]^{+}\right)$, square pyramid $\left(\left[\mathrm{Cu}(\mathrm{GlyGly})\left(\mathrm{H}_{2} \mathrm{O}\right)_{36}\right]^{+}, \quad\left[\mathrm{Cu}\left(\mathrm{H}_{-1} \mathrm{GlyGly}\right)\left(\mathrm{H}_{2} \mathrm{O}\right)_{36}\right], \quad\left[\mathrm{Cu}(\mathrm{Met})(\mathrm{OH})\left(\mathrm{H}_{2} \mathrm{O}\right)_{36}\right]\right.$, 
$\left[\mathrm{Cu}(\mathrm{Met})(\mathrm{OH})_{2}\left(\mathrm{H}_{2} \mathrm{O}\right)_{36}\right]^{-}$,

[Cu(HGlyGly)(Met) $\left.\left(\mathrm{H}_{2} \mathrm{O}\right)_{36}\right]$,

$\left[\mathrm{Cu}(\mathrm{GlyGly})(\mathrm{Met})\left(\mathrm{H}_{2} \mathrm{O}\right)_{36}\right]^{-}$and $\left.\left[\mathrm{Cu}(\mathrm{GlyGly})(\mathrm{Met})(\mathrm{OH})\left(\mathrm{H}_{2} \mathrm{O}\right)_{35}\right]^{2-}\right)$ and distorted square $\left(\left[\mathrm{Cu}(\mathrm{GlyGly})(\mathrm{OH})\left(\mathrm{H}_{2} \mathrm{O}\right)_{35}\right]^{-}\right)$. All the clusters presented an electronic configuration of ground state $t_{2 g}^{6} d_{z^{2}}^{2} d_{x^{2}-y^{2}}^{1}$ that agree with the Jahn-Teller distortion. In the neurodegenerative diseases the physiologic $\mathrm{pH}$ is slightly acidified. In the ternary species $\left[\mathrm{Cu}(\mathrm{GlyGly})(\mathrm{Met})\left(\mathrm{H}_{2} \mathrm{O}\right)_{36}\right]^{-}$, that is formed in $\mathrm{pH}$ 7 , the sulfur is not part of the coordination sphere of copper, indicating that it could exert an antioxidant action in biological systems under oxidative stress conditions.

\section{Keywords}

Bioinorganic; Alzheimer; DFT; equilibrium constants; copper(II) complexes; dipeptidies; amino acids. 


\section{Sumário}

1. Introdução 23

1.1 Introdução 23

1.2 Cobre em sistemas biológicos 25

1.3 Modos de coordenação do cobre(II) 28

$\begin{array}{lll}1.4 & \text { Clusters Cu(II)-água } & 29\end{array}$

1.5 Complexos de $\mathrm{Cu}$ (II) com alguns ligantes biológicos no estado sólido $\quad 37$

$\begin{array}{lll}1.6 & \text { Estresse oxidativo } & 39\end{array}$

$\begin{array}{lll}1.7 & \text { Metionina } & 41\end{array}$

1.8 A doença de Alzheimer (DA) 43

1.9 Modelos de solvatação $\quad 49$

1.10 Modelo do cluster contínuo 51

2. Objetivos 54

3. Justificativa e relevância $\quad 55$

4. Parte experimental 56

4.1 Materiais e Métodos $\quad 56$

$\begin{array}{lll}4.2 & \text { Equipamento } & 57\end{array}$

$\begin{array}{lll}4.3 & \text { Procedimentos } & 57\end{array}$

4.3.1 Titulações dos ligantes puros $\quad 57$

4.3.2 Titulação dos sistemas binários de $\mathrm{Cu}(\mathrm{II}): \mathrm{L}(\mathrm{L}=$ GlyGly e Met) na proporção metal:ligante 1:1 57

4.3.3 Titulação dos sistemas ternários $C u(I I): L_{1}: L_{2}\left(L_{1}=\right.$ GlyGly; $L_{2}=$ Met) na proporção 1:1:1 57

4.3.4 Cálculos teóricos $\quad 58$

5. Resultados e Discussões $\quad 59$

5.1 Modos de coordenação dos dipetídeos em complexos binários de $\mathrm{Cu}(\mathrm{II})$, em solução aquosa 59

5.2 Estudos potenciométricos dos sistemas binários Cu:GlyGly e Cu:Met e do sistema ternário Cu:GlyGly:Met a $25^{\circ} \mathrm{C}, \mu=0,1 \mathrm{~mol} \mathrm{~L}^{-1}$ $\left(\mathrm{KNO}_{3}\right)$

5.2.1 Estudo potenciométrico do sistema binário $\mathrm{Cu}$ :GlyGly na razão metal:ligante $1: 1$ a $25^{\circ} \mathrm{C}, \mu=0,1 \mathrm{~mol} \mathrm{~L}^{-1}\left(\mathrm{KNO}_{3}\right)$

5.2.2 Estudo potenciométrico do sistema binário $\mathrm{Cu}$ :Met na razão metal:ligante $1: 1$ a $25^{\circ} \mathrm{C}, \mu=0,1 \mathrm{~mol} \mathrm{~L}^{-1}\left(\mathrm{KNO}_{3}\right)$

5.2.3 Estudo potenciométrico do sistema ternário Cu:GlyGly:Met na razão metal: $\mathrm{L}_{1}: \mathrm{L}_{2}$ de $1: 1: 1$ a $25 \stackrel{\circ}{\circ} \mathrm{C}, \mu=0,1 \mathrm{~mol} \mathrm{~L}^{-1}\left(\mathrm{KNO}_{3}\right)$

5.3 Estudos DFT de sistemas binários e ternário de cobre(II) (Cu:GlyGly, Cu:Met e Cu:GlyGly:Met) 
5.3.1 Análise dos possíveis modos de coordenação da glicilglicina (GlyGly) ao íon cobre(II) em solução aquosa (RI-PBE/def2-SVP/ COSMO)

5.3.2 Otimização e parâmetros geométricos da espécie $\mathrm{CuL}^{+}(\mathrm{L}=$ GlyGly) obtidos pela metodologia DFT (RI-PBE/def2-SVP/COSMO)

5.3.3 Otimização e parâmetros geométricos da espécie $\mathrm{Cu}\left(\mathrm{H}_{-1} \mathrm{~L}\right)$ $\left(\mathrm{H}_{-1} \mathrm{~L}=\right.$ dipeptídeo glicilglicina desprotonado no nitrogênio peptídico) obtidos pela metodologia DFT (RI-PBE/def2-SVP/COSMO)

5.3.4 Otimização e parâmetros geométricos da espécie $\mathrm{Cu}\left(\mathrm{H}_{-1} \mathrm{~L}\right)(\mathrm{OH})^{-} \quad\left(\mathrm{H}_{-1} \mathrm{~L}=\right.$ dipeptídeo glicilglicina desprotonado no nitrogênio peptídico) obtidos pela metodologia DFT (RI-PBE/def2SVP/COSMO)

5.3.5 Análise dos possíveis modos de coordenação da metionina (Met) ao íon cobre(II) em solução aquosa (RI-PBE/def2-SVP/COSMO) 91

5.3.6 Otimização e parâmetros geométricos da espécie $\mathrm{CuL}^{+}$ ( $\mathrm{L}=$ Met) obtidos pela metodologia DFT (RI-PBE/def2-SVP/COSMO)

5.3.7 Otimização e parâmetros geométricos da espécie $\operatorname{CuL}(\mathrm{OH})(\mathrm{L}=$ Met) obtidos pela metodologia DFT (RI-PBE/def2-SVP/COSMO)

5.3.8 Otimização e parâmetros geométricos da espécie $\mathrm{CuL}(\mathrm{OH})_{2}{ }^{-}$ $(\mathrm{L}=\mathrm{Met})$ obtidos pela metodologia DFT (RI-PBE/def2-SVP/COSMO) 103 5.3.9 Análise dos possíveis modos de coordenação dos ligantes GlyGly e Met no complexo ternário de cobre(II) em solução aquosa (RI-PBE/def2-SVP/COSMO)

5.3.10 Otimização e parâmetros geométricos da espécie $\mathrm{CuHL}_{1} \mathrm{~L}_{2}$ $\left(\mathrm{HL}_{1}=\right.$ dipeptídeo glicilglicina protonado e $\mathrm{L}_{2}=$ metionina) obtidos pela metodologia DFT (RI-PBE/def2-SVP/COSMO)

5.3.110timização e parâmetros geométricos da espécie $\mathrm{CuL}_{1} \mathrm{~L}_{2}^{-}\left(\mathrm{L}_{1}=\right.$ glicilglicina e $\mathrm{L}_{2}=$ metionina) obtidos pela metodologia DFT (RI-PBE/ def2- SVP/COSMO)

5.3.12 Otimização e parâmetros geométricos da espécie $\mathrm{CuL}_{1} \mathrm{~L}_{2}(\mathrm{OH})^{2-}$ $\left(\mathrm{L}_{1}=\right.$ glicilglicina e $\mathrm{L}_{2}=$ metionina) obtidos pela metodologia DFT (RI$\mathrm{PBE} /$ def2-SVP/COSMO)

5.4 Estudos termodinâmicos DFT para os complexos formados nos sistemas binários Cu:GlyGly e Cu:Met e no sistema ternário Cu:GlyGly:Met 
5.4.1 Cálculos termodinâmicos e valores de pKa's dos complexos [Cu(GlyGly) $\left.\left(\mathrm{H}_{2} \mathrm{O}\right)_{5}\right]^{+}$e $\left[\mathrm{Cu}\left(\mathrm{H}_{-1}\right.\right.$ GlyGly) $\left.\left(\mathrm{H}_{2} \mathrm{O}\right)_{5}\right]$ com os funcionais B3LYP e PBE0 e conjunto de bases def2-TZVP

5.4.2 Cálculos termodinâmicos e valores de pKa's dos complexos $\left[\mathrm{Cu}(\mathrm{Met})\left(\mathrm{H}_{2} \mathrm{O}\right)_{4}\right]^{+}$e $\left[\mathrm{Cu}(\mathrm{Met})\left(\mathrm{H}_{2} \mathrm{O}\right)_{3}(\mathrm{OH})\right]$ com os funcionais B3LYP e PBE0 e conjunto de bases def2-TZVP

5.4.3 Cálculos termodinâmicos e de valores de pKa's dos complexos [Cu(HGlyGly)(Met) $\left(\mathrm{H}_{2} \mathrm{O}\right)_{2}$ ] e [Cu(GlyGly)(Met) $\left(\mathrm{H}_{2} \mathrm{O}\right)_{2}$ ] com os funcionais B3LYP e PBE0 e conjunto de bases def2-TZVP

5.5 Otimização dos clusters [Cu(GlyGly) $\left.\left(\mathrm{H}_{2} \mathrm{O}\right)_{36}\right]^{+}$, [Cu( $\mathrm{H}_{-1}$ GlyGly) $\left(\mathrm{H}_{2} \mathrm{O}\right)_{36}$ ], [Cu( $\mathrm{H}_{-1}$ GlyGly) $\left.(\mathrm{OH})\left(\mathrm{H}_{2} \mathrm{O}\right)_{35}\right]^{-}$, [Cu(Met) $\left.\left(\mathrm{H}_{2} \mathrm{O}\right)_{36}\right]^{+}$, [Cu(Met) $(\mathrm{OH})\left(\mathrm{H}_{2} \mathrm{O}\right)_{35}$ ], [Cu(Met) $\left.(\mathrm{OH})_{2}\left(\mathrm{H}_{2} \mathrm{O}\right)_{34}\right]^{-}$, [Cu(HGlyGly)(Met) $\left(\mathrm{H}_{2} \mathrm{O}\right)_{36}$ ], [Cu(GlyGly)(Met) $\left.\left(\mathrm{H}_{2} \mathrm{O}\right)_{36}\right]^{-}$e [Cu(GlyGly)(Met) $\left.(\mathrm{OH})\left(\mathrm{H}_{2} \mathrm{O}\right)_{35}\right]^{2-}$ por cálculos B3LYP/def2-TZVP/COSMO

6. Conclusões

7. Referências bibliográficas

8. Anexos 


\section{Índice de Figuras}

Figura 1. Estrutura cristalina da proteína plastocianina (Protein data bank; PDB) e uma visão ampliada da estrutura eletrônica do sítio ativo.Figura reproduzida com permissão da referência 5

Figura 2. Papel dos ligantes na função biológica de enzimas. (a) Interação alostérica entre o sítio ativo e o substrato em diferentes subunidades na enzima ceruloplasmina; (b) Organização dos resíduos que constituem o sítio catalítico de uma enzima com mais de um centro metálico; (c) Locais de reconhecimento da superfície e mecanismo de super troca para a transferência de elétrons; (d) Papel do sitio ativo para a formação dos canais de acesso ao substrato; (e) ambiente hidrofóbico; (f) Bolsa para a ligação do substrato próximo do sitio ativo metálico; (g) Resíduos de carga específica e ligações de hidrogênio próximo ao sitio metálico, necessários para exercer o papel catalítico da enzima e (h) Geometria específica do sitio metálico na qual pode ativar a enzima. Figura reproduzida com permissão da referência 5

Figura 3. Diagrama de orbitais moleculares do desdobramento do campo Cristalino de complexos $d^{\theta}$ sob efeito da distorção Janh-Teller com elongamento dos ligantes nas posições axiais. Figura reproduzida com permissão da referência 25

Figura 4. Estruturas otimizadas em fase gasosa (B3LYP/LACV3P+/6$311++(\mathrm{d}, \mathrm{p}))$ do complexo $\left[\mathrm{Cu}\left(\mathrm{H}_{2} \mathrm{O}\right)_{\mathrm{n}}\right]^{2+}(\mathrm{n}=4$ - 18) (átomos; cinza: cobre; vermelho: oxigênio e branco: hidrogênio). Figura reproduzida permissão da referência 25

Figura 5. Orbital LUMO e densidade de spin para o complexo $\left[\mathrm{Cu}\left(\mathrm{H}_{2} \mathrm{O}\right)_{10}\right]^{2+}$ (Figura 4. 10w-C). A densidade eletrônica é localizada preferencialmente no orbital $3 d_{\mathrm{x}^{2}-\mathrm{y}^{2}}$ e nos orbitais $\sigma$ dos pares isolados. Figura reproduzida com permissão da referência 25

Figura 6. Formação de espécies reativas de oxigênio formadas no so decorrer do processo de redução do oxigênio molecular $\mathrm{O}_{2}$ a $\mathrm{H}_{2} \mathrm{O}$

Figura 7. Dano oxidativo causado pelo ataque das espécies reativas de oxigênio (EROs) [78]

Figura 8. Processo de oxidação reversível da metionina, forma sulfóxido-metionina e sulfona devido ao ataque de espécies reativas de oxigênio

Figura 9. Processo proteolítico da proteína precursora amilóide (APP) ocasionado pela ação das secretases. A proteína APP é uma glicoproteína transmembrânicaipo-I. Figura reproduzida com permissão da referência 91 
Figura 10. Modelo para o estresse oxidativo causado por radicais livres associado ao peptídeo $A \beta$ na doença de Alzheimer. O peptídeo $A \beta$ inicia a formação de radicais livres os quais reagem rapidamente com várias espécies na membrana plasmática causando a oxidação de proteínas e a peroxidação lipídica. Produtos tóxicos da peroxidação lipídica, tais como HNE e acroleina, tendo meia-vida grandes em relação aos radicais livres, migram para diferentes partes dos neurônios causando várias alterações deletérias nas funções celulares, especialmente aumento expressivo na concentração de $\mathrm{Ca}^{2+}$ intracelular, levando a última instância a morte do neurônio.

Figura adaptada da referência 132

Figura 11. (a) Principais resíduos de aminoácidos do peptídeo $A \beta$ $\left(\mathrm{His}^{6} \mathrm{Tyr}^{10} \mathrm{His}^{13} \mathrm{His}^{14}\right.$ ) que acredita-se estarem envolvidos na coordenação a metais; (b) Modelo da coordenação do $\mathrm{Cu}^{2+}$ ao peptídeo $A \beta-42$. A coordenação envolve o oxigênio fenol do resíduo tirosina e os nitrogênios do anel imidazol dos resíduos de histidina em uma geometria quadrado planar. O modelo ilustra a geometria de coordenação do primeiro equivalente de cobre em $\mathrm{pH}$ fisiológico. A coordenação em elevados valores de $\mathrm{pH}$ provavelmente envolva a coordenação de grupos amida da cadeia do peptídeo. Figura reproduzida com permissão da referência 147

Figura 12. Cavidade do soluto para uma proteína cambrina com a média da área mapeada de cada tesserae de 0,4 A. Figura adaptada da referência 148

Figura 13. Modos de coordenação dos dipeptídeos que não possuem cadeia lateral com átomos com a capacidade coordenante. $\mathrm{Na}$ faixa de $\mathrm{pH}$ de 3 - 5 forma-se a espécie $\mathrm{CuL}^{+}$, na faixa de $\mathrm{pH} 5$ - 9 forma-se a espécie $\mathrm{Cu}\left(\mathrm{H}_{-1} \mathrm{~L}\right)$ e em valores de $\mathrm{pH}>9$ forma-se o complexo hidrolisado $\mathrm{Cu}\left(\mathrm{H}_{-1} \mathrm{~L}\right)(\mathrm{OH})$ -

Figura 14. Espectros de absorção na região do visível para o sistema Cu:GlyGly na proporção metal:ligante $1: 1\left(\left[\mathrm{Cu}^{2+}\right]=1,0 \times 10^{-3} \mathrm{~mol} \mathrm{~L}^{-1}\right.$, [GlyGly] $=1,0 \times 10^{-3} \mathrm{~mol} \mathrm{~L}^{-1}, \mu=0,1 \mathrm{~mol} \mathrm{~L}^{-1}, 25 \stackrel{\circ}{\circ}$

Figura 15. Espectro de infravermelho do sistema Cu:GlyGly na proporção metal:ligante $1: 1$ em $\mathrm{D}_{2} \mathrm{O}$ na concentração de $0,2 \mathrm{~mol} \mathrm{~L}^{-1}$; (a) $\mathrm{pH}=3$; (b) $\mathrm{pH}=4,5$; (c) $\mathrm{pH}=7$ e (d) $\mathrm{pH}=9$

Figura 16. Espectro de RPE a $298 \mathrm{~K}$ do sistema binário Cu:GlyGly na proporção metal:ligante 1:1 em diferentes valores de $\mathrm{pH}$ : (a) 4, (b) 5 , (c) 6 , (d) 7 e (e) 9

Figura 17. Curva de titulação potenciométrica para o sistema binário $\mathrm{Cu}: \mathrm{L}\left(\mathrm{L}=\right.$ GlyGly) na proporção metal:ligante $1: 1$ a $25^{\circ} \mathrm{C}, \mu=0,1 \mathrm{~mol}$ $\mathrm{L}^{-1}\left(\mathrm{KNO}_{3}\right)$ 
Figura 18. Diagrama de distribuição de espécies em função do $\mathrm{pH}$ para o sistema binário Cu:L ( $\mathrm{L}=$ GlyGly) obtido com auxílio do programa SPECIES [166]

Figura 19. Curva de titulação potenciométrica para o sistema binário Cu:L $\left(\mathrm{L}=\right.$ Met) na proporção metal:ligante $1: 1$ a $25^{\circ} \mathrm{C}, \mu=0,1 \mathrm{~mol} \mathrm{~L}^{-1}$ $\left(\mathrm{KNO}_{3}\right)$

Figura 20. Diagrama de distribuição de espécies em função do $\mathrm{pH}$ para o sistema binário $\mathrm{Cu}: \mathrm{L}(\mathrm{L}=\mathrm{Met})$ obtido com auxílio do programa SPECIES [166]

Figura 21. Curva de titulação potenciométrica para os sistema ternário $\mathrm{Cu}(\mathrm{II}): \mathrm{L}_{1}: \mathrm{L}_{2}\left(\mathrm{~L}_{1}=\right.$ GlyGly e $\mathrm{L}_{2}=$ Met) na proporção metal ligante 1:1:1 $\left(\mu=0,1 \mathrm{~mol} \mathrm{~L}-1,25^{\circ} \mathrm{C}\right)$

Figura 22. Diagrama de distribuição de espécies em função do $\mathrm{pH}$ para o sistema ternário $C u(I I): L_{1}: L_{2}\left(L_{1}=\right.$ GlyGly e $L_{2}=$ Met $)$ obtido com auxílio do programa SPECIES [166]

Figura 23. Possíveis modos de coordenação da glicilglicina ao íon cobre(II), em solução aquosa, formando a espécie $\mathrm{CuL}^{+}(\mathrm{L}=\mathrm{GlyGly})$ :

(a) $\mathrm{N}_{\text {amino }} \mathrm{O}_{\text {pept }}$; (b) $\mathrm{N}_{\text {amino }}$ e (c) $\mathrm{O}_{\text {carbox }}(\mathrm{RI}-\mathrm{PBE} /$ def2-SVP/COSMO) SVP/COSMO)

Figura 24. Possíveis modos de coordenação do ligante glicilglicina ao íon cobre(II), em solução aquosa, formando a espécie $\mathrm{Cu}\left(\mathrm{H}_{-1} \mathrm{~L}\right)\left(\mathrm{H}_{-1} \mathrm{~L}\right.$ = dipeptídeo desprotonado no nitrogênio peptídico). Sistema coordenante da geometria de partida: (a) $\mathrm{N}_{\text {amino }} \mathrm{N}_{\text {pept }} \mathrm{O}_{\text {carbox; }}$ (b) $\mathrm{N}_{\text {amino }} \mathrm{N}_{\text {pept }}$; (c) $\mathrm{N}_{\text {pept }} \mathrm{O}_{\text {carbox }}$; (d) $\mathrm{N}_{\text {amino }} \mathrm{NH}_{\text {pept }} \mathrm{O}_{\text {carbox }}(\mathrm{OH}$ na posição equatorial trans ao nitrogênio peptídico); (e) $\mathrm{N}_{\text {amino }} \mathrm{NH}_{\text {pept }}(\mathrm{OH}$ na posição equatorial trans ao nitrogênio peptídico; (f) $\mathrm{N}_{\text {amino }} \mathrm{O}_{\text {pept }}(\mathrm{OH}$ na posição equatorial trans ao nitrogênio do grupo amino) e (g) $\mathrm{N}_{\text {amino }} \mathrm{O}_{\text {pept }}(\mathrm{OH}$ na posição equatorial trans ao oxigênio peptídico) (RI$\mathrm{PBE} / \mathrm{def} 2-\mathrm{SVP} / \mathrm{COSMO})$

Figura 25. Possíveis modos de coordenação do dipeptídeo glicilglicina ao íon cobre(II), em solução aquosa, formando a espécie $\mathrm{Cu}\left(\mathrm{H}_{\text {. }}\right.$ $\left.{ }_{1} \mathrm{~L}\right)(\mathrm{OH})^{-}\left(\mathrm{H}_{-1} \mathrm{~L}=\right.$ dipeptídeo desprotonado no nitrogênio peptídico): (a) desprotonação da água na posição trans ao nitrogênio do grupo amino; (b) desprotonação da água na posição trans ao nitrogênio peptídico e (c) desprotonação da água na posição axial (RI-PBE/def2SVP/COSMO)

Figura 26. Estrutura otimizada da espécie $\mathrm{CuL}^{+}(\mathrm{L}=\mathrm{GlyGly})$ obtida com a presença de cinco moléculas de água (RI-PBE/def2-SVP/ COSMO) 
Figura 27. Distribuição de densidade de spin da espécie $\mathrm{CuL}^{+}(\mathrm{L}=$ glicilglicina) a partir de simulação B3LYP/def2-TZVP/COSMO como isosuperfície de 0,002 a.u.

Figura 28. Estrutura otimizada da espécie $\mathrm{Cu}\left(\mathrm{H}_{-1} \mathrm{~L}\right)(\mathrm{H}-1 \mathrm{~L}=$ dipeptídeo glicilglicina desprotonado no nitrogênio peptídico) obtida com a presença de cinco moléculas de água (RI-PBE/def2-SVP/COSMO)

Figura 29. Distribuição de densidade de spin da espécie $\mathrm{Cu}\left(\mathrm{H}_{-} \mathrm{L}\right)\left(\mathrm{H}_{\text {. }}\right.$ ${ }_{1} \mathrm{~L}$ = dipeptídeo glicilglicina desprotonado no nitrogênio peptídico) a partir de simulação B3LYP/def2-TZVP/COSMO como isosuperfície de 0,002 a.u.

Figura 30. Estrutura otimizada da espécie $\mathrm{Cu}\left(\mathrm{H}_{-1} \mathrm{~L}\right)(\mathrm{OH})^{-}\left(\mathrm{H}_{-1} \mathrm{~L}=\right.$ dipeptídeo glicilglicina desprotonado no nitrogênio peptídico) obtida com a presença de cinco moléculas de água (RI-PBE/def2-SVP/ COSMO)

Figura 31. Distribuição de densidade de spin da espécie $\mathrm{Cu}(\mathrm{H}$. $\left.{ }_{1} \mathrm{~L}\right)(\mathrm{OH})^{-}\left(\mathrm{H}_{-1} \mathrm{~L}=\right.$ dipeptídeo glicilglicina desprotonado no nitrogênio peptídico) a partir de simulação B3LYP/def2-TZVP/COSMO como isosuperfície de 0,002 a.u.

Figura 32. Possíveis modos de coordenação da metionina ao íon cobre(II), em solução aquosa, formando a espécie $\mathrm{CuL}^{+}(\mathrm{L}=\mathrm{Met})$ : (a) $\mathrm{N}_{\text {amino }} \mathrm{O}_{\text {carbox: }}$ (b) $\mathrm{N}_{\text {amino }}$; (c) $\mathrm{O}_{\text {carbox; }}$ (d) $\mathrm{N}_{\text {amino }} \mathrm{O}_{\text {carbox }} \mathrm{S}$; (e) $\mathrm{N}_{\text {amino }} \mathrm{S}$ e (f) OcarboxS (RI-PBE/def2-SVP/COSMO)

Figura 33. Possíveis modos de coordenação da metionina ao íon cobre(II), em solução aquosa, formando a espécie $\mathrm{CuL}(\mathrm{OH})(\mathrm{L}=\mathrm{Met})$ : (a) $\mathrm{N}_{\text {amino }} \mathrm{O}_{\text {carbox }} \mathrm{S}(\mathrm{OH}$ na posição equatorial trans ao oxigênio do grupo carboxílico); (b) $\mathrm{N}_{\text {amino }} \mathrm{O}_{\text {carbox }} \mathrm{S}$ ( $\mathrm{OH}$ na posição equatorial trans ao nitrogênio do grupo amino); (c) $\mathrm{N}_{\text {amino }} \mathrm{O}_{\text {carbox }} \mathrm{S}$ ( $\mathrm{OH}$ na posição axial); (d) $\mathrm{N}_{\text {amino }} \mathrm{O}_{\text {carbox }}(\mathrm{OH}$ na posição equatorial trans ao nitrogênio do grupo amino); (e) $\mathrm{N}_{\text {amino }} \mathrm{S}$ ( $\mathrm{OH}$ na posição equatorial trans ao nitrogênio do grupo amino) e (f) $\mathrm{O}_{\text {carbox }} \mathrm{S}(\mathrm{OH}$ na posição equatorial trans ao átomo de oxigênio do grupo carboxílico) (RI-PBE/def2SVPCOSMO)

Figura 34. Possíveis modos de coordenação da metionina ao íon cobre(II), em solução aquosa, formando a espécie $\mathrm{CuL}(\mathrm{OH})_{2}{ }^{-}(\mathrm{L}=$ Met): (a) coordenação $\mathrm{N}_{\text {amino }} \mathrm{O}_{\text {carbox }} \mathrm{SOH}_{a x} \mathrm{OH}$ ( $2^{\mathrm{a}}$ molécula de hidroxila na posição equatorial); (b) coordenação $\mathrm{N}_{\text {amino }} \mathrm{O}_{\text {carbox }} \mathrm{OH}_{\mathrm{ax}} \mathrm{OH}\left(2^{\mathrm{a}}\right.$ molécula de hidroxila na posição equatorial); (c) coordenação $\mathrm{N}_{\text {amino }} \mathrm{O}_{\text {carbox }} \mathrm{OH}_{\mathrm{ax}} \mathrm{OH}$ ( $2^{\mathrm{a}}$ molécula de hidroxila na posição equatorial); (d) coordenaçãa $\mathrm{N}_{\mathrm{amino}} \mathrm{SOH}_{\mathrm{ax}} \mathrm{OH}\left(2^{\mathrm{a}}\right.$ molécula de hidroxila na posição equatorial); (e) $\mathrm{N}_{\mathrm{amino}} \mathrm{SOH}_{\mathrm{ax}} \mathrm{OH}$ ( $2^{\mathrm{a}}$ segunda molécula de hidroxila na posição axial); (f) $\mathrm{O}_{\text {carbox }} \mathrm{SOH}_{\mathrm{ax}} \mathrm{OH}$ (2 $2^{\mathrm{a}}$ molécula de hidroxila na posição axial) e ( $\mathrm{g}$ ) $\mathrm{O}_{\text {carbox }} \mathrm{SOH}_{\mathrm{ax}} \mathrm{OH}\left(2^{\mathrm{a}}\right.$ molécula de hidroxila na posição axial) (RI-PBE/def2-SVP/COSMO) 
Figura 35. Estrutura otimizada da espécie $\mathrm{CuMet}^{+}$obtida com a presença de quatro moléculas de água (RI-PBE/def2-SVP/COSMO)

Figura 36. Distribuição de densidade de spin para a espécie $\mathrm{CuL}^{+}(\mathrm{L}=$ Met) a partir de simulação B3LYP/def2-TZVP/COSMO como isosuperfície de 0,002 a.u.

Figura 37. Estrutura otimizada da espécie $\mathrm{CuL}(\mathrm{OH})(\mathrm{L}=$ metionina) (RI-PBE/def2-SVP/COSMO)

Figura 38. Distribuição de densidade de spin da espécie $\mathrm{CuL}(\mathrm{OH})(\mathrm{L}=$ Met) a partir de simulação B3LYP/def2-TZVP/COSMO como isosuperfície de 0,002 a.u.

Figura 39. Estrutura otimizada da espécie $\mathrm{CuL}(\mathrm{OH})_{2}{ }^{-}(\mathrm{L}=$ metionina $)$ (RI-PBE/def2-SVP/COSMO)

Figura 40. Distribuição de densidade de spin da espécie $\mathrm{CuL}(\mathrm{OH})_{2}^{-}(\mathrm{L}$ = Met) a partir de simulação B3LYP/def2-TZVP/COSMO como isosuperfície de 0,002 a.u.

Figura 41. Possíveis modos de coordenação dos ligantes glicilglicina e metionina ao íon cobre(II), formando a espécie ternária $\mathrm{CuHL}_{1} \mathrm{~L}_{2}\left(\mathrm{~L}_{1}=\right.$ GlyGly e $L_{2}=$ Met): (a) sistema coordenante de $L_{1}\left(N_{\text {amino }} \mathrm{O}_{\text {pept }}\right)$ e de $L_{2}$ $\left(\mathrm{N}_{\text {amino }} \mathrm{O}_{\text {carbox }}\right)$ (nitrogênios trans); (b) sistema coordenante de $\mathrm{L}_{1}$ $\left(\mathrm{N}_{\text {amino }} \mathrm{O}_{\text {pept }}\right)$ e de $\mathrm{L}_{2} \quad\left(\mathrm{~N}_{\text {amino }} \mathrm{O}_{\text {carbox }}\right)$ (nitrogênios cis); (c) sistema coordenante de $\mathrm{L}_{1}$ ( $\left.\mathrm{N}_{\text {amino }}\right)$ e de $\mathrm{L}_{2}\left(\mathrm{~N}_{\text {amino }} \mathrm{O}_{\text {carbox }}\right)$; (d) sistema coordenante de $L_{1}\left(\mathrm{~N}_{\text {amino }} \mathrm{O}_{\text {pept }}\right)$ e de $\mathrm{L}_{2}\left(\mathrm{~N}_{\text {amino }} \mathrm{O}_{\text {carbox }} \mathrm{S}\right)$; (e) sistema coordenante de $\mathrm{L}_{1}\left(\mathrm{~N}_{\text {amino }} \mathrm{O}_{\text {pept }}\right)$ e de $\mathrm{L}_{2}\left(\mathrm{~N}_{\text {amino }} \mathrm{O}_{\text {carbox }}\right)$ (configuração merc); (f) sistema coordenante de $L_{1}\left(N_{a m i n o}\right)$ (posição equatorial) e de $\mathrm{L}_{2}\left(\mathrm{~N}_{\text {amino }} \mathrm{O}_{\text {carbox }} \mathrm{S}\right)$ e $(\mathrm{g})$ sistema coordenante de $\mathrm{L}_{1}\left(\mathrm{~N}_{\text {amino }}\right)$ (posição axial) e de $\mathrm{L}_{2}\left(\mathrm{~N}_{\text {amino }} \mathrm{O}_{\text {carbox }} \mathrm{S}\right)$ (RI-PBE/def2-SVP/COSMO)

Figura 42. Possíveis modos de coordenação dos ligantes glicilglicina e metionina ao íon cobre(II), formando a espécie ternária $\mathrm{CuL}_{1} \mathrm{~L}_{2}{ }^{-}\left(\mathrm{L}_{1}=\right.$ GlyGly e $L_{2}=$ Met): (a) sistema coordenante de $L_{1}\left(N_{\text {amino }} N_{\text {pept }}\right)$ e de $L_{2}$ ( $\left.\mathrm{N}_{\text {amino }} \mathrm{O}_{\text {carbox }} \mathrm{S}\right)$ com os átomos de nitrogênio dos grupos amino em uma configuração cis; (b) sistema coordenante de $L_{1}\left(N_{\text {amino }} N_{\text {pept }}\right)$ e de $\mathrm{L}_{2}\left(\mathrm{~N}_{\text {amino }} \mathrm{O}_{\text {carbox }} \mathrm{S}\right)$ com os átomos de nitrogênios dos grupos amino em uma configuração trans; (c) sistema coordenante de $\mathrm{L}_{1}$ $\left(\mathrm{N}_{\text {amino }} \mathrm{N}_{\text {pept }}\right)$ e de $\mathrm{L}_{2}\left(\mathrm{~N}_{\text {amino }} \mathrm{O}_{\text {carbox }} \mathrm{S}\right)$ com os nitrogênios dos grupos amino em uma configuração trans e merc; (d) sistema coordenante de $\mathrm{L}_{1}\left(\mathrm{~N}_{\text {amino }} \mathrm{N}_{\text {pept }}\right)$ e de $\mathrm{L}_{2}\left(\mathrm{~N}_{\text {amino }} \mathrm{O}_{\text {carbox }}\right)$; (e) sistema coordenante de $\mathrm{L}_{1}$ $\left(\mathrm{N}_{\text {amino }} \mathrm{N}_{\text {pept }}\right)$ e de $\mathrm{L}_{2}\left(\mathrm{~N}_{\text {amino }} \mathrm{O}_{\text {carbox }}\right)$ com os nitrogênios dos grupos amino em uma configuração cis; (f) sistema coordenante de $L_{1}$ $\left(\mathrm{N}_{\text {amino }} \mathrm{N}_{\text {pept }}\right)$ e de $\mathrm{L}_{2}\left(\mathrm{~N}_{\text {amino }} \mathrm{S}\right)$; (g) sistema coordenante de $\mathrm{L}_{1}$ $\left(\mathrm{N}_{\text {amino }} \mathrm{N}_{\text {pept }}\right)$ e de $\mathrm{L}_{2}\left(\mathrm{O}_{\text {carbox }} \mathrm{S}\right)$ e (h) sistema coordenante de $\mathrm{L}_{1}\left(\mathrm{~N}_{\text {amino }}\right)$ e de $L_{2}\left(N_{\text {amino }} \mathrm{O}_{\text {carbox }} S\right)$ com o átomo de nitrogênio peptídico protonado e a desprotonação ocorrendo na molécula de água trans ao nitrogênio peptídico (RI-PBE/def2-SVP/COSMO) 
Figura 43. Modos de coordenação dos ligantes glicilglicina $\left(L_{1}\right)$ e metionina $\left(L_{2}\right)$ ao íon cobre(II), em solução aquosa, formando a espécie ternária $\mathrm{CuL}_{1} \mathrm{~L}_{2}(\mathrm{OH})^{2-}$ : (a) sistema coordenante de $\mathrm{L}_{1}$ $\left(\mathrm{N}_{\text {amino }} \mathrm{N}_{\text {pept }}\right)$ e de $\mathrm{L}_{2}\left(\mathrm{~N}_{\text {amino }} \mathrm{O}_{\text {carbox }}\right) \mathrm{OH}$ com a desprotonação ocorrendo na molécula de água na posição axial e (b) sistema coordenante de $L_{1}$ $\left(\mathrm{N}_{\text {amino }} \mathrm{N}_{\text {pept }}\right)$ e de $\mathrm{L}_{2}\left(\mathrm{~N}_{\text {amino }} \mathrm{O}_{\text {carbox }}\right) \mathrm{OH}$ com a desprotonação ocorrendo na molécula de água na posição axial em uma geometria de partida octaédrica (RI-PBE/def2-SVP/COSMO)

Figura 44. Estrutura otimizada da espécie ternária $\mathrm{CuHL}_{1} \mathrm{~L}_{2}\left(\mathrm{HL}_{1}=\right.$ dipeptídeo glicilglicina protonado e $\mathrm{L}_{2}=$ metionina) (RI-PBE/def2-SVP COSMO)

Figura 45. Distribuição de densidade de spin da espécie ternária CuHGlyGlyMet obtida a partir de simulação B3LYP/def2-TZVP COSMO como isosuperfície de 0,002 a.u.

Figura 46. Estrutura otimizada da espécie ternária $\mathrm{CuL}_{1} \mathrm{~L}_{2}^{-}\left(\mathrm{L}_{1}=\right.$ glicilglicina e $\mathrm{L}_{2}=$ metionina) $(\mathrm{RI}-\mathrm{PBE} / \mathrm{def2}-\mathrm{SVP} / \mathrm{COSMO})$

Figura 47. Distribuição de densidade de spin da espécie ternária CuGlyGlyMet a partir de simulação B3LYP/def2-TZVP/COSMO como isosuperfície de 0,002 a.u.

Figura 48. Estrutura otimizada da espécie ternária $\mathrm{CuL}_{1} \mathrm{~L}_{2}(\mathrm{OH})^{2-}\left(\mathrm{L}_{1}=\right.$ glicilglicina e $\mathrm{L}_{2}=$ metionina) (RI-PBE/def2-SVP/COSMO)

Figura 49. Distribuição de densidade de spin da espécie ternária $\mathrm{CuL}_{1} \mathrm{~L}_{2}(\mathrm{OH})^{2-}\left(\mathrm{L}_{1}=\right.$ GlyGly e $\mathrm{L}_{2}=$ metionina) a partir de simulação B3LYP/def2-TZVP/COSMO como isosuperfície de 0,002 a.u.

Figura 50. Especiação via DFT (RI-PBE/def2-SVP/COSMO) para o sistema binário $\mathrm{Cu}$ :GlyGly

Figura 51. Especiação via DFT (RI-PBE/def2-SVP/COSMO) para o sistema binário Cu:Met

Figura 52. Especiação via DFT (RI-PBE/def2-SVP/COSMO) para o sistema ternário Cu:GlyGly:Met

Figura 53. Geometria otimizada do cluster [Cu(GlyGly) $\left.\left(\mathrm{H}_{2} \mathrm{O}\right)_{36}\right]^{+}(\mathrm{RI}-$ $\mathrm{PBE} / \mathrm{def} 2-\mathrm{SVP} / \mathrm{COSMO}$ )

Figura 54. Geometria otimizada do cluster $\left[\mathrm{Cu}\left(\mathrm{H}_{-1} \mathrm{GlyGly}\right)\left(\mathrm{H}_{2} \mathrm{O}\right)_{36}\right](\mathrm{RI}-$ $\mathrm{PBE} / \mathrm{def} 2-\mathrm{SVP} / \mathrm{COSMO}$ )

Figura 55. Geometria otimizada do cluster [ $\left.\mathrm{Cu}\left(\mathrm{H}_{-1} \mathrm{GlyGly}\right)(\mathrm{OH})\left(\mathrm{H}_{2} \mathrm{O}\right)_{35}\right]$ (RI-PBE/def2-SVP/COSMO) 
Figura 56. Densidade de spin obtida por simulação B3LYP/def2TZVP/COSMO com isosuperfície 0,002 a.u. para os clusters: (a) [Cu(GlyGly) $\left.\left(\mathrm{H}_{2} \mathrm{O}\right)_{36}\right]^{+}$, (b) [Cu( $\left.\left.\mathrm{H}_{-1} \mathrm{GlyGly}\right)\left(\mathrm{H}_{2} \mathrm{O}\right)_{36}\right]$ e (c) $\left[\mathrm{Cu}\left(\mathrm{H}_{-}^{-}\right.\right.$

${ }_{1}$ GlyGly) $\left.(\mathrm{OH})\left(\mathrm{H}_{2} \mathrm{O}\right)_{35}\right]$

Figura 57. Geometria otimizada do cluster $\left[\mathrm{Cu}(\mathrm{Met})\left(\mathrm{H}_{2} \mathrm{O}\right)_{36}\right]^{+}(\mathrm{RI}-\mathrm{PBE} /$ def2-SVP/COSMO)

Figura 58. Geometria otimizada do cluster $\left[\mathrm{Cu}(\mathrm{Met})(\mathrm{OH})\left(\mathrm{H}_{2} \mathrm{O}\right)_{35}\right](\mathrm{RI}-$ $\mathrm{PBE} /$ def2-SVP/COSMO)

Figura 59. Geometria otimizada do cluster $\left[\mathrm{Cu}(\mathrm{Met})(\mathrm{OH})_{2}\left(\mathrm{H}_{2} \mathrm{O}\right)_{34}\right]^{-}(\mathrm{RI}-$ $\mathrm{PBE} / \mathrm{def} 2-\mathrm{SVP} / \mathrm{COSMO}$ )

Figura 60. Densidade de spin obtida por simulação B3LYP/def2-TZVP com isosuperfície 0,002 a.u. para os clusters: (a) $\left[\mathrm{Cu}(\mathrm{Met})\left(\mathrm{H}_{2} \mathrm{O}\right)_{36}\right]^{+}$, (b) $\left[\mathrm{Cu}(\mathrm{Met})(\mathrm{OH})\left(\mathrm{H}_{2} \mathrm{O}\right)_{35}\right]$ e (c) $\left[\mathrm{Cu}(\mathrm{Met})(\mathrm{OH})_{2}\left(\mathrm{H}_{2} \mathrm{O}\right)_{34}\right]^{]}$

Figura 61. Geometria otimizada do cluster [Cu(HGlyGly)(Met) $\left.\left(\mathrm{H}_{2} \mathrm{O}\right)_{36}\right]$ (RI-PBE/def2-SVP/COSMO)

Figura 62. Geometria otimizada do cluster [Cu(GlyGly)(Met) $\left.\left(\mathrm{H}_{2} \mathrm{O}\right)_{36}\right]^{-}$ (RI-PBE/def2-SVP/COSMO)

Figura 63. Geometria otimizada do cluster [Cu(GlyGly)(Met)(OH) $\left.\left(\mathrm{H}_{2} \mathrm{O}\right)_{35}\right]^{2-}(\mathrm{RI}-\mathrm{PBE} /$ def2-SVP/COSMO)

Figura 64. Densidade de spin obtida por simulação B3LYP/def2-TZVP com isosuperfície 0,002 a.u. para os clusters: [Cu(HGlyGly)(Met) $\left(\mathrm{H}_{2} \mathrm{O}\right)_{36}$ ], (b) [Cu(GlyGly)(Met) $\left.\left(\mathrm{H}_{2} \mathrm{O}\right)_{36}\right]^{-}$e (c) $\left[\mathrm{Cu}(\mathrm{GlyGly})(\mathrm{Met})(\mathrm{OH})\left(\mathrm{H}_{2} \mathrm{O}\right)_{35}\right]^{2}$ 


\section{Índice de Tabelas}

Tabela 1. Ligantes biológicos endógenos

Tabela 2. Parâmetros de RPE para o sistema binário Cu:GlyGly na razão metal:ligante 1:1 em diferentes valores de pH obtidos após simulação dos espectros programa Easyspin [162]

Tabela 3. Constantes de formação das espécies presentes no sistema binário $C u: L\left(L=\right.$ GlyGly) na razão metal:ligante $1: 1$ a $25^{\circ} \mathrm{C}, \mu=0,1$ $\mathrm{mol} \mathrm{L}^{-1}\left(\mathrm{KNO}_{3}\right)$

Tabela 4. Constantes de formação das espécies presentes no sistema binário $C u: L(L=M e t)$ na razão metal:ligante $1: 1$ a $25{ }^{\circ} \mathrm{C}, \mu=0,1 \mathrm{~mol}$ $\mathrm{L}^{-1}\left(\mathrm{KNO}_{3}\right)$

Tabela 5. Constantes de formação das espécies presentes no sistema ternário $\mathrm{Cu}(\mathrm{II}): \mathrm{L}_{1}: \mathrm{L}_{2}\left(\mathrm{~L}_{1}=\mathrm{GlyGly}\right.$ e $\mathrm{L}_{2}=$ Met) na proporção metal: ligante $1: 1: 1$ a $25^{\circ} \mathrm{C}, \mu=0,1 \mathrm{~mol} \mathrm{~L}^{-1}\left(\mathrm{KNO}_{3}\right)$

Tabela 6. Energia relativa ( $\mathrm{kcal} \mathrm{mol}^{-1}$ ) dos possíveis modos de coordenação do dipeptídeo glicilglicina ao íon cobre(II), em solução aquosa, na faixa $2<\mathrm{pH}<4,23$, formando a espécie $\mathrm{CuL}^{+}(\mathrm{L}=$ GlyGly) (RI-PBE/def2-SVP/COSMO)

Tabela 7. Energia relativa $\left(\mathrm{kcal} \mathrm{mol}^{-1}\right)$ dos possíveis modos de coordenação do dipeptídeo glicilglicina ao íon cobre(II), em solução aquosa, formando a espécie $\mathrm{Cu}\left(\mathrm{H}_{-1} \mathrm{~L}\right)\left(\mathrm{H}_{-1} \mathrm{~L}=\right.$ dipeptídeo desprotonado no nitrogênio peptídico) (RI-PBE/def2-SVP/COSMO)

Tabela 8. Energia relativa $\left(\mathrm{kcal} \mathrm{mol}^{-1}\right)$ dos possíveis modos de coordenação do dipeptídeo glicilglicina ao íon cobre(II), em solução aquosa, formando a espécie $\mathrm{Cu}\left(\mathrm{H}_{-1} \mathrm{~L}\right)(\mathrm{OH})^{-}\left(\mathrm{H}_{-1} \mathrm{~L}=\right.$ dipeptídeo desprotonado no nitrogênio peptídico) (RI-PBE/def2-SVP/ COSMO)

Tabela 9. Parâmetros estruturais da espécie $\mathrm{CuL}^{+}(\mathrm{L}=\mathrm{GlyGly})$ (COSMO:RI-PBE/def2-SVP)

Tabela 10. Parâmetros estruturais da espécie $\mathrm{Cu}\left(\mathrm{H}_{-} \mathrm{L}\right)\left(\mathrm{H}_{-1} \mathrm{~L}=\right.$ dipeptídeo desprotonado no nitrogênio peptídico) (COSMO:RIPBE/def2-SVP)

Tabela 11. Parâmetros estruturais da espécie $\mathrm{Cu}\left(\mathrm{H}_{-1} \mathrm{~L}\right)(\mathrm{OH})^{-}\left(\mathrm{H}_{-1} \mathrm{~L}=\right.$ dipeptídeo glicilglicina desprotonado no nitrogênio peptídico) (COSMO:RI-PBE/def2-SVP)

Tabela 12. Energia relativa ( $\mathrm{kcal} \mathrm{mol}{ }^{-1}$ ) dos possíveis modos de coordenação da metionina ao íon cobre(II), em solução aquosa, formando a espécie $\mathrm{CuL}^{+}(\mathrm{L}=\mathrm{Met})(\mathrm{RI}-\mathrm{PBE} / \mathrm{def2}-\mathrm{SVP} / \mathrm{COSMO})$ 
Tabela 13. Energia relativa $\left(\mathrm{kcal} \mathrm{mol}^{-1}\right)$ dos possíveis modos de coordenação da metionina ao íon cobre(II), em solução aquosa, formando a espécie $\mathrm{CuL}(\mathrm{OH})$ ( $\mathrm{L}=$ metionina) (RI-PBE/def2-SVP/

COSMO)

Tabela 14. Energia relativa $\left(\mathrm{kcal} \mathrm{mol}^{-1}\right)$ dos possíveis modos de coordenação da metionina ao íon cobre(II), em solução aquosa, formando a espécie $\mathrm{CuL}(\mathrm{OH})_{2}{ }^{-}(\mathrm{L}=$ metionina) (RI-PBE/def2-SVP/

COSMO)

Tabela 15. Parâmetros estruturais da espécie $\mathrm{CuL}^{+}(\mathrm{L}=$ metionina $)$ (COSMO:RI-PBE/def2-SVP)

Tabela 16. Parâmetros estruturais da espécie $\mathrm{CuL}(\mathrm{OH})(\mathrm{L}=$ metionina) (COSMO:RI-PBE/def2-SVP)

Tabela 17. Parâmetros estruturais da espécie $\mathrm{CuL}(\mathrm{OH}) 2_{2}^{-}(\mathrm{L}=$ metionina) (RI-PBE/def2-SVP/COSMO)

Tabela 18. Energia relativa ( $\mathrm{kcal} \mathrm{mol}{ }^{-1}$ ) dos possíveis modos de coordenação dos ligantes ao íon cobre(II), em solução aquosa, formando a espécie ternária $\mathrm{CuHL}_{1} \mathrm{~L}_{2}\left(\mathrm{~L}_{1}=\right.$ glicilglicina e $\mathrm{L}_{2}=$ metionina) (RI-PBE/def2-SVP/ COSMO)

Tabela 19. Energia relativa $\left(\mathrm{kcal} \mathrm{mol}^{-1}\right)$ dos possíveis modos de coordenação dos ligantes ao íon cobre(II), em solução aquosa, formando a espécie ternária $\mathrm{CuL}_{1} \mathrm{~L}_{2}{ }^{-}\left(\mathrm{L}_{1}=\right.$ GlyGly e $\left.\mathrm{L}_{2}=\mathrm{Met}\right)(\mathrm{RI}-$ PBE/def2-SVP/ COSMO)

Tabela 20. Energia relativa $\left(\mathrm{kcal} \mathrm{mol}{ }^{-1}\right)$ dos possíveis modos de coordenação dos ligantes ao íon cobre(II), em solução aquosa, formando a espécie ternária $\mathrm{CuL}_{1} \mathrm{~L}_{2}(\mathrm{OH})^{2-}\left(\mathrm{L}_{1}=\right.$ GlyGly e $\mathrm{L}_{2}=$ Met $)$ (RI-PBE/def2-SVP/ COSMO)

Tabela 21. Parâmetros estruturais da espécie ternária $\mathrm{CuHL}_{1} \mathrm{~L}_{2}\left(\mathrm{HL}_{1}=\right.$ dipeptídeo glicilglicina protonado e $\mathrm{L}_{2}=$ metionina) $(\mathrm{RI}-\mathrm{PBE} / \mathrm{def} 2-$ SVP/COSMO)

Tabela 22. Parâmetros estruturais da espécie ternária $\mathrm{CuL}_{1} \mathrm{~L}_{2}^{-}\left(\mathrm{L}_{1}=\right.$ glicilglicina e $\mathrm{L}_{2}$ = metionina) (RI-PBE/def2-SVP/COSMO

Tabela 23. Parâmetros estruturais da espécie ternária $\mathrm{CuL}_{1} \mathrm{~L}_{2}(\mathrm{OH})^{2-}$ (L1 = GlyGly e L2 = metionina) $($ RI-PBE/def2-SVP/COSMO)

Tabela 24. Valores de $\Delta \mathrm{G}_{\text {solv }}^{*}\left(\mathrm{kcal} \mathrm{mol}^{-1}\right)$ para os complexos $\left[\mathrm{Cu}(\mathrm{GlyGly})\left(\mathrm{H}_{2} \mathrm{O}\right)_{5}\right]^{+}, \quad\left[\mathrm{Cu}\left(\mathrm{H}_{-1} \mathrm{GlyGly}\right)\left(\mathrm{H}_{2} \mathrm{O}\right)_{5}\right]$ e $\quad\left[\mathrm{Cu}\left(\mathrm{H}_{-}\right.\right.$ $\left.\left.{ }_{1} \mathrm{GlyGly}\right)\left(\mathrm{H}_{2} \mathrm{O}\right)_{4}(\mathrm{OH})\right]^{-}$e para as espécies $\mathrm{H}_{2} \mathrm{O}, \mathrm{H}_{3} \mathrm{O}^{+}$e $\mathrm{OH}^{-}$a $298 \mathrm{~K}$ e $1 \mathrm{~atm}$ (B3LYP e PBE0/def2-TZVP) 
Tabela 25. Energias livres de Gibbs ( $\mathrm{kcal} \mathrm{mol}^{-1}$ ) e valores de pKa para as reações de desprotonação dos complexos [ $\left.\mathrm{Cu}(\mathrm{GlyGly})\left(\mathrm{H}_{2} \mathrm{O}\right)_{5}\right]^{+}$e [Cu( $\mathrm{H}_{-1}$ GlyGly) $\left.\left(\mathrm{H}_{2} \mathrm{O}\right)_{5}\right]$, em solução aquosa a $298 \mathrm{~K} \mathrm{e} 1 \mathrm{~atm}$ (B3LYP/def2-TZVP)

Tabela 26. Energias livres de Gibbs ( $\mathrm{kcal} \mathrm{mol}^{-1}$ ) e valores de pKa para as reações de desprotonação dos complexos [ $\left.\mathrm{Cu}(\mathrm{GlyGly})\left(\mathrm{H}_{2} \mathrm{O}\right)_{5}\right]^{+} \mathrm{e}$ $\left[\mathrm{Cu}\left(\mathrm{H}_{-1} \mathrm{GlyGly}\right)\left(\mathrm{H}_{2} \mathrm{O}\right)_{5}\right]$, em solução aquosa a $298 \mathrm{~K}$ e $1 \mathrm{~atm}$ (PBE0/def2-TZVP)

Tabela 27. Valores de $\Delta \mathrm{G}_{\text {solv }}^{*}\left(\mathrm{kcal}^{\mathrm{mol}}{ }^{-1}\right)$ para os complexos $\left[\mathrm{Cu}(\mathrm{Met})\left(\mathrm{H}_{2} \mathrm{O}\right)_{4}\right]^{+}, \quad\left[\mathrm{Cu}(\mathrm{Met})\left(\mathrm{H}_{2} \mathrm{O}\right)_{3}(\mathrm{OH})\right]$ e $\left[\mathrm{Cu}(\mathrm{Met})\left(\mathrm{H}_{2} \mathrm{O}\right)_{2}(\mathrm{OH})_{2}\right]^{-}$e para as espécies $\mathrm{H}_{2} \mathrm{O}, \mathrm{H}_{3} \mathrm{O}^{+}$e $\mathrm{OH}^{-}$a $298 \mathrm{Ke} 1 \mathrm{~atm}$ (B3LYP e PBE0/def2-TZVP)

Tabela 28. Energias livres de Gibbs ( $\mathrm{kcal} \mathrm{mol}^{-1}$ ) e valores de pKa para as reações de desprotonação dos complexos $\left[\mathrm{Cu}(\mathrm{Met})\left(\mathrm{H}_{2} \mathrm{O}\right)_{4}\right]^{+}$e $\left[\mathrm{Cu}(\mathrm{Met})\left(\mathrm{H}_{2} \mathrm{O}\right)_{3}(\mathrm{OH})\right]$, em solução aquosa, a $298 \mathrm{~K} \mathrm{e} 1 \mathrm{~atm}$ (B3LYP/def2-TZVP)

Tabela 29. Energias livres de Gibbs ( $\mathrm{kcal} \mathrm{mol}^{-1}$ ) e valores de pKa para as reações de desprotonação dos complexos $\left[\mathrm{Cu}(\mathrm{Met})\left(\mathrm{H}_{2} \mathrm{O}\right)_{4}\right]^{+}$e $\left[\mathrm{Cu}(\mathrm{Met})\left(\mathrm{H}_{2} \mathrm{O}\right)_{3}(\mathrm{OH})\right]$, em solução aquosa, a 298

$\mathrm{Ke} 1 \mathrm{~atm}$ (PBE0/def2-TZVP

Tabela 30. Valores de $\Delta \mathrm{G}_{\text {solv }}^{*}\left(\mathrm{kcal} \mathrm{mol}^{-1}\right)$ para os complexos [Cu(HGlyGly)(Met) $\left.\left(\mathrm{H}_{2} \mathrm{O}\right)_{2}\right], \quad\left[\mathrm{Cu} \text { (GlyGly) }(\mathrm{Met})\left(\mathrm{H}_{2} \mathrm{O}\right)_{2}\right]^{-} \quad$ e [Cu(GlyGly)(Met) $\left.\left(\mathrm{H}_{2} \mathrm{O}\right)(\mathrm{OH})\right]^{2-}$ e para as espécies $\mathrm{H}_{2} \mathrm{O}, \mathrm{H}_{3} \mathrm{O}^{+}$e $\mathrm{OH}^{-}$ a $298 \mathrm{~K}$ e 1 atm (B3LYP e PBE0/def2-TZVP)

Tabela 31. Energias livres de Gibbs ( $\mathrm{kcal} \mathrm{mol}^{-1}$ ) e valores de pKa para as reações de desprotonação dos complexos [Cu(HGlyGly)(Met) $\left(\mathrm{H}_{2} \mathrm{O}\right)_{2}$ ] e [Cu(GlyGly)(Met) $\left.\left(\mathrm{H}_{2} \mathrm{O}\right)_{2}\right]^{-}$em solução aquosa, a $298 \mathrm{~K}$ e $1 \mathrm{~atm}$ (B3LYP/def2-TZVP)

Tabela 32. Energias livres de Gibbs ( $\mathrm{kcal} \mathrm{mol}^{-1}$ ) e valores de pKa para as reações de desprotonação dos complexos [Cu(HGlyGly)(Met) $\left(\mathrm{H}_{2} \mathrm{O}\right)_{2}$ ] e [Cu(GlyGly)(Met) $\left.\left(\mathrm{H}_{2} \mathrm{O}\right)_{2}\right]^{-}$em solução aquosa, a $298 \mathrm{~K}$ e 1 atm (PBE0/def2-TZVP) 


\section{1. \\ Introdução}

1.1

Introdução

Complexos metálicos com ligantes biológicos tem sido utilizados como modelos para o entendimento das diversas reações que ocorrem in vivo. O cobre no organismo humano e no encéfalo encontra-se coordenado a metaloproteínas. A concentração do íon cobre livre é extremamente baixa, na ordem de $10^{-15} \mathrm{M}$, o que evita efeitos deletérios causados por este elemento e também impede a sua competição com outros elementos essenciais tais como o zinco, o manganês e o ferro [1]. No meio extracelular, o cobre(II) encontra-se coordenado a aminoácidos ou pela proteína albumina, como parte do mecanismo que previne sua forma tóxica livre.

Verifica-se no envelhecimento um aumento significativo no teor do íon cobre(II) em diversas regiões do encéfalo [2]. No cérebro há uma alta concentração de gordura quando comparado ao plasma. Porém, nas diversas doenças neurodegenerativas, ocorre um aumento significativo na concentração de proteínas que uma vez presentes, formam agregados insolúveis dando origem a placas senis nas regiões do cérebro afetadas. Uma vez ligado a essas proteínas, o íon cobre, um metal redox, contribui para a geração de espécies reativas de oxigênio (ROS - reactive oxygen species), fazendo com que desencadeie os processos inflamatórios característicos dessas desordens.

A doença neurodegenerativa mais comum é a doença de Alzheimer (DA), sua incidência é de $10 \%$ nas pessoas com 65 anos e cresce para cerca de $50 \%$ após os 85 anos [3]. Nessa desordem, uma das características é a presença anormal de um fragmento de proteína, o resíduo $A \beta$ amilóide, que uma vez no líquido encefalorraquidiano, sofre maturação e oligomerização principalmente no hipocampo e na amídala [4]. Acredita-se que íons metálicos favoreçam esse 
processo de formação de placas. Os possíveis sítios de ligação do cobre nesse resíduo $\mathrm{A} \beta$ amilóide não são bem estabelecidos.

A metionina é um agente oxidante presente nos sistemas biológicos que tem a capacidade de modular o processo de estresse oxidativo característico de diversas desordens neurodegenerativas.

O presente trabalho tem como objetivos estudar um complexo ternário de cobre(II) com os ligantes glicilglicina e metionina, com intuito de investigar como um agente antioxidante interage com um complexo de cobre modelo de ligação a proteínas presentes, anormalmente, no sistema nervoso central de pacientes com desordens neurodegenerativas.

Foi realizado um estudo potenciométrico dos sistemas binários Cu:GlyGly e Cu:Met e ternário Cu:GlyGly:Met e foram calculadas as constantes de formação dos complexos. Uma vez calculadas as constantes de formação dos sistemas, foram gerados diagramas de distribuição de espécies em função do $\mathrm{pH}$ e as espécies mais relevantes foram identificadas. Porém, devido à falta de estruturas em solução aquosa, é difícil inferir os modos de coordenação dos ligantes nos complexos formados. Para as espécies complexadas mais relevantes, foi realizado um estudo DFT de todos os possíveis modos de coordenação dos ligantes, e foi possível identificar os sítios de ligação bem como a geometria dos complexos formados. Nas espécies estáveis, foi incluída uma segunda camada de sovatação para analisar os efeitos na geometria dos complexos. Portanto, o presente trabalho é um estudo experimental e teórico de complexos metálicos modelos, tanto de ligação do íon cobre(II) em proteínas e enzimas, bem como a ligação de um agente antioxidante a um sistema que pode induzir o estresse oxidativo. 


\section{2}

\section{Cobre em sistemas biológicos}

Aproximadamente metade de todas as estruturas conhecidas de proteínas no estado cristalino, do banco de dados de proteínas (protein data bank; PDB), contém íons metálicos em sua estrutura, os quais participam da neutralização, estrutura e função das proteínas $[5,6]$. Essas proteínas tem peso molecular entre de $500010^{7}$ Da com o íon metálico correspondendo a somente $0,1 \%$ do peso da proteína. Porém, na maioria dessas metaloproteínas, o íon metálico e sua esfera de coordenação são essenciais para a função biológica específica e formam o sítio catalítico ativo da proteína (Fig. 1).

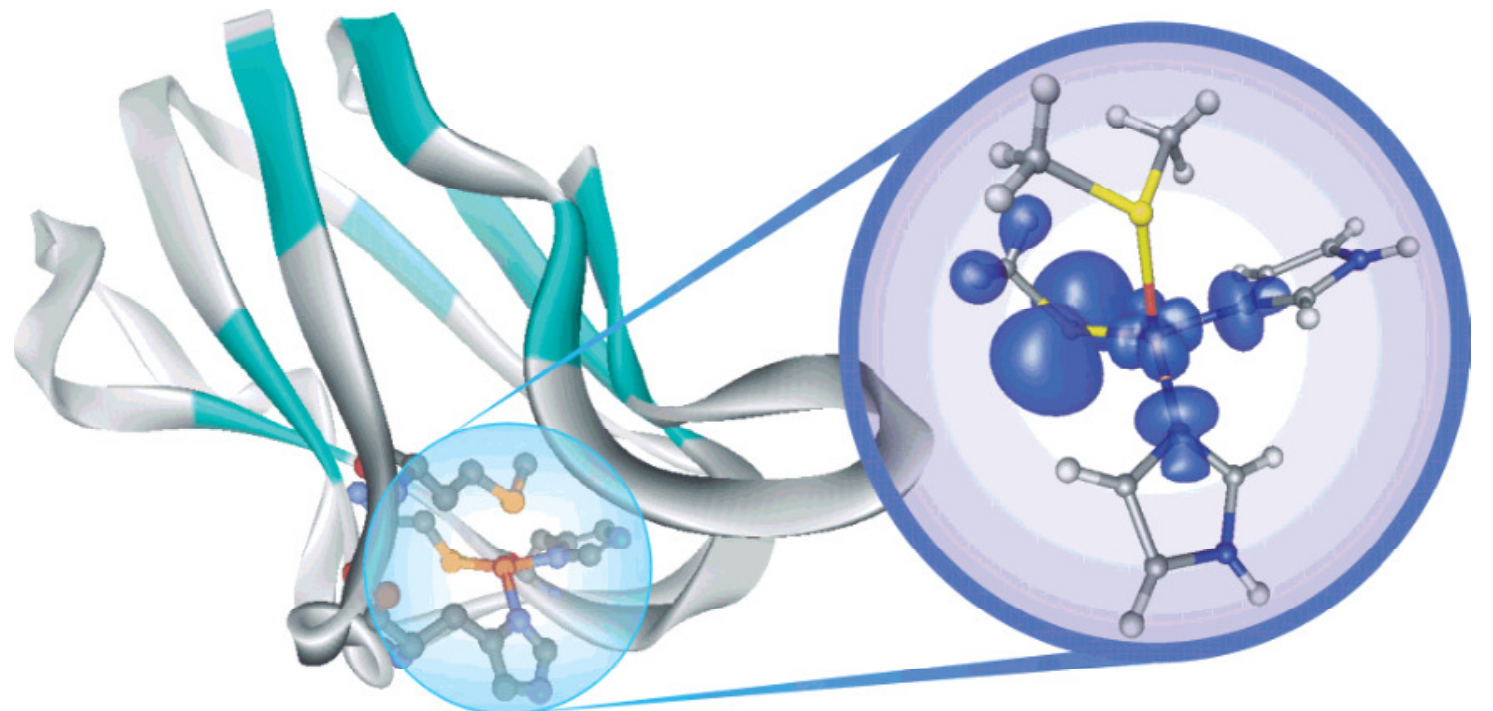

Figura 1. Estrutura cristalina da proteína plastocianina (Protein data bank; PDB) e uma visão ampliada da estrutura eletrônica do sítio ativo. Figura reproduzida com permissão da referência 5

Metaloproteínas são simplesmente complexos metálicos com a presença de ligantes notavelmente extensos, que possuem em sua estrutura átomos com a capacidade de doar pares eletrônicos e se coordenarem a centros metálicos positivos. A Tabela 1 mostra os átomos e alguns resíduos de aminoácidos que tem a capacidade de se ligar a centros metálicos e formar complexos metálicos em sistemas biológicos. 
Tabela 1. Ligantes biológicos endógenos

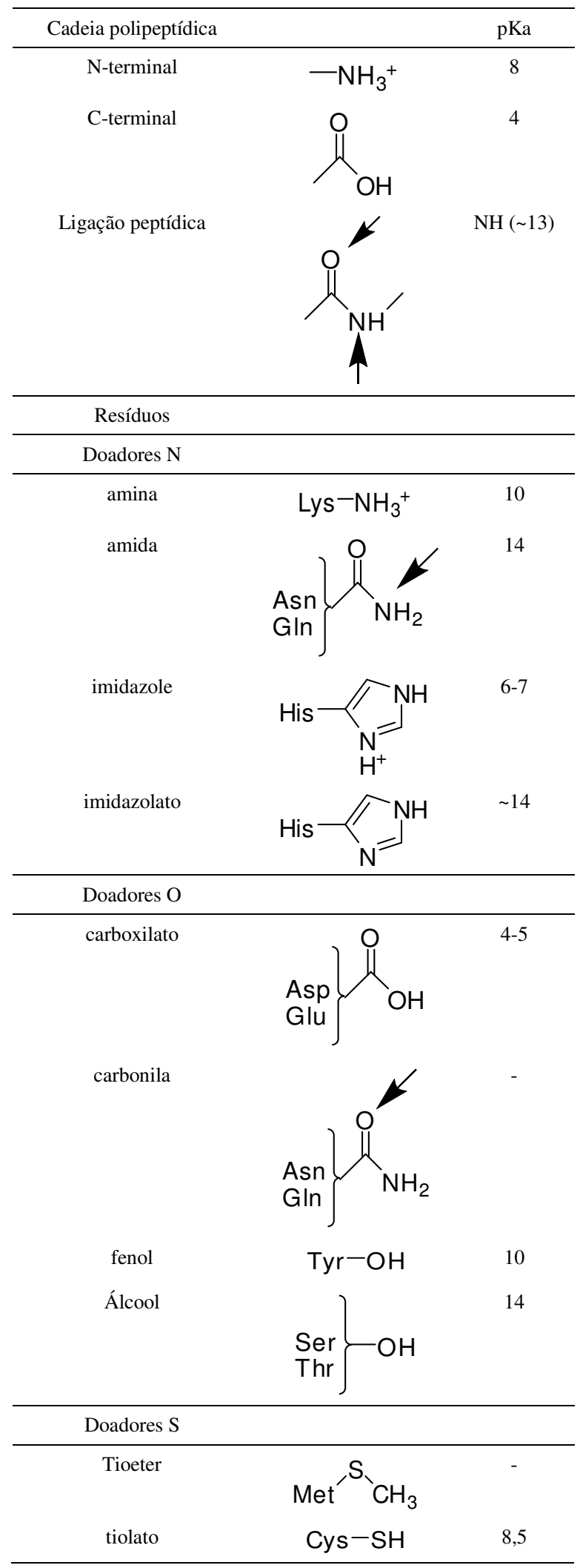

Além do mais, o centro catalítico da enzima pode definir a estrutura da proteína de primária a quaternária possibilitando assim, a metaloproteína exercer sua função catalítica específica. Na Figura 2 são mostradas algumas 
metaloenzimas de cobre e o papel do centro catalítico na atividade da enzima. As ligações dos átomos doadores aos centros metálicos formam fortes ligações covalentes, gerando complexos com geometrias bem específicas, definindo assim a estrutura da proteína e possibilitando ela exercer sua atividade catalítica específica.

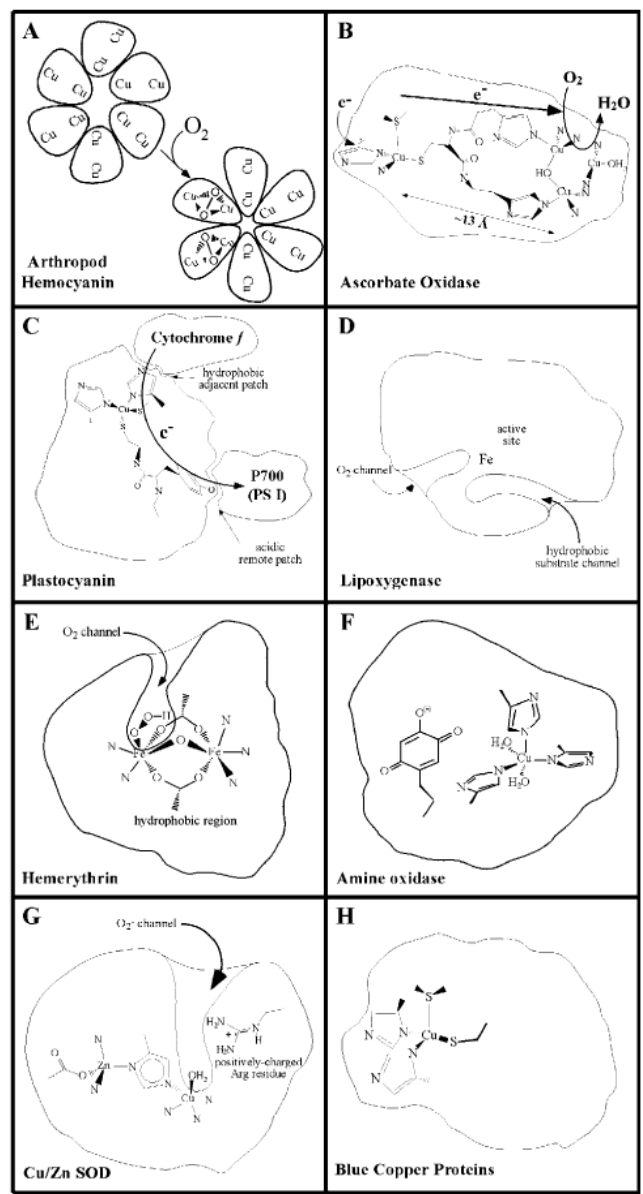

Figura 2. Papel dos ligantes na função biológica de enzimas. (a) Interação alostérica entre o sítio ativo e o substrato em diferentes subunidades na enzima ceruloplasmina; (b) Organização dos resíduos que constituem o sítio catalítico de uma enzima com mais de um centro metálico; (c) Locais de reconhecimento da superfície e mecanismo de super troca para a transferência de elétrons; (d) Papel do sitio ativo para a formação dos canais de acesso ao substrato; (e) ambiente hidrofóbico; (f) Bolsa para a ligação do substrato próximo do sitio ativo metálico; (g) Resíduos de carga específica e ligações de hidrogênio próximo ao sitio metálico, necessários para exercer o papel catalítico da enzima e (h) Geometria específica do sitio metálico na qual pode ativar a enzima. Figura reproduzida com permissão da referência 5 


\section{3}

\section{Modos de coordenação do cobre(II)}

$\mathrm{O}$ conhecimento dos modos de coordenação do íon $\mathrm{Cu}(\mathrm{II})$, em solução aquosa, é essencial para o entendimento das funções desse metal em sistemas biológicos [5,7-11]. Diversas estruturas de complexos de cobre com os mais variados ligantes, no estado sólido, são bastante reportadas na literatura [11-18] ao passo que, informações estruturais dos complexos em solução aquosa são menos disponíveis [17-24]. Surpreendentemente, a estrutura do complexo mais simples, $\mathrm{Cu}$ (II) em solução aquosa, é assunto de grande debate na literatura [25].

Embora cálculos de dinâmica molecular [26-31] forneçam informações estruturais para os complexos de $\mathrm{Cu}(\mathrm{II})$ em solução aquosa, tais cálculos não fornecem bons resultados para informações eletrônicas e falham na descrição da distorção Janh-Teller (Fig. 3) em torno do centro metálico, a não ser que sejam inseridos termos de correção do campo ligante estabilizando os clusters $\mathrm{Cu}$ (II)água em uma geometria octaédrica distorcida. Além do mais, modelos realísticos para os clusters de $\mathrm{Cu}-\mathrm{H}_{2} \mathrm{O}$ são pouco descritos na literatura.

Complexos de cobre hexacoordenados são encontrados em um grande número de estruturas cristalinas. Geralmente esses complexos mostram uma geometria octaédrica com a presença de comprimentos de ligação nas posições axiais maiores do que os comprimentos nas posições equatoriais. Considerações teóricas dos complexos com seis ligantes mostram que, certas deformações tornam os complexos mais estáveis do que uma geometria octaédrica regular. Uma consequência importante da distorção de Janh-Teller do íon $\mathrm{Cu}(\mathrm{II}), \mathrm{d}^{9}$, é a alta mobilidade dos ligantes axiais e a rápida troca na primeira camada de coordenação, comparado com outros metais divalentes da primeira série dos metais de transição. Outra consequência do efeito é a flexibilidade das geometrias de coordenação dos complexos de cobre no estado cristalino [11-18]. Por exemplo, estruturas cristalinas de complexos de cobre(II)-amino ácidos com números de coordenação 4,5 e 6 são encontradas na literatura, sugerindo que sejam pequenas as diferenças energéticas entre os diferentes números de coordenação [25]. Também, de acordo com o efeito Janh-Teller, muitas estruturas com geometrias distorcidas são encontradas na literatura. 


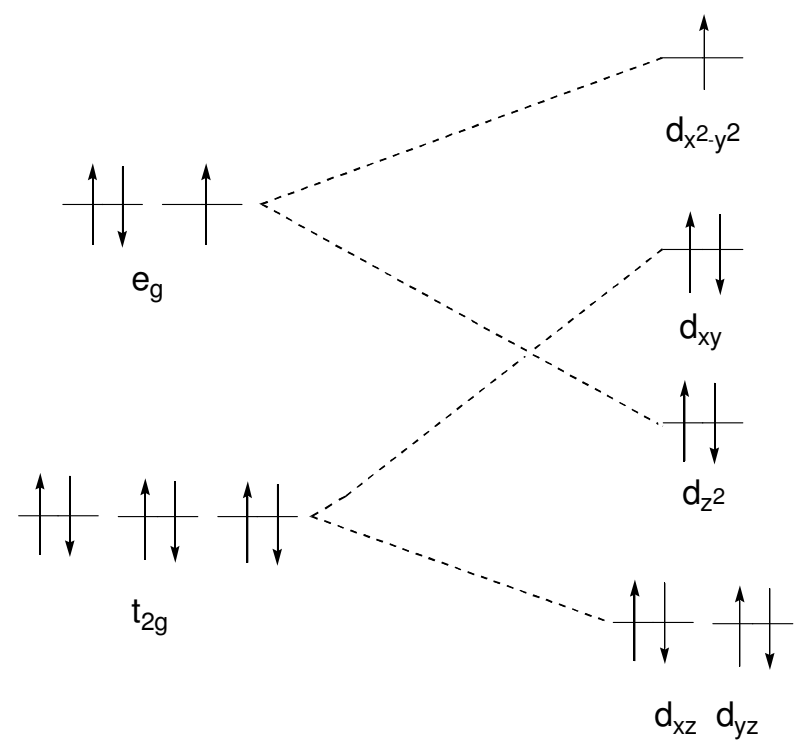

Figura 3. Diagrama de orbitais moleculares do desdobramento do Campo Cristalino de complexos $d^{9}$ sob efeito da distorção Janh-Teller com elongamento dos ligantes nas posições axiais. Figura reproduzida com permissão da referência 25

\section{4}

\section{Clusters Cu(II)-água}

Ainda existe uma grande discussão sobre a esfera de coordenação dos complexos de cobre(II) hidratados. Pasquarello et al. [32] utilizando a técnica de difração de nêutrons em grandes ângulos, combinado com a simulações de dinâmica molecular, questionaram o modelo clássico de seis ligantes em torno do $\mathrm{Cu}(\mathrm{II})$ e sugeriram que ocorre uma transformação em solução aquosa entre uma geometria piramidal de base quadrada e uma bipirâmide trigonal, discordando da distorção Jahn-Teller para a configuração de um octaedro distorcido. Um estudo realizado por Person et al. [18] aplicando tanto LAXS quanto EXAFS para compostos contendo o íon cobre(II), levando em consideração seis configurações geométricas diferentes: octaedro regular, octaedro com distorção Janh-Teller, quadrado-planar, bipirâmide trigonal, pirâmide quadrada e pirâmide quadrada com ligante elongado na posição axial. O complexo com a geometria octaédrica foi excluído, pois os resultados obtidos experimentalmente mostraram que as distancias $\mathrm{Cu}-\mathrm{O}$ são muito menores do que as esperadas para um octaedro regular que é de 2,07 Å. A geometria quadrado planar também foi excluída, pois, complexos quadrados planares $\mathrm{CuO}_{4}$ sem ligantes nas posições axiais só são formados quando existe impedimentos estéricos entre os ligantes, além do mais, 
complexos com geometria quadrado planar apresentam uma coloração verde escura. A geometria pirâmide quadrada e bipirâmide trigonal não forneceram bons resultados para o refinamento dos modelos assimétricos de distancias $\mathrm{Cu}-\mathrm{O}_{\mathrm{eq}}$ de $1,96 \AA$ e $\mathrm{Cu}-\mathrm{O}_{\mathrm{ax}}$ de 2,3 $\mathrm{\AA}$. A geometria octaédrica distorcida forneceu os melhores resultados no refinamento do que as geometrias bipirâmide trigonal e pirâmide quadrada. Além do mais, em cálculos ab initio, o modelo com a geometria bipirâmide trigonal mostrou valores de energia maiores do que as estruturas pirâmide quadrada e octaedro distorcido [33]. O número de coordenação seis está em boa concordância com os obtidos para o íon de cobre(II) em compostos sólidos [34]. Resumidamente, os dados de EXAFS indicam que o íon cobre(II), em solução aquosa e a temperatura ambiente, coordena a quatro moléculas de água localizados em um quadrado plano e que uma ou duas moléculas de água encontram-se coordenadas nas posições axiais em distâncias maiores do que nas posições equatoriais. Ambos os dados obtidos de análises LAXS e EXAFS mostraram que as geometrias pirâmide quadrada e bipirâmide trigonal não são modelos apropriados pois, os melhores refinamentos foram obtidos para o modelo com a geometria octaédrica distorcida. Portanto, o trabalho de Persson et al. mostrou que o complexo $\left[\mathrm{Cu}\left(\mathrm{H}_{2} \mathrm{O}\right)_{6}\right]^{+2}$ possui uma geometria octaédrica com enlogamento dos ligantes nas posições axiais, com quatro ligações equatoriais de 1,954 Å e duas ligações axiais de 2,289 Å, e não uma estrutura pentacoordenada. Por outro lado, dados de caracterização estrutural de complexos de $\mathrm{Cu}$ (II), em solução aquosa, não tem sido conclusivos.

Entretanto, estudos posteriores de espectros de estrutura fina de absorção de raio-X (EXAFS), para soluções aquosas de cobre(II) feitas por Benfatto et al. [22] e Frank et al. [23], indicaram que o melhor modelo experimental é uma geometria piramidal de base quadrada em relação a uma geometria tetracoordenada ou uma geometria octaédrica sujeita a uma distorção Janh-Teller. Os mesmos grupos de pesquisa [22,23] analisaram estruturas de espectros de absorção de raio-X próximos das bordas (XANES) e concluíram que um modelo de pirâmide de base quadrada com uma molécula de água elongada na posição axial (2,35 Å) fornece o melhor modelo para o complexo de cobre(II) em solução aquosa.

Recentemente, Chaboy et al. [24] usando dois canais de absorção para espectros de EXAFES e XANES para soluções de $\mathrm{Cu}-\mathrm{H}_{2} \mathrm{O}$, concluíram que 
estruturas com números de coordenação para o cobre de 4,5 e 6 são indistinguíveis e coexistem em solução aquosa.

Um problema encontrado em simulações de dinâmica molecular é como representar as ligações covalentes e a polarização dos ligantes nos complexos metálicos formados. Metais de transição, em particular complexos de cobre(II), são difíceis para modelar com adequados campos de força, e essa dificuldade é encontrada mesmo em cálculos $a b$ initio quanto se pretende descrever corretamente as distorções de Janh-Teller e as geométricas adequadas para o íon cobre(II) hidratado.

Cálculos teóricos realizados até a presente data não tem sido capazes de resolver esse debate sobre a estrutura dos complexos de cobre em solução aquosa. Duas simulações Car-Parrinello de dinâmica molecular (DM) (usando o funcional BLYP e uma função de base de onda plana) indicaram uma coordenação pentacoordenada para o cobre(II) [27,28]. Em contraste, simulações QM/MM MD (utilizando os métodos B3LYP e MP2 e um conjunto de base de valência dupla para a água e o conjunto de base LANL2DZ para o cobre) indicaram a presença de espécies com número de coordenação seis, com a presença da distorção JanhTeller [29-31].

$\mathrm{O}$ estudo da hidratação do $\mathrm{Cu}$ (II) tendo um pequeno número de moléculas ao redor do centro metálico pode ser importante na direção de um melhor entendimento dos efeitos peculiares de solvatação no seio de um sistema solvatado. Cálculos de estrutura eletrônica e análises de espectroscopia de massa são ferramentas adequadas para o estudo de cluster de complexos $\mathrm{Cu}-\mathrm{H}_{2} \mathrm{O}$ em fase gasosa [35]. Assume-se que existe uma relação entre o pico mais intenso no espectro de massa e a composição do íon cluster contendo a primeira camada de solvatação em torno do metal. Para o $\mathrm{Cu}(\mathrm{II})$, o sinal mais intenso corresponde ao cluster contendo oito moléculas de água [36,37]. Bérces et al. [38] atribuíram esses resultados para a estabilização de uma estrutura planar contendo quatro moléculas de água na primeira camada de solvatação com outras quatro moléculas de água formando uma segunda camada de solvatação. No modelo proposto por Bérces et al. as moléculas de água na segunda camada de solvatação estariam localizadas nos vértices de uma geometria quadrado planar ligadas por meio de ligações de hidrogênio as moléculas coordenadas ao centro metálico. 
Recentemente, Duncombe e colaboradores [39] realizaram um estudo mais detalhado de espectrometria de massa dos complexos $\left[\mathrm{Cu}\left(\mathrm{H}_{2} \mathrm{O}\right)_{n}\right]^{2+}$. Eles sugeriram que uma estrutura aberta bidimensional estabilizada por ligações de hidrogênio é formada, podendo conter mais do que 19 moléculas de água.

A maioria dos cálculos de estrutura eletrônica de clusters de cobre hidratados tem se limitado ao estudo com $n=8$. Portanto, o efeito de uma segunda e completa camada de hidratação na estrutura eletrônica e nos cálculos dos parâmetros termodinâmicos do complexo $\left[\mathrm{Cu}\left(\mathrm{H}_{2} \mathrm{O}\right)_{n}\right]^{2+}$ não tem sido considerados em muitos detalhes em estudos teóricos prévios.

Bryantsev et al. [25] apresentaram um modelo de cluster contínuo para estudar aspectos estruturais, energéticos e termodinâmicos da hidratação do íon cobre(II). Cálculos da estrutura eletrônica, tanto em fase gasosa como em fase aquosa, foram utilizados para determinar as geometrias estáveis e energias relativas de complexos de $\left[\mathrm{Cu}\left(\mathrm{H}_{2} \mathrm{O}\right)_{n}\right]^{2+}$ com o número de coordenação do íon cobre(II) de 4, 5 e 6 e como uma função do tamanho do cluster (n = 4-18). Resultados anteriores realizados pelo mesmo grupo mostraram uma preferência pelo número de coordenação 4 em fase gasosa e 5 em solução aquosa para $n \geq 8$. Os resultados de energia livre de solvatação calculados para o $\mathrm{Cu}$ (II), usando o modelo do cluster contínuo, mostrou uma boa concordância com os valores experimentais. No trabalho de Bryantsev et al. foram realizados cálculos DFT utilizando o funcional híbrido dos três parâmetros de Beck [40] e a função de correlação de Lee, Yang e Parr (B3LYP) [41]. A aplicação do método B3LYP tem fornecido resultados promissores no cálculo de sistemas íon-água [42-45]. Foram utilizados diferentes conjuntos de bases e os resultados mostraram que a utilização de funções difusas são necessárias para obter as estabilidades energéticas relativas desses complexos. Com isso, as geometrias dos complexos foram otimizadas utilizando um conjunto de base com funções difusas para os átomos leves 6$311 \mathrm{G}++(\mathrm{d}, \mathrm{p})$ e o padrão de potencial do núcleo efetivo Los Alamos não contraído LACVP [46], formando o conjunto de base de tripla-valência e função difusa LACV3P para o átomo de cobre. A coordenação do cobre no seio de uma solução aquosa e as propriedades termodinâmicas foram modelados pela inclusão de moléculas de água na vizinhança do íon metálico, o chamado modelo do cluster contínuo. A inserção de moléculas explícitas no modelo de dielétrico contínuo é bastante realístico, pois o modelo de dielétrico contínuo falha quando há uma 
concentração de densidade de carga com forte interação local soluto-solvente. No trabalho de Bryantsev et al. [25] foi verificado uma preferência por estruturas abertas com as moléculas de água de hidratação formando ligações de hidrogênio com as moléculas de água de coordenação. As estruturas testadas dos complexos $\left[\mathrm{Cu}\left(\mathrm{H}_{2} \mathrm{O}\right)_{n}\right]^{2+}$ para diferentes números de coordenação e tamanhos dos clusters são mostradas na Figura 4.

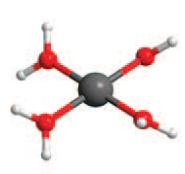

$4 w$

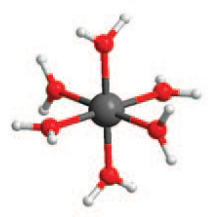

$6 w-c$

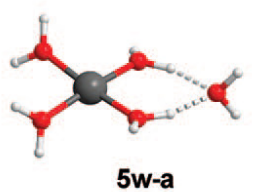

$5 w-a$

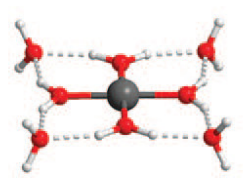

$8 w-a$

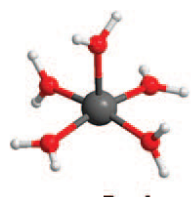

$5 w-b$

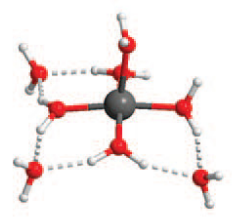

$8 w-b$

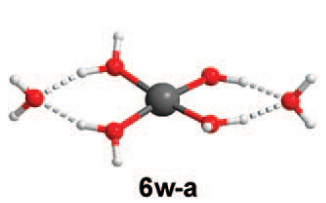

6w-a

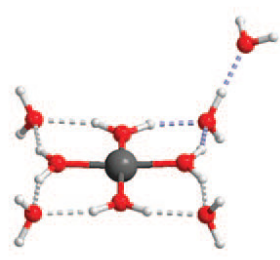

$9 w-a$

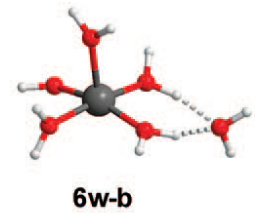

$6 w-b$

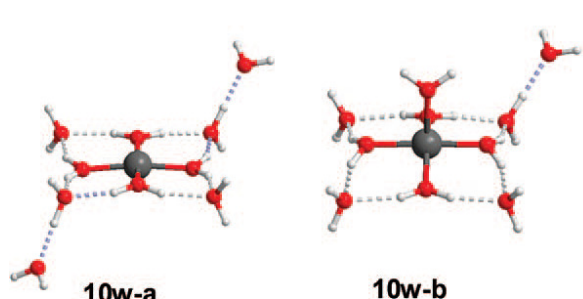

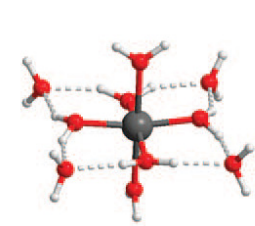

10w-c

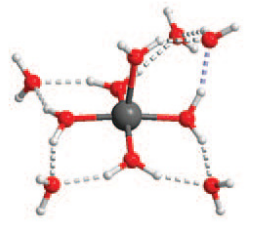

$10 w-d$

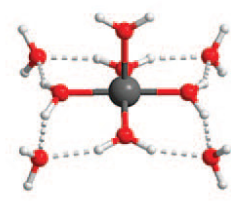

$9 w-b$
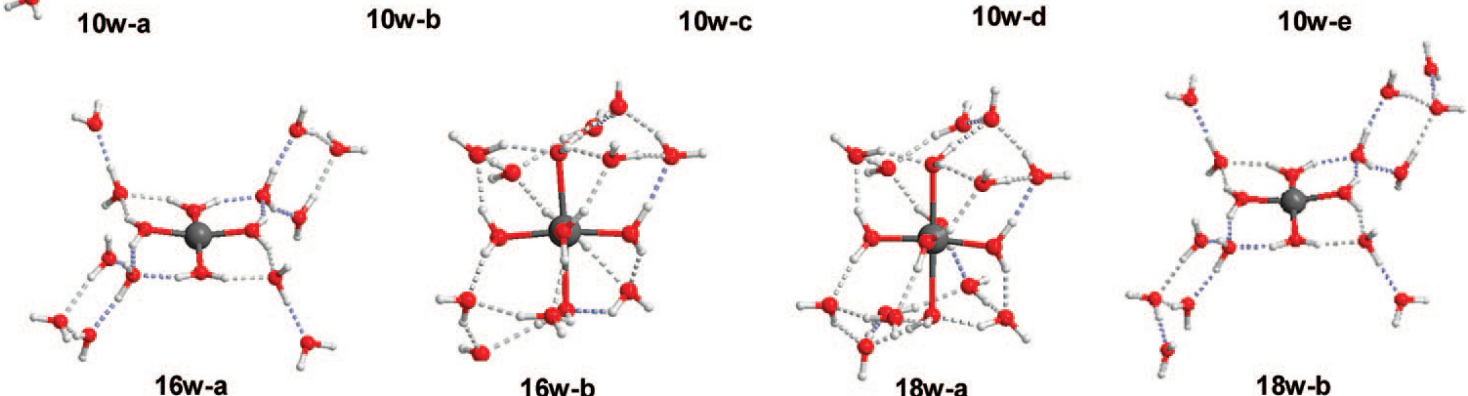

Figura 4. Estruturas otimizadas em fase gasosa (B3LYP/LACV3P+/6-311++(d,p)) do complexo $\left[\mathrm{Cu}\left(\mathrm{H}_{2} \mathrm{O}\right)_{n}\right]^{2+}(\mathrm{n}=4$ - 18) (átomos; cinza: cobre; vermelho: oxigênio e branco: hidrogênio). Figura reproduzida com permissão da referência 25

O cluster com 4 moléculas de água mostrou uma geometria quadrado planar. Também, o cluster com a presença de 5 moléculas de água, mostrou uma preferência de uma estrutura com o cobre tendo o número de coordenação 4, com a quinta molécula de água localizada no plano interagindo por ligações de hidrogênio com outras duas moléculas de água de coordenação (Fig. 4. 5w-a), em preferência a estrutura com a quinta molécula de água na posição axial (5w-b). Da mesma forma, o cluster $\left[\mathrm{Cu}\left(\mathrm{H}_{2} \mathrm{O}\right)_{8}\right]^{2+}$, a estrutura com 4 moléculas de água 
coordenadas ao cobre, com as outras quatro moléculas de água interagindo através de ligações de hidrogênio com as águas coordenadas ( $8 \mathrm{w}-\mathrm{a})$, mostrou uma maior estabilidade do que a estrutura pentacoordenada (8w-b). Para o cluster com 9 moléculas de água, a estrutura mais estável foi o arranjo com a nona molécula de água também interagindo por ligação de hidrogênio a uma molécula situada em um dos vértices da estrutura quadrado planar $(9 \mathrm{w}-\mathrm{a})$, em preferência a uma estrutura com a molécula de água na posição axial (9w-b). Da mesma forma, a estrutura (10w-a) foi a estrutura mais estável em fase gasosa do que as demais estruturas com $n=10$. Para o cluster $\left[\mathrm{Cu}\left(\mathrm{H}_{2} \mathrm{O}\right)_{16}\right]^{2+}$, a estrutura $(16 \mathrm{w}-\mathrm{a})$ foi a estrutura mais estável, como na estrutura (8w-a), onde as demais moléculas de água encontram-se interagindo através de ligações de hidrogênio formando a terceira esfera de hidratação. Da mesma forma, para o cluster $\left[\mathrm{Cu}\left(\mathrm{H}_{2} \mathrm{O}\right)_{18}\right]^{2+}$, a estrutura aberta foi a forma mais estável em fase gasosa (Figura 4. 18w-b).

Os resultados citados acima concordam com os resultados de espectrometria de massas para clusters de cobre hidratados realizados por Duncombe e colaboradores [39], com o número de moléculas de água de até 19. Nesse trabalho foi observado a redução de carga do átomo de cobre nas amostras devido a colisão de átomos de Xenônio (Xe), indicando que se tratava de estruturas abertas em que o gás de Xe podia colidir diretamente com o íon de $\mathrm{Cu}(\mathrm{II})$.

Analisando a energia de ligação de uma molécula de água coordenada na posição axial e a energia de ligação de uma molécula de água ligada a uma estrutura aberta de um cluster, por ligação de hidrogênio, Bryantsev et al. [25] mostraram que a energia de ligação das moléculas de água na periferia do cluster é maior do que a energia de ligação da molécula de água na posição axial. A interação desfavorável dos ligantes axiais nos complexos de $\mathrm{Cu}$ (II) hidratados pode ser compreendida analisando a estrutura eletrônica dos complexos. A Figura 5 mostra o orbital LUMO e a densidade eletrônica de spin do complexo $\left[\mathrm{Cu}\left(\mathrm{H}_{2} \mathrm{O}\right)_{10}\right]^{2+}(10 \mathrm{w}-\mathrm{c})$, indicando que a densidade do elétron desemparelhado é localizada principalmente no orbital $3 d_{\mathrm{x}^{2}-\mathrm{y}^{2}}$ do $\mathrm{Cu}(\mathrm{II})$ e nos pares de elétrons isolados tipo $\sigma$ das moléculas de água nas posições equatoriais. Ao passo que, os pares de elétrons isolados das moléculas de água nas posições axiais experimentam um forte iteração repulsiva com o orbital $3 d_{\mathrm{z}^{2}}$ do centro metálico. 


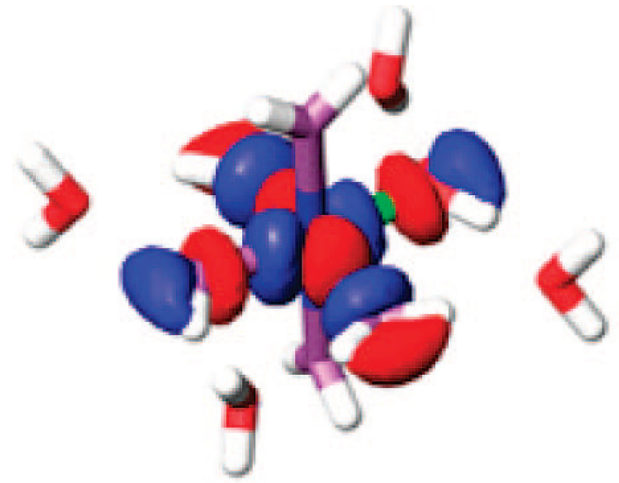

$\beta$-LUMO

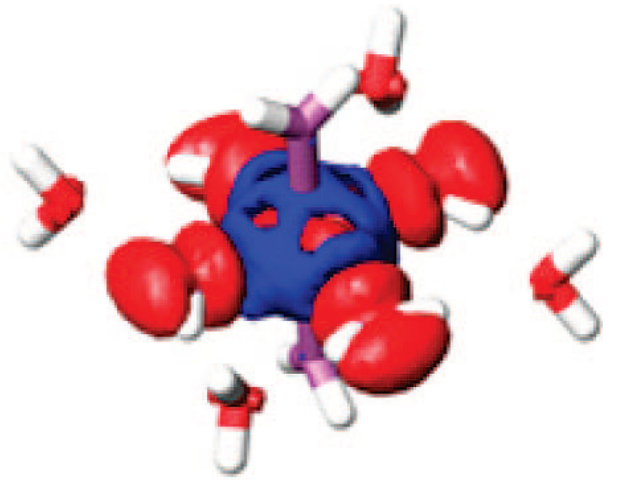

spin density

Figura 5. Orbital LUMO e densidade de spin para o complexo $\left[\mathrm{Cu}\left(\mathrm{H}_{2} \mathrm{O}\right)_{10}\right]^{2+}($ Fig. 4. 10wc). A densidade eletrônica é localizada preferencialmente no orbital $3 d_{x^{2}-y^{2}}$ do $\mathrm{Cu}(\mathrm{II}) \mathrm{e}$ nos orbitais $\sigma$ dos pares isolados. Figura reproduzida com permissão da referência 25

Análises da distribuição de carga do orbital atômico natural (NAO) dos complexos de $\mathrm{Cu}(\mathrm{II})$ indicaram uma maior transferência eletrônica das moléculas de água nas posições equatoriais para o centro metálico do que as moléculas de água nas posições axiais. Também, existe uma maior densidade de spin nas molécula de água nas posições equatoriais, sendo encontrado uma densidade de spin nula para as moléculas de água nas posições axiais. Foi verificado que a variação de carga do centro metálico varia pouco com o aumento do número de moléculas de água, variando de 1,54e (estrutura 4w) para 1,47e (18w-a). Entretanto, a carga total do cobre e das moléculas de água coordenadas ao metal (equatorial) diminui com o aumento do tamanho do complexo, indicando que a transferência de carga não se dá apenas entre o centro metálico e a primeira camada de coordenação, mas se estende significativamente para as posteriores esferas de hidratação. Esse fenômeno é observado para os íons metálicos, macios e divalente dos blocos $d$ e $f$ da tabela periódica.

Foram realizados cálculos de energia eletrônica e de energia livre de solvatação, em solução aquosa, utilizando o modelo de solvatação COSMO, para todos os complexos mostrados na Figura 4 [25]. De um modo geral, a presença de um meio com solvente aumentou a estabilidade dos clusters com número de coordenação alto comparado com as estabilidades em fase gasosa. Com isso, os isômeros pentacoordenados tornaram-se mais estáveis em fase aquosa para todos os isômeros com $\mathrm{n} \geq 8$. Por exemplo, a estrutura $8 \mathrm{w}$-a, a qual mostrou-se mais estável em fase gasosa, torna-se menos favorável do que a estrutura $8 \mathrm{w}$-b em fase 
aquosa. Para os clusters $\left[\mathrm{Cu}\left(\mathrm{H}_{2} \mathrm{O}\right)_{10}\right]^{2+}$, observou-se a transição de uma estrutura aberta em fase gasosa (10w-b, 10w-c) para uma estrutura mais compacta em fase aquosa (10w-d, 10w-e). A estrutura mais favorável em fase aquosa, foi o isômero (10w-d) (ver Figura 4), e a estabilização é atribuída a formação de ligações de hidrogênio entre uma molécula de água na periferia do cluster com moléculas de água nas posições axial e equatorial.

Como relatado, o número de coordenação do íon cobre(II) solvatado tem sido o assunto de grande discussão nos últimos anos. Os resultados propostos por Bryantsev et al. [25] indicaram o número de coordenação cinco, em fase aquosa, para complexos $\left[\mathrm{Cu}\left(\mathrm{H}_{2} \mathrm{O}\right)_{n}\right]^{2+}$ com $\mathrm{n}=8-10$. Também, para o cluster com 18 moléculas de água, cálculos B3LYP/LAV3P+/6-311++G(d,p) indicaram uma maior estabilidade para o complexo pentacoordenado com uma geometria pirâmide de base quadrada de cerca de $1,4 \mathrm{Kcal} \mathrm{mol}^{-1}$ em relação a estrutura octaédrica. Resultados semelhantes foram obtidos para clusters com $n=16$, no qual estão de acordo com as análises combinadas de EXAFS e XANES [23] de soluções aquosas de $\mathrm{Cu}(\mathrm{II})$. Modelos com número de coordenação quadro e seis para os complexos $\left[\mathrm{Cu}\left(\mathrm{H}_{2} \mathrm{O}\right)_{\mathrm{n}}\right]^{2+}$ não forneceram bons resultados.

A química de coordenação do $\mathrm{Cu}(\mathrm{II})$ com ligantes contendo nitrogênio e oxigênio determina como esse metal é transportado e como ele reage nos sistemas biológicos. A maioria dos trabalhos de cálculos de estrutura eletrônica descritos na literatura levam em consideração apenas a primeira esfera de coordenação ou hidratação. O efeito de uma segunda e completa camada de hidratação não tem sido levado em consideração em trabalhos anteriores.

O cobre(II) hidratado é a espécie predominante em solução aquosa em pH $<7$, ao passo que espécies mono e polihidroxiladas são formadas em quantidades significantes em $\mathrm{pH} \geq 7[47,48]$. As reações de hidrólise dos mais diversos complexos de cobre são fundamentais para o entendimento da completa especiação dos complexos de cobre em sistemas naturais, biológicos e em soluções alcalinas de importância industrial.

Cálculos computacionais precisos de mudança de energia livre para reações envolvendo íons de metais de transição, em solução aquosa, tem se tornado um desafio, principalmente devido a necessidade de se estimar precisamente o efeito da solvatação nessas reações [49-56]. 
Essas dificuldades podem ser maiores quando as reações envolvem a mudança de carga do centro metálico. Além do mais, os resultados de cálculos de energia livre de reações são extremamente sensíveis a escolha do modelo computacional e do modelo de cluster.

Recentes sucessos, na prescrição correta das energias livres em solução aquosa, tem sido atribuídas para a compensação dos erros em se aplicar um modelo do cluster contínuo, de funcional de densidade e de conjunto de bases [55$56]$.

Além do mais, o desenvolvimento de uma estratégia que seja capaz de melhorar sistematicamente o cálculo de energia livre de reações com o aumento do nível de teoria do cálculo e do tamanho do cluster pode ser um marco importante em nossa pesquisa para métodos mais precisos de cálculo computacional para sistemas envolvendo complexos biológcos altamente solvatados.

\section{5}

\section{Complexos de $\mathrm{Cu}(\mathrm{II})$ com alguns ligantes biológicos no estado sólido}

O estudo da interação do cobre(II) com peptídeos tem sido o foco de relevantes pesquisas nos últimos anos [57-59]. Também, complexos de cobre(II) com dipeptídeos e aminoácidos podem ser usados como modelos simples para o entendimento das propriedades dos centros de $\mathrm{Cu}(\mathrm{II})$ nos sítios ativos de diversas enzimas [57,60]. Além do mais, vários complexos de cobre contendo grupos ligantes simples, tem apresentado diversas atividades farmacológicas [60]. Por exemplo, complexos de cobre tendo como ligantes amino ácidos e oligopeptídicos tem apresentado atividades antiflamatória [61] e citostática.

O conhecimento da estrutura desses compostos tanto no estado sólido como em solução aquosa são essenciais para a compreensão de suas atividades. A estrutura cristalina de muitos complexos de cobre tendo os dipeptídeos como ligantes são conhecidas [57,61-66], onde diferentes modos de coordenação do metal tem sido reportados. Freenan [57] estabelecu por um primeiro momento que quando o dipeptídeo contém cadeias laterais não coordenantes, a estequiometria metal:ligante dos complexos é de 1:1. Nesses casos, o ligante coordena ao cobre(II) através dos átomos: nitrogênio do grupo amino, nitrogênio desprotonado 
do grupo peptídico e do oxigênio do grupo carboxílico. Na estrutura cristalina, o átomo de oxigênio do grupo carboxílico de um segundo ligante coordena-se ao átomo de cobre(II). Somente complexos de $\mathrm{Cu}(\mathrm{II})$ com dipeptídeos glicil-amino ácidos tem sido encontrados com as estequiometrias metal:ligante 1:1 e 1:2, apresentando-se como compostos monoméricos e diméricos [66,67]. Quando o dipeptídeo contém cadeias laterais com átomos com a capacidade coordenante tais como histidina, esses grupos também participam na coordenação $[68,69]$. Entretanto, existe uma falta de estudos sistemáticos na literatura para tais compostos.

Facchin et al. [61] sintetizaram e caracterizaram 4 complexos de cobre com os dipeptídeos gly-val, val-gly, val-phe e phe-phe. Todos os complexos apresentaram uma geometria piramidal de base quadrada. Nesses complexos, o íon $\mathrm{Cu}$ (II) ocupou o centro de uma geometria pirâmide de base quadrada, sendo coordenado equatorialmente a uma molécula do dipeptídeo agindo como um ligante tridentado. A quarta posição equatorial foi ocupada por uma átomo de oxigênio de um grupo carboxílico de uma segunda molécula do ligante dipeptídeo.

Yajima et al. [69] sintetizaram um complexo ternário de $\mathrm{Cu}$ (II) envolvendo o dipeptídeo gly-tyr e o ligante N-benzil-N-2-piridilmetilamina (bzp). A estrutura cristalina do complexo apresentou uma geometria pirâmide de base quadrada distorcida, com o dipeptídeo agindo como ligante tridentado. No complexo obtido, a ligação $\mathrm{Cu}-\mathrm{N}_{\text {pept }}$ foi menor do que a ligação $\mathrm{Cu}-\mathrm{N}_{\text {amino }}$, confirmando o caráter de ligação dupla $\mathrm{C}-\mathrm{N}_{\text {pept }}$ presente nos dipeptídeos.

García-Raso et al. [71] sintetizaram um complexo ternário [Cu(L-tyrgly)(isocyt)] $3 \mathrm{H}_{2} \mathrm{O}$. O complexo apresentou uma geometria quadrado planar distorcida com o ligante dipeptídeo agindo como um ligante tridentado e o nitrogênio heteroaromático da isocitosina ocupando a quarta posição de coordenação do complexo formado.

Em outro trabalho, Puspita et al. [72] sintetizaram outro complexo binário de cobre contendo um ligante de dipeptídeo com cadeia lateral contendo átomos com a capacidade coordenante: $\left[\mathrm{Cu}\left(\operatorname{ArgAspH} \mathrm{H}_{-1}\right)\right]$. O complexo formado apresentou uma geometria quadrado planar com o dipeptídeo agindo com um ligante tridentado e a quarta posição ocupada por um oxigênio carboxílico de uma segunda molécula do ligante dipeptídeo. 
Facchin et al. [73] sintetizaram um complexo binário de $\mathrm{Cu}(\mathrm{II})$ contendo o dipeptídeo his-gly como ligante e obtiveram um complexo hexacoordenado com duas moléculas de água ocupando as duas posições axiais do complexo, que apresentou uma geometria octaédrica distorcida. Nesse caso, o dipeptídeo agiu como um ligante bidentado formando um complexo com a razão metal ligante 1:2. Os átomos de $\mathrm{N}_{\text {amino }}$ e $\mathrm{N}_{\text {imid }}$ (imidazólico) foram os átomos envolvidos na coordenação do cobre nesse caso.

Continuando o estudo de complexos ternários, García-Raso et al. [74] sintetizaram alguns complexos ternário de cobre: $[\mathrm{Cu}(\mathrm{gly}-$ tyr)(benzimidazole) $] \cdot \mathrm{H}_{2} \mathrm{O}, \quad[\mathrm{Cu}($ ala-gly)(benzimidazole $)] \cdot 3 \mathrm{H}_{2} \mathrm{O} \quad$ e $\quad[\mathrm{Cu}(\mathrm{gly}-$ trp)(creatinina) $] \cdot 1,25 \mathrm{H}_{2} \mathrm{O}$. Todos os complexos apresentaram uma geometria quadrado planar distorcida com o ligante dipeptídeo agindo como um ligante tridentado e a quarta posição ocupada pelo nitrogênio heteroaromático tanto do ligante benzimidazole quanto do ligante creatinina.

\section{6}

\section{Estresse oxidativo}

Quando o oxigênio é parcialmente reduzido durante o processo de respiração celular há a formação de radicais livres, que são moléculas que apresentam um elétron desemparelhado na camada de valência (Fig. 6). A presença de um elétron desemparelhado faz dos radicais livres espécies altamente instáveis, de meias-vidas relativamente curtas e quimicamente muito reativas [75].

O estresse oxidativo é um desequilíbrio entre a produção de radicais livres, em particular das espécies reativas de oxigênio (EROs), e a capacidade do organismo em combater tais espécies, levando a um progressivo dano oxidativo. 


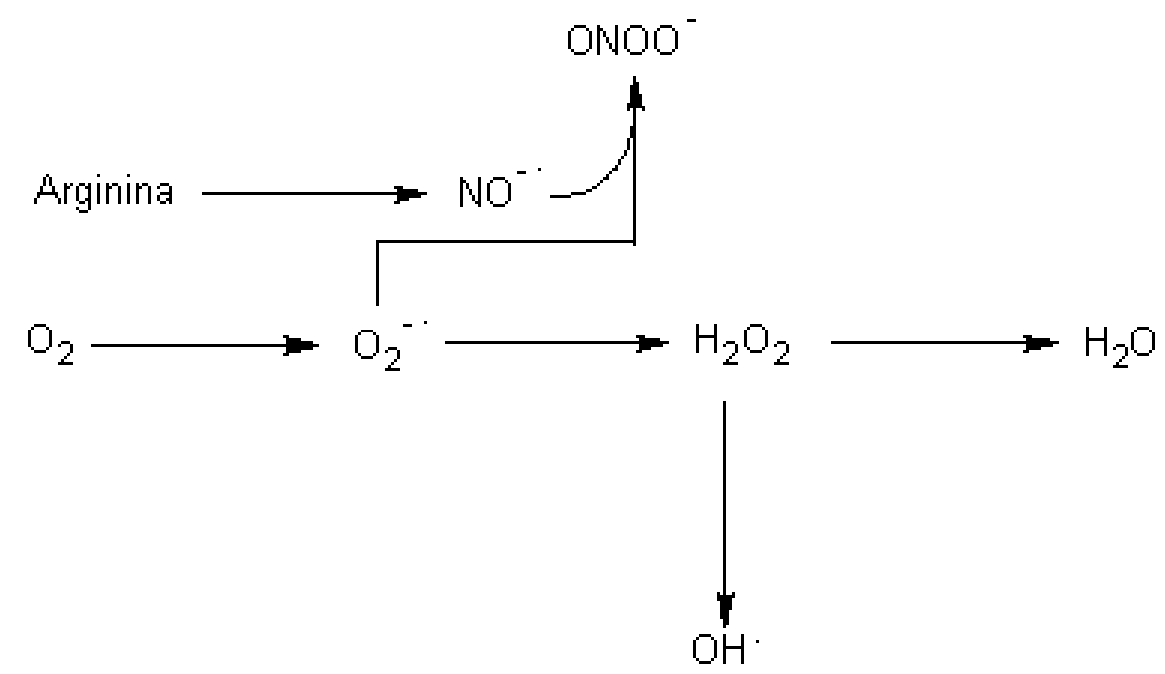

Figura 6. Formação de espécies reativas de oxigênio formadas no decorrer do processo de redução do oxigênio molecular $\mathrm{O}_{2}$ a $\mathrm{H}_{2} \mathrm{O}$

Sob condições fisiológicas, o metabolismo dos neurônios e das células glia produzem EROs. Aproximadamente 2-5\% do fluxo de elétrons da cadeia respiratória nas mitocôndrias produz ânion superóxido $\left(\mathrm{O}_{2}{ }^{-}\right)$e peróxido de hidrogênio $\left(\mathrm{H}_{2} \mathrm{O}_{2}\right)$ [76].

O estresse oxidativo é um dos mecanismos que desempenha papel central no processo de degeneração dos neurônios [77]. A formação em excesso dessas espécies oxidantes no tecido encefálico contribue para o dano neuronal por afetar diretamente proteínas, lipídeos e também DNA (Fig. 7) [78].

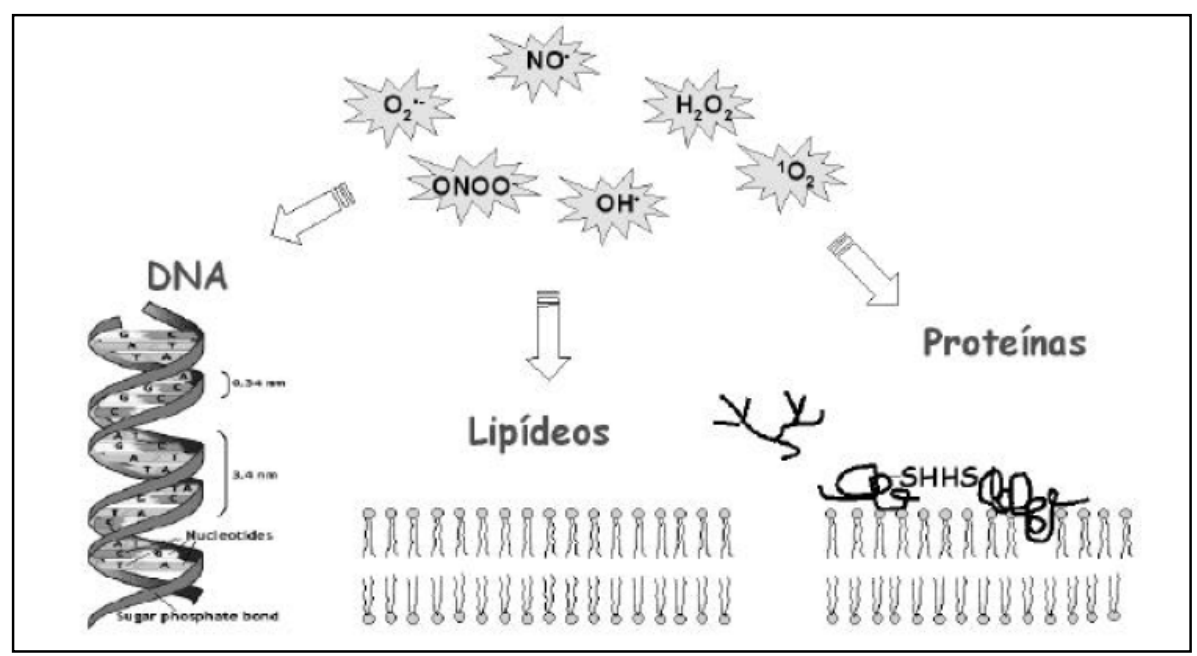

Figura 7. Dano oxidativo causado pelo ataque das espécies reativas de oxigênio (EROs) [78]

$\mathrm{O}$ equilíbrio entre a geração de oxidantes e a produção de agentes antioxidantes protege os componentes vitais da célula [79]. Nos tecidos afetados a atividade enzimática antioxidante é o processo de defesa primária contra as 
espécies pró-oxidantes geradas durante as diversas desordens em que são caracterizadas pelo estresse oxidativo. [80].

O fluido cerebral (líquido cefalorraquidiano) contém altas concentrações de agentes biológicos redutores tais como cisteína, ácido ascórbico, glutationa, metionina, homocisteína, entre outros. Estes redutores biológicos auxiliam na neuromodulação, protegem contra o estresse oxidativo e proporcionam substratos para a síntese de antioxidantes.

$\mathrm{O}$ ataque das espécies reativas de oxigênio na membrana, em particular do peróxido de hidrogênio, faz com que ocorra a lipoperoxidação, gerando um aumento na concentração dos subprodutos e uma produção de compostos antioxidantes no plasma. Esses indicadores biológicos tanto dos produtos da degradação da membrana como a geração de agentes antioxidantes são indícios do estresse oxidativo.

Deve salientar-se que os radicais livres têm preferência a se ligarem com as células gordurosas do que com outras estruturas. Como e cérebro e as células nervosas tem alta concentração de gordura e pouca capacidade regenerativa, faz do cérebro um órgão mais susceptível ao ataque dos EROs. Ataca membranas como nas mitocôndrias, afetando o processo responsável pela produção de energia. Assim, os radicais livres, a menos que sejam "capturados", podem causar danos substanciais ao tecido nervoso e também podem interferir no processo de produção de energia.

\section{7}

\section{Metionina}

O extresse oxidativo é um fator responsável pela disfunção dos tecidos internos dos vasos sanguíneos (células endoteliais) e participa de um papel importante na patologia de diversas doenças vasculares tais como arteroesclerose, diabetes ou de doenças neurodegenerativas [81].

Evidencias sugerem uma papel importante dos fatores nutricionais tais como antioxidantes, ácidos graxos, peptídeos bioativos ou amino ácidos livres na modulação da função endotelial. O aminoácido L-alanina e amino ácidos similares estruturalmente tem sido reportado para reduzir a morte de células endoteliais causadas pelas espécies reativas de oxigênio [82-85]. 
Similarmente, o aminoácido L-metionina mostra propriedades antioxidantes em vários modelos de estresse oxidativo. Efeitos antioxidantes da Lmetionina levam para a redução da peroxidação lipídica da membrana e restabelecem as mudanças no sistema da glutationa. Resíduos de metionina podem agir como um poderoso antioxidante endogêno em proteínas [86,87].

O mecanismo responsável pela citoproteção causada pelo aminoácido Lmetionina não são completamente compreendidos ainda. A atividade de sequestrar os radicais livres pode ser parcialmente explicada pela função quelante do átomo de enxofre presente na metiona. Entretanto, um plausível modo de ação pode ser a indução de genes protetivos e proteínas que reduzem o dano causado pelas espécies reativas de oxigênio (EROs).

Quando o resíduo de metionina sofre oxidação, é um indicador do processo de formação de radicais livres. A Figura 8 mostra o processo de oxidação da metionina: a oxidação forma sulfóxido e sulfona, respectivamente, ambos podendo ser regenerados por ação de agentes redutores.

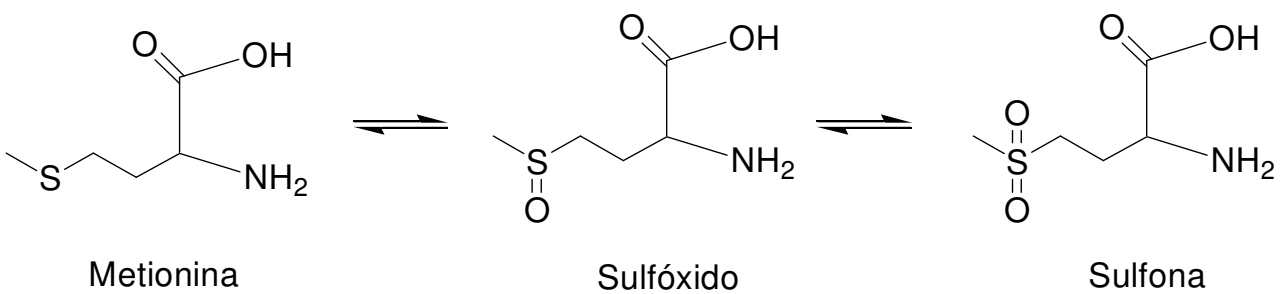

Figura 8. Processo de oxidação reversível da metionina, forma sulfóxido-metionina e sulfona devido ao ataque de espécies reativas de oxigênio

Baseados em evidências experimentais, tem-se sugerido que a metionina poderia exercer um mecanismo de proteção dos graves danos causados pelo processo de oxidação. Alguns pesquisadores recomendam um aprofundamento no estudo deste aminoácido, uma vez que há uma crescente necessidade de se encontrar potentes agentes antioxidantes que sejam capazes de chegar ao cérebro e ajudar a retardar o progresso desencadeado por doenças neurodegenerativas. 


\section{8}

\section{A doença de Alzheimer (DA)}

A doença que tem se tornado conhecida como a doença de Alzheimer (DA) foi descrita pela primeira vez pelo neurologista alemão Alois Alzheimer em 1902 [88]. Esta doença é a mais conhecida e a mais comum condição de demência neurodegenerativa. A causa exata da doença permanece esquivo desconhecida apesar do extraordinário volume de pesquisa sobre esta doença.

As mudanças comportamentais e neurológicas que ocorrem são progressivas e irreversíveis, mas tornam-se mais evidentes no estágio fatal. Sintomas incluem perda de memória, ansiedade, agressão, desilusão, depressão, desorientação e perda das facilidades intelectuais, incluindo cognitiva e eventualmente perda das funções fisiológicas devido à demência avançada. Esta doença afeta uma em cada dez pessoas com a idade de 65 anos e uma em cada duas pessoas com a idade de 80 anos [88].

Recentemente, tem-se renovado a especulação de que o desequilíbrio de metais é a causa da DA. Por muito tempo foi sugerido que depósitos de alumínio participam no aparecimento da DA, mas sem nenhum apoio real que evidencia essas teorias, essa especulação tem sido disseminada. Atualmente, tem sido sugerido que o cobre, possivelmente, participa no papel de surgimento da DA, devido a facilidade desse metal se ligar tanto a APP quanto a A $\beta$.

Atulamente, existem duas hipótese para o desencademaneto da doença de Alzheimer. Na hipótese amiloidogênica, a APP é quebrada sequencialmente pelas enzimas $\beta$-secretase (protease aspartil) e pela $\gamma$-secretase. A $\beta$-secretase produz dois fragmentos: APP $\beta$ s e $\beta$-CTF (Fig. 9). A enzima $\gamma$-secretase, que é um complexo com multi-subunidades (contendo genes das presenilinas 1 e 2), quebra o resíduo $\beta$-CTF para produzir o peptídeo $\beta$-amilóide, $A \beta$ (A $\beta-42$ e $A \beta-40)$, e o fragmento intracelular AICD. Alguns estudos recentes indicam que pode existir outros fatores envolvidos na ação das presenilinas e, portanto na quebra do fragmento transmembrânico da APP [89]. Mutações nos genes PS1 e PS2 induzem o aumento na produção do resíduo tóxico $A \beta-42$. Em indivíduos com a doença de Alzheimer, frações solúveis de agregados do peptídeo A $\beta$ são significantemente maiores do que em indivíduos saudáveis [90] e os dois 
peptídeos $\beta$-amilóide, $A \beta-42$ e $A \beta-40$, migram da célula para formar agregados, fibrilas e eventualmente placas neuríticas.

$O$ fragmento $A \beta$ pode existir como três frações bioquímicas no cérebro: associado a membrana celular, agregado e solúvel. Em indivíduos saudáveis, a maioria do fragmento $A \beta$ se encontra associado a membranas, com uma pequena quantidade dos monômeros solúveis detectados no fluido cerebroespinhal e no sangue [91]. A A $\beta$, possivelmente existe como uma conformação $\alpha$-hélice quando é parte da proteína transmembrânica da APP, com o terminal C hidrofóbico incorporado a membrana lipídica.

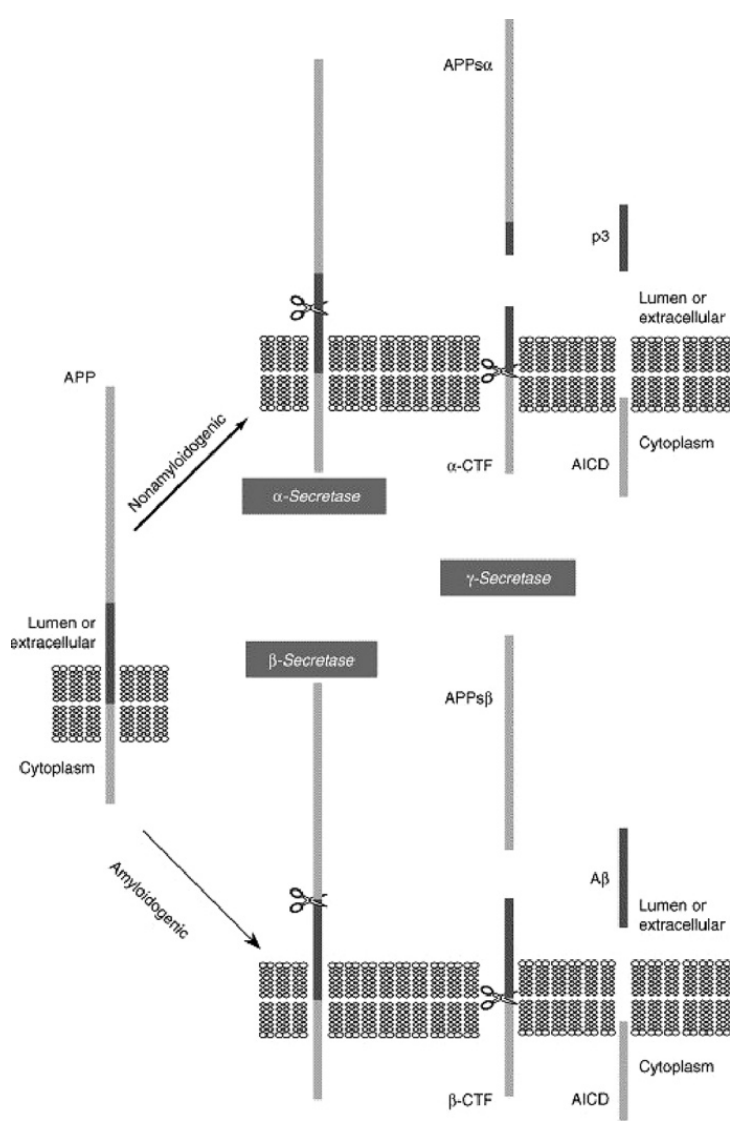

Figura 9. Processo proteolítico da proteína precursora amilóide (APP) ocasionado pela ação das secretases. A proteína APP é uma glicoproteína transmembrânica tipo-I. Figura reproduzida com permissão da referência 91

A acumulação e agregação de $A \beta$ é considerado ser o fator inicial na patologia da DA, embora é conhecido que o depósito ocorre por muitos anos, se não décadas, antes dos primeiro danos cognitivos. $\mathrm{A} \beta$ pode ser oxidado dentro das membranas, às vezes como um resultado do aumento dos níveis de $\mathrm{Cu}$ e $\mathrm{Fe}$ no cérebro [90]. 
O peptídeo $\mathrm{A} \beta$-amilóide, na forma de fibrilas insolúveis, é o principal componente das placas senis encontradas no cérebro dos pacientes com Alzheimer. Essa observação, em meados dos anos 80 [92,93], levou a hipótese que a deposição do peptídeo amilóide é o passo inicial para a patologia da doença de Alzheimer [93]. Esta hipótese ganhou força a partir de observações que as placas senis são rodeadas por células degeneradas [94,95] e que o peptídeo A $\beta$ é tóxico para culturas de neurônios [96-102].

Os cérebros dos pacientes com Alzheimer estão sujeitos a um aumento do estresse oxidativo, dano causado por radicais livres [103-106]. Com isso ocorre uma série de disfunções celulares e acredita-se que esse excesso de radicais livres seja responsável pela degeneração neuronal na DA. Várias evidências suportam esta hipótese: observa-se um aumento na oxidação de proteínas [107-109] e do DNA [104,109-113]; diminuição dos níveis de ácidos polinsaturados [113-116] juntamente com um aumento da peroxidação lipídica [117-120]; aumento dos níveis de 4-hidroxinonenal (HNE), que é um produto tóxico da peroxidação lipídica [121,122] e aumento dos níveis de isoprostanos, que são produtos da oxidação induzida por radicais livres no ácido araquidônico [128,129]. Várias revisões são disponíveis na literatura descrevendo o grande número de evidências que estabelecem o relacionamento entre o estresse oxidativo e a DA [105,106,124-128].

Os locais no cérebro dos pacientes de Alzheimer onde ocorre a neurodegeneração são os mesmos onde existe um estresse oxidativo e isto é associado a depósitos do peptídeo A $\beta$ [107]. Baseado nessas observações e no extenso estudo existente do estresse oxidativo e da neurotoxicidade associado com o peptídeo $A \beta$, foi proposto um modelo onde o estresse oxidativo associado com A $\beta$ leva a neurodegeneração na DA [128-131] (Fig. 10). De acordo com esse modelo, o peptídeo $A \beta$ é responsável diretamente pelo dano exercido pelos radicais livres nas membranas dos neurônios, levando para uma posterior perda neuronal nos cérebros de pacientes com Alzheimer. $\mathrm{O}$ mecanismo pelo qual o peptídeo $\mathrm{A} \beta$ exerce a toxicidade ainda permanece desconhecido, mas Varadarajan et al. [132] sugeriram, e outros autores confirmaram, que os radicais livres estão associados com a toxicidade da $\mathrm{A} \beta$.

O grande número de modificações celulares que ocorrem na doença de Alzheimer deixa o estudo sobre as causas e consequências da DA um pouco 
confuso. Alterações na resposta inflamatória, nas enzimas membranares, nas proteínas transportadoras, nas proteínas estruturais e do citoesqueleto, nos lipídeos, nas funções da mitocôndria, na homeostase do $\mathrm{Ca}^{2+}$, etc., tem sido documentadas na DA [104,105,126,132-135]. Uma maneira de descrever as inúmeras mudanças detectadas na patologia do Alzheimer é associa-las a ação dos radicais livres.

Uma vantagem desse modelo é que ele unifica em um modelo teórico coerente as características patológicas da DA, a princípio aparentemente desconectadas. Os inúmeros fenômenos inicializados pelo peptídeo amilóide e geração de radicais livres reativos, podem descrever para um vasto prejuízo nas funções dos neurônios. Os produtos tóxicos secundários produzidos pelo ataque dos radicais livres nas membranas,tais como HNE ou acroleína, embora menos reativos do que os radicais livres, alcançam uma meia-vida de minutos e até de horas, fazendo com que eles possam difundir dos seu locais de geração e causar prejuízos em sítios distantes. Além do mais, esses produtos secundários são fortes nucleofílicos, reagindo facilmente com resíduos em proteínas tais como cisteína, histidina ou lisinas ou com grupos de amino ácidos em lipídios. Este modelo é consistente com a dependência da idade para com a DA. Pessoas jovens que possuem uma grande capacidade antioxidante [136-138], são capazes de resistir ao estresse oxidativo, causado pelos radicais livres associados amiloide A $\beta$. Tais mecanismos antioxidantes são comprometidos com o aumento da idade ou com alguns fatores ambientais [130,131]. Portanto, o dano causado pela acumulação de radicais livres pode descrever, em parte, as várias alterações celulares e nas membranas observadas na DA. 


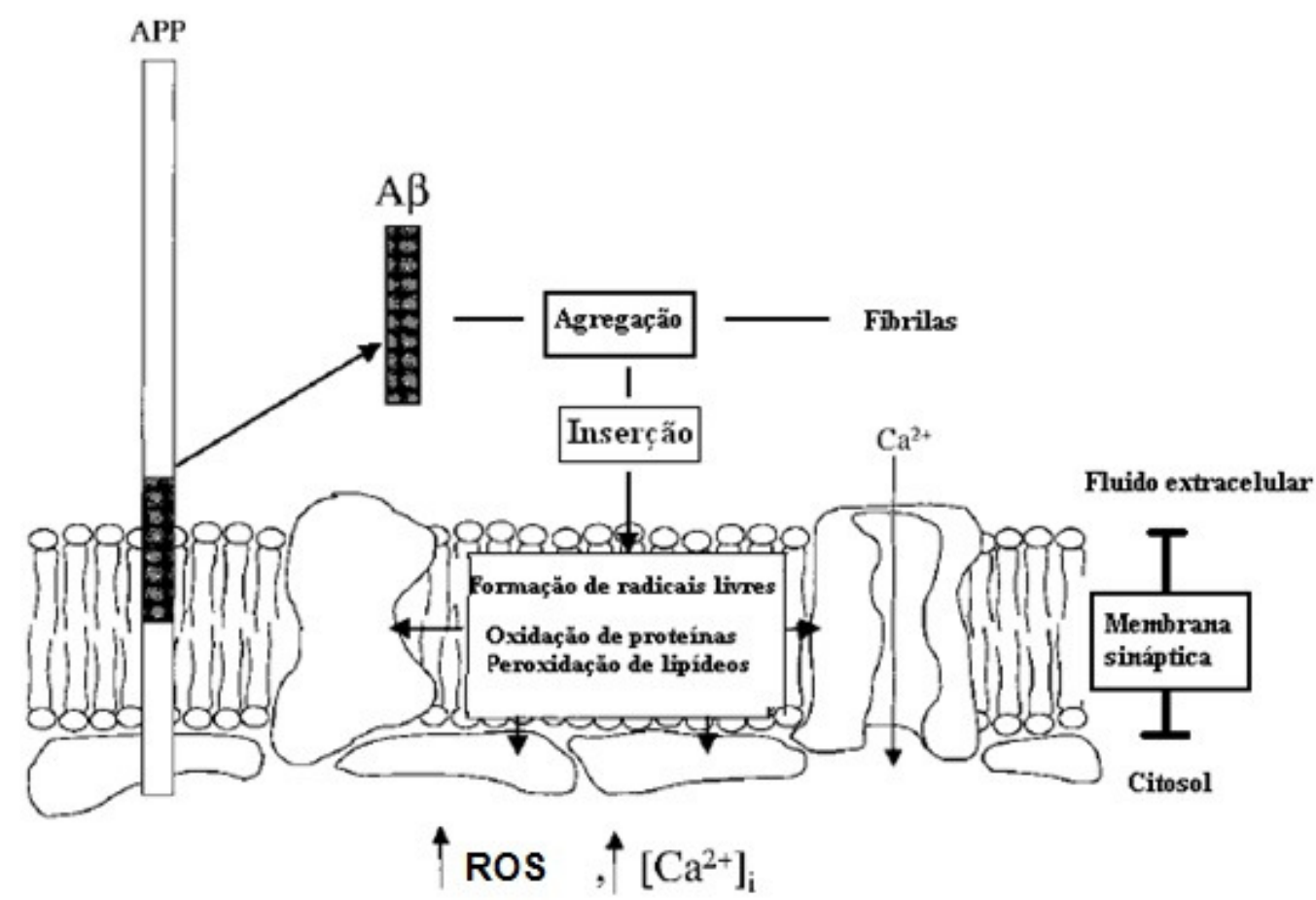

Figura 10. Modelo para o estresse oxidativo causado por radicais livres associado ao peptídeo $A \beta$ na doença de Alzheimer. O peptídeo $A \beta$ inicia a formação de radicais livres os quais reagem rapidamente com várias espécies na membrana plasmática causando a oxidação de proteínas e a peroxidação lipídica. Produtos tóxicos da peroxidação lipídica, tais como HNE e acroleína, tendo meia-vida grandes em relação aos radicais livres, migram para diferentes partes dos neurônios causando várias alterações deletérias nas funções celulares, especialmente aumento expressivo na concentração de $\mathrm{Ca}^{2+}$ intracelular, levando a última instância a morte do neurônio. Figura adaptada da referência 132

A estrutura e a composição detalhada dos centros das placas amilóides foram investigados através da microscopia Raman [139]. Espectros obtidos de amostras isoladas das placas senis de cérebros de pacientes, diagnosticados com Alzheimer, confirmaram que os núcleos nas placas senis são compostos principalmente pela proteína $A \beta-42$ com uma configuração de $\beta$-folha (Fig. 11a). Bandas dos espectros Raman foram caracterizadas e mostraram que o resíduo metionina se encontrava na forma sufóxido, sugerindo que a metionina é oxidada no interior das placas senis. $\mathrm{O}$ espectro Raman também mostrou que o $\mathrm{Cu}^{2+}$ coordena-se aos resíduos histidina nos centros das placas senis. O tratamento das placas senis com EDTA mostrou que esse agente complexante remove o cobre ligado ao resíduo histidina, acompanhado por uma perda na estrutura $\beta$-folha e uma solubilização dos depósitos amilóides. 
A quantidade exata de cobre em amostras extraídas dos núcleos das placas é cerca de $0,8 \mathrm{mg} \mathrm{L}^{-1}$ [140]. O envolvimento do cobre na patologia da DA é suportado pelo fato que este metal (junto com outros metais) tem elevada afinidade com $A \beta$ in vitro. Apesar de algumas divergências na literatura sobre as causas da DA, é largamente aceitável que o peptídeo A $\beta$ é um forte agente quelante para o $\mathrm{Cu}(\mathrm{II})$, e que essa coordenação tem levado a uma mudança na morfologia das fibrilas formadas, como já observado para o caso do zinco [141], ou a mediação da formação de espécies reativas de oxigênio como $\mathrm{H}_{2} \mathrm{O}_{2}, \mathrm{O}_{2}{ }^{-} \mathrm{e}$ $\mathrm{OH} \bullet$ via reações de Haber-Weiss e Fenton [142].

Resultados teóricos e experimentais indicam que os resíduos Tyr10, His13, His14 e possivelmente His6 da proteína $A \beta-42$ são os principais resíduos coordenados ao íon $\mathrm{Cu}$ (II) (Fig. 11b) [143]. Embora os sítios de coordenação do cobre já foram estabelecidos, estudos mostram que o peptídeo A $\beta-42$ pode ligar até 2,5 átomos de cobre por peptídeo [144].

Dong et al. [145,146] identificaram que apenas uma forma de ligação entre $\mathrm{Cu}(\mathrm{II})$ e o peptídeo $\mathrm{A} \beta-42$ parece ser neurotóxica. Este grupo já tinha desenvolvido várias pesquisas para determinar a forma de crescimento e evolução conformacional dos amilóides associados a diversas doenças neurodegenerativas, até mesmo os agregados amilóides associados às doenças priônicas.
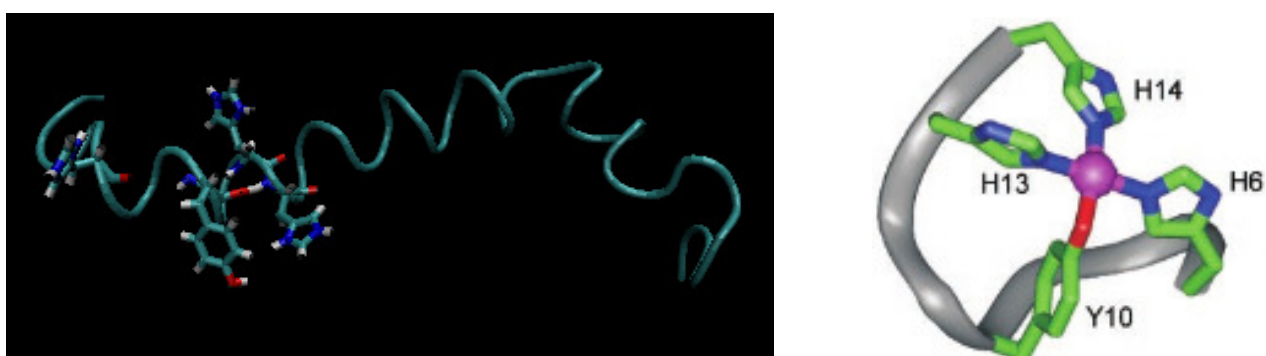

(a)

(b)

Figura 11. (a) Principais resíduos de aminoácidos do peptídeo $A \beta\left(\mathrm{His}^{6} \mathrm{Tyr}^{10} \mathrm{His}^{13} \mathrm{His}^{14}\right)$ que acredita-se estarem envolvidos na coordenação a metais; (b) Modelo da coordenação do $\mathrm{Cu}^{2+}$ ao peptídeo A $\beta$-42. A coordenação envolve o oxigênio fenol do resíduo tirosina e os nitrogênios do anel imidazol dos resíduos de histidina em uma geometria quadrado planar. $O$ modelo ilustra a geometria de coordenação do primeiro equivalente de cobre em $\mathrm{pH}$ fisiológico. A coordenação em elevados valores de $\mathrm{pH}$ provavelmente envolva a coordenação de grupos amida da cadeia do peptídeo. Figura reproduzida com permissão da referência 147 


\section{9}

\section{Modelos de solvatação}

Muitos processos químicos de relevância biológica e tecnologia ocorrem em fase condensada, em particular em soluções líquidas. Muitos tratamentos de cálculos teóricos não levam em consideração os efeitos do solvente. Com o avanço das técnicas de tratamento quântico, estão fazendo os cálculos ab initio um procedimento confiável no tratamento de interações soluto-solvente.

Entre as diversas aproximações propostas para descrever o efeito do solvente a nível $a b$ initio os modelos do dielétrico contínuo são os mais comuns devido sua flexibilidade e eficiência.

Em tais modelos a molécula do soluto é colocada em uma cavidade rodeada por um dielétrico contínuo de permissividade $\varepsilon$, no qual o campo reacional modifica a energia e as propriedades do soluto. Nos modelos ab initio mais avançados (PCM, SCIPCM, SCRF e COSMO), as cavidades tem o formato da molécula do soluto. O campo reacional é descrito em termos das cargas aparentes de polarização ou dos fatores do campo reacional que são incluídos no Hamiltoniano do soluto. Então, é possível realizar um procedimento interativo auto consistente, levando a uma função de onda entre o soluto e a polarização do solvente.

A precisão dos modelos de solvatação contínuos depende de vários fatores, o mais importante é o uso de condições limite de fronteira na superfície da cavidade que contém o soluto. Os métodos de solvatação PCM e SCRF definem as cavidades como envelopes de esferas centradas em átomos ou grupos atômicos.

Dentro da cavidade a constante dielétrica é a mesma que no vácuo, e fora da cavidade o valor da constante é a do solvente desejado. Uma vez que a cavidade tem sido definida, a superfície é mapeada lentamente por pequenas regiões (chamada tesserae). Cada região (tesserae) é caracterizada pela posição do seu centro, sua área, e o vetor normal eletrostático que passa pela superfície através do seu centro. Esses parâmetros geométricos podem ser diferenciados analiticamente com respeito ao movimento nuclear dos átomos. Algoritmos altamente eficientes tem sido recentemente desenvolvidos, com o objetivo de formar uma cavidade para solutos muito grandes (mil átomos) com um custo 
computacional limitado [148]. Um exemplo de cavidade, mapeada com uma área (tesserae) de 0,4 A é mostrada na Figura 12.

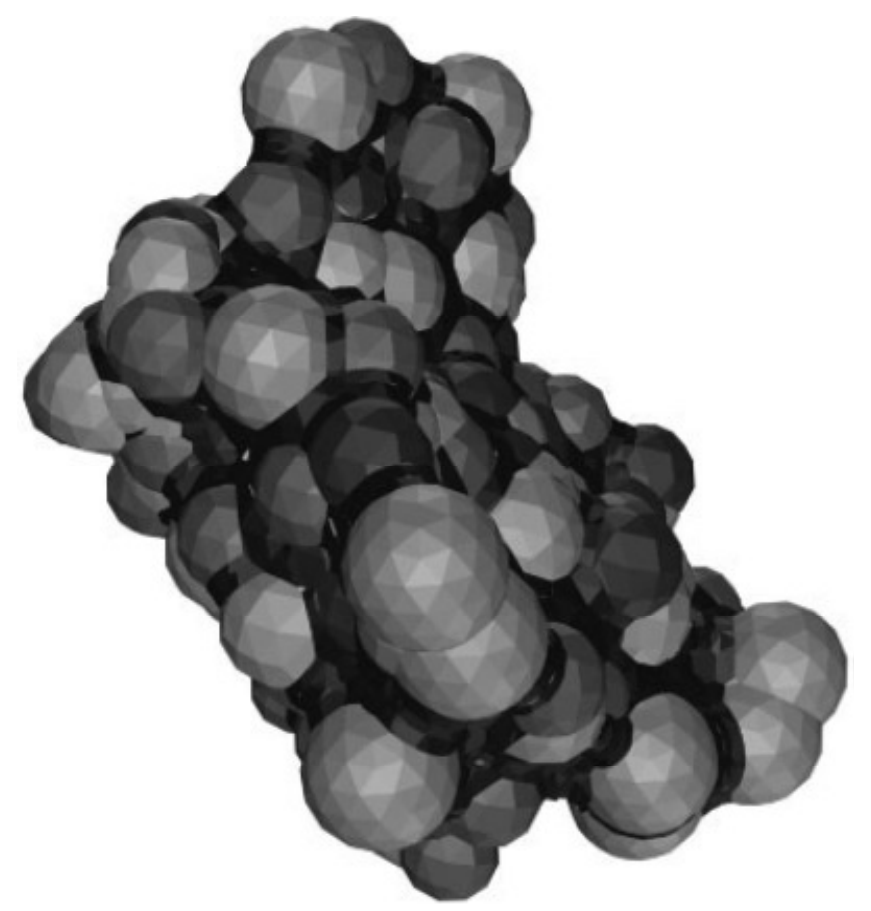

Figura 12. Cavidade do soluto para uma proteína cambrina com a média da área mapeada de cada tesserae de 0,4 Å. Figura adaptada da referência 148

Recentemente, Schäfer et.al. [149] propuseram um novo modelo de solvatação chamado COSMO (Conductor-like screening model), baseado na varredura em condutores nos quais não são interativos e permitem os cálculos de gradientes precisos sem restrições no formato da cavidade. As cargas na superfície são calculadas diretamente do potencial eletrostático da distribuição de carga dentro da cavidade. Isso leva a um melhoramento nas condições de fronteira, eliminando o potencial eletrostático na superfície de um condutor.

A aproximação COSMO leva a uma melhor precisão e é relativamente simples para cálculos de gradientes analíticos. A parte eletrostática da energia de solvatação é uma função quadrática da distribuição de carga do soluto e esta pode ser incluída no Hamiltoniano do soluto. O processo de cálculo auto consistente de otimização da distribuição de carga do soluto é feito simultâneo com a varredura do potencial incluído no ciclo auto consistente. Além do mais, o método COSMO é completamente variacional e os gradientes precisos podem ser rapidamente calculados. 
O método COSMO já vem sido usado em cálculos semi-empíricos e recentemente, os cálculos de energia usando o modelo COSMO vem sendo realizados pelo método DFT.

\subsection{0}

\section{Modelo do cluster contínuo}

Atualmente muito esforço tem sido dado no desenvolvimento de métodos para calcular, com certa precisão, as barreiras reacionais e energéticas ocorridas em fase condensada. Modelos com moléculas explicitas tornaram-se efetivos para a descrição dos sistemas em soluções líquidas entretanto, devido o alto nível de cálculos mecânico quânticos, somente um número limitado de moléculas do solvente podem ser incluídas.

Nos últimos 30 anos, tem sido feito um considerável esforço teórico para o desenvolvimento de métodos para calcular a energia livre de solvatação de espécies neutras e iônicas. Simulações em meios líquidos são consideradas como as aproximações mais precisas, pois as moléculas do solvente são incluídas explicitamente nos sistemas. Com isso, obtém-se uma boa precisão, levando em consideração um potencial intermolecular.

Modelos contínuos constituem uma boa alternativa para considerar o efeito do solvente. Esses modelos por serem práticos, fazem o modelo de dielétrico contínuo o mais usado nos dias de hoje.

Entre esses modelos contínuos, nós podemos destacar o modelo de solvatação contínuo (PCM) e sua variação baseado na isodensidade (IPCM). Esses métodos consideram o solvente como um dielétrico contínuo e o soluto com o uma molécula inserida em uma cavidade inserida dentro do dielétrico. Diferenças entre estes métodos baseiam-se na definição de como a cavidade do soluto interage com o dielétrico continuo. Contribuições adicionais para a energia livre de solvatação tais como os termos de dispersão e repulsão são incluídas nas diferentes aproximações. A definição de vizinhança da cavidade soluto-solvente não é única e não existe um consenso sobre a melhor escolha. Além do mais, moléculas do solvente na primeira camada de solvatação podem descrever por uma forte interação específica soluto-solvente que não são consideradas no 
modelo contínuo. Também, a aproximação do modelo contínuo, é baseada em uma resposta linear, no qual não é sempre correta.

Uma aproximação que melhora parte da deficiência do modelo do dielétrico contínuo consiste em adicionar, explicitamente, algumas moléculas do solvente interagindo com o soluto. A molécula formada é então inserida no dielétrico contínuo. Tal método tem sido utilizado por vários autores com diversas denominações: contínuo-discreto, campo reacional-supramolecular, semicontínuo e cluster-contínuo [149].

No presente trabalho nós utilizaremos o modelo do cluster-contínuo para calcular e energia livre de solvatação das reações de interesse. O potencial químico de uma espécie $\mathrm{X}$ em solução pode descrito como mostrado na Equação 1.

$$
\mathrm{X}_{(\mathrm{g})} \rightarrow \mathrm{X}_{(\mathrm{sol})}
$$

$\mu_{\mathrm{sol}}(\mathrm{X})=\mu_{\mathrm{g}}^{*}(\mathrm{X})+\Delta \mathrm{G}_{\mathrm{sol}}^{*}(\mathrm{X})+\mathrm{RT} \ln \left[\mathrm{X}_{(\mathrm{sol})}\right]$

onde o estado padrão $\left(^{*}\right)$ refere para 1 mol $\mathrm{L}^{-1}$. Ele pode ser facilmente transformado para um estado padrão a 1 atm $\left(^{\circ}\right)$ através da Equação 2:

$\mu_{\text {sol }}^{*}(\mathrm{X})=\mu_{\mathrm{sol}}^{\circ}(\mathrm{X})+\mathrm{RT} \ln [\check{\mathrm{R} T}]$

onde $\check{\mathrm{R}}=0,0082053 \mathrm{~K}^{-1}$. O termo $\Delta \mathrm{G}_{\text {sol }}^{*}(\mathrm{X})$ é a energia livre de sovatação como definido por definida por Ben-Naim [150] correspondendo ao processo (gás ideal, $\left.1 \mathrm{~mol} \mathrm{~L}^{-1}\right) \rightarrow$ (solução diluída ideal, $1 \mathrm{~mol} \mathrm{~L}^{-1}$ ). Essas duas propriedades são relacionadas pela Equação 3.

$$
\Delta \mathrm{G}_{\text {sol }}^{*}=\Delta \mathrm{G}_{\text {solv }}^{\circ}-\mathrm{RT} \ln (\check{\mathrm{R} T})
$$

O calculo teórico de pKa pode ser realizado pelo seguinte equilíbrio:

$$
\mathrm{HA}+\mathrm{H}_{2} \mathrm{O} \rightleftharpoons \mathrm{A}^{-}+\mathrm{H}_{3} \mathrm{O}^{+}
$$

A reação envolve a formação de espécies carregadas partindo de moléculas neutras, um problema para os cálculos teóricos. Por comparação, reações que conservem o número de espécies carregadas são mais apropriados para cálculos precisos de variação de energia livre. Portanto, em nossos 
equilíbrios químicos, quando partimos de espécies carregadas nós adotamos a reação entre o ácido e uma molécula de água; e quando partimos de espécies neutras nos reagimos como o ânion hidróxido, como mostrado nos equilíbrios abaixo. Com o uso das Equações (4) e (5) podemos calcular os valores de pKa para as espécies $\mathrm{HA}^{+}$e HA.

$\mathrm{HA}^{+}+\mathrm{H}_{2} \mathrm{O} \rightleftharpoons \mathrm{A}+\mathrm{H}_{3} \mathrm{O}^{+} \quad \mathrm{pK}_{\mathrm{a}}\left(\mathrm{HA}^{+}\right)=\frac{\Delta \mathrm{G}_{\mathrm{sol}}^{*}}{(2,303) \mathrm{RT}}-1,74$

$\mathrm{ou}$

$\mathrm{HA}+\mathrm{OH}^{-} \rightleftharpoons \mathrm{A}^{-}+\mathrm{H}_{2} \mathrm{O} \quad \mathrm{pK}_{\mathrm{a}}(\mathrm{HA})=\frac{\Delta \mathrm{G}_{\mathrm{sol}}^{*}}{(2,303) \mathrm{RT}}+15,74$

$\mathrm{O}$ uso de Equações para calcular os valores de $\mathrm{pK}_{\mathrm{a}}$ requer o cálculo de energia livre em fase gasosa em um alto nível de métodos $a b$ initio. No modelo de cluster contínuo, a ideia deste método é representar o íon (complexo) com um número ótimo de moléculas do solvente e então solvatar usando dielétrico contínuo. 


\section{2. \\ Objetivos}

A presente tese de doutoramento teve como objetivos principais:

- Calcular as constantes de formação de sistemas binários e ternário de cobre(II) por potenciometria;

- Determinar os valores dos pKa`s dos complexos de cobre(II) com resíduos de aminoácidos;

- Realizar especiação em função do $\mathrm{pH}$ dos sistemas binários e ternário de cobre(II);

- Identificar através de cálculos teóricos, os modos de coordenação dos ligantes glicilglicina e metionina com cobre(II) nos sistemas binários e ternário formados em solução aquosa, em uma ampla faixa de valores de $\mathrm{pH}$;

- Avaliar as propriedades termodinâmicas das principais espécies presentes nos sistemas estudados;

- Avaliar as geometrias e as propriedades eletrônicas dos complexos mais estáveis com a presença da primeira e segunda camada de solvatação (36 moléculas de água).

Para isso as seguintes estratégias foram adotadas:

- Utilização do programa BEST7 para cálculo das constantes de formação e dos valores de pKa`s dos complexos de cobre(II);

- Utilização do programa SPECIES para a geração de diagramas de distribuição de espécies em função do pH para os sistemas binários e ternário de cobre(II);

- Identificação das geometrias mais estáveis para as principais espécies com a presença da primeira e segunda camada de solvatação via cálculos DFT com inclusão do efeito do solvente;

- Geração de superfícies de distribuição de densidade de spin e identificação da estrutura eletrônica do estado fundamental para as principais espécies com a presença da primeira e segunda camada de solvatação. 


\section{3. Justificativa e relevância}

Em comum a todas as doenças neurodegenerativas é a presença anormal de proteínas no sistema nervoso central. O complexo binário $\mathrm{Cu}$ :GlyGly pode ser usado como um modelo biomimético para avaliar a ligação do metal a proteínas e enzimas.

Apesar das espécies presentes no sistema binário Cu:GlyGly serem estudadas desde a década de 60 [151], devido à falta de estruturas em solução aquosa, os modos de coordenação do $\mathrm{Cu}(\mathrm{II})$ não podem ser bem estabelecidos devido a labilidade desse íon.

Como o íon cobre(II) é um sítio redox, pode favorecer a formação de espécies reativas de oxigênio, causando um processo inflamatório (estresse oxidativo) característico de diversas desordens. O aminoácido metionina é um antioxidante presente no meio biológico que auxilia no processo de modulação do estresse oxidativo.

O recente avanço da técnicas de química computacional, possibilita avaliar as estruturas mais estáveis formadas em solução aquosa, levando em consideração os efeitos do solvente. A inclusão de uma segunda camada de solvatação nos complexos avaliados faz com que as geometrias e as estruturas eletrônicas dos complexos possam ser melhor estabelecidas.

No presente trabalho, foram estudados complexos modelos de $\mathrm{Cu}$ (II) com ligantes simples como: glicilglicina e metionina. Os estudos levaram a uma compreensão mais clara de como o $\mathrm{Cu}$ (II) se liga a resíduos de aminoácidos em solução aquosa. 


\section{4.}

Parte experimental

4.1

Materiais e Métodos

\section{Ligantes}

Glicilglicina (GlyGly) e metionina (Met) foram obtidos da Sigma-Aldrich Chem. Co.

\section{Sais de metais}

No presente trabalho foi utilizado o sal de nitrato cúprico trihidratado $\left(\mathrm{Cu}\left(\mathrm{NO}_{3}\right)_{2} \cdot 3 \mathrm{H}_{2} \mathrm{O}\right)$ procedente da MercK.

\section{Solução titulante}

Para as titulações potenciométricas utilizou-se uma solução de hidróxido de potássio $(\mathrm{KOH}) 1,0 \times 10^{-1} \mathrm{~mol} \mathrm{~L}^{-1}$ procedente da MercK.

\section{Eletrólito suporte}

A solução do eletrólito foi preparada utilizando nitrato de potássio $\left(\mathrm{KNO}_{3}\right)$ procedente da MercK.

\section{Soluções tampão}

Para calibração do pH metro foram utilizadas soluções tampão de pH 4,0 e 7,0 procedentes da Merck. 


\section{2}

\section{Equipamento}

- Titulação potenciométrica: Titulador automático modelo 809 Titrando da METRON com eletrodo combinado de vidro B375 com solução interna de $\mathrm{KCl}$ $1,0 \times 10^{-1} \mathrm{~mol} \mathrm{~L}^{-1}$.

\section{3}

\section{Procedimentos}

\subsection{1}

\section{Titulações dos ligantes puros}

100,0 mL de solução dos ligantes (GlyGly e Met) na concentração de 1,0 × $10^{-3}$ mol L ${ }^{-1}, 10,0 \mathrm{~mL}$ de $\mathrm{KNO}_{3}$ 1,2 $\mathrm{mol} \mathrm{L}^{-1}, 9,0 \mathrm{~mL}$ de água deionizada e $1,0 \mathrm{~mL}$ de $\mathrm{HCl} 1,0 \times 10^{-1} \mathrm{~mol} \mathrm{~L}^{-1}$, foram tituladas com adições sucessivas de $0,1 \mathrm{~mL}$ de $\mathrm{KOH}$ $1,0 \times 10^{-1} \mathrm{~mol} \mathrm{~L}^{-1}$. As titulações foram realizadas sob atmosfera de argônio.

\subsection{2}

Titulação dos sistemas binários de $\mathrm{Cu}(\mathrm{II}): \mathrm{L}(\mathrm{L}=$ GlyGly e Met) na proporção metal:ligante 1:1

$50,0 \mathrm{~mL}$ de solução dos ligantes na concentração de $2,0 \times 10^{-3} \mathrm{~mol} \mathrm{~L}^{-1}, 50,0 \mathrm{~mL}$ de água destilada, $10,0 \mathrm{~mL}$ de $\mathrm{KNO}_{3} 1,2 \mathrm{~mol} \mathrm{\textrm {L } ^ { - 1 }}$, $10,0 \mathrm{~mL}$ de solução de $\mathrm{Cu}\left(\mathrm{NO}_{3}\right)_{2} \cdot 3 \mathrm{H}_{2} \mathrm{O} 1,0 \times 10^{-2} \mathrm{~mol} \mathrm{~L}^{-1}$ foram tituladas com adições sucessivas de 0,1 $\mathrm{mL}$ de $\mathrm{KOH} 1,0 \times 10^{-1} \mathrm{~mol} \mathrm{~L}^{-1}$. As titulações foram realizadas sob atmosfera de argônio.

\subsection{3}

Titulação dos sistemas ternários $C u(I I): L_{1}: L_{2}\left(L_{1}=\right.$ GlyGly; $L_{2}=$ Met $)$ na proporção 1:1:1

$50,0 \mathrm{~mL}$ de solução do ligante $\mathrm{L}_{1}$ na concentração $2,0 . \times 10^{-3} \mathrm{~mol} \mathrm{~L}^{-1}, 50,0 \mathrm{~mL}$ de solução do ligante $\mathrm{L}_{2}$ na concentração 2,0.x $10^{-3} \mathrm{~mol} \mathrm{~L}^{-1}, 10,0 \mathrm{~mL}$ de $\mathrm{KNO}_{3} 1,2$ mol L ${ }^{-1}, 10,0 \mathrm{~mL}$ de solução de $\mathrm{CuNO}_{3} \cdot 3 \mathrm{H}_{2} \mathrm{O} 1,0 \times 10^{-2} \mathrm{~mol} \mathrm{~L}{ }^{-1}$ foram tituladas 
com adições sucessivas $0,1 \mathrm{~mL}$ de KOH $1,0 \times 10^{-1} \mathrm{~mol} \mathrm{~L}^{-1}$. As titulações foram realizadas sob atmosfera de argônio.

\subsection{4}

\section{Cálculos teóricos}

Os cálculos foram realizados utilizando a teoria do funcional de densidade (DFT) através do programa Turbomole 6.1 [152,153]. Foram utilizados 3 funcionais. O funcional não híbrido Perdew-Burke-Ernzerhof (PBE) [154] e os funcionais híbridos B3LYP [40] e PBE0 [155]. Os cálculos utilizando o funcional PBE foram realizados com a expansão das integrais Coulombianas em um conjunto de base de funções auxiliares, a chamada aproximação da resolução da identidade (RI-J) [157]. Todas as otimizações de geometria foram realizadas sem restrições de simetria utilizando o método RI-PBE e o conjunto de base def2-SVP [157], os efeitos de solvente foram incluídos através do método COSMO (Conductor-like Screening Model) [149], foi utilizado uma constante dielétrica para água igual a 78,3553. O calculo de frequências harmônicas foi realizado para caracterizar as geometrias obtidas como mínimos de energia e obter as contribuições nucleares para os cálculos termodinâmicos. As energia do ponto estacionário tanto em fase gasosa como em solução foram recalculadas utilizando o funcional B3LYP e PBE0 usando uma função de base maior def2-TZVP [158]. Os parâmetros termodinâmicos foram calculados como descrito por Pliego e Riveiros $[159,160]$. 


\section{5. \\ Resultados e Discussões}

Inspirado em estudos anteriores que descrevem os modos de coordenação do íon cobre(II) com fragmentos peptídicos, foi realizado um estudo sistemático via cálculos DFT explorando todas as possibilidades para a complexação do íon $\mathrm{Cu}$ (II) com o peptídeo GlyGly e também a associação ternária GlyGly + metionina. Os resultados são suportados por dados experimentais de potenciométria e espectroscopia (EPR, UV-visível e infravermelho).

\section{1}

\section{Modos de coordenação dos dipeptídeos em complexos binários de $\mathrm{Cu}(\mathrm{II})$, em solução aquosa}

Os dipeptídeos apresentam vários grupos funcionais que podem participar na coordenação de íons metálicos; o nitrogênio do grupo amino $\left(\mathrm{N}_{\mathrm{amino}}\right)$, o oxigênio $\left(\mathrm{O}_{\text {pept }}\right)$ e o nitrogênio $\left(\mathrm{N}_{\text {pept }}\right)$ da ligação peptídica e o oxigênio do grupo carboxílico $\left(\mathrm{O}_{\text {carbox }}\right)$. Em valores de $\mathrm{pH}$ de 3 a 5 , é descrito na literatura que os dipeptídeos que não apresentam cadeias laterais com a capacidade coordenante, ligam-se ao cobre(II) através dos átomos $\mathrm{N}_{\text {amino }}$ e $\mathrm{O}_{\text {pept }}$ formando a espécie CuL (L = dipeptídeo) $[151,58,161]$. Em valores de pH a partir de 5, na presença do íon cobre(II), ocorre a desprotonação do nitrogênio peptídico (amida), fazendo com que o dipeptídeo comporte-se como ligante tridentado através do sistema coordenante $\mathrm{N}_{\text {amino }} \mathrm{N}_{\text {pept }} \mathrm{O}_{\text {carbox }}$ dando origem a espécie $\mathrm{Cu}\left(\mathrm{H}_{-1} \mathrm{~L}\right)\left(\mathrm{H}_{-1} \mathrm{~L}\right.$ refere-se ao ligante dipeptídeo desprotonado no nitrogênio peptídico). A Figura 13 mostra os modos de coordenação de dipeptídeos com $\mathrm{Cu}(\mathrm{II})$ em solução aquosa, em uma ampla faixa de valores de $\mathrm{pH}$ mais aceitos na literatura $[151,58,161]$. 


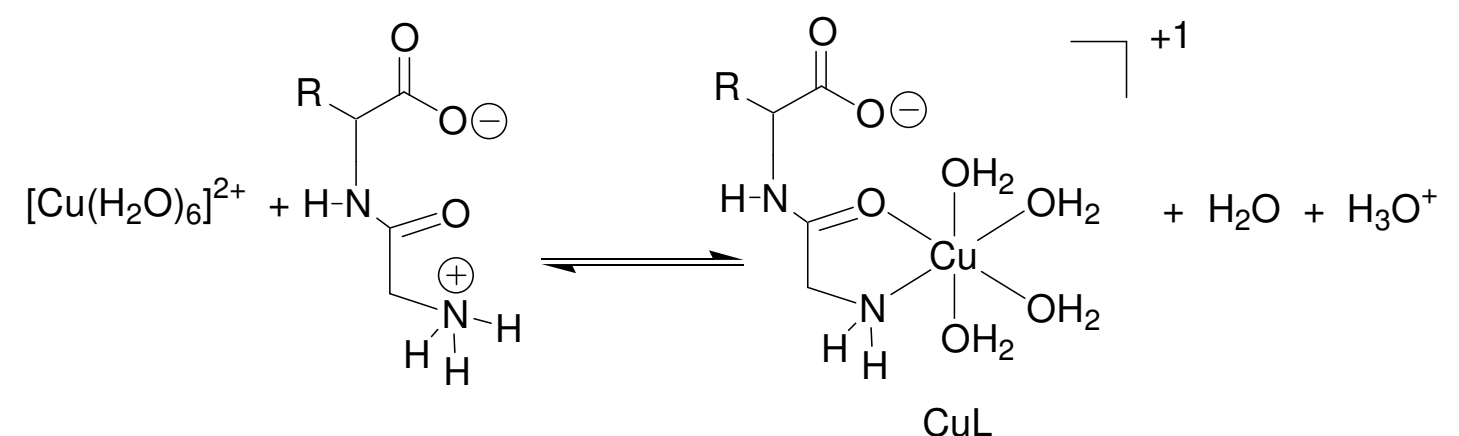<smiles></smiles>

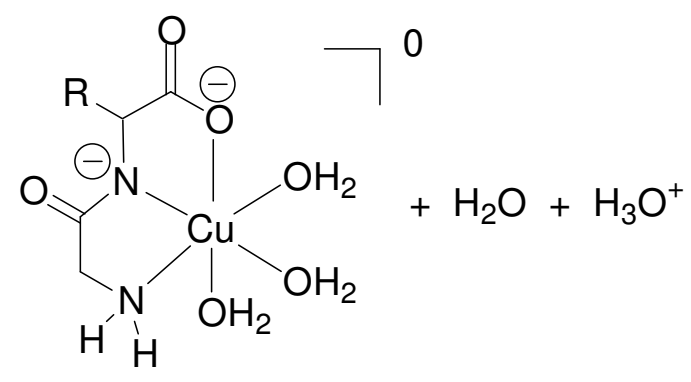

$$
\mathrm{Cu}\left(\mathrm{H}_{-1} \mathrm{~L}\right)
$$

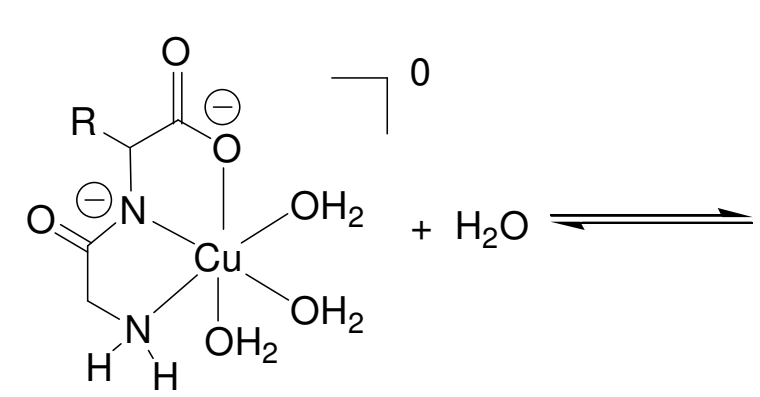

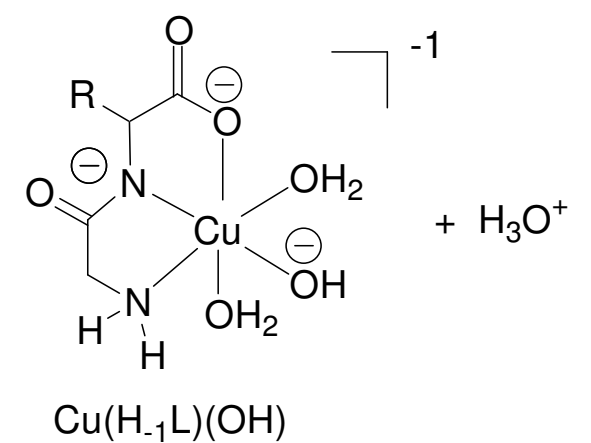

Figura 13. Modos de coordenação dos dipeptídeos que não possuem cadeia lateral com capacidade coordenante. $\mathrm{Na}$ faixa de $\mathrm{pH}$ de 3 - 5 forma-se a espécie $\mathrm{CuL}^{+}$, na faixa de pH 5 - 9 forma-se a espécie $\mathrm{Cu}\left(\mathrm{H}_{-1} \mathrm{~L}\right)$ e em valores de $\mathrm{pH}>9$ forma-se o complexo hidrolisado $\mathrm{Cu}\left(\mathrm{H}_{-1} \mathrm{~L}\right)(\mathrm{OH})^{-}$

O presente trabalho é uma investigação ampla dos modos de coordenação apresentados na Figura 13 para o sistema $\mathrm{Cu}(\mathrm{II})+$ glicilglicina. Como citado na introdução, o íon cobre tem papel importante no desenvolvimento de doenças neurodegenerativas. Também foi discutido que existe controvérsia a respeito das geometrias preferenciais que esse íon pode adotar.

Preliminarmente foi feito um estudo espectroscópico utilizando as técnicas de absorção eletrônica ultravioleta-visível, infravermelho e de ressonância paramagnética eletrônica para o sistema binário $\mathrm{Cu}$ :GlyGly na proporção metal:ligante 1:1, com intuito de analisar as mudanças espectrais ocorridas no 
sistema com a variação do $\mathrm{pH}$. Em valores de $\mathrm{pH}$ até aproximadamente 5, observa-se uma banda em 796 nm, atribuída a transição d-d do cobre(II) na espécie $\mathrm{CuL}^{+}(\mathrm{L}=$ GlyGly) . Acima de $\mathrm{pH}=5$, essa banda desaparece e surge uma banda mais intensa em torno de $630 \mathrm{~nm}$, que pode ser atribuída a formação da espécie $\mathrm{Cu}\left(\mathrm{H}_{-1} \mathrm{~L}\right)$. Em valores elevados de $\mathrm{pH}$, a diminuição nos valores de absorvância pode ser atribuído a formação da espécie $\mathrm{Cu}\left(\mathrm{H}_{-1} \mathrm{~L}\right)(\mathrm{OH})^{-}$(Fig. 14).

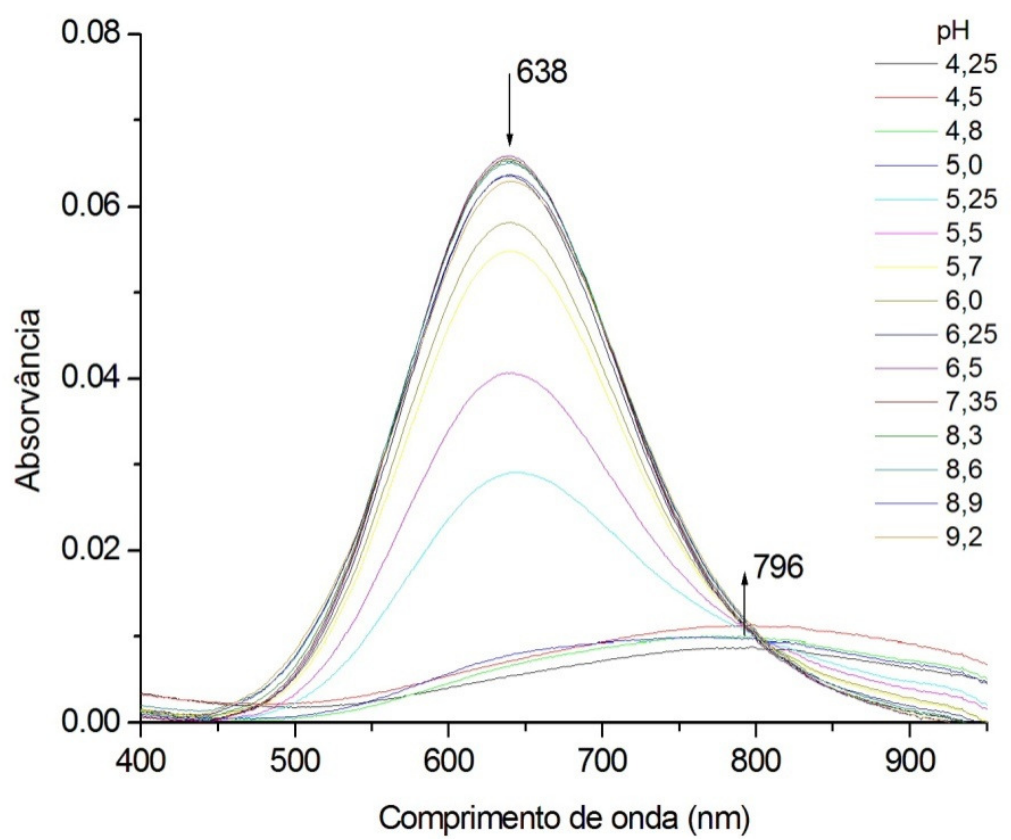

Figura 14. Espectros de absorção na região do visível para o sistema Cu:GlyGly na proporção metal:ligante $1: 1\left(\left[\mathrm{Cu}^{2+}\right]=1,0 \times 10^{-3} \mathrm{~mol} \mathrm{~L}^{-1}\right.$, [GlyGly] $=1,0 \times 10^{-3} \mathrm{~mol} \mathrm{~L}^{-1}, \mu=$ $\left.0,1 \mathrm{~mol} \mathrm{~L}^{-1}, 25 \stackrel{\circ}{\circ} \mathrm{C}\right)$

Em valores ácidos de $\mathrm{pH}$, o espectro de infravermelho do sistema Cu:GlyGly na região da carbonila mostra 3 bandas: 1644, 1670 e $1701 \mathrm{~cm}^{-1}$. Com o aumento do $\mathrm{pH}$, a banda em $1701 \mathrm{~cm}^{-1}$ desaparece e as demais bandas convergem para uma única banda em $1653 \mathrm{~cm}^{-1}$ (Fig. 15). Essa mudança espectral pode ser atribuída a mudança da espécie $\mathrm{CuL}^{+}$para a espécie $\mathrm{Cu}\left(\mathrm{H}_{-1} \mathrm{~L}\right)$. 

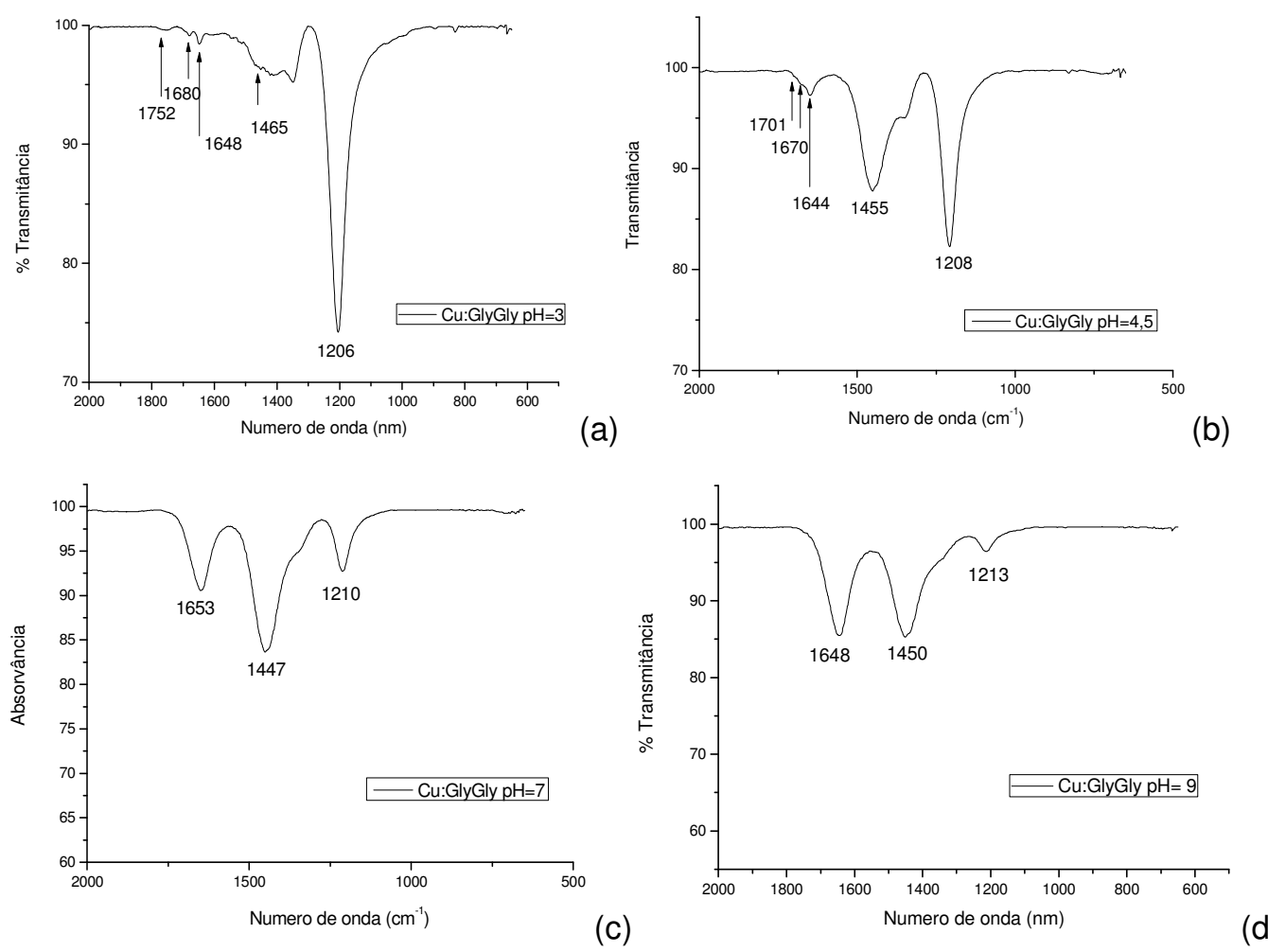

Figura 15. Espectro de infravermelho do sistema Cu:GlyGly na proporção metal:ligante 1:1 em $\mathrm{D}_{2} \mathrm{O}$ na concentração de $0,2 \mathrm{~mol} \mathrm{~L}^{-1}$; (a) $\mathrm{pH}=3$; (b) $\mathrm{pH}=4,5$; (c) $\mathrm{pH}=7$ e (d) $\mathrm{pH}=$ 9

Os espectros de resonância paramagnética eletrônica (RPE) para o sistema binário Cu:GlyGly na razão metal:ligante 1:1 à temperatura ambiente $(298 \mathrm{~K})$ (Fig. 16) são quase isotrópicos devido ao rápido movimento do elétron paramagnético Os espectros apresentaram 4 linhas devido o acoplamento hiperfino do elétron paramagnético com o spin nuclear do cobre(II) ( $\mathrm{I}=3 / 2)$. Os valores de $g$ (Tabela 2) obtidos após simulação dos espectros utilizando o programa Easyspin [162] sugerem uma configuração eletrônica do estado fundamental $t_{2 g}^{6} e_{g}^{3}\left(d_{z^{2}}^{2} d_{x^{2}-y^{2}}^{1}\right)[163-165]$. 

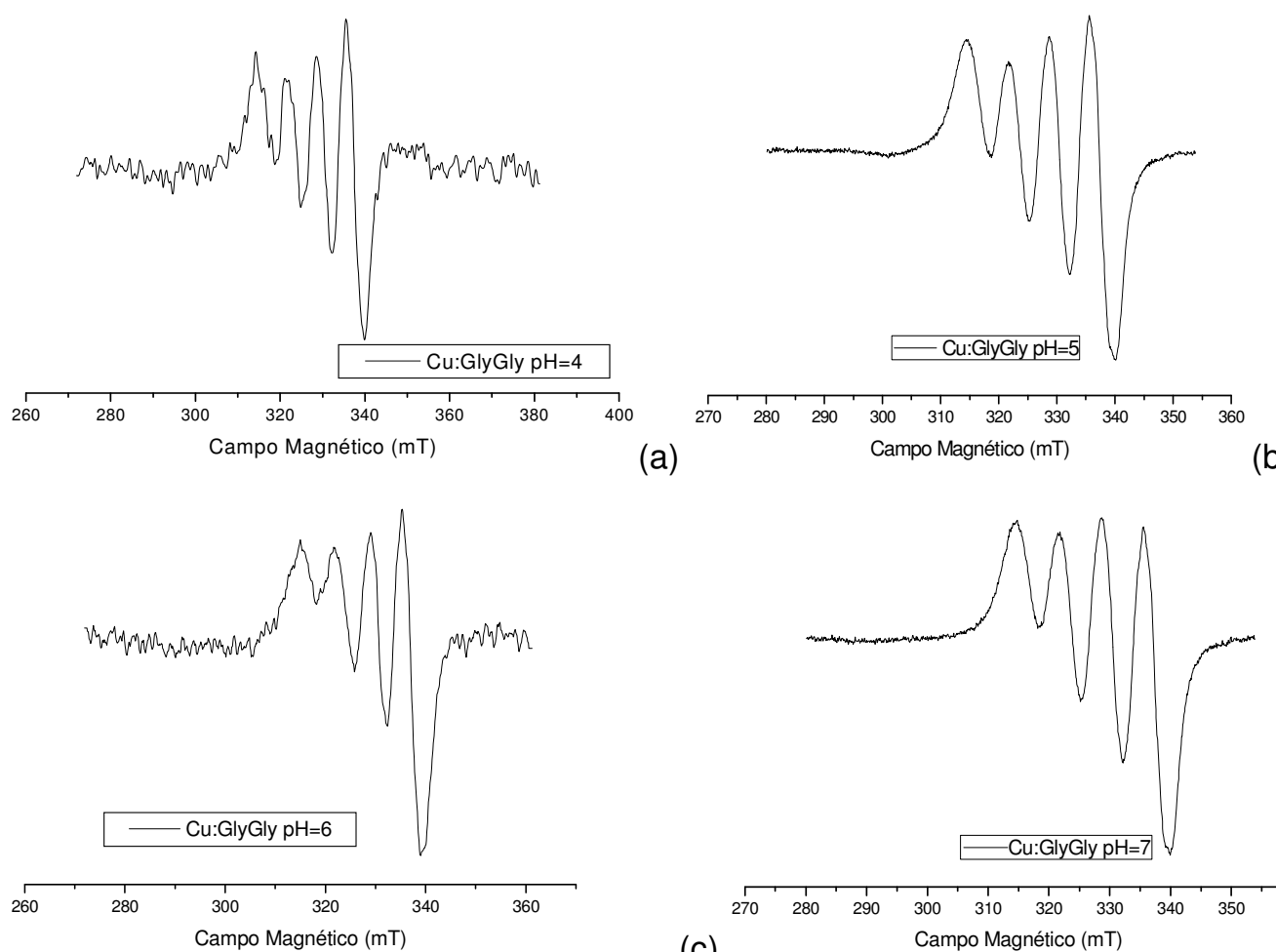

(b)

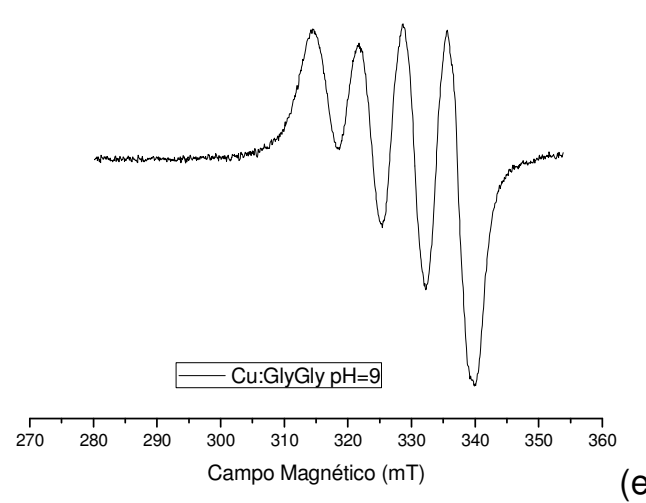

(c)

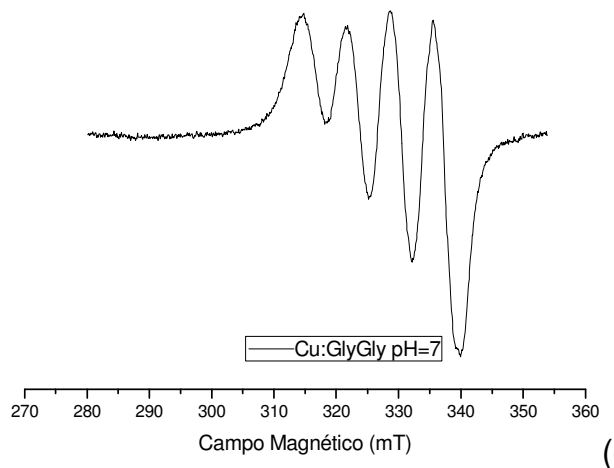

(d)

(e)

Figura 16. Espectro de RPE a $298 \mathrm{~K}$ do sistema binário Cu:GlyGly na proporção metal:ligante 1:1 em diferentes valores de pH: (a) 4, (b) 5, (c) 6, (d) 7 e (e) 9

Tabela 2. Parâmetros de RPE para o sistema binário Cu:GlyGly na razão metal:ligante 1:1 em diferentes valores de pH obtidos após simulação dos espectros utilizando o programa Easyspin [162]

\begin{tabular}{ccccccc}
\hline $\begin{array}{c}\text { Cu:GlyGly }(298 \mathrm{~K}) \\
\mathrm{pH}\end{array}$ & $\begin{array}{c}\Delta \mathrm{B}_{\mathrm{FWHM}}(\mathrm{mT}) \\
\text { Gauss; Lorentz }\end{array}$ & $g_{/ /}$ & $g_{\perp}$ & $g_{a v}$ & $A_{/ /}{ }^{\mathrm{a}}$ & $\mathrm{A}_{\perp}$ \\
\hline 4 & $2 ; 2$ & 2,355 & 2,012 & 2,184 & 160 & 22 \\
5 & $2 ; 2$ & 2,345 & 2,008 & 2,177 & 148 & 25 \\
6 & $2 ; 2$ & 2,339 & 2,006 & 2,173 & 147 & 15 \\
7 & $2 ; 2$ & 2,338 & 2,010 & 2,174 & 145 & 13 \\
9 & $2 ; 2$ & 2.340 & 2.008 & 2,174 & 140 & 12
\end{tabular}

${ }^{\mathrm{a}}$ Todas as constantes de acoplamento hiperfino em unidades de $10^{-4} \mathrm{~cm}^{-1}$ 
As mudanças nos parâmetros espectrais observadas acima sugerem que novas espécies estão sendo formadas com o aumento do pH. Porém, a falta de estruturas em solução aquosa, nos impede de inferir os modos de coordenação dos ligantes ao cobre nas diferentes espécies formadas nos diferentes sistemas. Com o objetivo de investigar os modos de coordenação não só dos dipeptideos, mas também de aminoácidos, foi realizado um estudo potenciométrico e teórico de sistemas de interesse biológico.

\section{2}

\section{Estudos potenciométricos dos sistemas binários Cu:GlyGly e Cu:Met e do sistema ternário Cu:GlyGly:Met a $25 \stackrel{\circ}{\circ}, \mu=0,1 \mathrm{~mol} \mathrm{~L}^{-1}\left(\mathrm{KNO}_{3}\right)$}

Foram realizadas as titulações potenciométricas dos sistemas binários Cu:GlyGly e $\mathrm{Cu}$ :Met e do sistema ternário Cu:GlyGly:Met a $25{ }^{\circ} \mathrm{C}$ e $\mu=0,1 \mathrm{~mol}$ $\mathrm{L}^{-1}\left(\mathrm{KNO}_{3}\right)$. Com os pontos das curvas de titulação potenciométrica e com auxílio do programa BEST7 [166] foi possível calcular as constantes de formação das principais espécies presentes nos sistemas. Com os valores das constantes e com auxílio do programa SPECIES [166] foi possível gerar diagramas de distribuição de espécies em função do pH. Os valores das constantes de formação obtidos no presente trabalho estão em boa concordância com os valores encontrados na literatura [167].

\subsection{1}

\section{Estudo potenciométrico do sistema binário Cu:GlyGly na razão metal:ligante $1: 1$ a $25 \stackrel{\circ}{\circ}, \mu=0,1 \mathrm{~mol} \mathrm{~L}^{-1}\left(\mathrm{KNO}_{3}\right)$}

A curva de titulação potenciométrica do sistema binário $\mathrm{Cu}$ :GlyGly na razão metal:ligante 1:1 mostra uma inflexão em $2 \mathrm{~mL}$ de $\mathrm{KOH}$ adicionado ao sistema (Fig.17). 


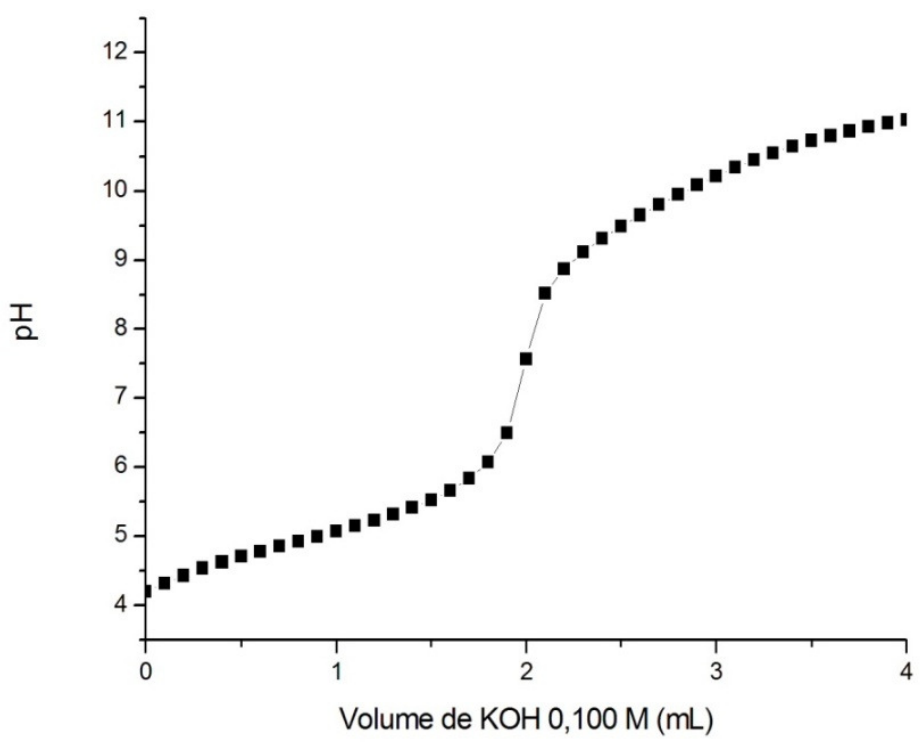

Figura 17. Curva de titulação potenciométrica para o sistema binário $C u: L(L=$ GlyGly) na razão metal:ligante $1: 1$ a $25^{\circ} \mathrm{C}, \mu=0,1 \mathrm{~mol} \mathrm{~L}^{-1}\left(\mathrm{KNO}_{3}\right)$

A Tabela 3 mostra os logarítimos das constantes de formação para as possíveis espécies presentes no sistema binário $\mathrm{Cu}$ :GlyGly.

Tabela 3. Constantes de formação das espécies presentes no sistema binário $C u: L(L=$ GlyGly) na razão metal:ligante $1: 1$ a $25 \stackrel{\circ}{\circ} \mathrm{C}, \mu=0,1 \mathrm{~mol} \mathrm{~L}^{-1}\left(\mathrm{KNO}_{3}\right)$

\begin{tabular}{|c|c|c|c|}
\hline Espécies & Equilíbrio & Constantes & $\log \beta$ \\
\hline CuGlyGly & $\mathrm{Cu}^{2+}+\underset{\text { CuGlyGlyGly }^{+}}{\text {GuGl }^{-}}$ & $\beta_{\text {CuGlyGly }}=\frac{\left[\text { CuGlyGly }^{+}\right]}{\left[\mathrm{Cu}^{2+}\right]\left[\text { GlyGly }^{-}\right]}$ & 5,55 \\
\hline \multirow[t]{2}{*}{$\mathrm{Cu}\left(\mathrm{H}_{-1}\right.$ GlyGly $)$} & $\begin{array}{l}\mathrm{Cu}^{2+}+\mathrm{GlyGly}^{-}+\mathrm{H}_{2} \mathrm{O} \rightleftharpoons \\
\quad \mathrm{Cu}\left(\mathrm{H}_{-1} \text { GlyGly }\right)+\mathrm{H}_{3} \mathrm{O}^{+}\end{array}$ & $\beta_{\mathrm{Cu}(\mathrm{H}-1 \mathrm{GlyGly})}=\frac{\left[\mathrm{Cu}\left(\mathrm{H}_{-1} \mathrm{GlyGly}\right)\right]\left[\mathrm{H}_{3} \mathrm{O}^{+}\right]}{\left[\mathrm{Cu}^{2+}\right]\left[\mathrm{GlyGly}^{-}\right]}$ & 1,32 \\
\hline & 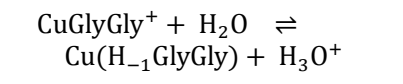 & $\mathrm{K}=\frac{\left[\mathrm{Cu}\left(\mathrm{H}_{-1} \text { GlyGly }\right)\right]\left[\mathrm{H}_{3} \mathrm{O}^{+}\right]}{[\text {CuGlyGly }}$ & $-4,23 * *$ \\
\hline \multirow[t]{2}{*}{$\mathrm{Cu}\left(\mathrm{H}_{-1} \mathrm{GlyGly}\right)(\mathrm{OH})$} & $\begin{array}{c}\mathrm{Cu}^{2+}+\mathrm{GlyGly}^{-}+2 \mathrm{H}_{2} \mathrm{O} \rightleftharpoons \\
\mathrm{Cu}\left(\mathrm{H}_{-1} \mathrm{GlyGly}\right)(\mathrm{OH})^{-}+2 \mathrm{H}_{3} \mathrm{O}^{+}\end{array}$ & $\begin{array}{l}\mathrm{K}_{\mathrm{Cu}(\mathrm{H}-1 \mathrm{GlyGly})(\mathrm{OH})} \\
=\frac{\left[\mathrm{Cu}\left(\mathrm{H}_{-1} \mathrm{GlyGly}\right)(\mathrm{OH})^{-}\right]\left[\mathrm{H}_{3} \mathrm{O}^{+}\right]^{2}}{\left[\mathrm{Cu}^{2+}\right]\left[\mathrm{GlyGly}^{-}\right]}\end{array}$ & $-8,24$ \\
\hline & $\begin{array}{l}\mathrm{Cu}\left(\mathrm{H}_{-1} \text { GlyGly }\right)+\mathrm{H}_{2} \mathrm{O} \rightleftharpoons \\
\mathrm{Cu}\left(\mathrm{H}_{-1} \text { GlyGly }\right)(\mathrm{OH})^{-}+\mathrm{H}_{3} \mathrm{O}^{+}\end{array}$ & $\begin{array}{l}\mathrm{K}_{\mathrm{Cu}(\mathrm{H}-1 \mathrm{GlyGly})(\mathrm{OH})} \\
=\frac{\left[\mathrm{Cu}\left(\mathrm{H}_{-1} \mathrm{GlyGly}\right)(\mathrm{OH})^{-}\right]\left[\mathrm{H}_{3} \mathrm{O}^{+}\right]}{\left[\mathrm{Cu}\left(\mathrm{H}_{-1} \mathrm{GlyGly}\right)\right]}\end{array}$ & $-9,56 * * *$ \\
\hline
\end{tabular}

${ }^{*}\left(\mathrm{H}_{-1} \mathrm{GlyGly}\right)$ : refere-se ao dipeptídeo desprotonado no nitrogênio peptídico.

${ }^{*} \log \mathrm{K}=\log \beta_{\mathrm{Cu}\left(\mathrm{H}_{-1} \mathrm{GlyGly}\right)}-\log \beta_{\text {CuGlyGly }}=1,32-5,55=-4,23$

${ }^{* * *} \log \mathrm{K}=\log \beta_{\mathrm{Cu}\left(\mathrm{H}_{-1} \mathrm{GlyGly}\right)(\mathrm{OH})}-\log \beta_{\mathrm{Cu}_{\left(\mathrm{H}_{-1} \mathrm{GlyGly}\right)}}=-8,24-1,32=-9,56$

O equilíbrio envolvido na desprotonação da espécie $\mathrm{CuGlyGly}^{+}$para formar $\mathrm{Cu}\left(\mathrm{H}_{-1}\right.$ GlyGly) é mostrado abaixo e a constante $\mathrm{Ka}_{1}$ é dada pela Equação 6. 


$$
\begin{gathered}
\text { CuGlyGly }{ }^{+}+\mathrm{H}_{2} \mathrm{O} \rightleftharpoons \mathrm{Cu}\left(\mathrm{H}_{-1} \text { GlyGly }\right)+\mathrm{H}_{3} \mathrm{O}^{+} \\
\mathrm{Ka}_{1}=\frac{\left[\mathrm{Cu}\left(\mathrm{H}_{-1} \text { GlyGly }\right)\right]\left[\mathrm{H}_{3} \mathrm{O}^{+}\right]}{\left[\text {CuGlyGly }{ }^{+}\right]}
\end{gathered}
$$

Como os valores das constantes de formação $\beta_{\text {CuGlyGly }}$ e $\beta_{\mathrm{Cu}\left(\mathrm{H}_{-1} \mathrm{GlyGly}\right)}$ podemos determinar o valor de $\mathrm{pKa} \mathrm{a}_{1}$ para o complexo formado no sistema binário Cu:GlyGly (Equações 7-10):

$$
\begin{aligned}
& \mathrm{Ka}_{1}=\beta_{\mathrm{Cu}\left(\mathrm{H}_{-1} \text { GlyGly }\right)} \cdot \frac{1}{\beta_{\text {CuGlyGly }}} \\
& \mathrm{Ka}_{1}=\frac{\left[\mathrm{Cu}\left(\mathrm{H}_{-1} \mathrm{GlyGly}\right]\left[\mathrm{H}_{3} \mathrm{O}^{+}\right]\right.}{\left[\mathrm{Cu}^{2+}\right]\left[\mathrm{GlyGly}^{-}\right]} \cdot \frac{\left[\mathrm{Cu}^{2+}\right]\left[\mathrm{GlyGly}^{-}\right]}{\left[\mathrm{CuGlyGly}^{+}\right]}=\frac{\left[\mathrm{Cu}\left(\mathrm{H}_{-1} \mathrm{GlyGly}\right)\right]\left[\mathrm{H}_{3} \mathrm{O}^{+}\right]}{\left[\mathrm{CuGlyGly}^{+}\right]} \\
& \mathrm{pKa}_{1}=-\log \mathrm{Ka}_{1} \\
& \mathrm{pKa}_{1}=-\left(\log \beta_{\mathrm{Cu}\left(\mathrm{H}_{-1} \text { GlyGly }\right)}-\log \beta_{\text {CuGlyGly }}\right)
\end{aligned}
$$

Substituindo os valores da Tabela 3, podemos calcular o valor de $\mathrm{pKa}_{1}$ para a espécie CuGlyGly+:

$$
\begin{gathered}
\mathrm{pKa}_{1}=-(1,32-5,55) \\
\mathrm{pKa}_{1}=4,23
\end{gathered}
$$

Esse valor refere-se ao $\mathrm{pH}$ onde ocorre a desprotonação do nitrogênio peptídico.

$\mathrm{O}$ equilíbrio envolvido na desprotonação da espécie $\mathrm{Cu}\left(\mathrm{H}_{-1} \mathrm{GlyGly}\right)$ para formar $\mathrm{Cu}\left(\mathrm{H}_{-1} \mathrm{GlyGly}\right)(\mathrm{OH})^{-}$é mostrado abaixo e a constante de acidez é calculada segundo as Equações 11-15:

$$
\mathrm{Cu}\left(\mathrm{H}_{-1} \text { GlyGly }\right)+\mathrm{H}_{2} \mathrm{O} \rightleftharpoons \mathrm{Cu}\left(\mathrm{H}_{-1} \text { GlyGly }\right)(\mathrm{OH})^{-}+\mathrm{H}_{3} \mathrm{O}^{+}
$$




$$
\begin{aligned}
& \mathrm{Ka}_{2}=\frac{\left[\mathrm{Cu}\left(\mathrm{H}_{-1} \mathrm{GlyGly}\right)(\mathrm{OH})^{-}\right]\left[\mathrm{H}_{3} \mathrm{O}^{+}\right]}{\left[\mathrm{Cu}\left(\mathrm{H}_{-1} \mathrm{Gly} \text { Gly }\right)\right]} \\
& \mathrm{Ka}_{2}=\beta_{\mathrm{Cu}\left(\mathrm{H}_{-1} \text { GlyGly }(\mathrm{OH})\right.} \cdot \frac{1}{\beta_{\mathrm{Cu}\left(\mathrm{H}_{-1} \text { GlyGly }\right)}} \\
& \mathrm{Ka}_{2}=\frac{\left[\mathrm{Cu}\left(\mathrm{H}_{-1} \mathrm{GlyGly}\right)(\mathrm{OH})^{-}\right]\left[\mathrm{H}_{3} \mathrm{O}^{+}\right]^{2}}{\left[\mathrm{Cu}^{2+}\right]\left[\mathrm{GlyGly}^{-}\right]} \cdot \frac{\left[\mathrm{Cu}^{2+}\right]\left[\mathrm{GlyGly}^{-}\right]}{\left[\mathrm{Cu}\left(\mathrm{H}_{-1} \mathrm{GlyGly}^{-}\right]\left[\mathrm{H}_{3} \mathrm{O}^{+}\right]\right.}= \\
& \frac{\left[\mathrm{Cu}\left(\mathrm{H}_{-1} \mathrm{GlyGly}\right)(\mathrm{OH})^{-}\right]\left[\mathrm{H}_{3} \mathrm{O}^{+}\right]}{\left[\mathrm{Cu}\left(\mathrm{H}_{-1} \mathrm{GlyGly}\right)\right]} \\
& \mathrm{pKa}_{2}=-\log \mathrm{Ka}_{2} \\
& \mathrm{pKa}_{2}=-\left(\log \beta_{\mathrm{Cu}\left(\mathrm{H}_{-1} \mathrm{GlyGly}\right)(\mathrm{OH})}-\log \beta_{\mathrm{Cu}\left(\mathrm{H}_{-1} \mathrm{GlyGly}\right)}\right)
\end{aligned}
$$

Substituindo os valores da Tabela 3, calculamos o valor de $\mathrm{pKa}_{2}$ para a espécie $\mathrm{Cu}\left(\mathrm{H}_{-1} \mathrm{GlyGly}\right)$ como mostrado abaixo:

$$
\begin{gathered}
\mathrm{pKa}_{2}=-(-8,24-1,32) \\
\mathrm{pKa}_{2}=9,56
\end{gathered}
$$

Esse valor refere-se ao $\mathrm{pH}$ onde ocorre a hidrólise de uma molécula de água coordenada ao metal, possivelmente situado no plano equatorial do complexo.

O diagrama de distribuição de espécies para o sistema binário Cu:GlyGly é mostrado na Figura 18. Na faixa de $\mathrm{pH}$ entre 4 - 6, a espécie CuGlyGly ${ }^{+}$é presente no sistema somente em pequenas concentrações $(\sim 5 \%)$. A partir de $\mathrm{pH}$ 4,23, a espécie $\mathrm{Cu}\left(\mathrm{H}_{-1}\right.$ GlyGly) ( $\mathrm{H}_{-1}$ GlyGly refere-se ao dipeptídeo desprotonado no nitrogênio peptídico) passa a predominar no sistema até $\mathrm{pH} 9,56$, onde a partir desse valor de $\mathrm{pH}$, a espécie $\mathrm{Cu}\left(\mathrm{H}_{-1} \mathrm{GlyGly}\right)(\mathrm{OH})^{-}$passa a prevalecer no sistema $(\sim 50 \%)$. A partir de $\mathrm{pH}$ em torno de 10,5 , a espécie $\mathrm{Cu}(\mathrm{OH})_{4}{ }^{2-}$ predomina no sistema até valores elevados de $\mathrm{pH}$. 


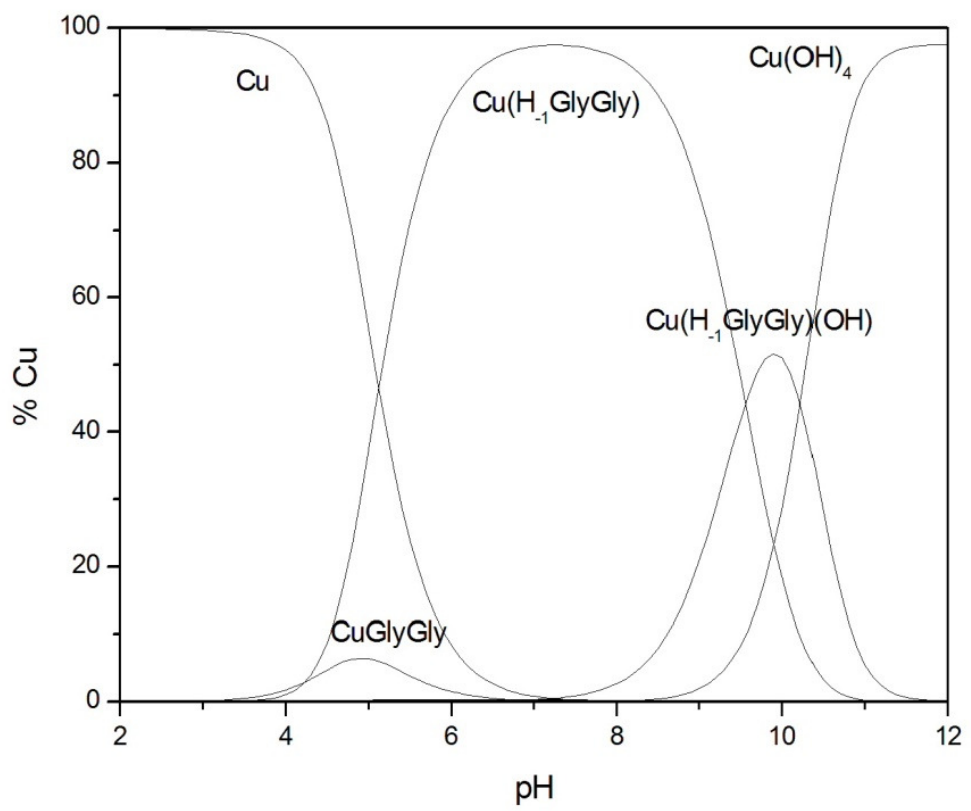

Figura 18. Diagrama de distribuição de espécies em função do pH para o sistema binário Cu:L ( $\mathrm{L}$ = GlyGly) obtido com auxílio do programa SPECIES [166] 


\section{2 .2}

\section{Estudo potenciométrico do sistema binário Cu:Met na razão metal:ligante $1: 1$ a $25 \stackrel{\circ}{\circ}, \mu=0,1 \mathrm{~mol} \mathrm{~L}^{-1}\left(\mathrm{KNO}_{3}\right)$}

A curva de titulação potenciométrica do sistema binário $\mathrm{Cu}$ :Met na razão metal:ligante 1:1 mostra duas inflexões (Fig. 19).

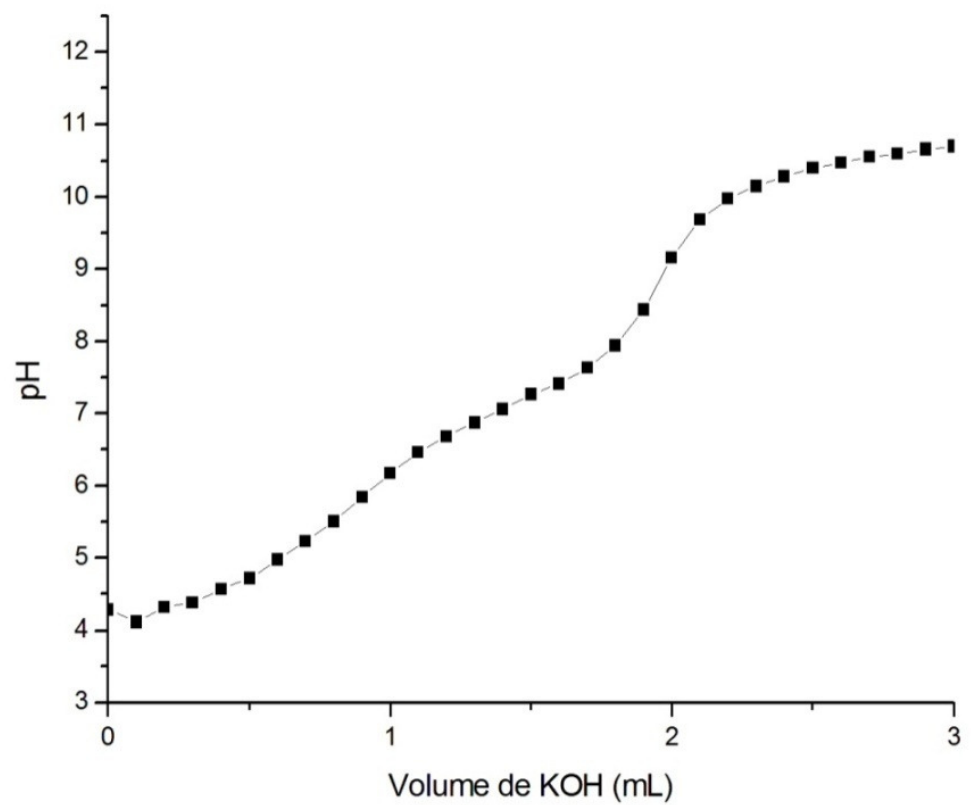

Figura 19. Curva de titulação potenciométrica para o sistema binário $C u: L(L=M e t)$ na proporção metal:ligante $1: 1$ a $25 \stackrel{\circ}{\circ} \mathrm{C}, \mu=0,1 \mathrm{~mol} \mathrm{~L}^{-1}\left(\mathrm{KNO}_{3}\right)$

A Tabela 4 mostra os valores dos logarítimos das constantes de formação das principais espécies presentes no sistema binário $\mathrm{Cu}$ :Met obtidos com auxílio do programa BEST7 [166]. 
Tabela 4. Constantes de formação das espécies presentes no sistema binário $C u: L$ ( $L=$ Met) na razão metal:ligante $1: 1$ a $25 \stackrel{\circ}{\circ} \mathrm{C}, \mu=0,1 \mathrm{~mol} \mathrm{~L}^{-1}\left(\mathrm{KNO}_{3}\right)$

\begin{tabular}{|c|c|c|c|}
\hline Espécies & Equilíbrio & Quociente de Equilíbrio & $\log \mathrm{K}$ \\
\hline CuMet & $\begin{array}{l}\mathrm{Cu}^{2+}+\mathrm{Met}^{-} \rightleftharpoons \\
\underset{\mathrm{CuMet}^{+}}{ }\end{array}$ & $\beta_{\text {CuMet }}=\frac{\left[\mathrm{CuMet}^{+}\right]}{\left[\mathrm{Cu}^{2+}\right]\left[\mathrm{Met}^{-}\right]}$ & 7,85 \\
\hline $\operatorname{CuMet}(\mathrm{OH})$ & $\begin{array}{l}\mathrm{Cu}^{2+}+\mathrm{Met}^{-}+\mathrm{H}_{2} \mathrm{O} \rightleftharpoons \\
\quad \operatorname{CuMet}(\mathrm{OH})+\mathrm{H}_{3} \mathrm{O}^{+}\end{array}$ & $\beta_{\text {CuMet }(\mathrm{OH})}=\frac{[\operatorname{CuMet}(\mathrm{OH})]\left[\mathrm{H}_{3} \mathrm{O}^{+}\right]}{\left[\mathrm{Cu}^{2+}\right]\left[\mathrm{Met}^{-}\right]}$ & 1,12 \\
\hline \multirow{3}{*}{$\operatorname{CuMet}(\mathrm{OH})_{2}$} & $\begin{array}{c}\operatorname{CuMet}^{+}+\mathrm{H}_{2} \mathrm{O} \rightleftharpoons \\
\operatorname{CuMet}(\mathrm{OH})+\mathrm{H}_{3} \mathrm{O}^{+}\end{array}$ & $\mathrm{K}_{\text {CuMet(OH) }}=\frac{[\operatorname{CuMet}(\mathrm{OH})]\left[\mathrm{H}_{3} \mathrm{O}^{+}\right]}{\left[\mathrm{CuMet}^{+}\right]}$ & $-6,73^{*}$ \\
\hline & $\begin{array}{l}\mathrm{Cu}^{2+}+\mathrm{Met}^{-}+2 \mathrm{H}_{2} \mathrm{O} \rightleftharpoons \\
\text { CuMet }(\mathrm{OH})_{2}^{-}+2 \mathrm{H}_{3} \mathrm{O}^{+}\end{array}$ & $\beta_{\operatorname{CuMet}(\mathrm{OH})_{2}}=\frac{\left[\operatorname{CuMet}(\mathrm{OH})_{2}^{-}\right]\left[\mathrm{H}_{3} \mathrm{O}^{+}\right]^{2}}{\left[\mathrm{Cu}^{2+}\right]\left[\mathrm{Met}^{-}\right]}$ & $-8,55$ \\
\hline & $\begin{array}{l}\operatorname{CuMet}(\mathrm{OH})+\mathrm{H}_{2} \mathrm{O} \rightleftharpoons \\
\operatorname{CuMet}(\mathrm{OH})_{2}^{-}+\mathrm{H}_{3} \mathrm{O}^{+}\end{array}$ & $\mathrm{K}_{\mathrm{CuMet}(\mathrm{OH})_{2}}=\frac{\left[\operatorname{CuMet}(\mathrm{OH})_{2}^{-}\right]\left[\mathrm{H}_{3} \mathrm{O}^{+}\right]}{[\operatorname{CuMet}(\mathrm{OH})]}$ & $-9,67 * *$ \\
\hline
\end{tabular}

${ }^{* \star} \log \mathrm{K}_{\mathrm{CuMet}(\mathrm{OH})}=\log \beta_{\mathrm{CuMet}(\mathrm{OH})}-\log \beta_{\mathrm{CuMet}}=1,12-7,85=-6,73$

${ }^{* * *} \log \mathrm{K}_{\mathrm{CuMet}(\mathrm{OH})_{2}}=\log \beta_{\mathrm{CuMet}(\mathrm{OH})_{2}}-\log \beta_{\mathrm{CuMet}(\mathrm{OH})}=-8,55-1,12=-9,67$

A desprotonação da espécie $\mathrm{CuMet}^{+}$para formar $\mathrm{CuMet}(\mathrm{OH})$ é mostrada no equilíbrio abaixo e constante de acidez $\mathrm{Ka}_{1}$ é dada pela Equação 16:

$$
\begin{aligned}
& \text { CuMet }^{+}+\mathrm{H}_{2} \mathrm{O} \rightleftharpoons \operatorname{CuMet}(\mathrm{OH})+\mathrm{H}_{3} \mathrm{O}^{+} \\
& \mathrm{Ka}_{1}=\frac{[\operatorname{CuMet}(\mathrm{OH})]\left[\mathrm{H}_{3} \mathrm{O}^{+}\right]}{\left[\mathrm{CuMet}^{+}\right]}
\end{aligned}
$$

Como os valores das constantes de formação $\beta_{\mathrm{CuMet}}$ e $\beta_{\mathrm{CuMet(OH)}}$ podemos determinar o valor de $\mathrm{pKa}_{1}$ para o complexo formado no sistema binário $\mathrm{Cu}$ :Met na proporção metal ligante 1:1 (Equações 17-20):

$$
\begin{aligned}
& \mathrm{Ka}_{1}=\beta_{\text {CuMet }(\mathrm{OH}) \cdot \frac{1}{\beta_{\mathrm{CuMet}}}} \\
& \mathrm{Ka}_{1}=\frac{[\mathrm{CuMet}(\mathrm{OH})]\left[\mathrm{H}_{3} \mathrm{O}^{+}\right]}{\left[\mathrm{Cu}^{2+}\right]\left[\mathrm{Met}^{-}\right]} \cdot \frac{\left[\mathrm{Cu}^{2+}\right]\left[\mathrm{Met}^{-}\right]}{\left[\mathrm{CuMet}^{+}\right]}=\frac{[\mathrm{CuMet}(\mathrm{OH})]\left[\mathrm{H}_{3} \mathrm{O}^{+}\right]}{\left[\mathrm{CuMet}^{+}\right]} \\
& \mathrm{pKa}_{1}=-\log \mathrm{Ka}_{1} \\
& \mathrm{pKa}_{1}=-\left(\log \beta_{\mathrm{CuMet}(\mathrm{OH})}-\log \beta_{\mathrm{CuMet}}\right)
\end{aligned}
$$


Substituindo os valores da Tabela 4, calculamos o valor de $\mathrm{pKa}_{1}$ para a espécie $\mathrm{CuMet}^{+}$:

$$
\begin{gathered}
\mathrm{pKa}_{1}=-(1,12-7,85) \\
\mathrm{pKa}_{1}=6,73
\end{gathered}
$$

Esse valor refere-se ao $\mathrm{pH}$ onde ocorre a hidrólise de uma molécula de água coordenada ao metal.

A segunda desprotonação, que refere a perda de um próton da espécie $\operatorname{CuMet}(\mathrm{OH})$ para formar $\operatorname{CuMet}(\mathrm{OH})_{2}{ }^{-}$, é mostrada no equilíbrio abaixo e a segunda constante de acidez é dada pela Equação 21:

$$
\begin{gathered}
\operatorname{CuMet}(\mathrm{OH})+\mathrm{H}_{2} \mathrm{O} \rightleftharpoons \operatorname{CuMet}(\mathrm{OH})_{2}^{-}+\mathrm{H}_{3} \mathrm{O}^{+} \\
\mathrm{Ka}_{2}=\frac{\left[\operatorname{CuMet}(\mathrm{OH})_{2}^{-}\right]\left[\mathrm{H}_{3} \mathrm{O}^{+}\right]}{[\operatorname{CuMet}(\mathrm{OH})]}
\end{gathered}
$$

O valor da segunda constante de acidez é calculada da seguinte forma (Equações 22-25):

$$
\begin{aligned}
& \mathrm{Ka}_{2}=\beta_{\mathrm{CuMet}(\mathrm{OH})_{2}} \cdot \frac{1}{\beta_{\mathrm{CuMet}(\mathrm{OH})}} \\
& \mathrm{Ka}_{2}=\frac{\left[\mathrm{CuMet}(\mathrm{OH})_{2}^{-}\right]\left[\mathrm{H}_{3} \mathrm{O}^{+}\right]^{2}}{\left[\mathrm{Cu}^{2+}\right]\left[\mathrm{Met}^{-}\right]} \cdot \frac{\left[\mathrm{Cu}^{2+}\right]\left[\mathrm{Met}^{-}\right]}{[\mathrm{CuMet}(\mathrm{OH})]\left[\mathrm{H}_{3} \mathrm{O}^{+}\right]}=\frac{\left[\mathrm{CuMet}(\mathrm{OH})_{2}^{-}\right]\left[\mathrm{H}_{3} \mathrm{O}^{+}\right]}{[\mathrm{CuMet}(\mathrm{OH})]} \\
& \mathrm{pKa}_{2}=-\log \mathrm{Ka}_{2} \\
& \mathrm{pKa}_{2}=-\left(\log \beta_{\mathrm{CuMet}(\mathrm{OH})_{2}}-\log \beta_{\mathrm{CuMet}(\mathrm{OH})}\right)
\end{aligned}
$$

Então, substituindo os valores da Tabela 4, a constante $\mathrm{pKa}_{2}$ para a espécie $\mathrm{CuMet}(\mathrm{OH})$ pode ser obtida:

$$
\mathrm{pKa}_{2}=-(-8,55-1,12)
$$




$$
\mathrm{pKa}_{2}=9,67
$$

Esse valor refere-se ao pH onde ocorre a segunda desprotonação de uma molécula de água coordenada ao metal.

A Figura 20 mostra o diagrama de distribuição de espécies em função do pH para o sistema binário $\mathrm{Cu}$ :Met. $\mathrm{Na}$ faixa de $\mathrm{pH}$ entre 4 - 6,73, há a predominância da espécie $\mathrm{CuMet}^{+}$. A partir de $\mathrm{pH}$ 6,73, a espécie $\mathrm{CuMet}(\mathrm{OH})$ passa a prevalecer no sistema em elevadas concentrações $(\sim 90 \%)$ até $\mathrm{pH} 9,67$, onde a partir desse valor de $\mathrm{pH}$ a espécie $\operatorname{CuMet}(\mathrm{OH})_{2}{ }^{-}$passa a predominar no sistema em pequenas concentrações ( $40 \%)$. Como no sistema estudado anteriormente, a espécie $\mathrm{Cu}(\mathrm{OH})_{4}{ }^{2-}$ predomina em valores elevados de $\mathrm{pH}$.

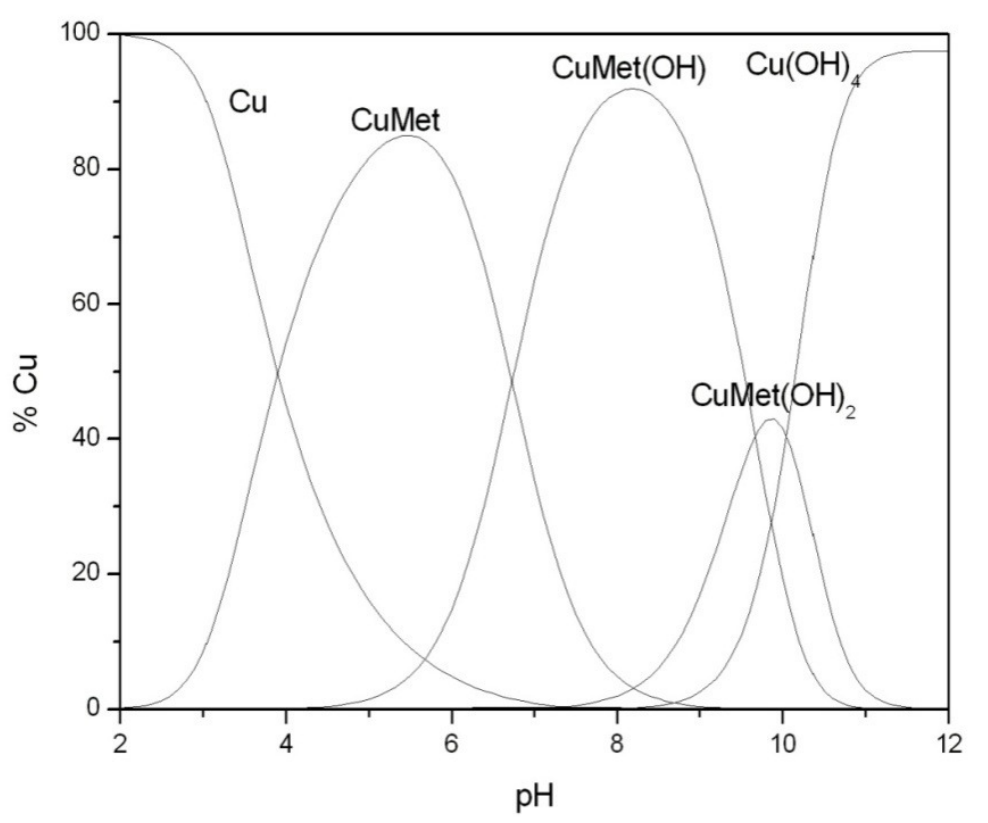

Figura 20. Diagrama de distribuição de espécies em função do pH para o sistema binário Cu:L ( $L$ = Met) obtido com auxílio do programa SPECIES [166] 


\subsection{3}

\section{Estudo potenciométrico do sistema ternário $\mathrm{Cu}$ :GlyGly:Met na razão} metal:ligante 1:1:1 a $25 \stackrel{\circ}{\circ}, \mu=0,1 \mathrm{~mol} \mathrm{~L}^{-1}\left(\mathrm{KNO}_{3}\right)$

A curva de titulação potencimétrica do sistema ternário Cu:GlyGly:Met mostra uma inflexão em 2,0 mL de base adicionada (Fig. 21).

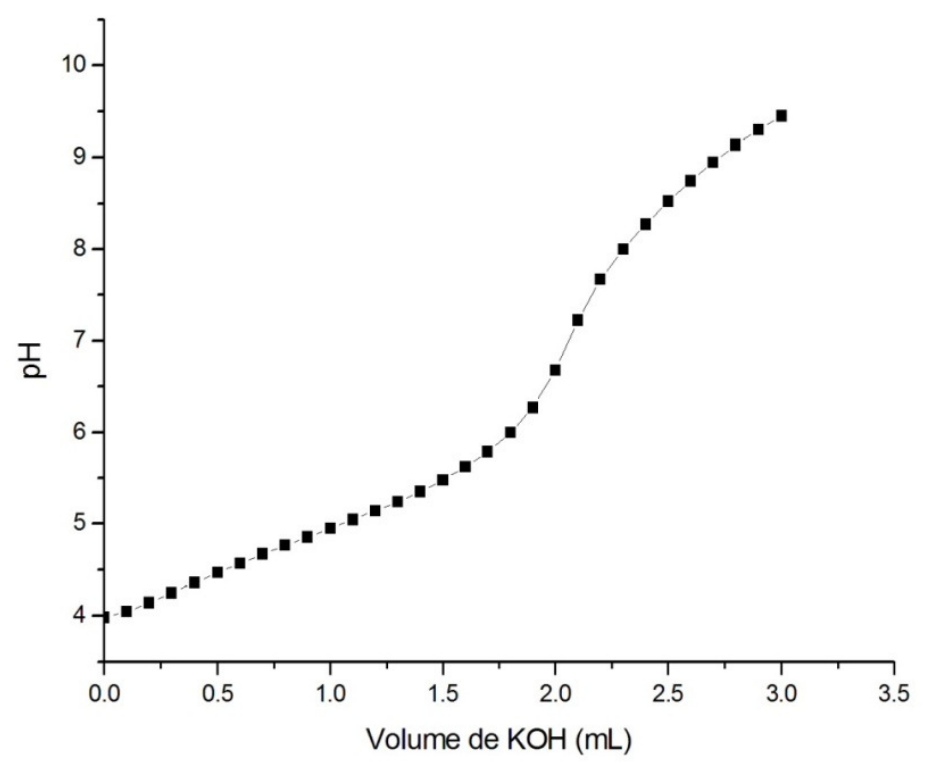

Figura 21. Curva de titulação potenciométrica para os sistema ternário $\mathrm{Cu}(\mathrm{II}): \mathrm{L}_{1}: \mathrm{L}_{2}\left(\mathrm{~L}_{1}=\right.$ GlyGly e $L_{2}=$ Met) na proporção metal:ligante 1:1:1 $\left(\mu=0,1 \mathrm{~mol} \mathrm{~L}^{-1}, 25 \stackrel{\circ}{\circ}\right)$

Foram propostas as seguintes espécies: CuHGlyGlyMet (protonação refere-se ao nitrogênio peptídico), CuGlyGlyMet e CuGlyGlyMet(OH) ${ }^{2-}$ (Tabela $5)$. 
Tabela 5. Constantes de formação das espécies presentes no sistema ternário $\mathrm{Cu}(\mathrm{II}): \mathrm{L}_{1}: \mathrm{L}_{2}\left(\mathrm{~L}_{1}=\right.$ GlyGly e $\mathrm{L}_{2}=$ Met) na proporção metal:ligante $1: 1: 1$ a $25^{\circ} \mathrm{C}, \mu=0,1 \mathrm{~mol}$ $\mathrm{L}^{-1}\left(\mathrm{KNO}_{3}\right)$

\begin{tabular}{|c|c|c|c|}
\hline Espécies & Equilíbrio & Quociente de Equilíbrio & $\log \mathrm{K}$ \\
\hline CuGlyGlyMet & $\begin{array}{c}\mathrm{Cu}^{2+}+\text { GlyGly }^{2-}+\text { Met }^{-} \\
\text {CuGlyGlyMet } t^{-}\end{array}$ & $\beta_{\text {CuGlyGlyMet }}=\frac{[\text { CuGlyGlyMet }]}{\left[\mathrm{Cu}^{2+}\right]\left[\mathrm{GllyGly}^{2-}\right]\left[\mathrm{Met}^{-}\right]}$ & 15,67 \\
\hline CuHGlyGlyMet & $\begin{array}{l}\mathrm{Cu}^{2+}+\mathrm{GlyGly}^{2-}+\mathrm{Met}^{-}+\mathrm{H}_{3} \mathrm{O}^{+} \\
\rightleftharpoons \mathrm{Cu}\left(\mathrm{H}_{3} \mathrm{O}^{+}\right) \mathrm{GlyGlyMet}\end{array}$ & 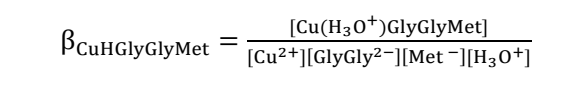 & 19,84 \\
\hline & $\begin{array}{l}\mathrm{Cu}\left(\mathrm{H}_{3} \mathrm{O}^{+}\right) \text {GlyGlyMet } \rightleftharpoons \\
\text { CuGlyGlyMet} t^{-}+\mathrm{H}_{3} \mathrm{O}^{+}\end{array}$ & $\mathrm{K}_{\text {CuGlyGlyMet }}=\frac{\left[\mathrm{CuGlyGlyMet}^{-}\right]\left[\mathrm{H}_{3} \mathrm{O}^{+}\right]}{\left[\mathrm{Cu}\left(\mathrm{H}_{3} \mathrm{O}^{+}\right) \mathrm{GlyGlyMet}^{-}\right.}$ & $-4,17^{*}$ \\
\hline CuGlyGlyMet(OH) & $\begin{array}{c}\mathrm{Cu}^{2+}+\mathrm{GlyGly}^{2-}+\mathrm{Met}^{-}+\mathrm{H}_{2} \mathrm{O} \leftrightharpoons \\
\text { CuGlyGlyMet}(\mathrm{OH})^{2-}+\mathrm{H}_{3} \mathrm{O}^{+}\end{array}$ & $\beta_{\text {CuGlyglymet(OH) }}=\frac{\left[\text { CuGlyGlyMet }(\mathrm{OH})^{2-}\right]\left[\mathrm{H}_{3} \mathrm{O}^{+}\right]}{\left[\mathrm{Cu}^{2+}\right]\left[\mathrm{GlyGly}^{2-}\right]\left[\mathrm{Met}^{-}\right]}$ & 8,22 \\
\hline & $\begin{array}{l}\text { CuGlyGlyMet }^{-}+\mathrm{H}_{2} \mathrm{O} \leftrightharpoons \\
\text { CuGlyGlyMet }(\mathrm{OH})^{2-}+\mathrm{H}_{3} \mathrm{O}^{+}\end{array}$ & $\mathrm{K}=\frac{\left[\text { CuGlyGlyMet }(\mathrm{OH})^{2-}\right]\left[\mathrm{H}_{3} \mathrm{O}^{+}\right]}{\left[\mathrm{CuGlyGlyMet}^{-}\right]}$ & $-7,45^{* *}$ \\
\hline
\end{tabular}

${ }^{*} \log \mathrm{K}=\log \beta_{\text {CuGlyGlyMet }}-\log \beta_{\text {CuHGlyGlyMet }}=15,67-19,84=-4,17$

${ }^{* *} \log \mathrm{K}=\log \beta_{\text {CuGlyGlyMet(OH) }}-\log \beta_{\text {CuGlyGlyMet }}=8,22-15,67=-7,45$

A primeira desprotonação da espécie CuHGlyGlyMet para formar CuGlyGlyMet é mostrada no equilíbrio abaixo e constante de acidez $\mathrm{Ka}_{1}$ é dada pela Equação 26:

$$
\begin{aligned}
& \mathrm{Cu}\left(\mathrm{H}_{3} \mathrm{O}^{+}\right) \text {GlyGlyMet }+\mathrm{H}_{2} \mathrm{O} \rightleftharpoons \text { CuGlyGlyMet }^{-}+\mathrm{H}_{3} \mathrm{O}^{+} \\
& \mathrm{Ka}_{1}=\frac{\left[\mathrm{CuGlyGlyMet}^{-}\right]\left[\mathrm{H}_{3} \mathrm{O}^{+}\right]}{\left[\mathrm{Cu}\left(\mathrm{H}_{3} \mathrm{O}^{+}\right) \text {GlyGlyMet }\right]^{-}}
\end{aligned}
$$

Com os valores das constantes de formação $\beta_{\text {CuGlyGlyMet }}$ e $\beta_{\text {CuHGlyGlyMet }}$ podemos determinar o valor de $\mathrm{pKa}_{1}$ para o complexo formado no sistema ternário de acordo com as Equações 27-30:

$$
\begin{gathered}
\mathrm{Ka}_{1}=\beta_{\text {CuGlyGlyMet }} \cdot \frac{1}{\beta_{\text {CuHGlyGlyMet }}} \\
\mathrm{Ka}_{1}=\frac{\left[\text { CuGlyGlyMet }^{-}\right]}{\left[\mathrm{Cu}^{2+}\right]\left[\text { GlyGly }^{2-}\right]\left[\mathrm{Met}^{-}\right]} \cdot \frac{\left[\mathrm{Cu}^{2+}\right]\left[\mathrm{GlyGly}^{2-}\right]\left[\mathrm{Met}^{-}\right]\left[\mathrm{H}_{3} \mathrm{O}^{+}\right]}{\left[\mathrm{Cu}\left(\mathrm{H}_{3} \mathrm{O}^{+}\right) \text {GlyGlyMet }\right]^{27}}=\frac{\left[\mathrm{CuGlyGlyMet}^{-}\right]\left[\mathrm{H}_{3} \mathrm{O}^{+}\right]}{\left[\mathrm{Cu}\left(\mathrm{H}_{3} \mathrm{O}^{+}\right) \mathrm{GlyGlyMet}^{-}\right]}
\end{gathered}
$$

$\log \mathrm{Ka}_{1}=\log \beta_{\text {CuGlyGlyMet }}-\log \beta_{\text {CuHGlyGlyMet }}$ 
$\mathrm{pKa}_{1}=-\log \mathrm{Ka}_{1}$

Então, substituindo os valores da Tabela 5, a constante $\mathrm{pKa}_{1}$ para a espécie CuHGlyGlyMet pode ser obtida:

$$
\begin{gathered}
\mathrm{pKa}_{1}=-(15,67-19,84) \\
\mathrm{pKa}_{1}=4,17
\end{gathered}
$$

O valor de 4,17 refere-se ao pH onde ocorre a desprotonação do nitrogênio peptídico (GlyGly) no complexo ternário formado em solução aquosa.

A segunda desprotonação, que refere a perda de um próton da espécie CuGlyGlyMet para formar CuGlyGlyMet $(\mathrm{OH})^{2}$, é mostrada no equilíbrio abaixo e a segunda constante de acidez é dada pela Equação 31:

$$
\begin{aligned}
& \text { CuGlyGlyMet }^{-}+\mathrm{H}_{2} \mathrm{O} \rightleftharpoons \text { CuGlyGlyMet }(\mathrm{OH})^{2-}+\mathrm{H}_{3} \mathrm{O}^{+}
\end{aligned}
$$

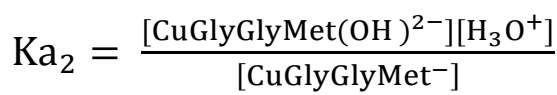

Como os valores das constantes de formação $\beta_{\text {CuGlyGlyMet }}$ e $\beta_{\text {CuGlyGlyMet(OH) }}$ podemos determinar o valor de $\mathrm{pKa}_{2}$ para a espécie CuGlyGlyMet ${ }^{-}$(Equações 3235):

$$
\begin{aligned}
& \mathrm{Ka}_{2}=\beta_{\text {CuGlyGlyMet }(\mathrm{OH})} \cdot \frac{1}{\beta_{\text {CuGlyGlyMet }}} \\
& \mathrm{Ka}_{2}=\frac{\left[\mathrm{CuGlyGlyMet}(\mathrm{OH})^{2-}\right]\left[\mathrm{H}_{3} \mathrm{O}^{+}\right]}{\left[\mathrm{Cu}^{2+}\right]\left[\mathrm{GlyGly}^{2-}\right]\left[\mathrm{Met}^{-}\right]} \cdot \frac{\left[\mathrm{Cu}^{2+}\right]\left[\mathrm{GlyGly}^{2-}\right]\left[\mathrm{Met}^{-}\right]}{\left[\mathrm{CuGlyGlyMet}^{-}\right]}=
\end{aligned}
$$

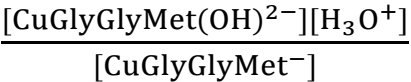

$\log \mathrm{Ka}_{2}=\log \beta_{\text {CuGlyGlyMet(OH) }}-\log \beta_{\text {CuGlyGlyMet }}$

$\mathrm{pKa}_{2}=-\log \mathrm{Ka}_{2}$

Então, substituindo os valores da Tabela 5, a constante $\mathrm{pKa}_{2}$ para a espécie CuGlyGlyMet pode ser obtida:

$$
\mathrm{pKa}_{2}=-(8,22-15,67)
$$




$$
\mathrm{pKa}_{2}=7,45
$$

Esse valor refere-se ao $\mathrm{pH}$ onde ocorre desprotonação de uma molécula de água coordenada ao metal no complexo ternário.

A Figura 22 mostra o diagrama de distribuição de espécies em função do pH para o sistema ternário Cu:GlyGly:Met na razão 1:1:1. A espécie CuHGlyGlyMet coexiste com o íon cobre(II) em valores baixos de $\mathrm{pH}$. A primeira desprotonação ocorre em 4,17, onde a espécie CuGlyGlyMet passa a predominar em grandes concentrações ( $80 \%$ ). Aqui, a espécie CuGlyGlyMet refere-se ao dipeptídeo desprotonado no nitrogênio peptídico. A segunda desprotonação ocorre em $\mathrm{pH} 7,45$, onde a espécie CuGlyGlyMet $(\mathrm{OH})^{2-}$ passa a prevalecer em grandes proporções no sistema até valores elevados de $\mathrm{pH}$. Nesse caso, a espécie $\mathrm{Cu}(\mathrm{OH})_{4}{ }^{2-}$ só passa a predominar no sistema em valores de $\mathrm{pH}$ maiores que 11.

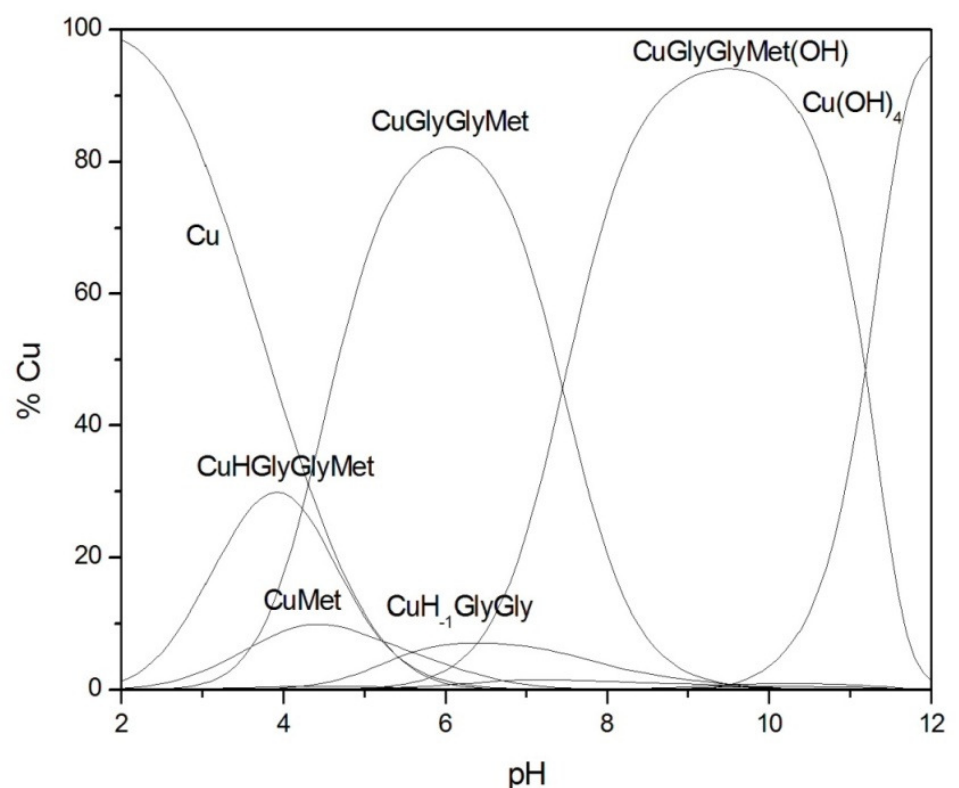

Figura 22. Diagrama de distribuição de espécies em função do pH para o sistema ternário $\mathrm{Cu}(\mathrm{II}): \mathrm{L}_{1}: \mathrm{L}_{2}\left(\mathrm{~L}_{1}=\right.$ GlyGly e $\mathrm{L}_{2}=$ Met) obtido com auxílio do programa SPECIES [166] 


\section{3}

\section{Estudos DFT de sistemas binários e ternário de cobre(II) (Cu:GlyGly, Cu:Met e Cu:GlyGly:Met)}

Os possíveis modos de coordenação dos ligantes glicilglicina e metionina ao íon cobre(II), em uma ampla faixa de valores de $\mathrm{pH}$, foram investigados utilizando a teoria do funcional de densidade (DFT) com auxílio do programa TURBOMOLE 6.1 [152,153].

\subsection{1}

\section{Análise dos possíveis modos de coordenação da glicilglicina (GlyGly) ao íon cobre(II) em solução aquosa (RI-PBE/def2- SVP/COSMO)}

Foram testados todos os possíveis modos de coordenação do ligante glicilglicina ao cobre em uma ampla faixa de pH. Abaixo são descritos os modos de coordenação das geometrias de partida bem como os modos de coordenação e as geometrias das estruturas otimizadas.

\section{- Formação da espécie $\mathrm{CuL}^{+}(2<\mathrm{pH}<4,23)$}

Em valores ácidos de $\mathrm{pH}$, sabe-se que não ocorre a desprotonação dos ligantes dipeptídeos nos complexos de $\mathrm{Cu}$ (II) formados em solução aquosa [151]. Nessa faixa de $\mathrm{pH}(2<\mathrm{pH}<4,23)$, existem três possíveis modos de coordenação do dipeptídeo ao íon cobre(II) formando a espécie $\mathrm{CuL}^{+}$( $\mathrm{L}=$ GlyGly): (1) o dipeptídeo comportando-se como ligante bidentado através do nitrogênio do grupo amino e do oxigênio peptídico pelo sistema coordenante $\mathrm{N}_{\text {amino }} \mathrm{O}_{\text {pept }}$ (Fig. 23a); (2) o dipeptídeo agindo como ligante monodentado através do nitrogênio do grupo amino (Fig. 23b) e (3) o dipeptídeo agindo como ligante monodentado através do oxigênio do grupo carboxílico (Fig. 23c).

As estruturas foram otimizadas considerando a presença de 5 moléculas de água ao redor do íon metálico para facilitar a comparação de energia entre as estruturas propostas. 

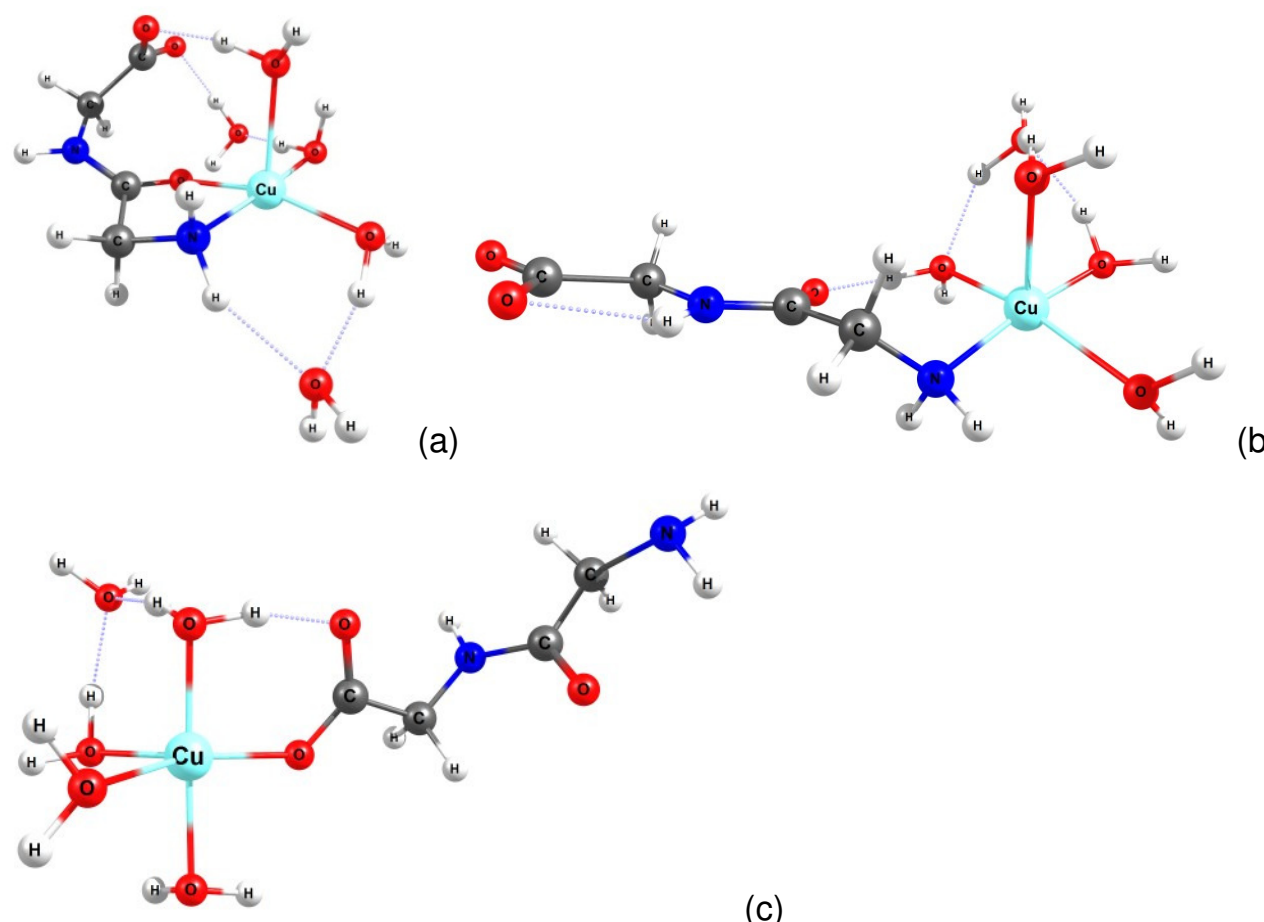

(c)

Figura 23. Possíveis modos de coordenação do ligante glicilglicina ao íon cobre(II), em solução aquosa, formando a espécie $\mathrm{CuL}^{+}\left(\mathrm{L}=\right.$ GlyGly): (a) $\mathrm{N}_{\text {amino }} \mathrm{O}_{\text {pept }}$; (b) $\mathrm{N}_{\text {amino }}$ e (c) $\mathrm{O}_{\text {carbox }}(\mathrm{RI} \mathrm{I} \mathrm{PBE} /$ def2-SVP/COSMO)

Observa-se que em todas as estruturas otimizadas o centro metálico apresenta-se pentacoordenado, porém em geometrias diferentes. Enquanto que nas propostas de coordenação (1) e (2) (Fig. 23a e 23b) os complexes apresentaram uma geometria pirâmide de base quadrada, na proposta (3) (Fig. 23c) o complexo apresentou uma geometria bipirâmide trigonal.

A proposta (1) apresentada na Figura 23a, mostrou uma maior estabilidade de 15 e $12 \mathrm{kcal} \mathrm{mol}^{-1}$ em relação as propostas (2) e (3), respectivamente (ver Tabela 6). O resultado concorda com o descrito na literatura $[58,151]$ em que, nessa faixa de $\mathrm{pH}$, os dipeptídeos comportam-se como ligantes bidentados através do sistema coordenante $\mathrm{N}_{\text {amino }} \mathrm{O}_{\text {pept }}[58]$. 
Tabela 6. Energia relativa ( $\mathrm{kcal} \mathrm{mol}{ }^{-1}$ ) dos possíveis modos de coordenação do dipeptídeo glicilglicina ao íon cobre(II), em solução aquosa, na faixa $2<\mathrm{pH}<4,23$, formando a espécie $\mathrm{CuL}^{+}$( $\mathrm{L}=$ GlyGly) (RI-PBE/def2-SVP/COSMO)

\begin{tabular}{cc}
\hline $\begin{array}{c}\text { Espécie } \mathrm{CuL}^{+} \\
\text {(modo de coordenação) }\end{array}$ & Energia relativa \\
\hline $\mathrm{N}_{\text {amino }} \mathrm{O}_{\text {pept }}$ & 0,00 \\
$\mathrm{~N}_{\text {amino }}$ & 15,00 \\
$\mathrm{O}_{\text {carbox }}$ & 12,00 \\
\hline${ }^{*}$ Energia total + OC corr
\end{tabular}

Na proposta (1) (Fig. 23a) o complexo apresentou um maior número de ligações de hidrogênio do que as propostas (2) e (3) (Fig. 23b e 23c), aumentando a estabilidade do complexo quando o sistema coordenante for $\mathrm{N}_{\text {amino }} \mathrm{O}_{\text {pept }}$.

\section{- Formação da espécie $\mathrm{Cu}\left(\mathrm{H}_{-1} \mathrm{~L}\right)(4,23<\mathrm{pH}<9,56)$}

Em valores de $\mathrm{pH}$ acima de 4,23, na presença do íon cobre(II), os dipeptídeos tendem a sofrer desprotonação do nitrogênio peptídico, fazendo com que eles atuem como ligantes tridentados através do sistema coordenante $\mathrm{N}_{\text {amino }} \mathrm{N}_{\text {pept }} \mathrm{O}_{\text {carbox }}$ [58]. Em um intuito de checar a estrutura mais estável para a espécie $\mathrm{Cu}\left(\mathrm{H}_{-1} \mathrm{~L}\right)\left(\mathrm{H}_{-1} \mathrm{~L}=\right.$ glicilglicina desprotonado no nitrogênio peptídico), as seguintes estruturas foram otimizadas: (1) o dipeptídeo comportando-se como ligante tridentado através do nitrogênio do grupo amino, do nitrogênio desprotonado da ligação peptídica e pelo oxigênio do grupo carboxílico (sistema coordenante $\mathrm{N}_{\text {amino }} \mathrm{N}_{\text {pept }} \mathrm{O}_{\text {carbox }}$ ) (Fig. 24a); (2) o dipeptídeo comportando-se como ligante bidentado coordenado através do nitrogênio do grupo amino e do nitrogênio desprotonado da ligação peptídica e sem a participação do oxigênio carboxílico $\left(\mathrm{N}_{\text {amino }} \mathrm{N}_{\text {pept }}\right)$ (Fig. 24b); (3) o dipeptídeo comportando-se como ligante bidentado coordenado através do oxigênio do grupo carboxílico e do nitrogênio desprotonado da ligação peptídica $\left(\mathrm{N}_{\text {pept }} \mathrm{O}_{\text {carbox }}\right)$ (Fig. 24c); (4) o dipeptídeo agindo como ligante tridentado pelo sistema $\mathrm{N}_{\text {amino }} \mathrm{NH}_{\text {pept }} \mathrm{O}_{\text {carbox }}$ e a desprotonação ocorrendo em uma molécula de água na posição equatorial trans ao nitrogênio do grupo peptídico (Fig. 24d); (5) o dipeptídeo agindo como ligante bidentado pelo sistema $\mathrm{N}_{\text {amino }} \mathrm{NH}_{\text {pept }}$ com a desprotonação ocorrendo na molécula de água trans ao nitrogênio do grupo peptídico (Fig. 24e); (6) o dipeptídeo agindo como ligante bidentado pelo sistema $\mathrm{N}_{\text {amino }} \mathrm{O}_{\text {pept }}$ e a desprotonação ocorrendo na molécula de 
água trans ao nitrogênio do grupo amino (Fig. 24f) e (7) o dipeptídeo agindo como ligante bidentado pelo sistema $\mathrm{N}_{\text {amino }} \mathrm{O}_{\text {pept }}$ e a desprotonação ocorrendo na água localizada na posição trans ao oxigênio peptídico (Fig. 24g).

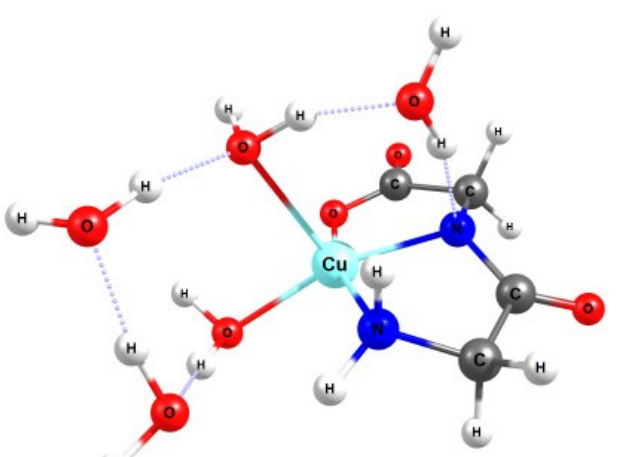

(H

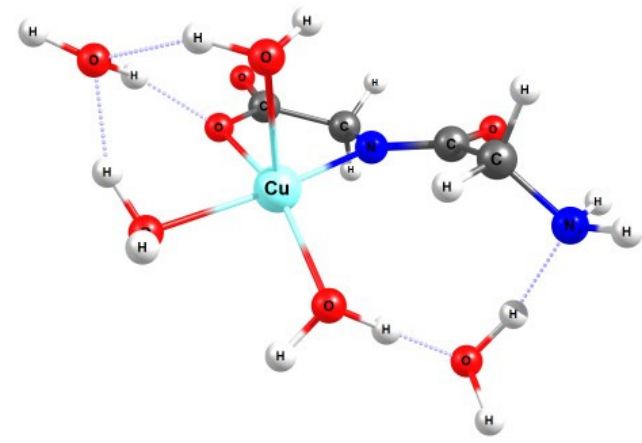

(c)

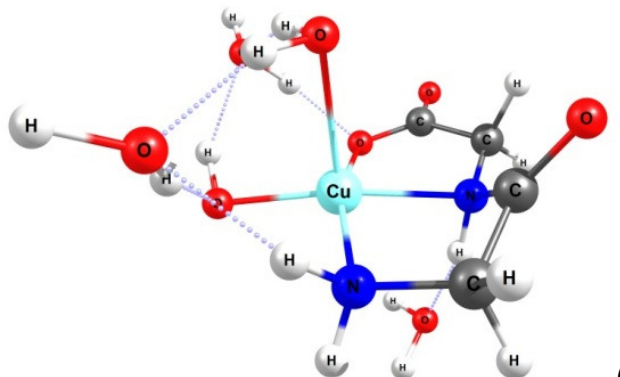

(d)
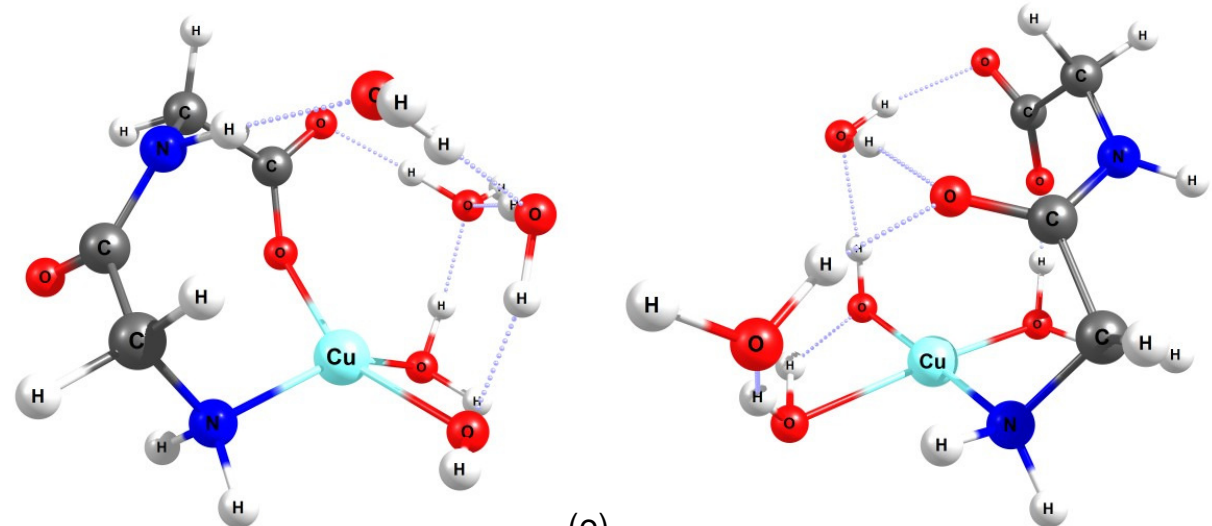

(e) 


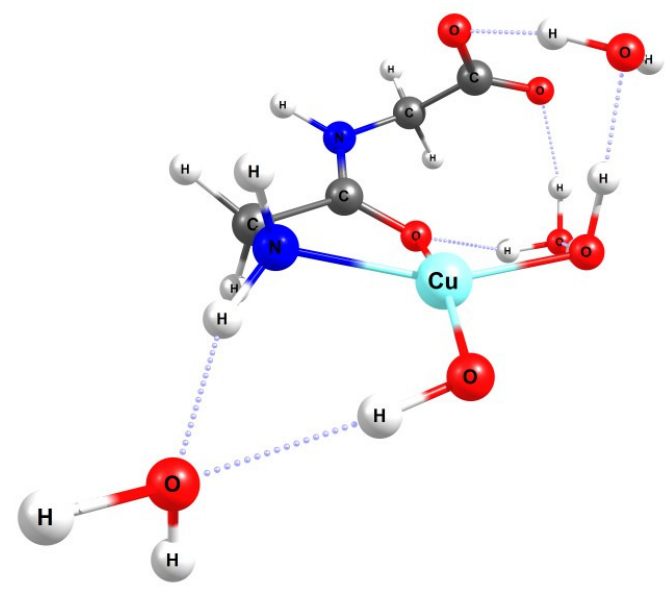

(g)

Figura 24. Possíveis modos de coordenação do ligante glicilglicina ao íon cobre(II), em solução aquosa, formando a espécie $\mathrm{Cu}\left(\mathrm{H}_{-} \mathrm{L}\right) \quad\left(\mathrm{H}_{-} \mathrm{L}=\right.$ dipeptídeo desprotonado no nitrogênio peptídico). Sistema coordenante da geometria de partida: (a) $\mathrm{N}_{\text {amino }} \mathrm{N}_{\text {pept }} \mathrm{O}_{\text {carbox }}$; (b) $\mathrm{N}_{\text {amino }} \mathrm{N}_{\text {pept }}$; (c) $\mathrm{N}_{\text {pept }} \mathrm{O}_{\text {carbox }}$; (d) $\mathrm{N}_{\text {amino }} \mathrm{NH}_{\text {pept }} \mathrm{O}_{\text {carbox }}(\mathrm{OH}$ na posição equatorial trans ao nitrogênio peptídico); (e) $\mathrm{N}_{\text {amino }} \mathrm{NH}_{\text {pept }}(\mathrm{OH}$ na posição equatorial trans ao nitrogênio peptídico; (f) $\mathrm{N}_{\text {amino }} \mathrm{O}_{\text {pept }}(\mathrm{OH}$ na posição equatorial trans ao nitrogênio do grupo amino) e (g) $\mathrm{N}_{\text {amino }} \mathrm{O}_{\text {pept }}(\mathrm{OH}$ na posição equatorial trans ao oxigênio peptídico) (RI-PBE/def2SVP/COSMO)

Observa-se que a espécie $\mathrm{Cu}\left(\mathrm{H}_{-1} \mathrm{~L}\right)$ assume diferentes geometrias. Enquanto que nas propostas de coordenação (1), (2), (5), (6) e (7) (Fig. 24a, 24b, $24 \mathrm{e}, 24 \mathrm{f}$ e $24 \mathrm{~g}$ ) os complexos assumem uma geometria quadrado distorcido, nas propostas (3) e (4) (Fig. 24c e 24d) os complexos apresentaram uma geometria pirâmide de base quadrada.

Dentre as propostas citadas acima, o modo de coordenação (2), com o dipeptídeo comportando-se como ligante bidentado pelo sistema coordenante $\mathrm{N}_{\text {amino }} \mathrm{N}_{\text {pept }}$ (Fig. 24b) mostrou uma maior estabilidade de $2 \mathrm{kcal} \mathrm{mol}^{-1}$ em relação a proposta (1) (Fig. 24a), onde o dipeptídeo atua como ligante tridentado pelo sistema coordenante $\mathrm{N}_{\text {amino }} \mathrm{N}_{\text {pept }} \mathrm{O}_{\text {carbox }}$.

A desprotonação poderia ocorrer em uma molécula de água situada na posição equatorial do complexo ao invés de ocorrer no nitrogênio peptídico. $\mathrm{Na}$ proposta (5), onde inicialmente o dipeptídeo coordenava ao centro metálico pelo sistema $\mathrm{N}_{\text {amino }} \mathrm{NH}_{\text {pept }}$, com a desprotonação ocorrendo em uma molécula de água na posição equatorial (Fig. 24e), após otimização de geometria, o nitrogênio peptídico saiu da esfera de coordenação e a estrutura mostrou uma menor 
estabilidade de cerca de $11 \mathrm{kcal} \mathrm{mol}^{-1}$ em relação a estrutura mais estável mostrada na Figura 24b (Tabela 7).

Com o aumento do $\mathrm{pH}$, o dipeptídeo poderia coordenar ao metal sem a desprotonação do nitrogênio peptídico e sim a desprotonação ocorrer em uma das moléculas de água coordenadas ao metal. Foram testadas duas propostas com o dipeptídeo atuando como ligante bidentado e com a desprotonação ocorrendo em uma molécula de água trans ao nitrogênio do grupo amino ou trans ao oxigênio peptídico (propostas (6) e (7)). As estruturas mostraram menores estabilidades de 16 e $17 \mathrm{kcal} \mathrm{mol}^{-1}$, respectivamente, em relação a proposta (2) onde o complexo mostrou maior estabilidade (Fig. 24b). Então, a desprotonação do nitrogênio da ligação peptídica é cerca de $16 \mathrm{kcal} \mathrm{mol}^{-1}$ mais favorável do que a desprotonação de uma molécula de água coordenada ao metal no complexo formado entre o cobre(II) e o dipeptídeo glicilglicina, em solução aquosa.

Tabela 7. Energia relativa ( $\mathrm{kcal} \mathrm{mol}^{-1}$ ) dos possíveis modos de coordenação do dipeptídeo glicilglicina ao íon cobre(II), em solução aquosa, formando a espécie $\mathrm{Cu}\left(\mathrm{H}_{-1} \mathrm{~L}\right)$ $\left(\mathrm{H}_{-1} \mathrm{~L}=\right.$ dipeptídeo desprotonado no nitrogênio peptídico) (RI-PBE/def2-SVP/COSMO)

\begin{tabular}{cc}
\hline $\begin{array}{c}\text { Espécie } \mathrm{Cu}\left(\mathrm{H}_{-1} \mathrm{~L}\right) \\
\text { (modo de coordenação) }\end{array}$ & Energia relativa \\
\hline $\mathrm{N}_{\text {amino }} \mathrm{N}_{\text {pept }} \mathrm{O}_{\text {carbox }}$ & 2,00 \\
$\mathrm{~N}_{\text {amino }} \mathrm{N}_{\text {pept }}$ & 0,00 \\
$\mathrm{~N}_{\text {pept }} \mathrm{O}_{\text {carbox }}$ & 13,00 \\
$\mathrm{~N}_{\text {aminoo }} \mathrm{NH}_{\text {pept }} \mathrm{O}_{\text {carbox }} \mathrm{OH}^{\mathrm{a}}$ & 14,00 \\
$\mathrm{~N}_{\text {amino }} \mathrm{NH}_{\text {pept }} \mathrm{OH}^{\mathrm{a}}$ & 11,00 \\
$\mathrm{~N}_{\text {amino }} \mathrm{O}_{\text {pept }} \mathrm{OH}^{\mathrm{b}}$ & 16,00 \\
$\mathrm{~N}_{\text {amino }} \mathrm{O}_{\text {pept }} \mathrm{OH}^{\mathrm{c}}$ & 17,00 \\
\hline
\end{tabular}

${ }^{a} \mathrm{OH}$ na posição equatorial trans ao nitrogênio protonado do grupo peptídico

${ }^{\mathrm{b}} \mathrm{OH}$ na posição equatorial trans ao nitrogênio do grupo amino

${ }^{\mathrm{C}} \mathrm{OH}$ na posição equatorial trans ao oxigênio peptídico

\section{- Formação da espécie $\mathrm{Cu}\left(\mathrm{H}_{-1} \mathrm{~L}\right)(\mathrm{OH})^{-}(9,56<\mathrm{pH}<10,5)$}

Como a estrutura mais estável para a espécie $\mathrm{Cu}\left(\mathrm{H}_{-1} \mathrm{~L}\right)$ foi aquela no qual o dipeptídeo comportou-se como ligante bidentado pelo sistema coordenante $\mathrm{N}_{\text {amino }} \mathrm{N}_{\text {peptíd }}$ (Fig. 25b), nós partimos dessa estrutura e testamos três formas de desprotonação de uma das moléculas de água coordenada ao centro metálico, para formar a espécie hidrolisada: $\mathrm{Cu}\left(\mathrm{H}_{-1} \mathrm{~L}\right)(\mathrm{OH})^{-}\left(\mathrm{H}_{-1} \mathrm{~L}=\right.$ glicilglicina desprotonado no nitrogênio peptídico): (1) desprotonação de uma molécula de água na posição equatorial trans ao átomo de nitrogênio do grupo amino (Fig. 25a); (2) 
desprotonação de uma molécula de água na posição equatorial trans ao átomo de nitrogênio peptídico (Fig. 25b) e (3) desprotonação de uma molécula na posição axial (uma das moléculas de água do complexo foi colocada na posição axial) (Fig. 25c).

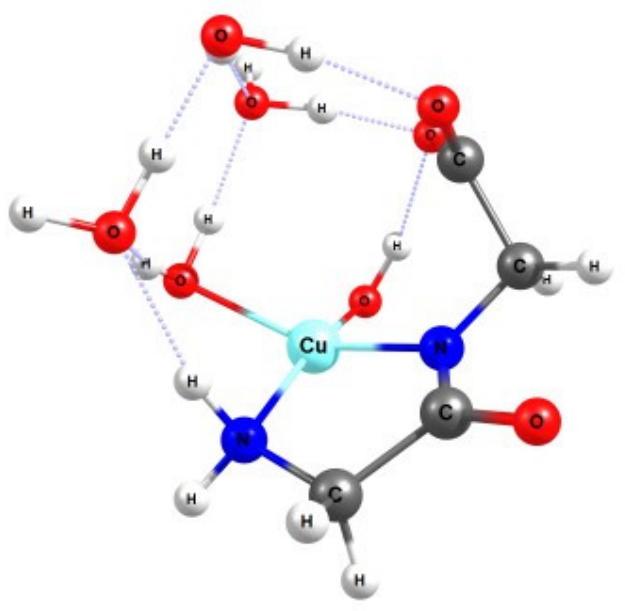

(a)

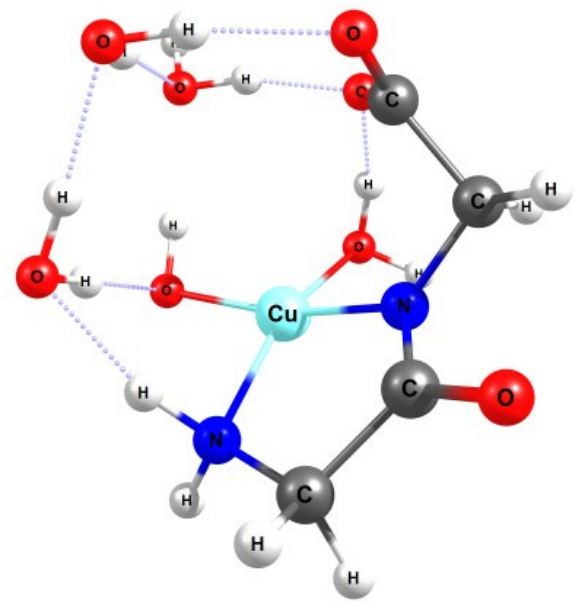

(b)

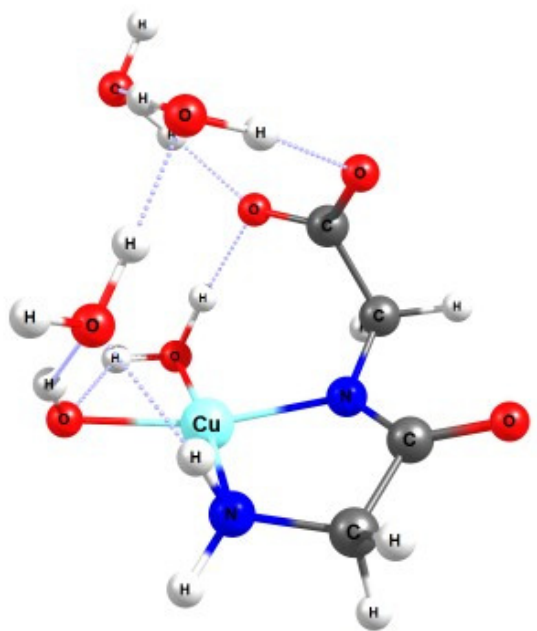

(c)

Figura 25. Possíveis modos de coordenação do dipeptídeo glicilglicina ao íon cobre(II), em solução aquosa, formando a espécie $\mathrm{Cu}\left(\mathrm{H}_{-1} \mathrm{~L}\right)(\mathrm{OH})^{-}\left(\mathrm{H}_{-1} \mathrm{~L}=\right.$ dipeptídeo desprotonado no nitrogênio peptídico): (a) desprotonação da água na posição trans ao nitrogênio do grupo amino; (b) desprotonação da água na posição trans ao nitrogênio peptídico e (c) desprotonação da água na posição axial (RI-PBE/def2-SVP/COSMO)

A Figura 25 mostra as estruturas otimizadas para todas as propostas de formação da espécie $\mathrm{Cu}\left(\mathrm{H}_{-1} \mathrm{~L}\right)(\mathrm{OH})^{-}\left(\mathrm{H}_{-1} \mathrm{~L}=\right.$ dipeptídeo desprotonado no nitrogênio peptídico). Todas as estruturas apresentaram um número de coordenação 4. Entre as propostas de coordenação, a proposta (2) (Fig. 25b) apresentou uma maior estabilidade de $9 \mathrm{kcal} \mathrm{mol}^{-1}$ em relação a proposta (1), com 
a desprotonação ocorrendo na molécula de água trans ao átomo de nitrogênio do grupo amino (Fig. 25a) (Tabela 8). Na proposta (3), onde partimos de uma desprotonação de uma molécula de água na posição axial, após convergência de energia, a molécula de hidroxila se deslocou para a posição equatorial trans ao átomo de nitrogênio peptídico.

Podemos inferir após cálculos teóricos que a desprotonação de uma das moléculas de água coordenadas ao cobre(II), na espécie binária $\mathrm{Cu}\left(\mathrm{H}_{-1} \mathrm{~L}\right)$ para formar $\mathrm{Cu}\left(\mathrm{H}_{-1}\right)(\mathrm{OH})$, se dá preferencialmente na molécula de água coordenada ao metal situada na posição equatorial trans ao átomo de nitrogênio peptídico.

Tabela 8. Energia relativa ( $\mathrm{kcal} \mathrm{mol}{ }^{-1}$ ) dos possíveis modos de coordenação do dipeptídeo glicilglicina ao íon cobre(II), em solução aquosa, formando a espécie $\mathrm{Cu}(\mathrm{H}$. $\left.{ }_{1} \mathrm{~L}\right)(\mathrm{OH})^{-}\left(\mathrm{H}_{-} \mathrm{L}=\right.$ dipeptídeo desprotonado no nitrogênio peptídico) (RI-PBE/def2-SVP/ COSMO)

\begin{tabular}{cc}
\hline $\begin{array}{c}\text { Espécie } \mathrm{Cu}\left(\mathrm{H}_{-1} \mathrm{~L}\right)(\mathrm{OH})^{-} \\
\text {(modo de coordenação) }\end{array}$ & $\begin{array}{c}\text { Energia } \\
\text { relativa }\end{array}$ \\
\hline $\mathrm{N}_{\text {amino }} \mathrm{N}_{\text {pept }} \mathrm{OH}_{\mathrm{eq}}{ }^{a}$ & 9,00 \\
$\mathrm{~N}_{\text {amino }} \mathrm{N}_{\text {pept }} \mathrm{OH}_{\mathrm{eq}}$ & 0,00 \\
$\mathrm{~N}_{\text {amino }} \mathrm{N}_{\text {pept }} \mathrm{OH}_{\mathrm{ax}}$ & 1,00 \\
\hline${ }^{\mathrm{a}}$ Hidroxila na posição trans ao grupo amino \\
${ }^{\mathrm{b}}$ Hidroxila na posição trans ao grupo peptídico
\end{tabular}

\section{3 .2}

\section{Otimização e parâmetros geométricos da espécie $\mathrm{CuL}^{+}(\mathrm{L}=\mathrm{GlyGly})$ obtidos pela metodologia DFT (RI-PBE/def2-SVP/COSMO)}

Após análise dos possíveis modos de coordenação do dipeptídeo glicilglicina ao íon metálico $\mathrm{Cu}(\mathrm{II})$, em uma ampla faixa de valores de $\mathrm{pH}$, seguimos para a descrição dos parâmetros geométricos das estruturas mais estáveis.

Complexos de cobre apresentam uma grande variedade de geometrias, devido a diferença de energia entre as estruturas serem pequenas. Eles podem assumir geralmente geometrias quadrado planar, pirâmide de base quadrada, bipirâmide trigonal e octaédrica.

Para a espécie $\mathrm{CuL}^{+}(\mathrm{L}=$ GlyGly) a estrutura mais estável foi aquela em que o dipeptídeo comportou-se como ligante bidentado pelo sistema coordenante $\mathrm{N}_{\text {amino }} \mathrm{O}_{\text {pept }}$. A estrutura de partida continha duas moléculas de água nas posições 
axiais do complexo em uma geometria octaédrica. Após otimização de geometria, uma das moléculas de água da posição axial saiu da esfera de coordenação do metal e o complexo assumiu uma geometria pirâmide de base quadrada (Fig. 26). Na geometria otimizada, a molécula de água coordenada ao metal na posição axial apresentou um comprimento de ligação $\mathrm{Cu}-\mathrm{O}_{\mathrm{ax}}$ de 2,246 $\AA$, maior do que os comprimentos de ligação nas posições equatoriais: $\mathrm{Cu}-\mathrm{O}_{\text {pept }}, \mathrm{C}-\mathrm{N}_{\text {amino }}$ e $\mathrm{Cu}-\mathrm{O}_{\text {eq. }}$. Nossos resultados concordam com algumas estruturas pentacoordenadas descritas na literatura, em solução aquosa, para o complexo $\left[\mathrm{Cu}\left(\mathrm{H}_{2} \mathrm{O}\right)\right]^{2+}$ e os valores de comprimentos de ligação encontrados estão próximos aos relatados [27]. Nossos resultados concordam com o efeito Jahn-Teller que é descrito como a labilidade dos ligantes nas posições axiais e a predominância de estruturas com ligantes axiais situados a maiores distâncias dos centros metálicos do que os ligantes nas posições equatoriais. Os principais parâmetros geométricos da espécie $\mathrm{CuL}^{+}$assim como alguns valores de comprimentos de ligação e ângulos obtidos do Cambridge Crystallographic Data Centre (CCDC), para complexos semelhantes, são mostrados na Tabela 9. 


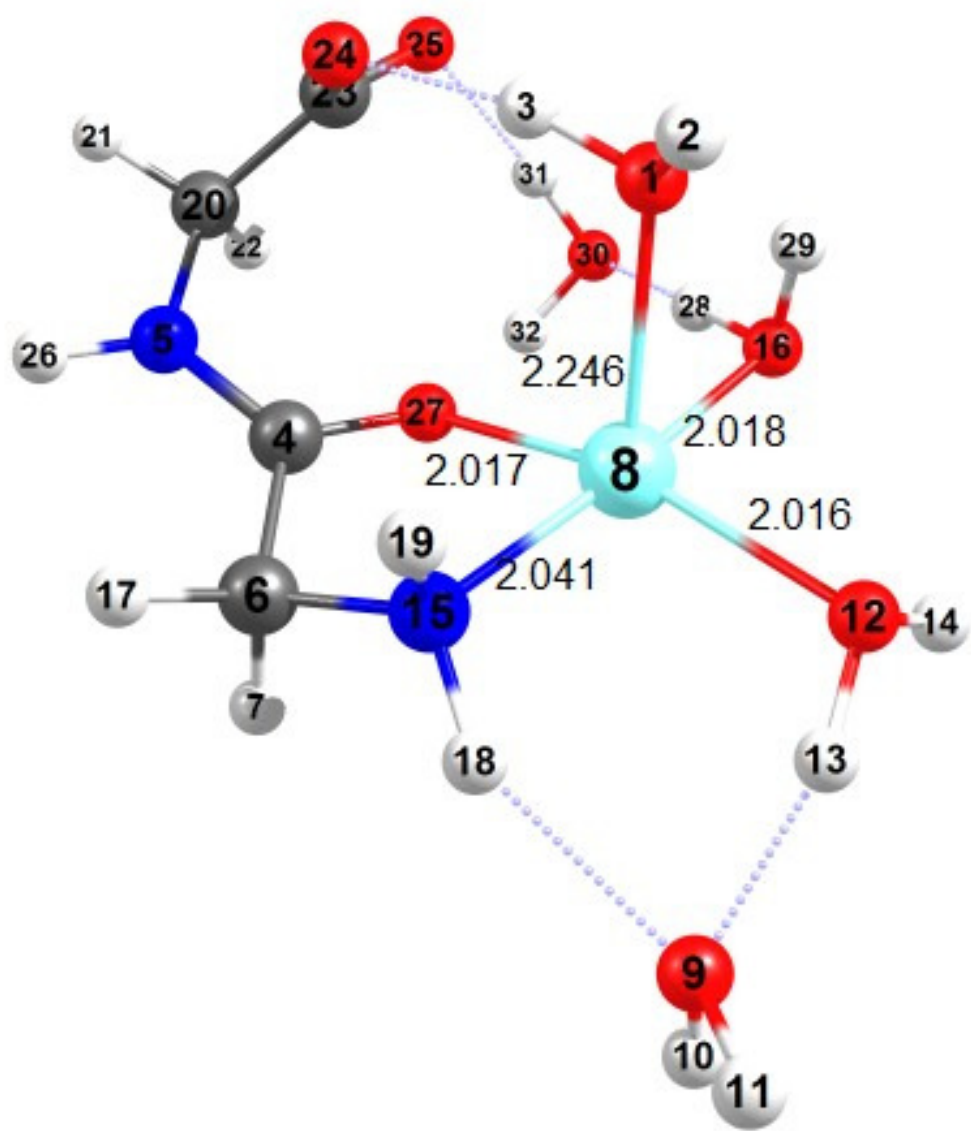

Figura 26. Estrutura otimizada da espécie $\mathrm{CuL}^{+}(\mathrm{L}=\mathrm{GlyGly})$ obtida com a presença de cinco moléculas de água (RI-PBE/def2-SVP/COSMO)

Tabela 9. Parâmetros estruturais da espécie $\mathrm{CuL}^{+}(\mathrm{L}=$ GlyGly) (COSMO:RI-PBE/def2SVP)

\begin{tabular}{|c|c|c|c|c|c|c|c|c|}
\hline Átomos & $\begin{array}{l}\text { Ligações } \\
\text { (A) }\end{array}$ & CCDC & Átomos & $\begin{array}{c}\text { Ângulos } \\
\left({ }^{\circ}\right)\end{array}$ & CCDC & Átomos & $\begin{array}{c}\text { Diedros } \\
\left({ }^{\circ}\right)\end{array}$ & CCDC \\
\hline $\mathrm{Cu}-\mathrm{N}_{15}$ & 2,041 & 2,02 & $\mathrm{CuN}_{15} \mathrm{O}_{27}$ & 83,07 & 83,33 & $\mathrm{~N}_{15} \mathrm{CuO}_{27} \mathrm{O}_{16}$ & 179,56 & - \\
\hline $\mathrm{Cu}-\mathrm{O}_{27}$ & 2,017 & 1,98 & $\mathrm{CuO}_{27} \mathrm{O}_{16}$ & 92,40 & - & $\mathrm{O}_{27} \mathrm{CuO}_{16} \mathrm{O}_{12}$ & 162,25 & - \\
\hline $\mathrm{Cu}-\mathrm{O}_{16}$ & 2,018 & - & $\mathrm{CuO}_{16} \mathrm{O}_{12}$ & 90,08 & - & $\mathrm{O}_{12} \mathrm{CuN}_{15} \mathrm{O}_{27}$ & 162,18 & - \\
\hline $\mathrm{Cu}-\mathrm{O}_{12}$ & 2,016 & - & $\mathrm{CuO}_{12} \mathrm{~N}_{15}$ & 94,38 & - & $\mathrm{N}_{15} \mathrm{CuO}_{12} \mathrm{O}_{16}$ & 179,03 & \\
\hline \multirow[t]{4}{*}{$\mathrm{Cu}-\mathrm{O}_{1}$} & 2,246 & 2,30 & $\mathrm{CuO}_{1} \mathrm{~N}_{15}$ & 101,76 & 89,83 & $\mathrm{O}_{1} \mathrm{CuN}_{15} \mathrm{O}_{27}$ & 93,67 & 99,77 \\
\hline & & & $\mathrm{CuO}_{1} \mathrm{O}_{27}$ & 94,98 & 99,68 & $\mathrm{O}_{1} \mathrm{CuO}_{27} \mathrm{O}_{16}$ & 78,29 & - \\
\hline & & & $\mathrm{CuO}_{1} \mathrm{O}_{16}$ & 78,13 & - & $\mathrm{O}_{1} \mathrm{CuO}_{16} \mathrm{O}_{12}$ & 103,16 & - \\
\hline & & & $\mathrm{CuO}_{1} \mathrm{O}_{12}$ & 102,89 & - & $\mathrm{O}_{1} \mathrm{CuO}_{12} \mathrm{~N}_{15}$ & 103,12 & - \\
\hline
\end{tabular}

CCDC: Cambridge Crystallographic Data Centre

Utilizamos o funcional híbrido B3LYP com um conjunto de bases def2TZVP para obter a energia do ponto estacionário e com isso foi possível gerar uma superfície de distribuição de densidade de spin. A Figura 27 indica que a densidade do elétron desemparelhado está localizado no orbital $3 d_{x^{2}-y^{2}}$ do cobre(II) e nos orbitais dos pares eletrônicos dos átomos de oxigênio e nitrogênio 
coordenados ao metal nas posições equatoriais, sugerindo uma configuração eletrônica do estado fundamental $t_{2 g}^{6} e_{g}^{3}\left(d_{z^{2}}^{2} d_{x^{2}-y^{2}}^{1}\right)$.

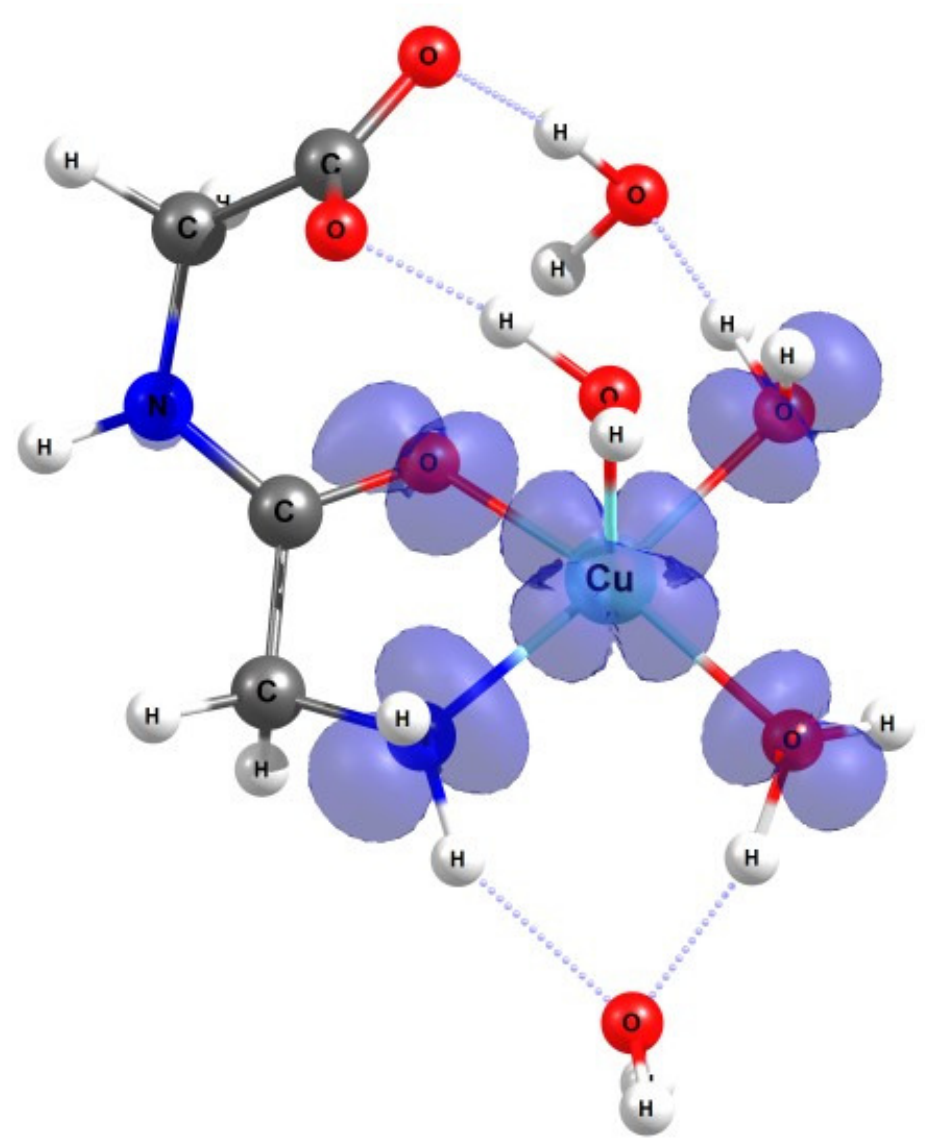

Figura 27. Distribuição de densidade de spin da espécie $\mathrm{CuL}^{+}(\mathrm{L}=$ glicilglicina) a partir de simulação B3LYP/def2-TZVP/COSMO como isosuperfície de 0,002 a.u.

\section{3 .3}

Otimização e parâmetros geométricos da espécie $\mathrm{Cu}\left(\mathrm{H}_{-1} \mathrm{~L}\right)\left(\mathrm{H}_{-1} \mathrm{~L}=\right.$ dipeptídeo glicilglicina desprotonado no nitrogênio peptídico) obtidos pela metodologia DFT (RI-PBE/def2-SVP/COSMO)

Muitas referências apontam que o dipeptídeo glicilglicina coordena-se ao cobre, na faixa de $\mathrm{pH}$ entre 5 - 9, pelo sistema coordenante tridentado $\mathrm{N}_{\text {amino }} \mathrm{N}_{\text {pept }} \mathrm{O}_{\text {carbox }}$ [58]. Porém, a estrutura mais estável identificada após cálculos DFT, foi aquela em que o ligante teve comportamento bidentado, sem a participação do átomo de oxigênio do grupo carboxílico na esfera de coordenação do centro metálico. A estrutura apresentou uma geometria quadrado distorcido

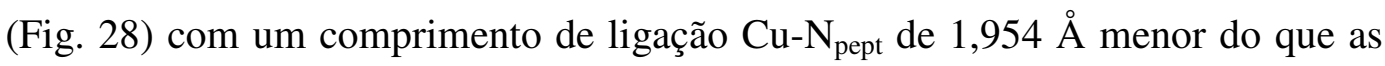
demais ligações do cobre aos átomos coordenantes. 


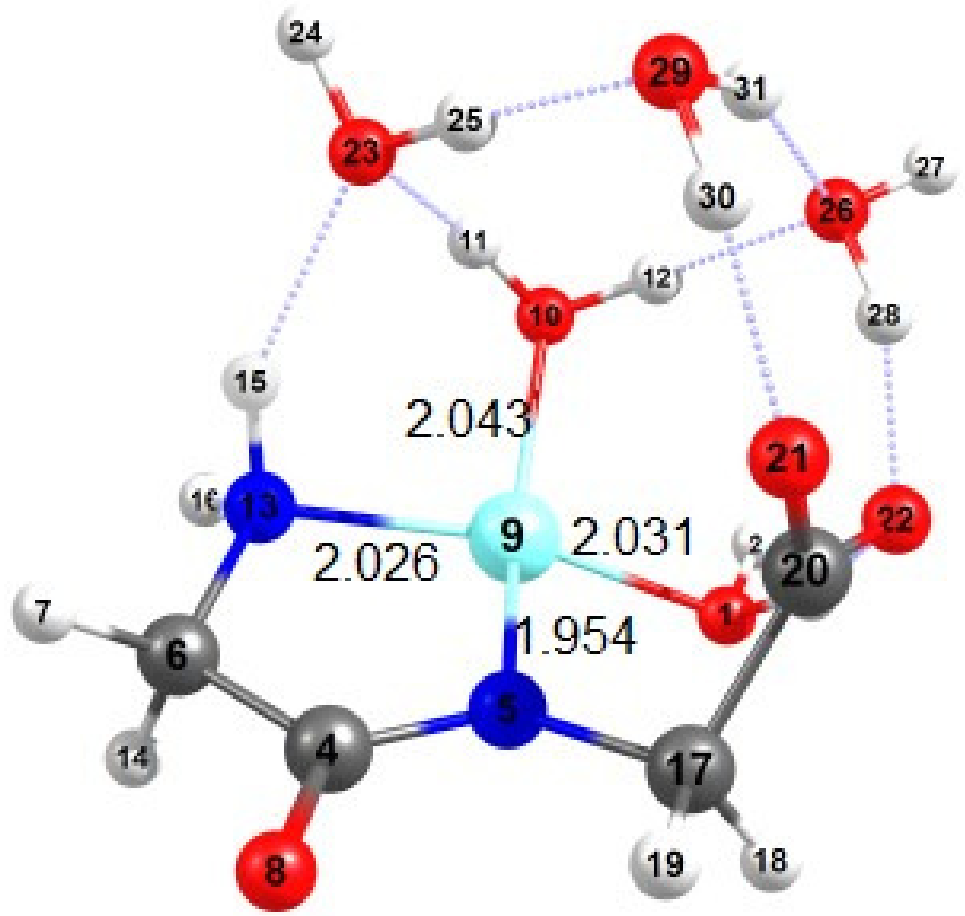

Figura 28. Estrutura otimizada da espécie $\mathrm{Cu}\left(\mathrm{H}_{-1} \mathrm{~L}\right)\left(\mathrm{H}_{-1} \mathrm{~L}=\right.$ dipeptídeo glicilglicina desprotonado no nitrogênio peptídico) obtida com a presença de cinco moléculas de água (RI-PBE/def2-SVP/COSMO)

A Tabela 10 mostra os parâmetros geométricos em torno do centro metálico para a espécie $\mathrm{Cu}\left(\mathrm{H}_{-1}\right.$ GlyGly) e alguns dados obtidos do CCDC.

Tabela 10. Parâmetros estruturais da espécie $\mathrm{Cu}\left(\mathrm{H}_{-1} \mathrm{~L}\right)\left(\mathrm{H}_{-1} \mathrm{~L}=\right.$ dipeptídeo desprotonado no nitrogênio peptídico) (COSMO:RI-PBE/def2-SVP)

\begin{tabular}{ccccccccc}
\hline Átomos & $\begin{array}{c}\text { Ligações } \\
(\mathrm{A})\end{array}$ & $\mathrm{CCDC}$ & Átomos & $\begin{array}{c}\text { Ângulos } \\
\left({ }^{\circ}\right)\end{array}$ & CCDC & Átomos & $\begin{array}{c}\text { Diedros } \\
\left({ }^{\circ}\right)\end{array}$ & CCDC \\
\hline $\mathrm{Cu}-\mathrm{N}_{13}$ & 2,026 & 2,02 & $\mathrm{~N}_{13} \mathrm{CuN}_{5}$ & 83,81 & 83,23 & $\mathrm{~N}_{13} \mathrm{Cu}_{10} \mathrm{O}_{1}$ & 166,40 & - \\
$\mathrm{Cu}-\mathrm{N}_{5}$ & 1,954 & 1,95 & $\mathrm{~N}_{5} \mathrm{CuO}_{1}$ & 95,52 & - & $\mathrm{N}_{13} \mathrm{CuN}_{5} \mathrm{O}_{1}$ & 164,01 & - \\
$\mathrm{Cu} \mathrm{O}_{10}$ & 2,043 & 1,99 & $\mathrm{O}_{1} \mathrm{CuO}_{10}$ & 92,93 & - & $\mathrm{O}_{10} \mathrm{CuO}_{1} \mathrm{~N}_{4}$ & 151,93 & - \\
$\mathrm{Cu}-\mathrm{O}_{1}$ & 2,031 & 1,99 & $\mathrm{~N}_{13} \mathrm{CuO}_{10}$ & 95,36 & 100,81 & $\mathrm{~N}_{5} \mathrm{CuN}_{13} \mathrm{O}_{10}$ & 150,58 & 160,0 \\
\hline
\end{tabular}

CCDC: Cambridge Crystallographic Data Centre

A Figura 29 mostra a distribuição de densidade de spin para a espécie $\mathrm{Cu}\left(\mathrm{H}_{-1} \mathrm{~L}\right)\left(\mathrm{H}_{-1} \mathrm{~L}=\right.$ dipeptídeo desprotonado no nitrogênio peptídico) indicando forte contribuição do orbital $3 d_{x^{2}-y^{2}}$ do $\mathrm{Cu}$ (II) e dos orbitais dos ligantes na posições equatoriais na distribuição eletrônica do estado fundamental. 


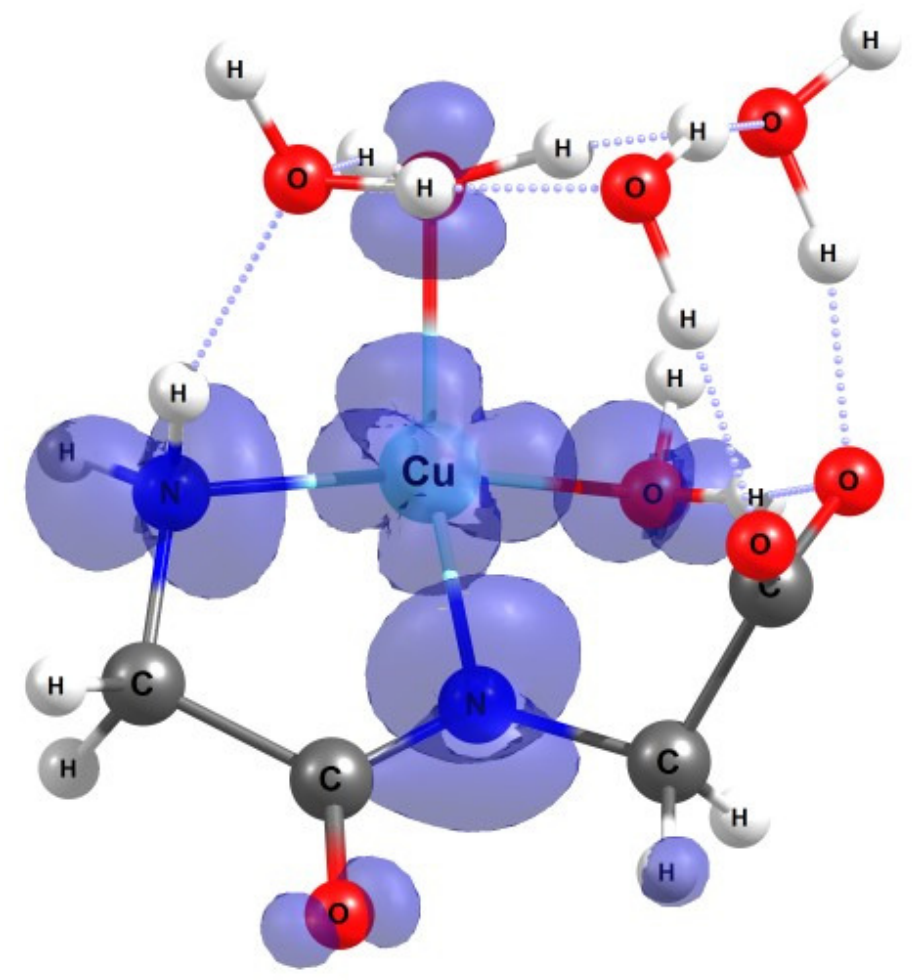

Figura 29. Distribuição de densidade de spin da espécie $\mathrm{Cu}\left(\mathrm{H}_{-1} \mathrm{~L}\right)\left(\mathrm{H}_{-1} \mathrm{~L}=\right.$ dipeptídeo glicilglicina desprotonado no nitrogênio peptídico) a partir de simulação B3LYP/def2TZVP/COSMO como isosuperfície de 0,002 a.u.

\section{3 .4}

Otimização e parâmetros geométricos da espécie $\mathrm{Cu}\left(\mathrm{H}_{-1} \mathrm{~L}\right)(\mathrm{OH})^{-}\left(\mathrm{H}_{-1} \mathrm{~L}\right.$ = dipeptídeo glicilglicina desprotonado no nitrogênio peptídico) obtidos pela metodologia DFT (RI-PBE/def2-SVP/COSMO)

Nós testamos três possíveis propostas para a desprotonação da molécula de água coordenada ao centro metálico: $\mathrm{OH}_{\mathrm{eq}}$ trans ao nitrogênio amino, $\mathrm{OH}_{\mathrm{eq}}$ trans ao nitrogênio peptídico e a colocação de uma molécula de hidroxila na posição axial $\left(\mathrm{OH}_{\mathrm{ax}}\right)$. Após otimização de energia, verificou-se uma maior estabilidade da estrutura contendo a hidroxila na posição equatorial trans ao nitrogênio peptídico do que as demais propostas testadas. O complexo mostrou um número de coordenação 4 e uma geometria quadrado distorcida (Fig. 30). 


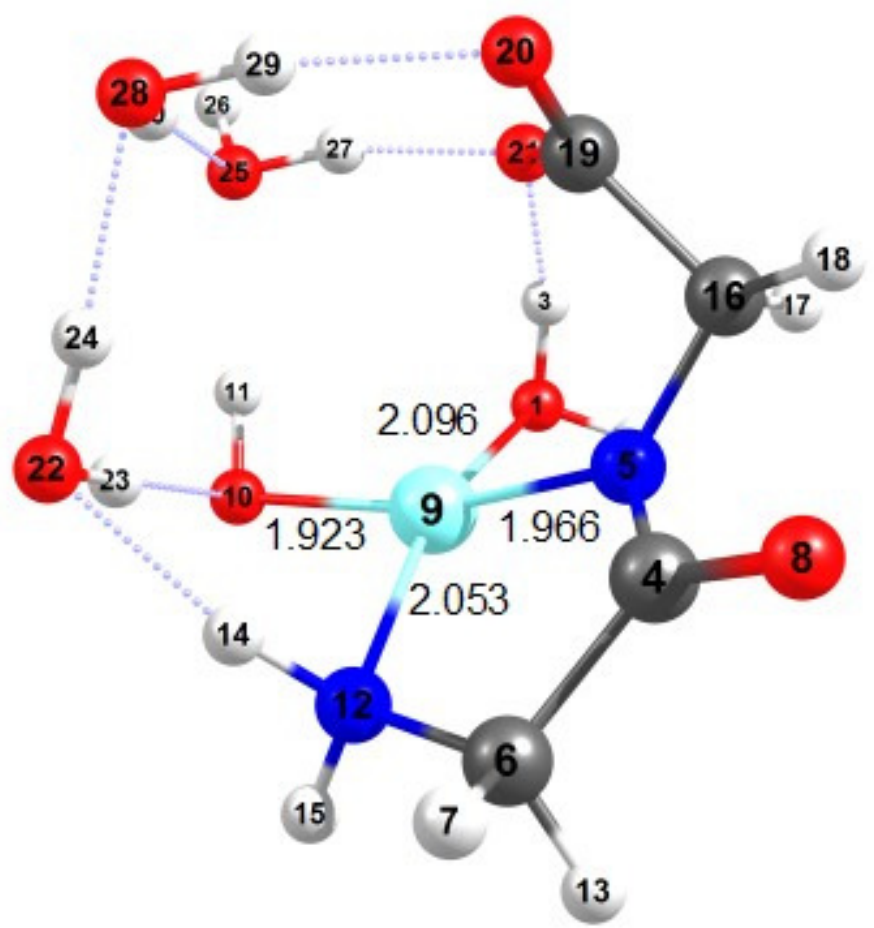

Figura 30. Estrutura otimizada da espécie $\mathrm{Cu}\left(\mathrm{H}_{-1} \mathrm{~L}\right)(\mathrm{OH})^{-}\left(\mathrm{H}_{-1} \mathrm{~L}=\right.$ dipeptídeo glicilglicina desprotonado no nitrogênio peptídico) obtida com a presença de cinco moléculas de água (RI-PBE/def2-SVP/COSMO)

A Tabela 11 mostra os parâmetros geométricos em torno do centro metálico para a espécie $\mathrm{Cu}\left(\mathrm{H}_{-1} \mathrm{GlyGly}\right)(\mathrm{OH})^{-}$e alguns dados obtidos do CCDC.

Tabela 11. Parâmetros estruturais da espécie $\mathrm{Cu}\left(\mathrm{H}_{-1} \mathrm{~L}\right)(\mathrm{OH})^{-}\left(\mathrm{H}_{-1} \mathrm{~L}=\right.$ dipeptídeo glicilglicina desprotonado no nitrogênio peptídico) (COSMO:RI-PBE/def2-SVP)

\begin{tabular}{lcccccccc}
\hline Átomos & $\begin{array}{c}\text { Ligações } \\
(\mathrm{A})\end{array}$ & CCDC & Átomos & $\begin{array}{c}\text { Ángulos } \\
\left({ }^{\circ}\right)\end{array}$ & CCDC & Átomos & $\begin{array}{c}\text { Diedros } \\
\left({ }^{\circ}\right)\end{array}$ & CCDC \\
\hline $\mathrm{Cu}-\mathrm{N}_{12}$ & 2,053 & 2,02 & $\mathrm{~N}_{12} \mathrm{CuN}_{5}$ & 82,95 & 83,23 & $\mathrm{~N}_{12} \mathrm{CuN}_{5} \mathrm{O}_{1}$ & 162,73 & - \\
$\mathrm{Cu}-\mathrm{N}_{5}$ & 1,966 & 1,90 & $\mathrm{~N}_{5} \mathrm{CuO}_{1}$ & 94,51 & - & $\mathrm{N}_{5} \mathrm{CuO}_{1} \mathrm{O}_{10}$ & 161,00 & - \\
$\mathrm{Cu}-\mathrm{O}_{1}$ & 2,096 & 1,98 & $\mathrm{O}_{1} \mathrm{CuO}_{10}$ & 94,30 & - & $\mathrm{O}_{1} \mathrm{CuO}_{10} \mathrm{~N}_{12}$ & 164,71 & - \\
$\mathrm{Cu}-\mathrm{O}_{10}$ & 1,923 & 1,99 & $\mathrm{~N}_{12} \mathrm{CuO}_{10}$ & 93,95 & - & $\mathrm{O}_{10} \mathrm{CuN}_{12} \mathrm{~N}_{5}$ & 159,20 & 160,0 \\
\hline
\end{tabular}

CCDC: Cambridge Crystallographic Data Centre

A Figura 31 mostra a distribuição de densidade de spin para a espécie $\mathrm{Cu}\left(\mathrm{H}_{-1} \mathrm{~L}\right)(\mathrm{OH})$, indicando que a densidade do elétron desemparelhado está localizada no orbital $3 d_{x^{2}-y^{2}}$ do cobre(II) e nos orbitais dos pares eletrônicos dos oxigênios e dos nitrogênios coordenados ao metal nas posições equatoriais. $O$ resultado sugere uma configuração eletrônica para o estado fundamental $t_{2 g}^{6} e_{g}^{3}\left(d_{z^{2}}^{2} d_{x^{2}-y^{2}}^{1}\right)$ 


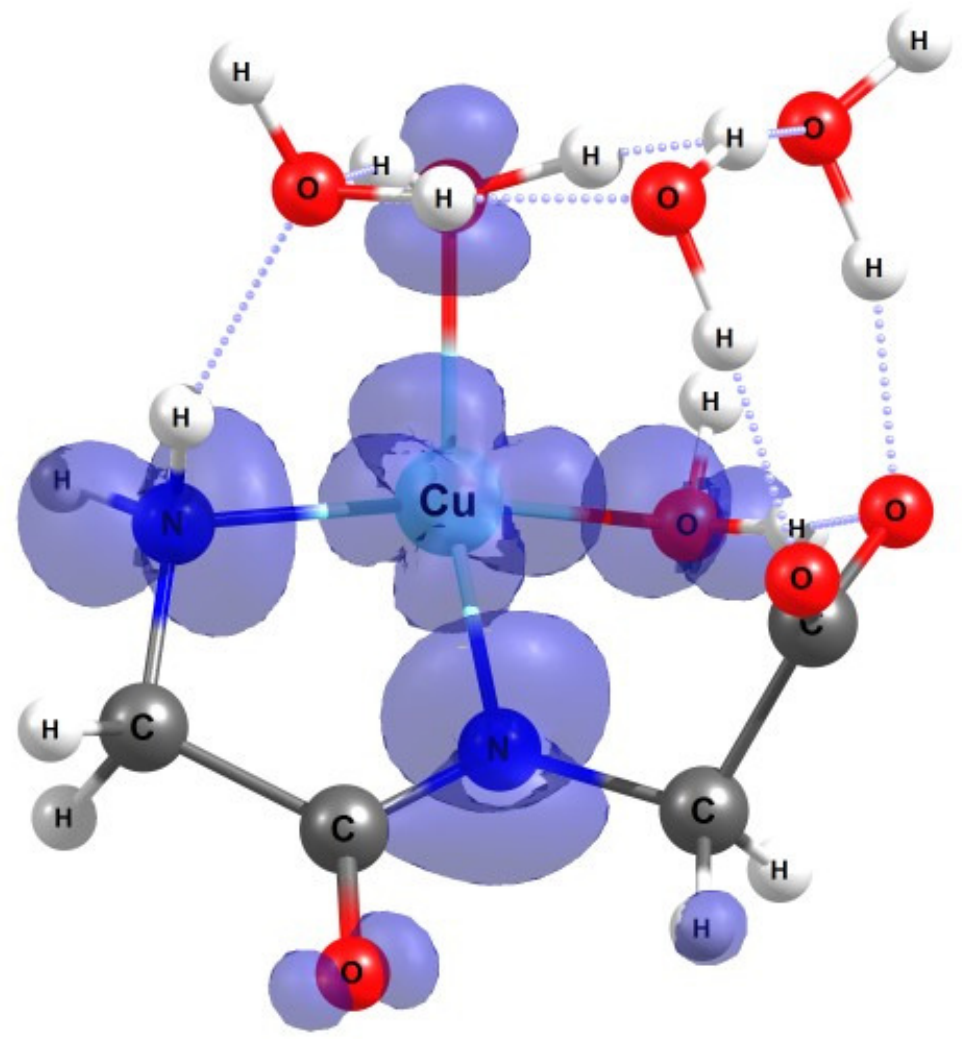

Figura 31. Distribuição de densidade de spin da espécie $\mathrm{Cu}\left(\mathrm{H}_{-1} \mathrm{~L}\right)(\mathrm{OH})^{-}\left(\mathrm{H}_{-1} \mathrm{~L}=\right.$ dipeptídeo glicilglicina desprotonado no nitrogênio peptídico) a partir de simulação B3LYP/def2-TZVP/COSMO como isosuperfície de 0,002 a.u.

\section{3 .5}

Análise dos possíveis modos de coordenação da metionina (Met) ao íon cobre(II) em solução aquosa (RI-PBE/def2-SVP/COSMO)

Foram testados todos os possíveis modos de coordenação do ligante metionina ao cobre em uma ampla faixa de valores de $\mathrm{pH}$. Abaixo são descritas as propostas de modos de coordenação da metionina bem como a descrição das geometrias otimizadas.

\section{- Formação da espécie $\mathrm{CuL}^{+}(4<\mathrm{pH}<6,73)$}

Foram testados todos os possíveis modos de coordenação do aminoácido metionina ao íon cobre(II): (1) o aminoácido comportando-se como ligante bidentado pelo sistema coordenante $\mathrm{N}_{\text {amino }} \mathrm{O}_{\text {carbox }}$ (Fig. 32a); (2) a metionina comportando-se como ligante monodentado através do átomo de nitrogênio (Fig. 
32b); (3) a metionina também monodentada através do átomo de oxigênio (Fig. 32c); (4) a metionina agindo como ligante tridentado pelo sistema coordenante $\mathrm{N}_{\text {amino }} \mathrm{O}_{\text {carbox }} \mathrm{S}$ (Fig. 32d); (5) a metionina agindo como ligante bidentado pelo sistema $\mathrm{N}_{\text {amino }} \mathrm{S}$ e (6) a metionina agindo como ligante bidentado pelo sistema $\mathrm{O}_{\text {carbox }} \mathrm{S}$. Considerou-se todas as estruturas iniciais com uma geometria octaédrica com as moléculas de água completando a esfera de coordenação do centro metálico totalizando quatro moléculas de água nos complexos.

A Figura 32 mostra as estruturas otimizadas para as diferentes propostas de modos de coordenação da metionina ao $\mathrm{Cu}(\mathrm{II})$. Observa-se que para as propostas (1)-(3) (Fig. 32a-c) os complexos apresentaram uma geometria pirâmide de base quadrada enquanto que, nas propostas (4) e (5) (Fig.32d e 32e), os complexos assumiram uma geometria bipirâmide trigonal.
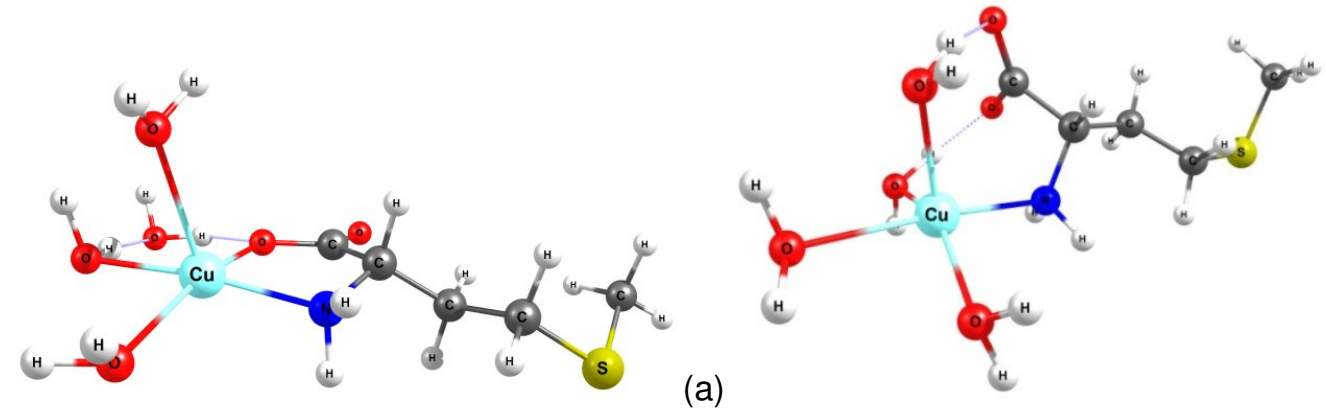

(a)

(b)

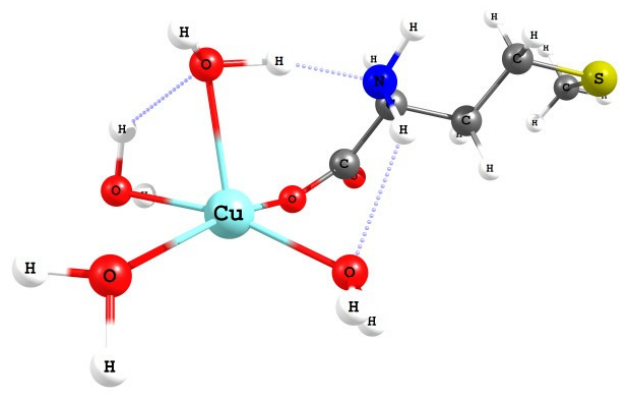

(C)

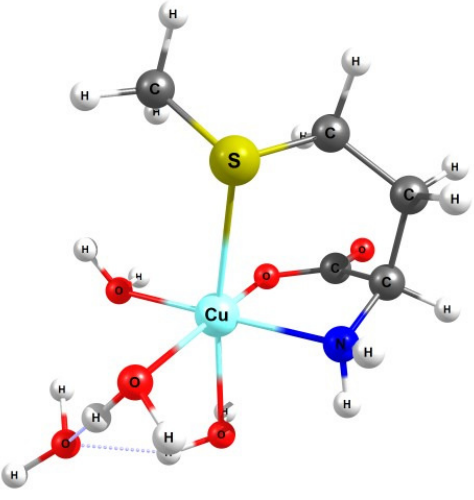

(d) 

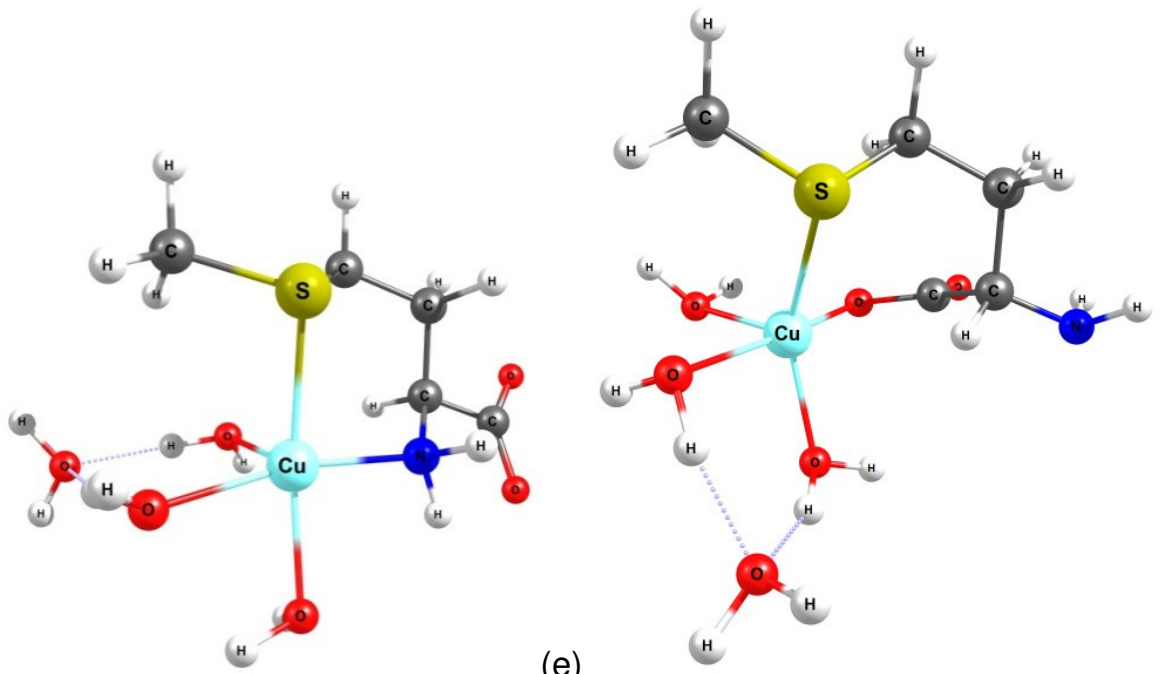

(f)

Figura 32. Possíveis modos de coordenação da metionina ao íon cobre(II), em solução aquosa, formando a espécie $\mathrm{CuL}^{+}(\mathrm{L}=\mathrm{Met})$ : (a) $\mathrm{N}_{\text {amino }} \mathrm{O}_{\text {carbox }}$ : (b) $\mathrm{N}_{\text {amino }}$; (c) $\mathrm{O}_{\text {carbox }}$; (d) $\mathrm{N}_{\text {amino }} \mathrm{O}_{\text {carbox }} \mathrm{S}$; (e) $\mathrm{N}_{\text {amino }} \mathrm{S}$ e (f) $\mathrm{O}_{\text {carbox }} \mathrm{S}$ (RI-PBE/def2-SVP/COSMO)

O complexo com a metionina comportando-se como ligante tridentado (proposta 4), apresentou uma maior estabilidade do que os outros modos de coordenação testados (Tabela 12). A participação do enxofre na esfera de coordenação do cobre(II), na posição axial, forma um complexo 2,00 kcal mol ${ }^{-1}$ mais estável do que o complexo com o ligante agindo como bidentado pelo sistema coordenante $\mathrm{N}_{\text {amino }} \mathrm{O}_{\text {carbox }}$.

Tabela 12. Energia relativa $\left(\mathrm{kcal} \mathrm{mol}^{-1}\right)$ dos possíveis modos de coordenação da metionina ao íon cobre(II), em solução aquosa, formando a espécie $\mathrm{CuL}^{+}(\mathrm{L}=\mathrm{Met})(\mathrm{RI}-$ $\mathrm{PBE} /$ def2-SVP/ COSMO)

\begin{tabular}{cc}
\hline Espécie $\mathrm{CuL}^{+}$ & $\begin{array}{c}\text { Energia } \\
\text { (modo de coordenação) }\end{array}$ \\
\hline $\mathrm{N}_{\text {amino }} \mathrm{O}_{\text {carbox }}$ & 2,00 \\
$\mathrm{~N}_{\text {amino }}$ & 15,0 \\
$\mathrm{O}_{\text {carbox }}$ & 18,0 \\
$\mathrm{~N}_{\text {amino }} \mathrm{O}_{\text {carbox }} \mathrm{S}$ & 0,00 \\
$\mathrm{~N}_{\text {amino }} \mathrm{S}$ & 7,00 \\
$\mathrm{O}_{\text {carbox }} \mathrm{S}$ & 10,00 \\
\hline
\end{tabular}

- Formação da espécie $\mathrm{CuL}(\mathrm{OH})(6,73<\mathrm{pH}<9,67)$

Acima de pH 6,73, ocorre a hidrólise de uma das moléculas de água coordenadas ao metal. A partir da geometria mais estável para a espécie $\mathrm{CuMet}^{+}$ (sistema coordenante $\mathrm{N}_{\text {amino }} \mathrm{O}_{\text {carbox }} \mathrm{S}$ ), foram testadas as seguintes possibilidades de 
hidrólise de uma molécula de água coordenada ao metal: (1) desprotonação da molécula de água situada na posição equatorial trans ao oxigênio do grupo carboxílico (Fig. 33a); (2) desprotonação da molécula de água situada na posição equatorial trans ao átomo de nitrogênio do grupo amino (Fig. 33b); (3) desprotonação da molécula de água situada na posição axial (Fig. 33c); (4) o aminoácido comportando-se como ligante bidentado sem a participação do enxofre na esfera de coordenação do metal e com a hidroxila na posição equatorial trans ao átomo de nitrogênio do grupo amino (Fig. 33d); (5) o aminoácido comportando-se como ligante bidentado sem a participação do oxigênio na esfera de coordenação do metal e com a hidroxila na posição equatorial trans ao átomo de nitrogênio do grupo amino (Fig. 33e) e (6) o aminoácido comportando-se como ligante bidentado sem a participação do nitrogênio na esfera de coordenação do metal e com a hidroxila na posição equatorial trans ao átomo de oxigênio do grupo carboxílico (Fig. 33f).

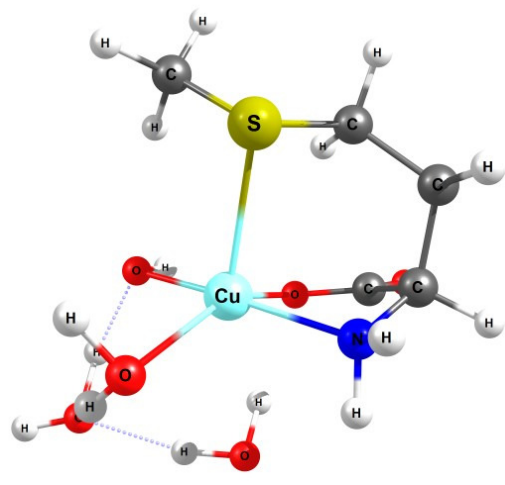

(a)

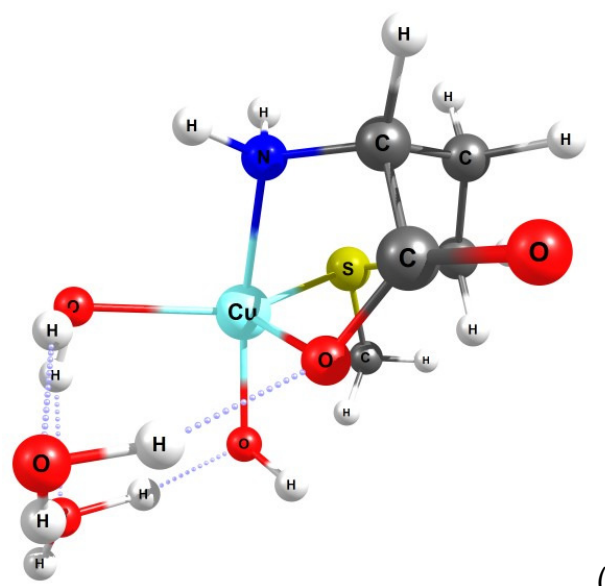

(b)

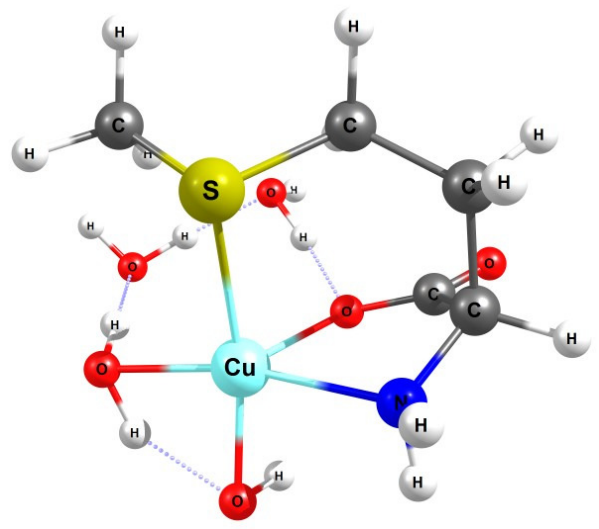

(c)

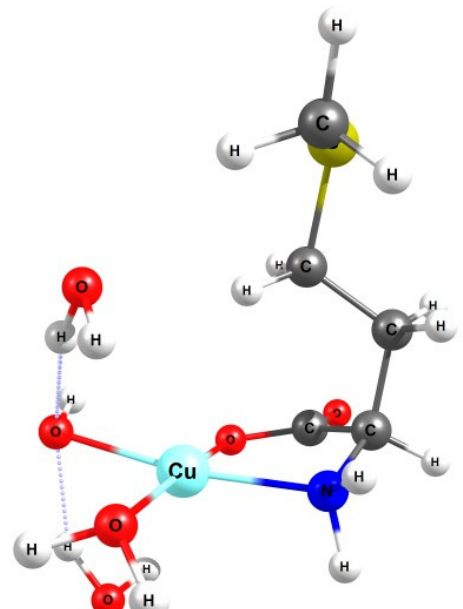

(d) 

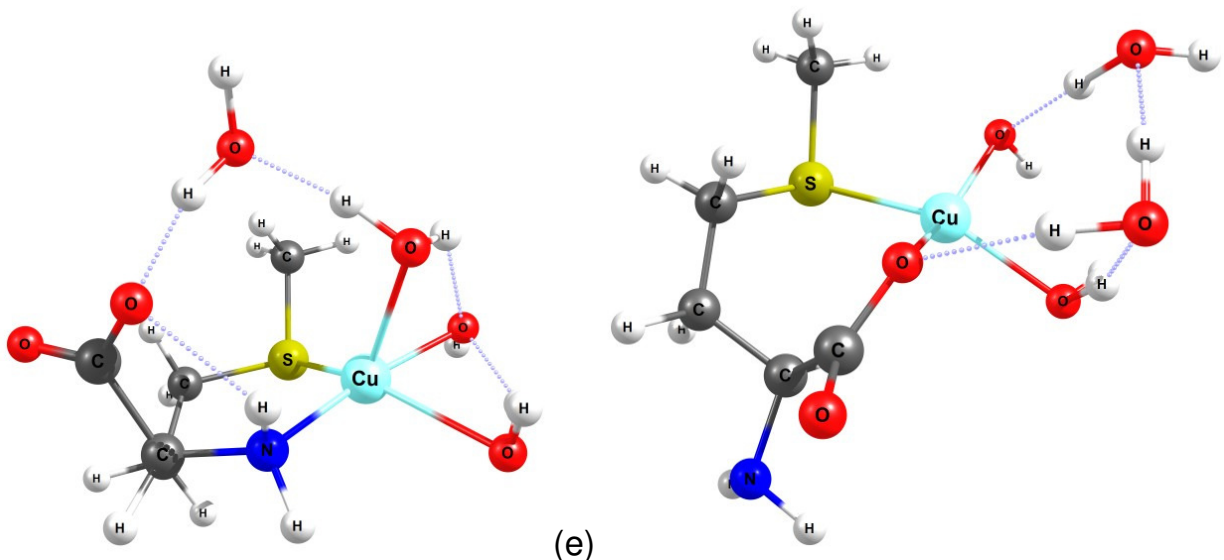

(e)

Figura 33. Possíveis modos de coordenação da metionina ao íon cobre(II), em solução aquosa, formando a espécie $\operatorname{CuL}(\mathrm{OH})\left(\mathrm{L}=\right.$ Met): (a) $\mathrm{N}_{\text {amino }} \mathrm{O}_{\text {carbox }} \mathrm{S}(\mathrm{OH}$ na posição equatorial trans ao oxigênio do grupo carboxílico); (b) $\mathrm{N}_{\text {amino }} \mathrm{O}_{\text {carbox }} \mathrm{S}(\mathrm{OH}$ na posição equatorial trans ao nitrogênio do grupo amino); (c) $\mathrm{N}_{\text {amino }} \mathrm{O}_{\text {carbox }} \mathrm{S}$ ( $\mathrm{OH}$ na posição axial); (d) $\mathrm{N}_{\text {amino }} \mathrm{O}_{\text {carbox }}(\mathrm{OH}$ na posição equatorial trans ao nitrogênio do grupo amino); (e) $\mathrm{N}_{\text {amino }} \mathrm{S}$ ( $\mathrm{OH}$ na posição equatorial trans ao nitrogênio do grupo amino) e (f) $\mathrm{O}_{\text {carbox }} \mathrm{S}(\mathrm{OH}$ na posição equatorial trans ao átomo de oxigênio do grupo carboxílico) (RI-PBE/def2SVP/COSMO)

Nas propostas de coordenação (1) e (5), os complexos que inicialmente possuíam uma geometria octaédrica (ver Fig. 32d), após convergência de energia, apresentaram uma geometria pirâmide de base quadrada. Na proposta (1) (Fig. 33a) a molécula de hidroxila que inicialmente estava na posição equatorial trans ao átomo de oxigênio do grupo carboxílico, após convergência de energia, foi deslocada para a posição equatorial trans ao átomo de nitrogênio do grupo amino. Para as propostas (3) e (4), após convergência de energia, os complexos apresentaram uma geometria bipirâmide trigonal (Fig. 33b e c).

A hidrólise da molécula de água localizada na posição equatorial trans ao átomo de nitrogênio do grupo amino é $2 \mathrm{kcal} \mathrm{mol}^{-1}$ mais favorável do que a hidrólise de uma molécula de água trans ao átomo de oxigênio do grupo carboxílico (Tabela 13).

Considerando que a hidrólise ocorra na molécula de água trans ao átomo de nitrogênio do grupo amino, testamos três possibilidades diferentes de modos de coordenação da metionina agindo como ligante bidentado (hipóteses (4)-(6)). As estruturas otimizadas (Figura 33d-f) mostraram menores estabilidades de 13, 10 e $15 \mathrm{kcal} \mathrm{mol}^{-1}$, respectivamente, em relação a estrutura mais estável com a metionina agindo como ligante tridentado pelo sistema coordenante $\mathrm{N}_{\text {amino }} \mathrm{O}_{\text {carbox }} \mathrm{S}$ 
e com a hidrólise ocorrendo na posição equatorial trans ao átomo de nitrogênio do grupo amino (Fig. 33b).

Tabela 13. Energia relativa ( $\mathrm{kcal}^{\mathrm{mol}}{ }^{-1}$ ) dos possíveis modos de coordenação da metionina ao íon cobre(II), em solução aquosa, formando a espécie $\mathrm{CuL}(\mathrm{OH})(\mathrm{L}=$ metionina) (RI-PBE/def2-SVP/ COSMO)

\begin{tabular}{|c|c|}
\hline $\begin{array}{c}\text { Espécie } \mathrm{CuL}(\mathrm{OH}) \\
\text { (modo de coordenação) }\end{array}$ & Energia relativa \\
\hline $\mathrm{N}_{\text {amino }} \mathrm{O}_{\text {carbox }} \mathrm{SOH}^{\mathrm{a}}$ & 2,00 \\
\hline $\mathrm{N}_{\text {amino }} \mathrm{O}_{\text {carbox }} \mathrm{SOH}^{\mathrm{b}}$ & 0,00 \\
\hline $\mathrm{N}_{\text {amino }} \mathrm{O}_{\text {carbox }} \mathrm{SOH}_{\mathrm{ax}}$ & 4,00 \\
\hline $\mathrm{N}_{\text {amino }} \mathrm{O}_{\text {carbox }} \mathrm{OH}^{\mathrm{b}}$ & 13,00 \\
\hline $\mathrm{N}_{\text {amino }} \mathrm{SOH}_{\mathrm{eq}}^{\mathrm{b}}$ & 10,00 \\
\hline $\mathrm{O}_{\text {carbox }} \mathrm{SOH}_{\mathrm{eq}}^{\mathrm{a}}$ & 15,0 \\
\hline
\end{tabular}

\section{- Formação da espécie $\mathrm{CuL}(\mathrm{OH})_{2}{ }^{-}(9,67<\mathrm{pH}<10)$}

A partir da estrutura mais estável para a espécie $\operatorname{CuMet}(\mathrm{OH})$ (ver Fig. 33b), foi testada somente a desprotonação da molécula de água coordenada ao metal na posição equatorial em uma geometria bipirâmide trigonal. Porém, a presença de mais de uma molécula de hidroxila na esfera de coordenação do metal poderia fazer com que a metionina passasse a se comportar como ligante bidentado, e a segunda desprotonação ocorrer tanto na posição axial quanto na equatorial. Nesses casos, uma das moléculas de água do complexo foi colocada na esfera de coordenação do metal para completar o numero de coordenação 6 .

A seguir são descritas as possíveis estruturas para a formação da espécie CuMet $(\mathrm{OH})_{2}{ }^{-}$: (1) a segunda molécula de hidroxila localizada na posição equatorial, a partir da estrutura mais estável para a espécie $\mathrm{CuMet}(\mathrm{OH})$ mostrada na Figura 33b (Fig. 34a); (2) a metionina agindo como ligante bidentado pelo sistema $\mathrm{O}_{\text {carbox }} \mathrm{N}_{\text {amino }}$ e a segunda molécula de hidroxila na posição equatorial (posição que era ocupada pelo átomo de enxofre) (Fig. 34b); (3) a metionina agindo como ligante bidentado pelo sistema $\mathrm{O}_{\text {carbox }} \mathrm{N}_{\text {amino }}$ e a segunda molécula de hidroxila na posição equatorial (Fig. 34c); (4) a metionina agindo como ligante bidentado pelo sistema $\mathrm{N}_{\text {amino }} \mathrm{S}$ e a segunda molécula de hidroxila na posição equatorial (posição ocupada pelo oxigênio do grupo carboxílico) (Fig. 34d); (5) a metionina agindo como ligante bidentado pelo sistema $\mathrm{N}_{\text {amino }} \mathrm{S}$ e a segunda 
molécula de hidroxila na posição equatorial (Fig. 34e); (6) a metionina agindo como ligante bidentado pelo sistema $\mathrm{O}_{\text {carbox }} \mathrm{S}$ e a segunda molécula de hidroxila na posição axial (posição ocupada pelo nitrogênio) (Fig. 34f) e (7) a metionina agindo como ligante bidentado pelo sistema $\mathrm{O}_{\text {carbox }} \mathrm{S}$ e a segunda molécula de hidroxila na posição axial (Fig. 34g).

A Figura 34 mostra as geometrias otimizadas para as possíveis estruturas da espécies $\mathrm{CuMet}(\mathrm{OH})_{2}{ }^{-}$.
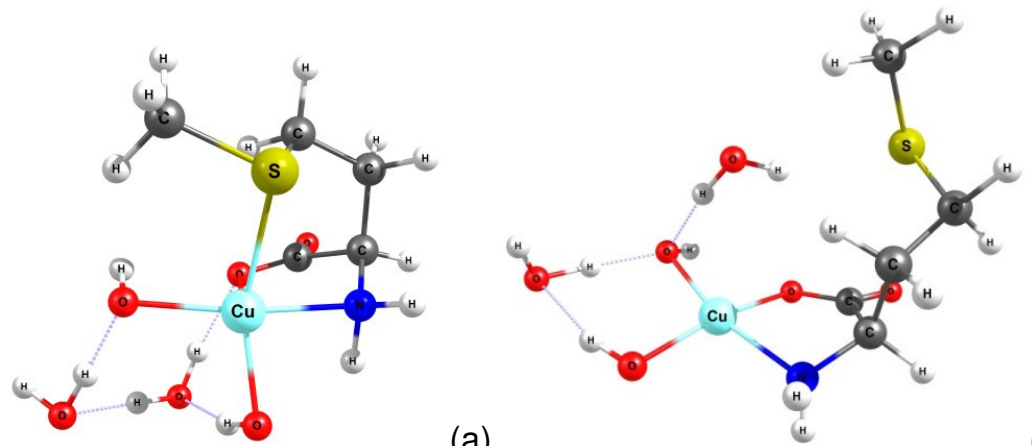

(a)

(b)
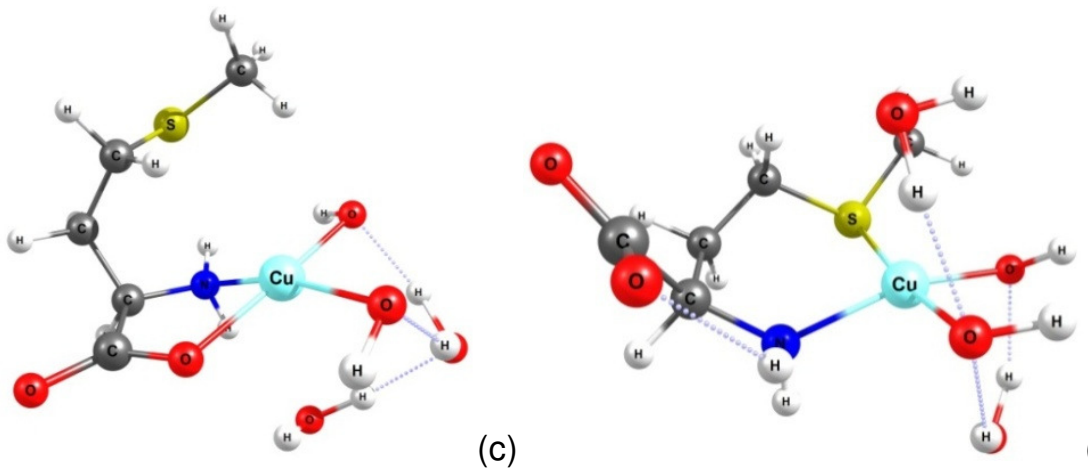

c)
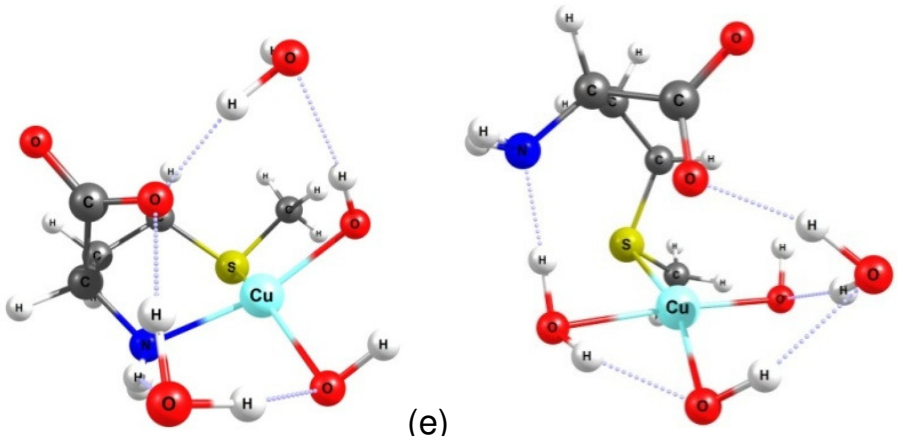

(f) 


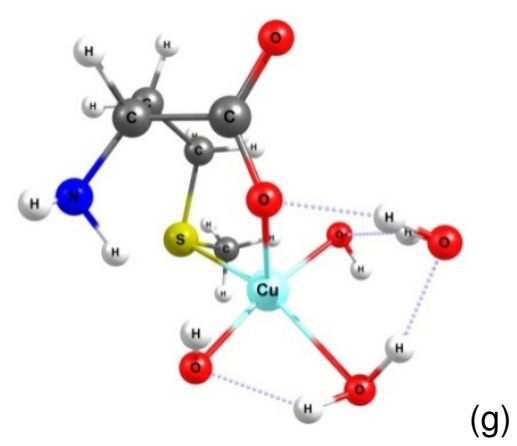

Figura 34. Possíveis modos de coordenação da metionina ao íon cobre(II), em solução aquosa, formando a espécie $\mathrm{CuL}(\mathrm{OH})_{2}{ }^{-}\left(\mathrm{L}=\right.$ Met): (a) coordenação $\mathrm{N}_{\text {amino }} \mathrm{O}_{\text {carbox }} \mathrm{SOH}_{\mathrm{ax}} \mathrm{OH}$ ( $2^{\mathrm{a}}$ molécula de hidroxila na posição equatorial); (b) coordenação $\mathrm{N}_{\text {amino }} \mathrm{O}_{\text {carbox }} \mathrm{OH}_{\mathrm{ax}} \mathrm{OH}\left(2^{\mathrm{a}}\right.$ molécula de hidroxila na posição equatorial); (c) coordenação $\mathrm{N}_{\text {amino }} \mathrm{O}_{\text {carbox }} \mathrm{OH}_{\mathrm{ax}} \mathrm{OH}\left(2^{\mathrm{a}}\right.$ molécula de hidroxila na posição equatorial); (d) coordenação $\mathrm{N}_{a \operatorname{mino}} \mathrm{SOH}_{\mathrm{ax}} \mathrm{OH}\left(2^{\mathrm{a}}\right.$ molécula de hidroxila na posição equatorial); (e) $\mathrm{N}_{\mathrm{amino}} \mathrm{SOH}_{\mathrm{ax}} \mathrm{OH}\left(2^{\mathrm{a}}\right.$ segunda molécula de hidroxila na posição axial); (f) $\mathrm{O}_{\text {carbox }} \mathrm{SOH}_{\mathrm{ax}} \mathrm{OH}$ ( $2^{\mathrm{a}}$ molécula de hidroxila na posição axial) e (g) $\mathrm{O}_{\text {carbox }} \mathrm{SOH}_{\mathrm{ax}} \mathrm{OH}$ ( $2^{\mathrm{a}}$ molécula de hidroxila na posição axial) (RI-PBE/def2SVP/COSMO)

A entrada de uma segunda molécula de hidroxila deslocou o enxofre da esfera de coordenação do metal. Esse modo de coordenação apresentou uma maior estabilidade de $6 \mathrm{kcal} \mathrm{mol}^{-1}$ em relação a espécie apresentando o enxofre coordenado ao centro metálico (Tabela 14). As duas moléculas de hidroxila da espécie $\mathrm{CuL}(\mathrm{OH})_{2}{ }^{-}(\mathrm{L}=$ metionina $)$ se localizaram em posições equatoriais de uma geometria quadrado distorcida (Fig. 34c).

Tabela 14. Energia relativa $\left(\mathrm{kcal} \mathrm{mol}^{-1}\right)$ dos possíveis modos de coordenação da metionina ao íon cobre(II), em solução aquosa, formando a espécie $\mathrm{CuL}(\mathrm{OH})_{2}^{-}(\mathrm{L}=$ metionina) (RI-PBE/def2-SVP/ COSMO)

\begin{tabular}{cc}
\hline $\begin{array}{c}\text { Espécie } \mathrm{CuL}(\mathrm{OH})_{2}{ }^{-} \\
\text {(modo de coordenação) }\end{array}$ & Energia relativa \\
\hline $\mathrm{N}_{\text {amino }} \mathrm{O}_{\text {carbox }} \mathrm{SOH}_{\mathrm{ax}} \mathrm{OH}_{\mathrm{eq}}$ & 6,00 \\
$\mathrm{~N}_{\mathrm{amino}} \mathrm{O}_{\text {carbox }} \mathrm{OH}_{\mathrm{ax}} \mathrm{OH}_{\mathrm{ax}}$ & 6,00 \\
$\mathrm{~N}_{\mathrm{amino}} \mathrm{O}_{\text {carbox }} \mathrm{OH}_{\mathrm{ax}} \mathrm{OH}_{\mathrm{eq}}$ & 0,00 \\
$\mathrm{~N}_{\mathrm{amino}} \mathrm{SOH}_{\mathrm{ax}} \mathrm{OH}_{\mathrm{eq}}$ & 11,00 \\
$\mathrm{~N}_{\text {amino }} \mathrm{SOH}_{\mathrm{ax}} \mathrm{OH}_{\mathrm{ax}}$ & 4,00 \\
$\mathrm{O}_{\text {carbox }} \mathrm{SOH}_{\mathrm{ax}} \mathrm{OH}_{\mathrm{ax}}$ & 12,00 \\
$\mathrm{O}_{\text {carbox }} \mathrm{SOH}_{\mathrm{ax}} \mathrm{OH}_{\mathrm{eq}}$ & 10,0 \\
\hline
\end{tabular}




\subsection{6}

\section{Otimização e parâmetros geométricos da espécie $\mathrm{CuL}^{+}(\mathrm{L}=\mathrm{Met})$ obtidos pela metodologia DFT (RI-PBE/def2-SVP/COSMO)}

A estrutura mais estável foi aquela em que a metionina comportou-se como ligante tridentado pelo sistema coordenante $\mathrm{N}_{\text {amino }} \mathrm{O}_{\text {carbox }} \mathrm{S}$ em uma geometria octaédrica (Fig. 35). Os comprimentos de ligação nas posições axiais apresentaram maiores valores do que os comprimentos de ligação nas posições equatoriais, em concordância com o efeito Janh-Teller que descreve o afastamento dos ligantes no eixo z. O comprimento de ligação $\mathrm{Cu}-\mathrm{S}$ está próximo ao valor encontrado para complexos obtidos no estado sólido (2,69 ^) [168], indicando a participação do átomo de enxofre na esfera de coordenação do centro metálico em uma geometria octaédrica. Em todas as estruturas inicias, foram adotadas uma geometria octaédrica com a presença de quatro moléculas de água para uma possível comparação de energia entre as estruturas. Para o caso do ligante comportando-se como tridentado, a geometria otimizada permaneceu em uma geometria octaédrica com três moléculas de água completando a esfera de coordenação do metal e a quarta molécula ligada por meio de ligações de hidrogênio com outras duas moléculas de água coordenadas ao metal (Fig. 35).

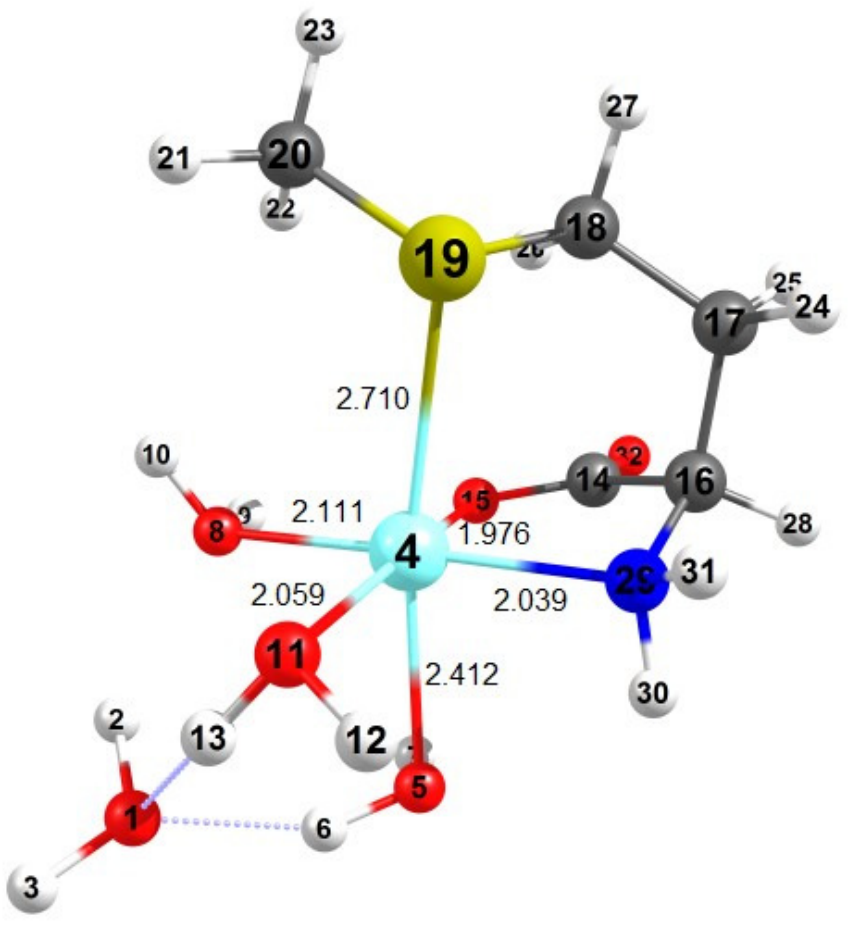

Figura 35. Estrutura otimizada da espécie $\mathrm{CuMet}^{+}$obtida com a presença de quatro moléculas de água (RI-PBE/def2-SVP/COSMO) 
A Tabela 15 mostra os parâmetros geométricos em torno do centro metálico para a espécie $\mathrm{CuL}^{+}(\mathrm{L}=$ metionina) e alguns dados obtidos do CCDC.

Tabela 15. Parâmetros estruturais da espécie $\mathrm{CuL}^{+}(\mathrm{L}=$ metionina) (COSMO:RIPBE/def2-SVP)

\begin{tabular}{ccccccccc}
\hline Átomos & $\begin{array}{c}\text { Ligações } \\
(\mathrm{A})\end{array}$ & CCDC & Átomos & $\begin{array}{c}\hat{\text { Ángulos }} \\
\left({ }^{\circ}\right)\end{array}$ & $\mathrm{CCDC}$ & Átomos & $\begin{array}{c}\text { Diedros } \\
\left({ }^{\circ}\right)\end{array}$ & CCDC \\
\hline $\mathrm{Cu}-\mathrm{N}_{29}$ & 2,039 & 2,01 & $\mathrm{~N}_{29} \mathrm{CuO}_{11}$ & 101,659 & & $\mathrm{~N}_{29} \mathrm{CuO}_{11} \mathrm{O}_{8}$ & 173,98 & - \\
$\mathrm{Cu}-\mathrm{O}_{15}$ & 1,976 & 1,95 & $\mathrm{O}_{11} \mathrm{CuO}_{8}$ & 87,597 & - & $\mathrm{O}_{11} \mathrm{CuO}_{8} \mathrm{O}_{15}$ & 173,507 & - \\
$\mathrm{Cu}-\mathrm{O}_{8}$ & 2,111 & - & $\mathrm{O}_{8} \mathrm{CuO}_{15}$ & 87,397 & - & $\mathrm{O}_{8} \mathrm{CuO}_{15} \mathrm{~N}_{29}$ & 175,151 & - \\
$\mathrm{Cu}-11$ & 2,059 & - & $\mathrm{CuN}_{29} \mathrm{O}_{15}$ & 87,712 & 85,09 & $\mathrm{O}_{15} \mathrm{CuN}_{29} \mathrm{O}_{11}$ & 172,966 & - \\
$\mathrm{Cu}-\mathrm{O}_{5}$ & 2,412 & 2,67 & $\mathrm{O}_{5} \mathrm{CuN}_{29}$ & 85,263 & 85,76 & $\mathrm{~N}_{29} \mathrm{CuO}_{5} \mathrm{O}_{11}$ & 102,047 & - \\
$\mathrm{Cu}-\mathrm{S}$ & 2,710 & 2,69 & $\mathrm{O}_{5} \mathrm{CuO}_{11}$ & 86,209 & - & $\mathrm{O}_{11} \mathrm{CuO}_{5} \mathrm{O}_{8}$ & 87,625 & - \\
& & & $\mathrm{O}_{5} \mathrm{CuO}_{8}$ & 89,456 & - & $\mathrm{O}_{8} \mathrm{CuO}_{5} \mathrm{O}_{15}$ & 87,420 & - \\
& & & $\mathrm{O}_{5} \mathrm{CuO}_{15}$ & 87,257 & 86,59 & $\mathrm{O}_{15} \mathrm{CuN}_{29} \mathrm{O}_{5}$ & 87,833 & 85,20 \\
& & & $\mathrm{SCuN}_{29}$ & 84,754 & - & $\mathrm{N}_{29} \mathrm{CuSO}_{15}$ & 81,966 & 84,98 \\
& & & $\mathrm{SCuO}_{11}$ & 90,273 & - & $\mathrm{O}_{11} \mathrm{CuSN}_{29}$ & 101,683 & - \\
& & & $\mathrm{SCuO}_{8}$ & 101,322 & - & $\mathrm{O}_{8} \mathrm{CuSO}_{11}$ & 87,601 & - \\
& & & $\mathrm{SCuO}_{15}$ & 97,073 & - & $\mathrm{O}_{15} \mathrm{CuSO}_{8}$ & 88,750 & - \\
\hline
\end{tabular}

CCDC: Cambridge Crystallographic Data Centre

A Figura 36 mostra a distribuição de densidade de spin para a espécie $\mathrm{CuL}^{+}(\mathrm{L}=\mathrm{Met})$, sugerindo uma configuração eletrônica para o estado fundamental $t_{2 g}^{6} e_{g}^{3}\left(d_{z^{2}}^{2} d_{x^{2}-y^{2}}^{1}\right)$.

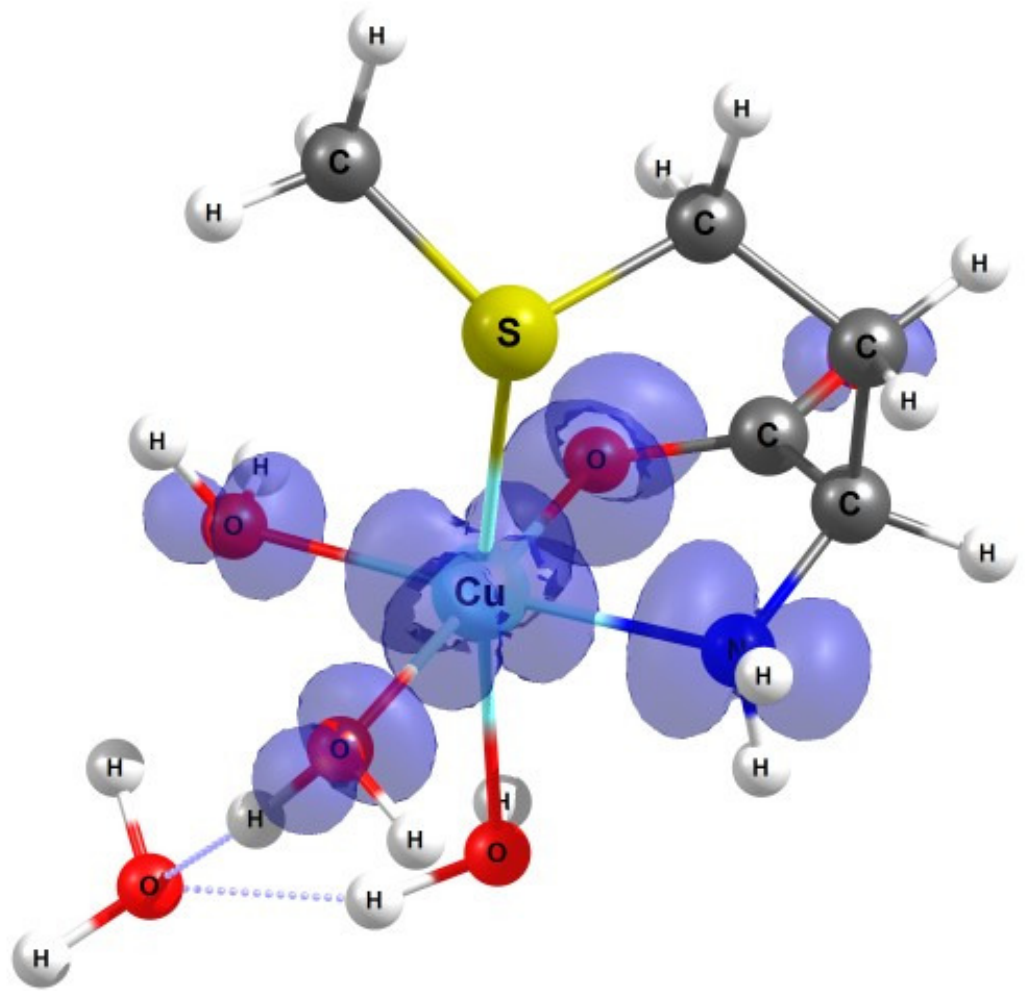

Figura 36. Distribuição de densidade de spin para a espécie $\mathrm{CuL}^{+}(\mathrm{L}=\mathrm{Met})$ a partir de simulação B3LYP/def2-TZVP/COSMO como isosuperfície de 0,002 a.u. 


\subsection{7}

Otimização e parâmetros geométricos da espécie $\mathrm{CuL}(\mathrm{OH})$ (L = Met) obtidos pela metodologia DFT (RI-PBE/def2-SVP/COSMO)

Foram testadas todas as possíveis formas de desprotonação da molécula de água coordenada ao cobre a partir da estrutura mais estável para a espécie $\mathrm{CuMet}^{+}$ (ver Fig. 33d). A estrutura mais estável foi aquela na qual a primeira hidrólise ocorreu em uma molécula de água situada em uma posição equatorial trans ao nitrogênio do grupo amino. A estrutura apresentou uma geometria bipirâmide trigonal com o átomo de enxofre localizado na posição equatorial (Fig. 37). Possivelmente, a presença de elétrons livres na camada de valência do nitrogênio sejam doados para o centro metálico, aumentando a força da ligação do metal ao átomo de oxigênio da molécula de água trans ao nitrogênio. Com isso ocorre o enfraquecimento da ligação $\mathrm{OH}$, facilitando a hidrólise trans ao átomo de nitrogênio do grupo amino para formar a espécie $\mathrm{CuMet}(\mathrm{OH})$.

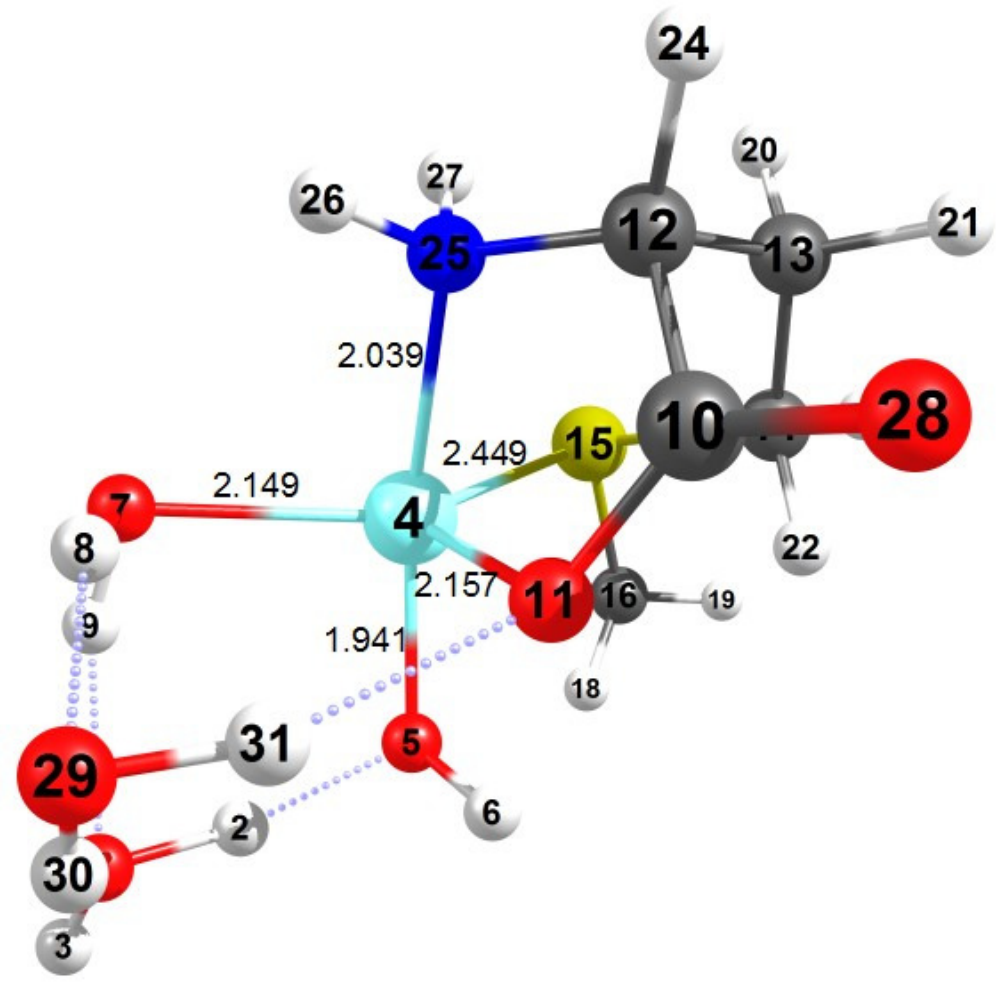

Figura 37. Estrutura otimizada da espécie $\mathrm{CuL}(\mathrm{OH})$ ( $\mathrm{L}=$ metionina) (RI-PBE/def2SVP/COSMO) 
A Tabela 16 mostra os parâmetros geométricos em torno do centro metálico para a espécie $\mathrm{CuL}(\mathrm{OH})(\mathrm{L}=$ metionina $)$ e alguns dados obtidos do CCDC.

Tabela 16. Parâmetros estruturais da espécie $\mathrm{CuL}(\mathrm{OH})(\mathrm{L}=$ metionina) (COSMO:RIPBE/def2-SVP)

\begin{tabular}{|c|c|c|c|c|c|c|c|c|}
\hline Átomos & $\begin{array}{l}\text { Ligações } \\
\text { (A) }\end{array}$ & $\mathrm{CCDC}$ & Átomos & $\begin{array}{c}\text { Ângulos } \\
\left({ }^{\circ}\right)\end{array}$ & CCDC & Átomos & $\begin{array}{c}\text { Diedros } \\
\left({ }^{\circ}\right)\end{array}$ & CCDC \\
\hline $\mathrm{Cu}^{-N_{25}}$ & 2,039 & 2,01 & $\mathrm{~N}_{25} \mathrm{CuO}_{11}$ & 79,06 & - & $\mathrm{N}_{25} \mathrm{CuO}_{11} \mathrm{O}_{5}$ & 175,405 & - \\
\hline $\mathrm{Cu}-\mathrm{O}_{11}$ & 2,157 & - & $\mathrm{O}_{11} \mathrm{CuO}_{5}$ & 92,128 & - & $\mathrm{O}_{11} \mathrm{CuO}_{5} \mathrm{~N}_{25}$ & 27,159 & - \\
\hline $\mathrm{Cu}-\mathrm{O}_{5}$ & 1,941 & - & $\mathrm{O}_{5} \mathrm{CuN}_{25}$ & 170,078 & - & $\mathrm{O}_{7} \mathrm{CuN}_{25} \mathrm{O}_{11}$ & 102,046 & - \\
\hline $\mathrm{Cu}-\mathrm{O}_{7}$ & 2,149 & - & $\mathrm{SCu} \mathrm{N} \mathrm{N}_{25}$ & 84,705 & 85,09 & $\mathrm{O}_{7} \mathrm{CuO}_{11} \mathrm{O}_{5}$ & 95,901 & - \\
\hline \multirow[t]{6}{*}{$\mathrm{Cu}-\mathrm{S}$} & 2,449 & 2,67 & $\mathrm{SCuO}_{11}$ & 113,008 & - & $\mathrm{O}_{7} \mathrm{CuO}_{5} \mathrm{~N}_{25}$ & 129,441 & - \\
\hline & & & $\mathrm{SCuO}_{5}$ & 94,700 & - & $\mathrm{SCuN}_{25} \mathrm{O}_{11}$ & 114,690 & - \\
\hline & & & $\mathrm{SCuO}_{7}$ & 143,081 & - & $\mathrm{SCuO}_{11} \mathrm{O}_{5}$ & 96,019 & - \\
\hline & & & $\mathrm{O}_{7} \mathrm{CuO}_{25}$ & 91,010 & - & $\mathrm{SCuO}_{5} \mathrm{~N}_{25}$ & 86,138 & - \\
\hline & & & $\mathrm{O}_{7} \mathrm{CuO}_{11}$ & 113,008 & . & & & \\
\hline & & & $\mathrm{O}_{7} \mathrm{CuO}_{5}$ & 95,322 & - & & & \\
\hline
\end{tabular}

CCDC: Cambridge Crystallographic Data Centre

A distribuição de densidade de spin da espécie $\mathrm{CuMet}(\mathrm{OH})$ (Fig. 38) mostra a participação do orbital $3 d_{z^{2}}$ do $\mathrm{Cu}(\mathrm{II})$ e dos elétrons dos ligantes nas posições equatoriais e axiais, sugerindo uma configuração do estado fundamental $t_{2 g}^{6} e_{g}^{3}\left(d_{x^{2}-y^{2}}^{2} d_{\mathrm{z}^{2}}^{1}\right)$

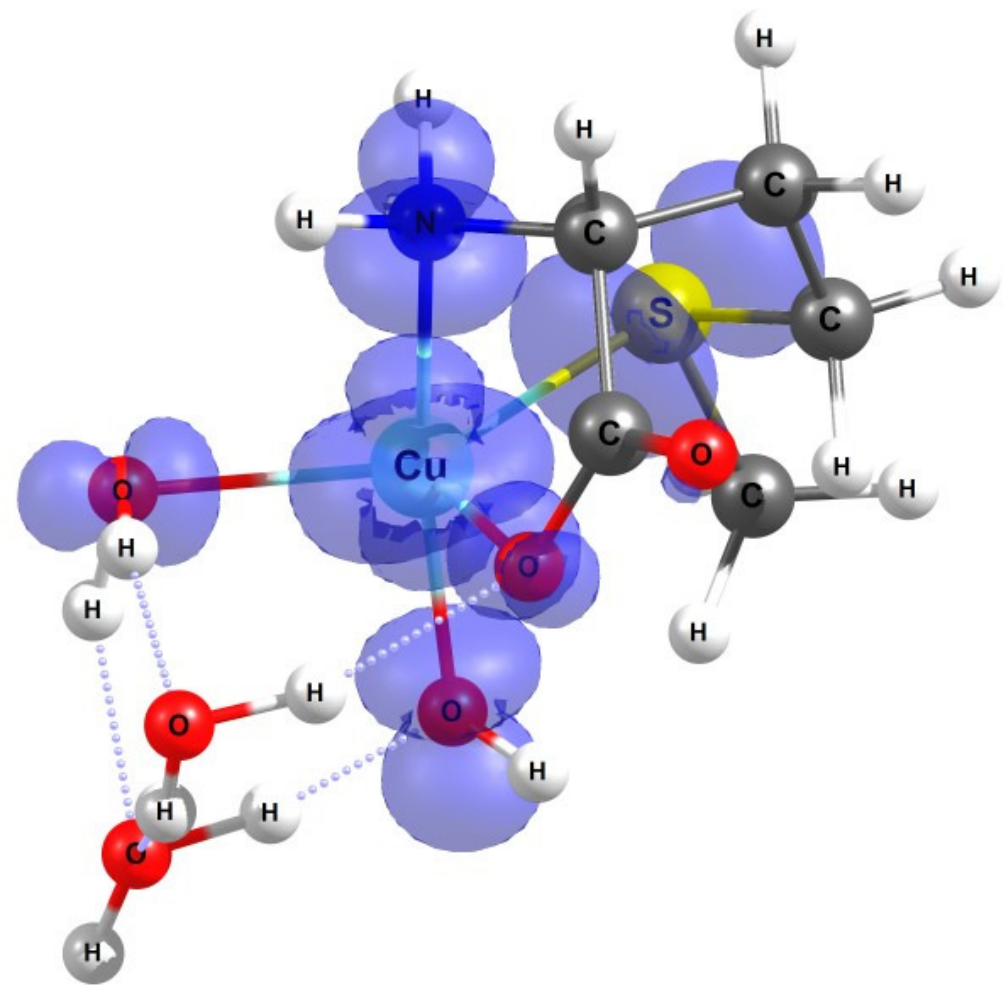

Figura 38. Distribuição de densidade de spin da espécie $\operatorname{CuL}(\mathrm{OH})(\mathrm{L}=\mathrm{Met})$ a partir de simulação B3LYP/def2-TZVP/COSMO como isosuperfície de 0,002 a.u. 


\subsection{8}

\section{Otimização e parâmetros geométricos da espécie $\mathrm{CuL}(\mathrm{OH})_{2}^{-}(\mathrm{L}=\mathrm{Met})$ obtidos pela metodologia DFT (RI-PBE/def2-SVP/COSMO)}

Foram testados os possíveis modos de coordenação da metionina, com a presença de duas hidroxilas na esfera de coordenação do cobre nos complexos formados. A geometria da estrutura mais estável é mostrada na Figura 39 e alguns parâmetros geométricos em torno do metal são apresentados na Tabela 17. A estrutura mais estável foi aquela em que a hidrólise ocorreu em uma molécula de água situada na posição equatorial trans ao átomo de oxigênio do grupo carboxílico, com a saída do átomo de enxofre da esfera de coordenação do centro metálico.

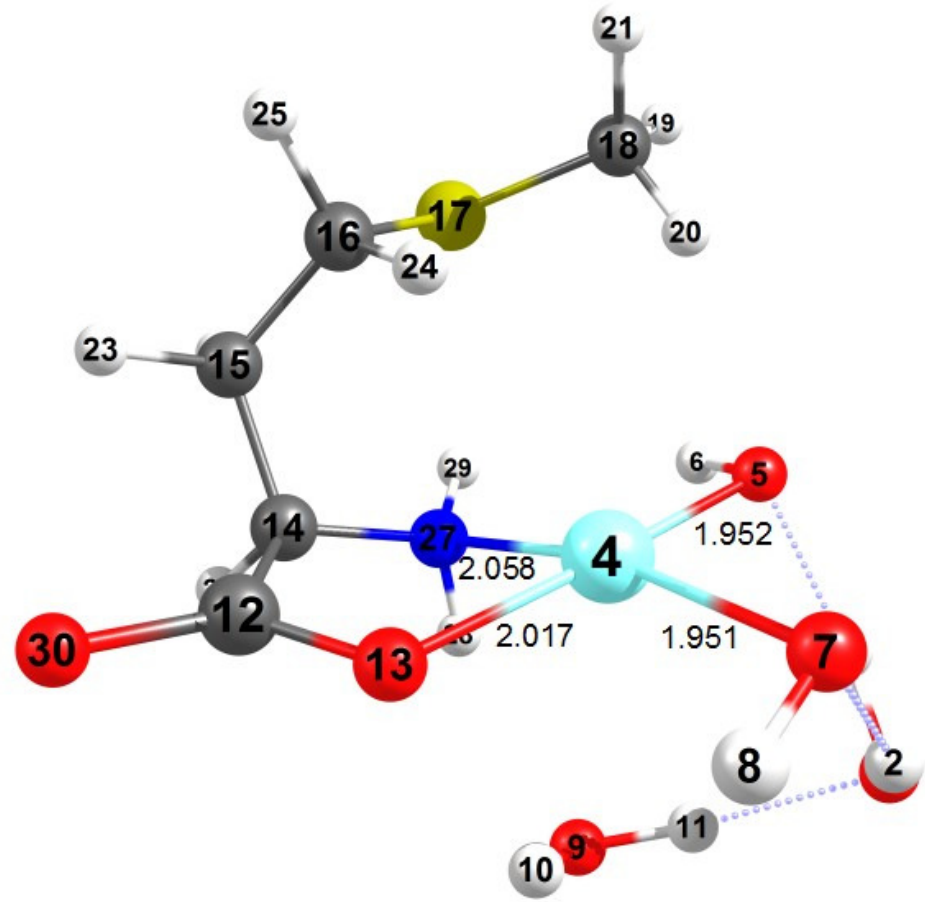

Figura 39. Estrutura otimizada da espécie $\mathrm{CuL}(\mathrm{OH})_{2}^{-}(\mathrm{L}=$ metionina) (RI-PBE/def2SVP/COSMO)

Tabela 17. Parâmetros estruturais da espécie $\mathrm{CuL}(\mathrm{OH})_{2}^{-}(\mathrm{L}=$ metionina) (RI-PBE/def2SVP/COSMO)

\begin{tabular}{ccccccccc}
\hline Átomos & $\begin{array}{c}\text { Ligações } \\
(\mathrm{A})\end{array}$ & CCDC & Átomos & $\begin{array}{c}\hat{A} \text { ngulos } \\
\left({ }^{\circ}\right)\end{array}$ & CCDC & Átomos & $\begin{array}{c}\text { Diedros } \\
\left({ }^{\circ}\right)\end{array}$ & CCDC \\
\hline $\mathrm{Cu}-\mathrm{N}_{27}$ & 2,058 & 1,997 & $\mathrm{~N}_{27} \mathrm{CuO}_{13}$ & 81,181 & 81,526 & $\mathrm{~N}_{27} \mathrm{CuO}_{13} \mathrm{O}_{7}$ & 170,206 & 164,87 \\
$\mathrm{Cu}-\mathrm{O}_{13}$ & 2,017 & 1,965 & $\mathrm{O}_{13} \mathrm{CuO}_{7}$ & 89,143 & - & $\mathrm{O}_{13} \mathrm{CuO}_{7} \mathrm{O}_{5}$ & 179,262 & - \\
$\mathrm{Cu}-\mathrm{O}_{5}$ & 1,952 & 1,909 & $\mathrm{O}_{7} \mathrm{CuO}_{5}$ & 92,595 & - & $\mathrm{O}_{7} \mathrm{CuO}_{5} \mathrm{~N}_{27}$ & 170,372 & - \\
$\mathrm{Cu}-\mathrm{O}_{7}$ & 1,951 & - & $\mathrm{O}_{5} \mathrm{CuN}_{27}$ & 97,231 & 93,995 & $\mathrm{O}_{5} \mathrm{CuO}_{27} \mathrm{O}_{13}$ & 178,970 & \\
\hline \multicolumn{2}{c}{$\mathrm{CCDC}:$ Cambridge Crystallographic Data Centre }
\end{tabular}


A Figura 40 mostra a participação do orbital $3 d_{x^{2}-y^{2}}$ do $\mathrm{Cu}(\mathrm{II})$ e dos orbitais dos ligantes coordenados nas posições equatoriais na distribuição de densidade de spin da espécie $\operatorname{CuMet}(\mathrm{OH})_{2}{ }^{-}$, sugerindo uma configuração eletrônica para o estado fundamental $t_{2 g}^{6} e_{g}^{3}\left(d_{z^{2}}^{2} d_{x^{2}-y^{2}}^{1}\right)$.

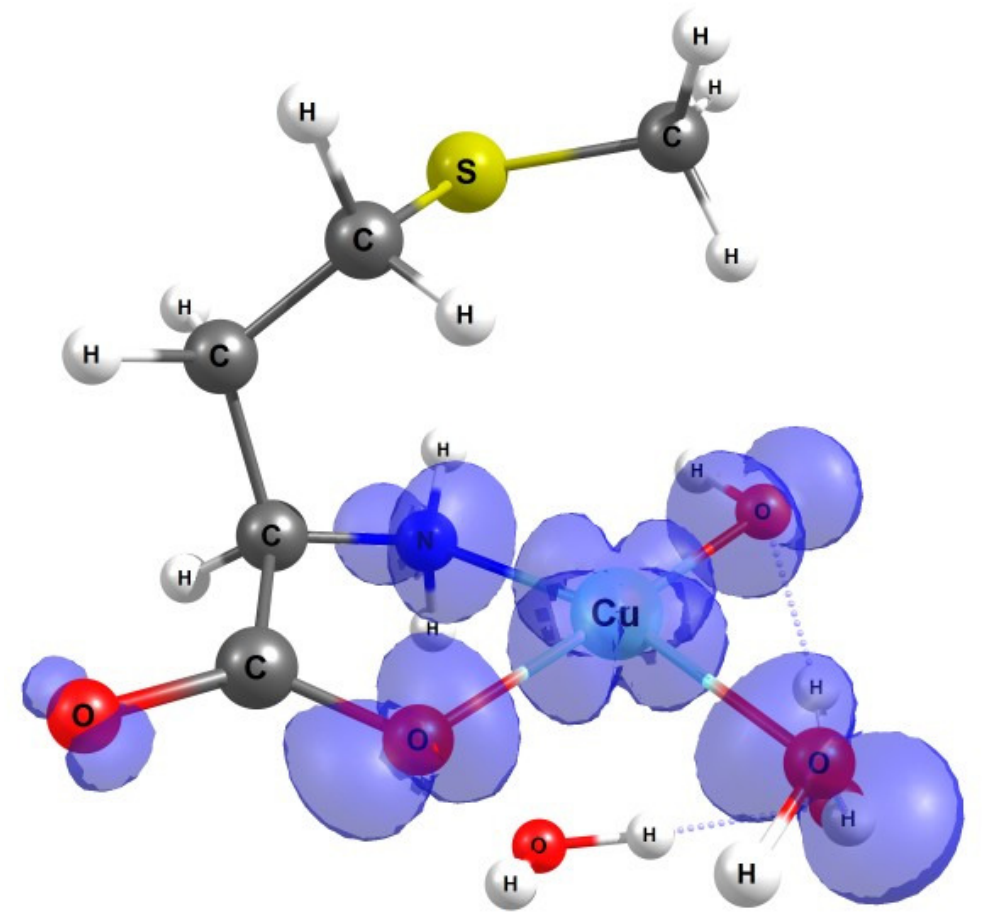

Figura 40. Distribuição de densidade de spin da espécie $\mathrm{CuL}(\mathrm{OH})_{2}^{-}(\mathrm{L}=$ Met) a partir de simulação B3LYP/def2-TZVP/COSMO como isosuperfície de 0,002 a.u.

\section{3 .9}

\section{Análise dos possíveis modos de coordenação dos ligantes GlyGly e Met no complexo ternário de cobre(II) em solução aquosa (RI- PBE/def2-SVP/COSMO)}

Uma vez estudados os complexos binários, partimos para o estudo do complexo ternário de $\mathrm{Cu}$ (II) tendo como ligantes o dipeptídeo glicilglicina e o amino ácido metionina. Testamos as possíveis espécies formadas em uma ampla faixa de valores de $\mathrm{pH}$. Abaixo são descritas as geometrias de partida bem como os modos de coordenação e as geometrias das estruturas otimizadas. 
- Formação da espécie $\mathrm{CuHL}_{1} \mathrm{~L}_{2}\left(\mathrm{HL}_{1}=\right.$ dipeptídeo glicilglicina protonado e $\mathrm{L}_{2}=$ metionina) $(2<\mathrm{pH}<4,17)$

Foram testadas as seguintes propostas para os modos de coordenação dos ligantes glicilglicina e metionina ao $\mathrm{Cu}(\mathrm{II})$ : (1) com os ligantes agindo como bidentados, o dipeptídeo pelo sistema coordenante $\mathrm{N}_{\text {amino }} \mathrm{O}_{\text {pept }}$ e a metionina pelo sistema $\mathrm{N}_{\text {amino }} \mathrm{O}_{\text {carbox }}$ (Fig. 41a) com os átomos de nitrogênio em uma configuração trans e duas moléculas de água localizadas nas posições axiais completando a esfera de coordenação 6 do cobre em uma geometria octaédrica; (2) com os ligantes agindo como bidentados, o dipeptídeo pelo sistema coordenante $\mathrm{N}_{\text {amino }} \mathrm{O}_{\text {pept }}$ e a metionina pelo sistema $\mathrm{N}_{\text {amino }} \mathrm{O}_{\text {carbox }}$ (Fig. 41b) com os átomos de nitrogênio em uma configuração cis e duas moléculas de água localizadas nas posições axiais em uma geometria octaédrica; (3) o dipeptídeo agindo como ligante monodentado pelo $\mathrm{N}_{\text {amino }}$ na posição equatorial e a metionina agindo como ligante bidentado pelo sistema coordenante $\mathrm{N}_{\text {amino }} \mathrm{O}_{\text {carbox }}$ com uma molécula de água na posição equatorial e uma na posição axial de uma geometria octaédrica (Fig. 41c); (4) o dipeptídeo agindo como ligante bidentado pelo sistema $\mathrm{N}_{\text {amino }} \mathrm{O}_{\text {pept }}$ e a metionina agindo como ligante tridentado pelo sistema coordenante $\mathrm{N}_{\text {amino }} \mathrm{O}_{\text {carbox }} \mathrm{S}$ (Fig. 41d); (5) com os ligantes agindo como ligantes bidentados, o dipeptídeo através do sistema coordenante $\mathrm{N}_{\text {amino }} \mathrm{O}_{\text {pept }}$ e a metionina pelo sistema $\mathrm{N}_{\text {amino }} \mathrm{O}_{\text {carbox }}$ em uma configuração meridional (merc) com duas moléculas de água completando a esfera de coordenação de uma geometria octaédrica (Fig. 41e); (6) o dipeptídeo agindo como ligante monodentado pelo nitrogênio do grupo amino e a metionina como ligante tridentado pelo sistema coordenante $\mathrm{N}_{\text {amino }} \mathrm{O}_{\text {carbox }} \mathrm{S}$ (Fig. 41f) e (7) o dipeptídeo como ligante monodentado pelo $\mathrm{N}_{\text {amino }}$ sendo localizado na posição axial e a metionina como ligante tridentado $\left(\mathrm{N}_{\text {amino }} \mathrm{O}_{\text {carbox }} \mathrm{S}\right)$ em uma geometria octaédrica (Fig. 41g).

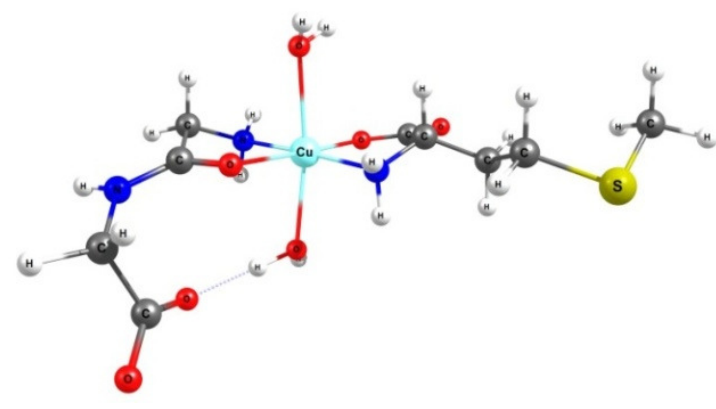

(a)

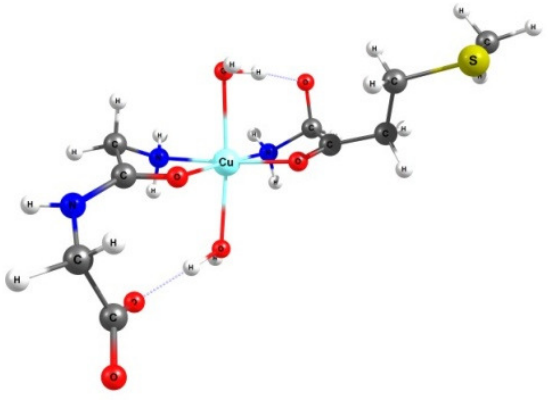

(b) 


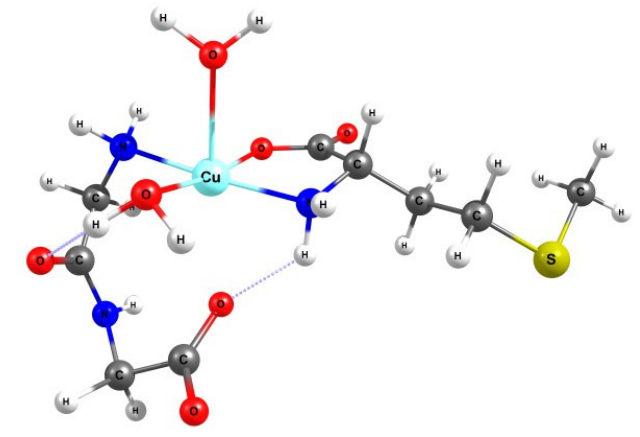

(c)

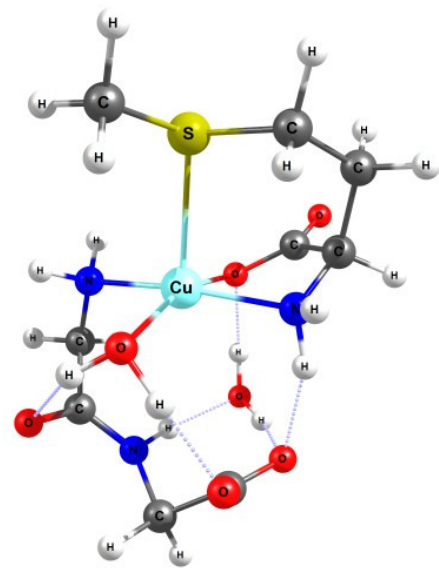

(d)
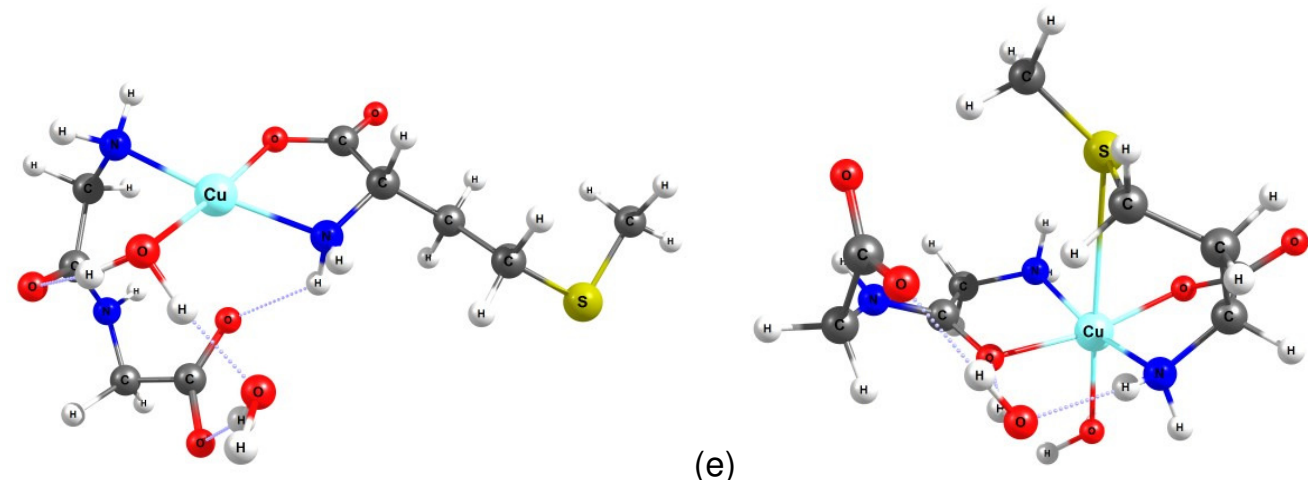

(e)

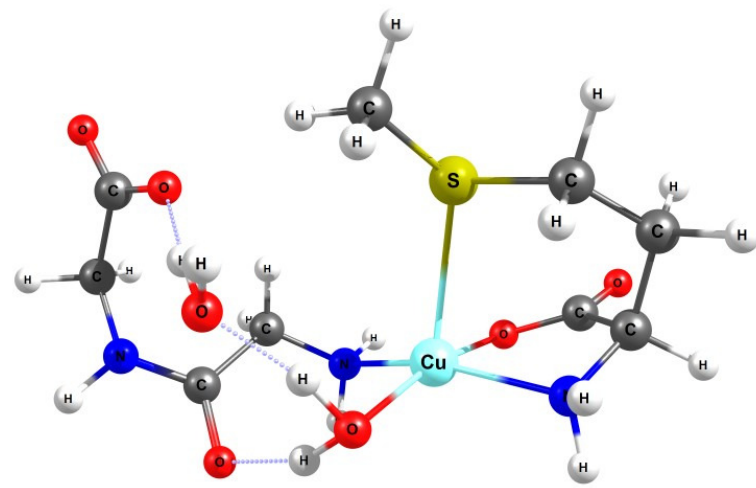

(g)

Figura 41. Possíveis modos de coordenação dos ligantes glicilglicina e metionina ao íon cobre(II), formando a espécie ternária $\mathrm{CuHL}_{1} \mathrm{~L}_{2}\left(\mathrm{~L}_{1}=\right.$ GlyGly e $\mathrm{L}_{2}=$ Met): (a) sistema coordenante de $\mathrm{L}_{1}\left(\mathrm{~N}_{\text {amino }} \mathrm{O}_{\text {pept }}\right)$ e de $\mathrm{L}_{2}\left(\mathrm{~N}_{\text {amino }} \mathrm{O}_{\text {carbox }}\right)$ (nitrogênios trans); (b) sistema coordenante de $\mathrm{L}_{1}\left(\mathrm{~N}_{\text {amino }} \mathrm{O}_{\text {pept }}\right)$ e de $\mathrm{L}_{2}\left(\mathrm{~N}_{\text {amino }} \mathrm{O}_{\text {carbox }}\right)$ (nitrogênios cis); (c) sistema coordenante de $L_{1}\left(\mathrm{~N}_{\text {amino }}\right)$ e de $L_{2}\left(\mathrm{~N}_{\text {amino }} \mathrm{O}_{\text {carbox }}\right)$; (d) sistema coordenante de $L_{1}$ $\left(\mathrm{N}_{\text {amino }} \mathrm{O}_{\text {pept }}\right)$ e de $\mathrm{L}_{2}\left(\mathrm{~N}_{\text {amino }} \mathrm{O}_{\text {carbox }} \mathrm{S}\right)$; (e) sistema coordenante de $\mathrm{L}_{1}\left(\mathrm{~N}_{\text {amino }} \mathrm{O}_{\text {pept }}\right)$ e de $\mathrm{L}_{2}$ $\left(\mathrm{N}_{\text {amino }} \mathrm{O}_{\text {carbox }}\right)$ (configuração merc); (f) sistema coordenante de $\mathrm{L}_{1} \quad\left(\mathrm{~N}_{\text {amino }}\right)$ (posição equatorial) e de $L_{2}$ ( $\left.\mathrm{N}_{\text {amino }} \mathrm{O}_{\text {carbox }} \mathrm{S}\right)$ e (g) sistema coordenante de $\mathrm{L}_{1}\left(\mathrm{~N}_{\text {amino }}\right)$ (posição axial) e de $\mathrm{L}_{2}\left(\mathrm{~N}_{\text {amino }} \mathrm{O}_{\text {carbox }} \mathrm{S}\right)$ (RI-PBE/def2-SVP/COSMO)

A estrutura mais estável foi aquela na qual o aminoácido comportou-se como ligante tridentado, com a participação do enxofre na esfera de coordenação 
do centro metálico (proposta (4), ver Fig. 41d). Nessa estrutura, o dipeptídeo comportou-se como ligante monodentado através do átomo de nitrogênio do grupo amino em uma posição equatorial trans ao nitrogênio do grupo amino da metionina. Embora, na geometria inicial o dipeptídeo estava comportando-se como ligante bidentado, na estrutura otimizada, o oxigênio do grupo peptídico saiu da esfera de coordenação do centro metálico. O complexo apresentou uma geometria pirâmide de base quadrada com uma das moléculas de água do complexo completando o número de coordenação 5 para o $\mathrm{Cu}(\mathrm{II})$. A cadeia do dipeptídeo se deslocou para o eixo axial e com essa configuração estrutural, possibilitou a ocorrência de cinco ligações de hidrogênio no complexo ternário formado.

A Tabela 18 mostra as energias relativas para todos os possíveis modos de coordenação dos ligantes glicilglicina e metionina ao cobre(II), formando a espécie ternária CuHGlyGlyMet.

Tabela 18. Energia relativa $\left(\mathrm{kcal} \mathrm{mol}^{-1}\right)$ dos possíveis modos de coordenação dos ligantes ao íon cobre(II), em solução aquosa, formando a espécie ternária $\mathrm{CuHL}_{1} \mathrm{~L}_{2}\left(\mathrm{~L}_{1}=\right.$ glicilglicina e $\mathrm{L}_{2}=$ metionina) (RI-PBE/def2-SVP/ COSMO)

\begin{tabular}{cc}
\hline Espécie $\mathrm{CuHL}_{1} \mathrm{~L}_{2}$ & Energia relativa \\
(modos de coordenação de $\mathrm{L}_{1}$ e $\left.\mathrm{L}_{2}\right)$ & \\
\hline$\left(\mathrm{N}_{\text {amino }} \mathrm{O}_{\text {pept }}\right)\left(\mathrm{N}_{\text {amino }} \mathrm{O}_{\text {carbox }}\right)^{\mathrm{a}}$ & 10,0 \\
$\left(\mathrm{~N}_{\text {amino }} \mathrm{O}_{\text {pept }}\right)\left(\mathrm{N}_{\text {amino }} \mathrm{O}_{\text {carbox }}\right)^{\mathrm{b}}$ & 43,22 \\
$\left(\mathrm{~N}_{\text {amino }}\right)\left(\mathrm{N}_{\text {amino }} \mathrm{O}_{\text {carbox }}\right)$ & 6,00 \\
$\left(\mathrm{~N}_{\text {amino }} \mathrm{O}_{\text {pept }}\right)\left(\mathrm{N}_{\text {amino }} \mathrm{O}_{\text {carbox }} \mathrm{S}\right)$ & 0,00 \\
$\left(\mathrm{~N}_{\text {aminoo }} \mathrm{O}_{\text {pept }}\right)\left(\mathrm{N}_{\text {aminoo }} \mathrm{O}_{\text {carbox }}\right)^{\mathrm{c}}$ & 0,03 \\
$\left(\mathrm{~N}_{\text {amino }}\right)\left(\mathrm{N}_{\text {amino }} \mathrm{O}_{\text {carbox }} \mathrm{S}\right)$ & 10,0 \\
$\left(\mathrm{~N}_{\text {amino }}\right)\left(\mathrm{N}_{\text {amino }} \mathrm{O}_{\text {carbox }} \mathrm{S}\right)^{\mathrm{d}}$ & 4,00 \\
\hline${ }^{\mathrm{a}}$ Nitrogênio na configuração trans & \\
${ }^{b}$ Nitrogênios na configuração cis & \\
${ }^{\mathrm{c}}$ Ligantes em uma configuração merc \\
${ }^{\mathrm{d}}$ Dipeptídeo monodentado na posição axial
\end{tabular}

- Formação da espécie $\mathrm{CuL}_{1} \mathrm{~L}_{2}^{-}\left(\mathrm{L}_{1}=\right.$ glicilglicina e $\mathrm{L}_{2}=$ metionina $)(4,17<$ $\mathrm{pH}<7,45)$

Todas as estruturas foram testadas com a presença de duas moléculas de água na estrutura dos complexos. Nas estruturas de partida foram inseridas moléculas de água na esfera de coordenação, visto que, forma-se uma nova espécie com a desprotonação do nitrogênio do grupo amido. Foram testadas 
diferentes estruturas para a primeira desprotonação do complexo ternário formando a espécie $\mathrm{CuL}_{1} \mathrm{~L}_{2}^{-}:$(1) o dipeptídeo agindo como ligante bidentado pelo sistema $\mathrm{N}_{\text {amino }} \mathrm{N}_{\text {pept }}$ e a metionina agindo como ligante tridentado pelo sistema coordenante $\mathrm{N}_{\text {amino }} \mathrm{O}_{\text {carbox }} \mathrm{S}$, com os átomos de nitrogênio dos grupos amino em uma configuração cis no complexo ternário formado (Fig 42a); (2) o dipeptídeo agindo como ligante bidentado pelo sistema coordenante $\mathrm{N}_{\text {amino }} \mathrm{N}_{\text {pept }}$ e a metionina agindo como ligante tridentado pelo sistema coordenante $\mathrm{N}_{\text {amino }} \mathrm{O}_{\text {carbox }} \mathrm{S}$ com os grupos amino da glicilglicina e da metionina em uma configuração trans no complexo ternário (Fig 42b); (3) o dipeptídeo atuando como ligante bidentado pelo nitrogênio do grupo amino na posição equatorial e pelo nitrogênio desprotonado do grupo peptídico na posição axial e a metionina agindo como ligante tridentado (Fig. 42c); (4) o dipeptídeo agindo como ligante bidentado pelo sistema coordenante $\mathrm{N}_{\text {amino }} \mathrm{N}_{\text {pept }}$ e a metionina pelo sistema $\mathrm{N}_{\text {amino }} \mathrm{O}_{\text {carbx }}$ sem a participação do enxofre na esfera de coordenação do metal (Fig. 42d); (5) o dipeptídeo agindo como ligante bidentado pelo sistema $\mathrm{N}_{\text {amino }} \mathrm{N}_{\text {pept }}$ e a metionina pelo sistema $\mathrm{N}_{\text {amino }} \mathrm{O}_{\text {carbx }}$ com os nitrogênios dos grupos amino em uma configuração cis (Fig. 42e); (6) o dipeptídeo agindo como ligante bidentado pelo sistema $\mathrm{N}_{\text {amino }} \mathrm{N}_{\text {pept }}$ e a metionina pelo sistema $\mathrm{N}_{\text {amino }} \mathrm{S}$ sem a participação do oxigênio do grupo carboxílico na esfera de coordenação do metal (Fig. 42f); (7) o dipeptídeo agindo como ligante bidentado pelo sistema coordenante $\mathrm{N}_{\text {amino }} \mathrm{N}_{\text {pept }}$ e a metionina pelo sistema $\mathrm{O}_{\text {carbox }} \mathrm{S}$ sem a participação do nitrogênio do grupo amino na esfera de coordenação do metal (Fig. 42g) e (8) o dipeptídeo atuando como ligante monodentado pelo $\mathrm{N}_{\text {amino }}$ e a metionina como ligante tridentado com a desprotonação ocorrendo em uma molécula de água trans ao átomo de nitrogênio peptídico (Fig. 42h). 


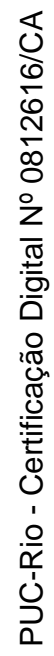
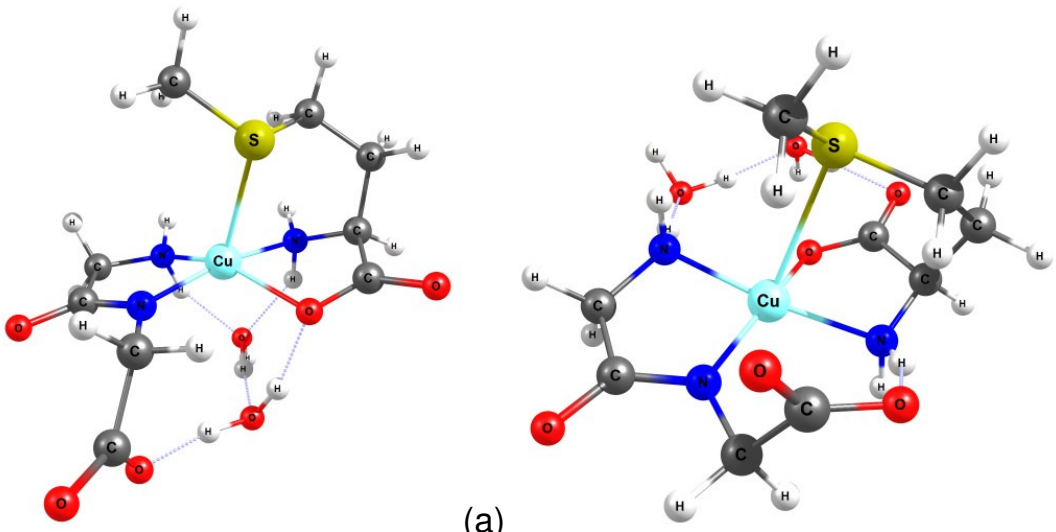

(a)

(b)
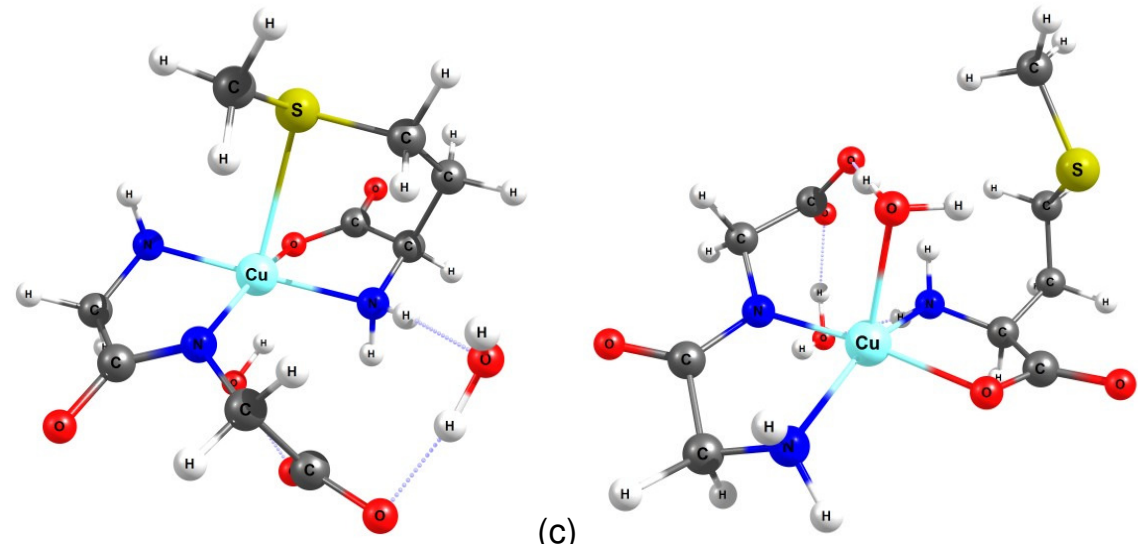

(c)

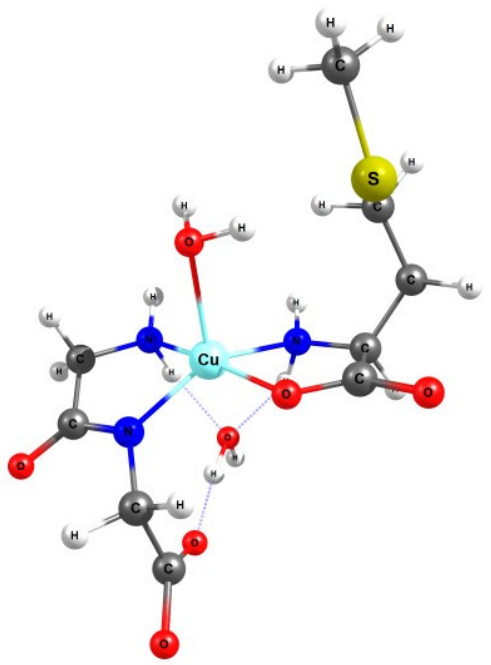

(e)

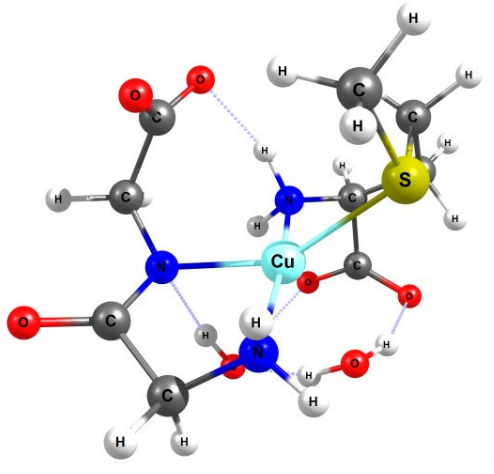




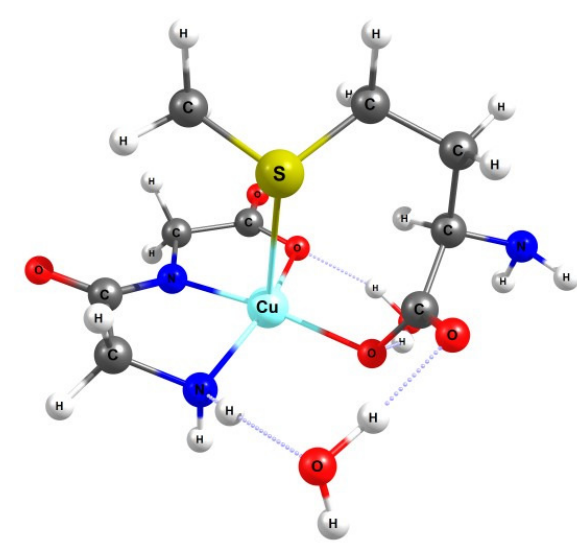

(g)

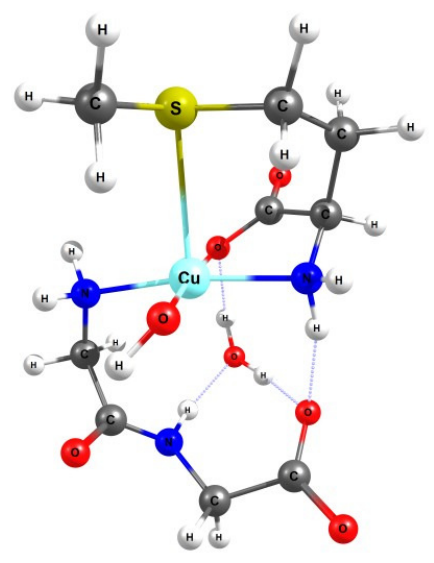

(h)

Figura 42. Possíveis modos de coordenação dos ligantes glicilglicina e metionina ao íon cobre(II), formando a espécie ternária $\mathrm{CuL}_{1} \mathrm{~L}_{2}^{-}\left(\mathrm{L}_{1}=\right.$ GlyGly e $\mathrm{L}_{2}=$ Met): (a) sistema coordenante de $L_{1}\left(N_{\text {amino }} N_{\text {pept }}\right)$ e de $L_{2}\left(N_{\text {amino }} \mathrm{O}_{\text {carbox }} S\right)$ com os átomos de nitrogênio dos grupos amino em uma configuração cis; (b) sistema coordenante de $L_{1}\left(\mathrm{~N}_{\text {amino }} \mathrm{N}_{\text {pept }}\right)$ e de $\mathrm{L}_{2}\left(\mathrm{~N}_{\text {amino }} \mathrm{O}_{\text {carbox }} \mathrm{S}\right)$ com os átomos de nitrogênios dos grupos amino em uma configuração trans; (c) sistema coordenante de $\mathrm{L}_{1}\left(\mathrm{~N}_{\text {amino }} \mathrm{N}_{\text {pept }}\right)$ e de $\mathrm{L}_{2}\left(\mathrm{~N}_{\text {amino }} \mathrm{O}_{\text {carbox }} \mathrm{S}\right)$ com os nitrogênios dos grupos amino em uma configuração trans e merc; (d) sistema coordenante de $L_{1}\left(N_{\text {amino }} N_{\text {pept }}\right)$ e de $L_{2}\left(N_{\text {amino }} \mathrm{O}_{\text {carbox }}\right)$; (e) sistema coordenante de $L_{1}$ $\left(\mathrm{N}_{\text {amino }} \mathrm{N}_{\text {pept }}\right)$ e de $\mathrm{L}_{2}\left(\mathrm{~N}_{\text {amino }} \mathrm{O}_{\text {carbox }}\right)$ com os nitrogênios dos grupos amino em uma configuração cis; (f) sistema coordenante de $L_{1}\left(N_{\text {amino }} N_{\text {pept }}\right)$ e de $L_{2}\left(N_{\text {amino }} S\right)$; (g) sistema coordenante de $L_{1}\left(N_{\text {amino }} N_{\text {pept }}\right)$ e de $L_{2}\left(\mathrm{O}_{\text {carbox }} S\right)$ e $(h)$ sistema coordenante de $L_{1}\left(N_{\text {amino }}\right)$ e de $\mathrm{L}_{2}\left(\mathrm{~N}_{\text {amino }} \mathrm{O}_{\text {carbox }} \mathrm{S}\right)$ com o átomo de nitrogênio peptídico protonado e a desprotonação ocorrendo na molécula de água trans ao nitrogênio peptídico (RIPBE/def2-SVP/COSMO)

A estrutura mais estável da espécie $\mathrm{CuL}_{1} \mathrm{~L}_{2}^{-}$, foi aquela em que os ligantes glicilglicina e metionina comportaram-se como ligantes bidentados pelo sistema coordenante $\mathrm{N}_{\text {amino }} \mathrm{N}_{\text {pept }}$ e $\mathrm{N}_{\text {amino }} \mathrm{O}_{\text {carbox }}$, respectivamente (proposta (4), ver Fig. 42d). Esse modo de coordenação foi $2 \mathrm{kcal} \mathrm{mol}^{-1}$ mais estável do que o modo de coordenação da metionina agindo como ligante tridentado (Tabela 19). 
Tabela 19. Energia relativa ( $\mathrm{kcal} \mathrm{mol}^{-1}$ ) dos possíveis modos de coordenação dos ligantes ao íon cobre(II), em solução aquosa, formando a espécie ternária $\mathrm{CuL}_{1} \mathrm{~L}_{2}^{-}\left(\mathrm{L}_{1}=\right.$ GlyGly e $\left.\mathrm{L}_{2}=\mathrm{Met}\right)(\mathrm{RI}-\mathrm{PBE} /$ def2-SVP/ COSMO)

\begin{tabular}{cc}
\hline Espécie $\mathrm{CuL}_{1} \mathrm{~L}_{2}{ }^{-}$ & Energia relativa \\
$\left(\right.$modos de coordenação de $\mathrm{L}_{1}$ e $\left.\mathrm{L}_{2}\right)$ & \\
\hline$\left(\mathrm{N}_{\text {amino }} \mathrm{N}_{\text {pept }}\right)\left(\mathrm{N}_{\text {amino }} \mathrm{O}_{\text {carbox }} \mathrm{S}\right)^{\mathrm{a}}$ & 3,00 \\
$\left(\mathrm{~N}_{\text {amino }} \mathrm{N}_{\text {pept }}\right)\left(\mathrm{N}_{\text {amino }} \mathrm{O}_{\text {carbox }} \mathrm{S}\right)^{\mathrm{b}}$ & 2,00 \\
$\left(\mathrm{~N}_{\text {amino }} \mathrm{N}_{\text {pept }}\right)\left(\mathrm{N}_{\text {amino }} \mathrm{O}_{\text {carbox }} \mathrm{S}\right)^{\mathrm{c}}$ & 2,00 \\
$\left(\mathrm{~N}_{\text {amino }} \mathrm{N}_{\text {pept }}\right)\left(\mathrm{N}_{\text {amino }} \mathrm{O}_{\text {carbox }}\right)$ & 0,00 \\
$\left(\mathrm{~N}_{\text {amino }} \mathrm{N}_{\text {pept }}\right)\left(\mathrm{N}_{\text {amino }} \mathrm{O}_{\text {carbox }}\right)^{\mathrm{a}}$ & 9,00 \\
$\left(\mathrm{~N}_{\text {amino }} \mathrm{N}_{\text {pept }}\right)\left(\mathrm{N}_{\text {amino }} \mathrm{S}\right)^{\mathrm{c}}$ & 6,00 \\
$\left(\mathrm{~N}_{\text {amino }} \mathrm{N}_{\text {pept }}\right)\left(\mathrm{O}_{\text {carbox }} \mathrm{S}\right)$ & 11,0 \\
$\left(\mathrm{~N}_{\text {amino }}\right)\left(\mathrm{N}_{\text {amino }} \mathrm{O}_{\text {carbox }} \mathrm{S}\right)^{\mathrm{d}}$ & 5,00 \\
\hline
\end{tabular}

${ }^{a}$ Nitrogênios dos grupos amino em uma posição cis

${ }^{\mathrm{b}}$ Nitrogênios dos grupos amino em uma configuração trans

${ }^{c}$ Ligantes em uma configuração trans e merc

${ }^{d}$ Dipeptídeo monodentado com desprotonação ocorrendo na molécula de água trans ao nitrogênio peptídico

- Formação da espécie $\mathrm{CuL}_{1} \mathrm{~L}_{2}(\mathrm{OH})^{2-}\left(\mathrm{L}_{1}=\right.$ glicilglicina e $\mathrm{L}_{2}=$ metionina $)$

$(7,45<\mathrm{pH}<11)$

A partir da estrutura mais estável da espécie $\mathrm{CuL}_{1} \mathrm{~L}_{1}{ }^{-}$, mostrada na Fig. $42 \mathrm{~d}$, foram testadas as seguintes formas de desprotonação para formar a espécie $\mathrm{CuL}_{1} \mathrm{~L}_{2}(\mathrm{OH})^{2-}$ : (1) desprotonação ocorrendo na molécula de água coordenada ao metal situada na posição axial (Fig. 43a); (2) a molécula de água do complexo foi colocada na posição axial trans a molécula de água coordenada ao metal (Fig. 43b). Abaixo são mostradas as 2 estruturas otimizadas para a espécie $\mathrm{CuL}_{1} \mathrm{~L}_{2}(\mathrm{OH})^{2-}$. 


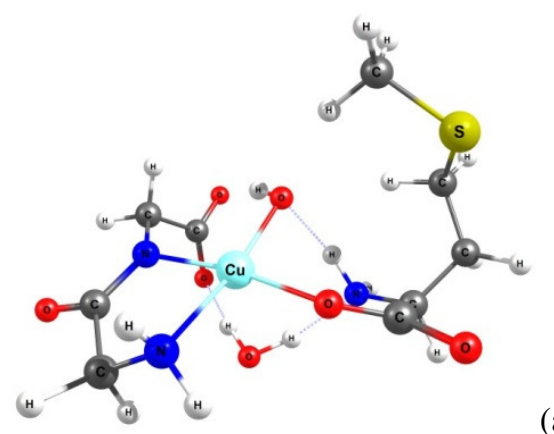

(a)

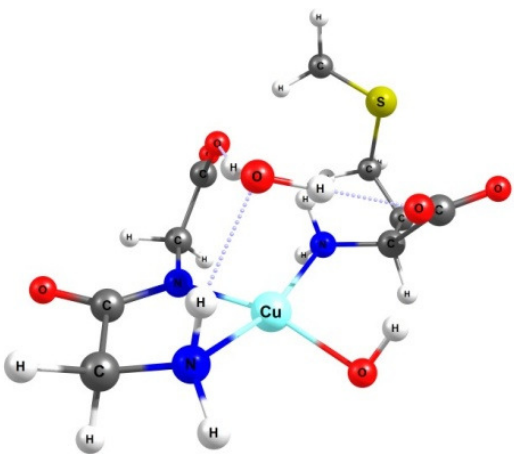

(b)

Figura 43. Modos de coordenação dos ligantes glicilglicina $\left(L_{1}\right)$ e metionina $\left(L_{2}\right)$ ao íon cobre(II), em solução aquosa, formando a espécie ternária $\mathrm{CuL}_{1} \mathrm{~L}_{2}(\mathrm{OH})^{2-}$ : (a) sistema coordenante de $\mathrm{L}_{1}\left(\mathrm{~N}_{\text {amino }} \mathrm{N}_{\text {pept }}\right)$ e de $\mathrm{L}_{2}\left(\mathrm{~N}_{\text {amino }} \mathrm{O}_{\text {carbox }}\right) \mathrm{OH}$ com a desprotonação ocorrendo na molécula de água na posição axial e (b) sistema coordenante de $L_{1}\left(N_{\text {amino }} N_{\text {pept }}\right)$ e de $\mathrm{L}_{2}\left(\mathrm{~N}_{\text {amino }} \mathrm{O}_{\text {carbox }}\right) \mathrm{OH}$ com a desprotonação ocorrendo na molécula de água na posição axial em uma geometria de partida octaédrica (RI-PBE/def2-SVP/COSMO)

O complexo inicialmente apresentava o ligante metionina agindo como ligante bidentado pelo sistema coordenante $\mathrm{N}_{\text {amino }} \mathrm{O}_{\text {carbox }}$ e também uma molécula de hidroxila na posição axial (Fig. 43a). Após convergência de energia, o nitrogênio do grupo amino saiu da esfera de coordenação do centro metálico e a hidroxila, que estava inicialmente na posição axial, se deslocou para a posição equatorial situada trans ao átomo de nitrogênio do grupo amino do ligante dipeptídeo.

O comportamento do segundo isômero foi o inverso; o oxigênio do grupo carboxílico do ligante metionina saiu da esfera de coordenação do metal e a hidroxila que inicialmente estava na posição axial foi deslocada para a posição equatorial situada trans ao nitrogênio do grupo peptídico (Fig. 43b). A Tabela 20 mostra os valores de energia dos dois isômeros para a espécie $\mathrm{CuL}_{1} \mathrm{~L}_{2}(\mathrm{OH})^{2-}$.

O resultado mostra que a desprotonação da molécula de água se dá preferencialmente na molécula de água trans ao nitrogênio do grupo peptídico. 
Tabela 20. Energia relativa ( $\mathrm{kcal} \mathrm{mol}{ }^{-1}$ ) dos possíveis modos de coordenação dos ligantes ao íon cobre(II), em solução aquosa, formando a espécie ternária $\mathrm{CuL}_{1} \mathrm{~L}_{2}(\mathrm{OH})^{2-}$ $\left(L_{1}=\right.$ GlyGly e $L_{2}=$ Met $)(R I-P B E /$ def2-SVP/ COSMO)

\begin{tabular}{cc}
\hline $\begin{array}{c}\text { Espécie } \mathrm{CuL}_{1} \mathrm{~L}_{2}(\mathrm{OH})^{-2} \\
\left.\text { (modos de coordenação de } \mathrm{L}_{1} \text { e } \mathrm{L}_{2}\right)\end{array}$ & Energia relativa \\
\hline $\left.\mathrm{N}_{\text {amino }} \mathrm{N}_{\text {pept }}\right)\left(\mathrm{N}_{\text {amino }} \mathrm{O}_{\text {carbox }} \mathrm{OH}_{\mathrm{ax}}\right)$ & 2,00 \\
$\left(\mathrm{~N}_{\mathrm{amino}} \mathrm{N}_{\text {pept }}\right)\left(\mathrm{N}_{\text {amino }} \mathrm{O}_{\text {carbox }} \mathrm{OH}_{\mathrm{ax}}\right)^{\mathrm{b}}$ & 0,00 \\
\hline${ }^{\mathrm{b}} \mathrm{OH}$ trans a molécula de água coordenada ao metal
\end{tabular}

5.3.10

Otimização e parâmetros geométricos da espécie $\mathrm{CuHL}_{1} \mathrm{~L}_{2}\left(\mathrm{HL}_{1}=\right.$ dipeptídeo glicilglicina protonado e $\mathrm{L}_{2}=$ metionina) obtidos pela metodologia DFT (RI-PBE/def2-SVP/COSMO)

A espécie $\mathrm{CuHL}_{1} \mathrm{~L}_{2}$ mostrou uma geometria pirâmide de base quadrada, com os comprimentos de ligação nas posições equatoriais maiores do que o comprimento na posição axial (Fig. 44).

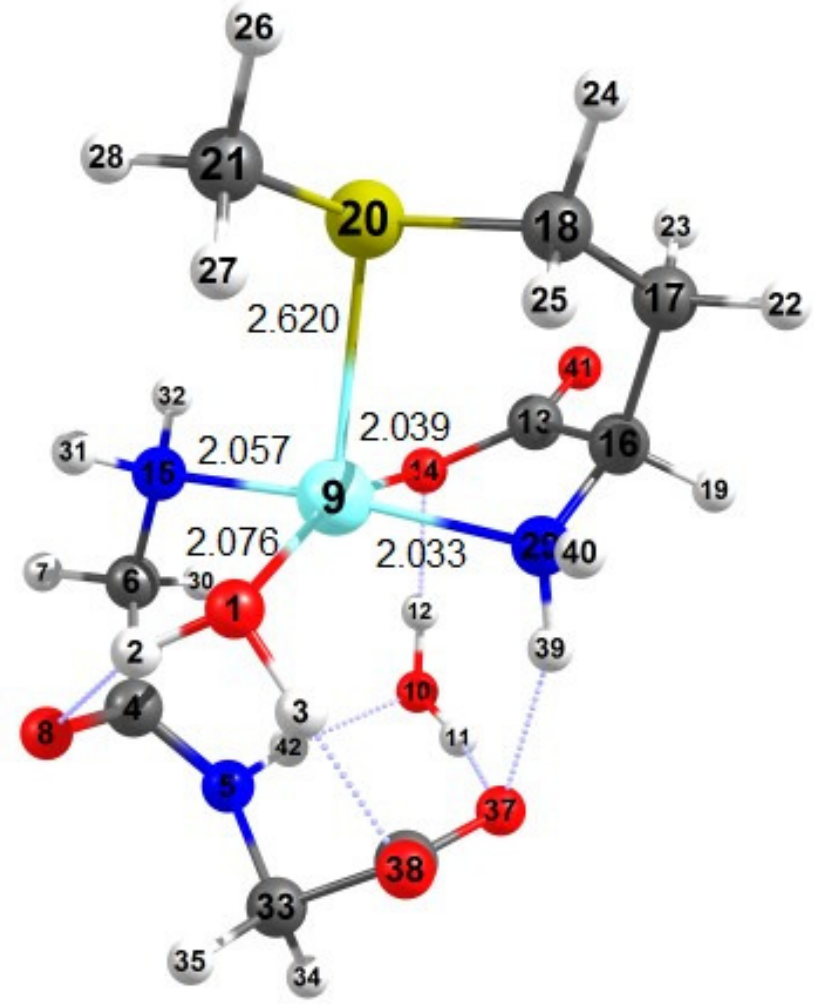

Figura 44. Estrutura otimizada da espécie ternária $\mathrm{CuHL}_{1} \mathrm{~L}_{2}\left(\mathrm{HL}_{1}=\right.$ dipeptídeo glicilglicina protonado e $\mathrm{L}_{2}=$ metionina) $(\mathrm{RI}-\mathrm{PBE} /$ def2-SVP/COSMO)

Alguns parâmetros geométricos em torno do centro metálico para a espécie $\mathrm{CuHL}_{1} \mathrm{~L}_{2}$ são apresentados na Tabela 21. 
Tabela 21. Parâmetros estruturais da espécie ternária $\mathrm{CuHL}_{1} \mathrm{~L}_{2}\left(\mathrm{HL}_{1}=\right.$ dipeptídeo glicilglicina protonado e $\mathrm{L}_{2}$ = metionina) $(\mathrm{RI}-\mathrm{PBE} /$ def2-SVP/COSMO)

\begin{tabular}{|c|c|c|c|c|c|c|c|c|}
\hline Átomos & $\begin{array}{l}\text { Ligações } \\
\text { (A) }\end{array}$ & CCDC & Átomos & $\begin{array}{c}\text { Ângulos } \\
\left({ }^{\circ}\right)\end{array}$ & CCDC & Átomos & $\begin{array}{c}\text { Diedros } \\
\left({ }^{\circ}\right)\end{array}$ & CCDC \\
\hline $\mathrm{Cu}-\mathrm{N}_{15}$ & 2,057 & - & $\mathrm{O}_{1} \mathrm{CuN}_{15}$ & 93,674 & - & $\mathrm{N}_{29} \mathrm{CuO}_{1} \mathrm{~N}_{15}$ & 169,790 & - \\
\hline $\mathrm{Cu}-\mathrm{O}_{14}$ & 2,039 & - & $\mathrm{N}_{15} \mathrm{CuO}_{14}$ & 90,492 & - & $\mathrm{O}_{1} \mathrm{CuN1}{ }_{5} \mathrm{O}_{14}$ & 161,943 & - \\
\hline $\mathrm{Cu}-\mathrm{N} 29$ & 2,033 & - & $\mathrm{O}_{14} \mathrm{CuN}_{29}$ & 79,978 & - & $\mathrm{N}_{15} \mathrm{CuO}_{14} \mathrm{~N}_{29}$ & 172,286 & - \\
\hline $\mathrm{Cu}-\mathrm{O}_{1}$ & 2,149 & - & $\mathrm{N}_{29} \mathrm{CuO}_{1}$ & 93,075 & - & $\mathrm{O}_{14} \mathrm{CuN}_{29} \mathrm{O}_{1}$ & 162,706 & - \\
\hline \multirow[t]{6}{*}{$\mathrm{Cu}-\mathrm{S}$} & 2,620 & - & $\mathrm{O}_{1} \mathrm{CuS}$ & 104,612 & - & $\mathrm{N}_{29} \mathrm{CuSO}_{1}$ & 93,773 & - \\
\hline & & & $\mathrm{N}_{15} \mathrm{CuS}$ & 95,886 & - & $\mathrm{O}_{1} \mathrm{CuSN}_{15}$ & 95,362 & - \\
\hline & & & $\mathrm{O}_{14} \mathrm{CuS}$ & 92,876 & - & $\mathrm{N}_{15} \mathrm{CuSO}_{14}$ & 90,792 & - \\
\hline & & & $\mathrm{N}_{29} \mathrm{CuS}$ & 92,266 & - & $\mathrm{O}_{14} \mathrm{CuSN}_{29}$ & 80,073 & - \\
\hline & & & $\mathrm{O}_{7} \mathrm{SO}_{5}$ & 95,322 & - & $\mathrm{O}_{11} \mathrm{CuSN}_{29}$ & 101,683 & - \\
\hline & & & $\mathrm{CuSO}_{11}$ & 90,273 & - & & & \\
\hline
\end{tabular}

CCDC: Cambridge Crystallographic Data Centre

A Figura 45 mostra a distribuição de densidade de spin para a espécie $\mathrm{CuHL}_{1} \mathrm{~L}_{2}\left(\mathrm{HL}_{1}=\right.$ dipeptídeo glicilglicina protonado e $\mathrm{L}_{2}=$ metionina $)$ indicando a participação do orbital $3 d_{x^{2}-y^{2}}$ do $\mathrm{Cu}(\mathrm{II})$, dos orbitais dos ligantes nas posições equatoriais e também do orbital do oxigênio da carbonila do grupo carboxílico do ligante metionina. A distribuição de densidade de spin sugere uma configuração eletrônica do estado fundamental $t_{2 g}^{6} e_{g}^{3}\left(d_{z^{2}}^{2} d_{x^{2}-y^{2}}^{1}\right)$.

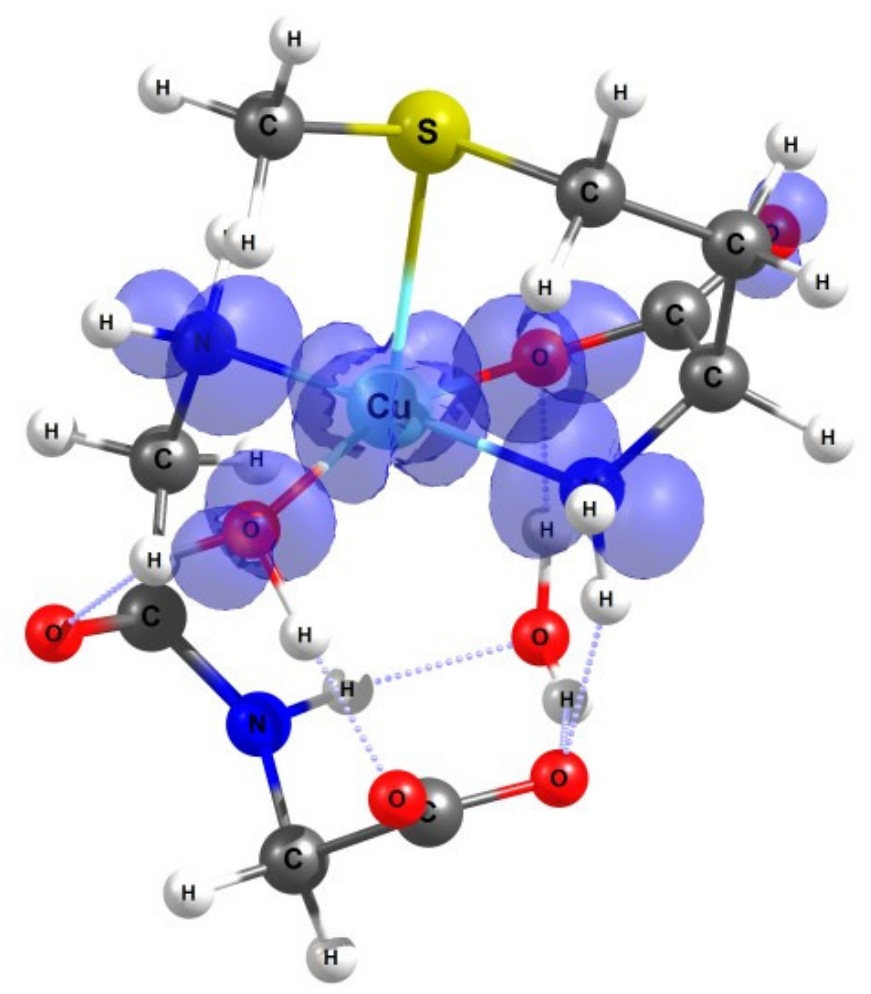

Figura 45. Distribuição de densidade de spin da espécie ternária CuHGlyGlyMet obtida a partir de simulação B3LYP/def2-TZVP/COSMO como isosuperfície de 0,002 a.u. 


\subsubsection{1}

Otimização e parâmetros geométricos da espécie $\operatorname{CuL}_{1} L_{2}^{-}\left(L_{1}=\right.$ glicilglicina e $\mathrm{L}_{2}=$ metionina) obtidos pela metodologia DFT (RIPBE/def2-SVP/COSMO)

A estrutura da espécie ternária $\mathrm{CuL}_{1} \mathrm{~L}_{2}^{-}$também apresentou uma geometria pirâmide de base quadrada como no caso da espécies $\mathrm{CuHL}_{1} \mathrm{~L}_{2}$, porém o átomo de enxofre saiu da esfera de coordenação do metal dando lugar a uma ligação com uma molécula de água na posição axial (Fig. 46). Novamente, o comprimento de ligação na posição axial foi maior do os comprimentos nas posições equatoriais. A estrutura apresentou os nitrogênios dos grupos amino em uma configuração trans. A Tabela 22 mostra os parâmetros geométricos em torno do centro metálico para a estrutura da espécie ternária $\mathrm{CuL}_{1} \mathrm{~L}_{2}^{-}\left(\mathrm{L}_{1}=\right.$ glicilglicina e $\mathrm{L}_{2}=$ metionina $)$.

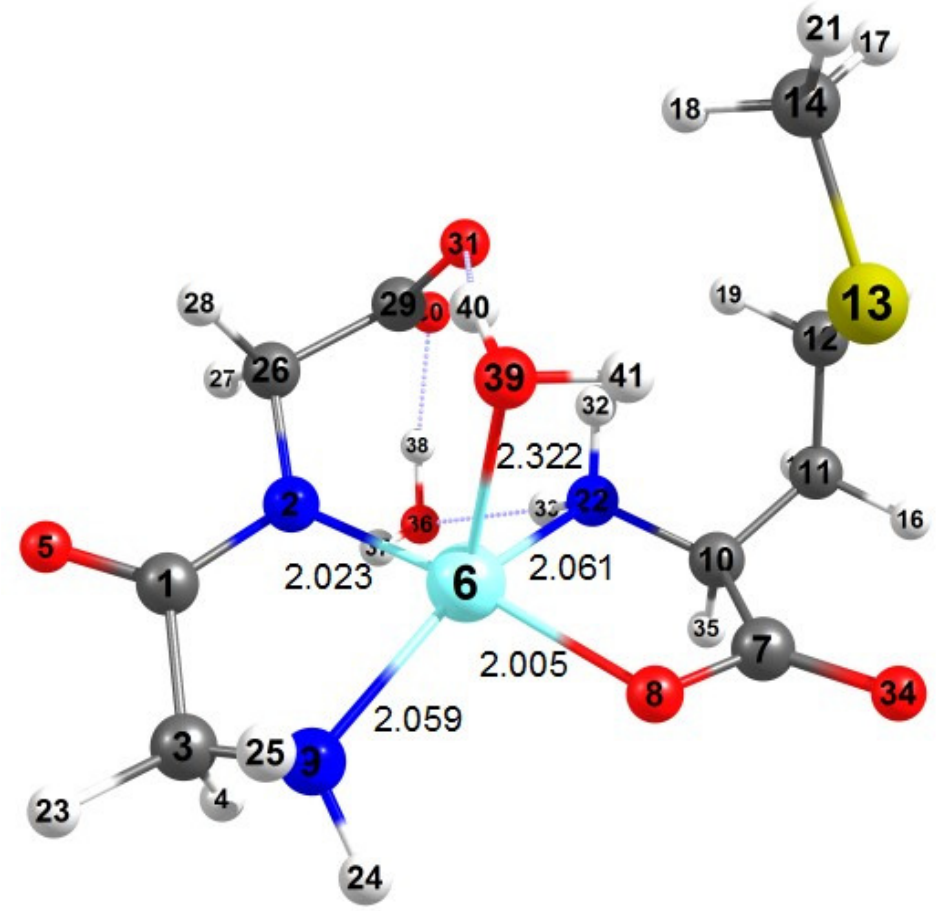

Figura 46. Estrutura otimizada da espécie ternária $\mathrm{CuL}_{1} \mathrm{~L}_{2}{ }^{-}\left(\mathrm{L}_{1}=\right.$ glicilglicina e $\mathrm{L}_{2}=$ metionina) (RI-PBE/def2-SVP/COSMO) 
Tabela 22. Parâmetros estruturais da espécie ternária $\mathrm{CuL}_{1} \mathrm{~L}_{2}^{-}\left(\mathrm{L}_{1}=\right.$ glicilglicina e $\mathrm{L}_{2}=$ metionina) (RI-PBE/def2-SVP/COSMO)

\begin{tabular}{ccccccccc}
\hline Átomos & $\begin{array}{c}\text { Ligações } \\
(\mathrm{A})\end{array}$ & $\mathrm{CCDC}$ & Átomos & $\begin{array}{c}\hat{A} \text { Angulos } \\
\left({ }^{\circ}\right)\end{array}$ & $\mathrm{CCDC}$ & Átomos & $\begin{array}{c}\text { Diedros } \\
\left({ }^{\circ}\right)\end{array}$ & CCDC \\
\hline $\mathrm{Cu}-\mathrm{N}_{9}$ & 2,059 & - & $\mathrm{N}_{9} \mathrm{CuN}_{2}$ & 82,959 & - & $\mathrm{N}_{9} \mathrm{CuN}_{2} \mathrm{~N}_{22}$ & 157,821 & - \\
$\mathrm{Cu}-\mathrm{N}_{2}$ & 2,023 & - & $\mathrm{N}_{2} \mathrm{CuO}_{22}$ & 100,571 & - & $\mathrm{N}_{2} \mathrm{CuN}_{22} \mathrm{O}_{8}$ & 174,709 & - \\
$\mathrm{Cu}-\mathrm{N}_{22}$ & 2,061 & - & $\mathrm{N}_{22} \mathrm{CuO}_{8}$ & 82,557 & - & $\mathrm{N}_{22} \mathrm{CuO}_{8} \mathrm{~N}_{9}$ & 158,352 & - \\
$\mathrm{Cu}-\mathrm{O}_{8}$ & 2,005 & - & $\mathrm{N}_{9} \mathrm{CuO}_{39}$ & 107,449 & - & $\mathrm{O}_{8} \mathrm{CuN}_{9} \mathrm{~N}_{2}$ & 176,307 & - \\
$\mathrm{Cu}-\mathrm{O}_{39}$ & 2,322 & - & $\mathrm{N}_{2} \mathrm{CuO}_{39}$ & 95,114 & - & $\mathrm{N}_{9} \mathrm{CuO}_{39} \mathrm{~N}_{2}$ & 84,210 & - \\
& & & $\mathrm{N}_{22} \mathrm{CuO}_{39}$ & 94,135 & - & $\mathrm{N}_{2} \mathrm{CuO}_{39} \mathrm{~N}_{22}$ & 101,019 & - \\
& & & $\mathrm{O}_{8} \mathrm{CuO}_{39}$ & 89,841 & - & $\mathrm{N}_{22} \mathrm{CuO}_{39} \mathrm{O}_{8}$ & 82,526 & - \\
& & & & & $\mathrm{O}_{8} \mathrm{CuO}_{39} \mathrm{~N}_{9}$ & 92,244 & - \\
\hline
\end{tabular}

CCDC: Cambridge Crystallographic Data Centre

A Figura 47 mostra a distribuição de densidade de spin para a espécie ternária $\mathrm{CuL}_{1} \mathrm{~L}_{2}^{-}\left(\mathrm{L}_{1}=\right.$ glicilglicina e $\mathrm{L}_{2}=$ metionina $)$ indicando a participação do orbital $3 d_{x^{2}-y^{2}}$ do $\mathrm{Cu}(\mathrm{II})$ e dos orbitais dos ligantes nas posições equatoriais, sugerindo uma configuração eletrônica do estado fundamental $t_{2 g}^{6} e_{g}^{3}\left(d_{z^{2}}^{2} d_{x^{2}-y^{2}}^{1}\right)$.

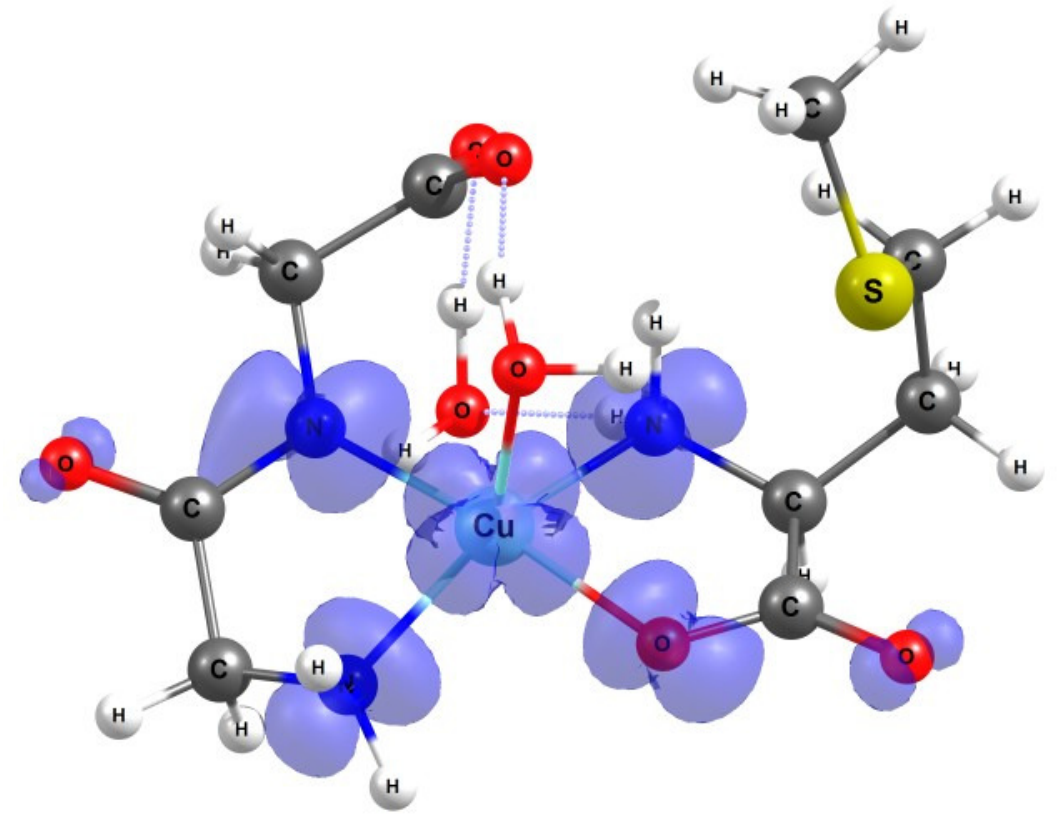

Figura 47. Distribuição de densidade de spin da espécie ternária CuGlyGlyMet a partir de simulação B3LYP/def2-TZVP/COSMO como isosuperfície de 0,002 a.u.

\section{3 .12}

Otimização e parâmetros geométricos da espécie $\mathrm{CuL}_{1} \mathrm{~L}_{2}(\mathrm{OH})^{2-}\left(\mathrm{L}_{1}=\right.$ glicilglicina e $\mathrm{L}_{2}=$ metionina) obtidos pela metodologia DFT (RIPBE/def2-SVP/COSMO)

A molécula de hidroxila, que na geometria de partida estava localizada na posição axial, após otimização de energia, se deslocou para a posição equatorial 
trans ao nitrogênio do grupo peptídico, com a saída do oxigênio do grupo carboxílico do ligante metionina da esfera de coordenação do centro metálico (Fig. 48). O complexo apresentou uma geometria quadrado distorcida com uma ligação $\mathrm{Cu}-\mathrm{O}$ mais forte do que as ligações $\mathrm{Cu}-\mathrm{N}$. A Tabela 23 mostra os parâmetros geométricos em torno do centro metálico.

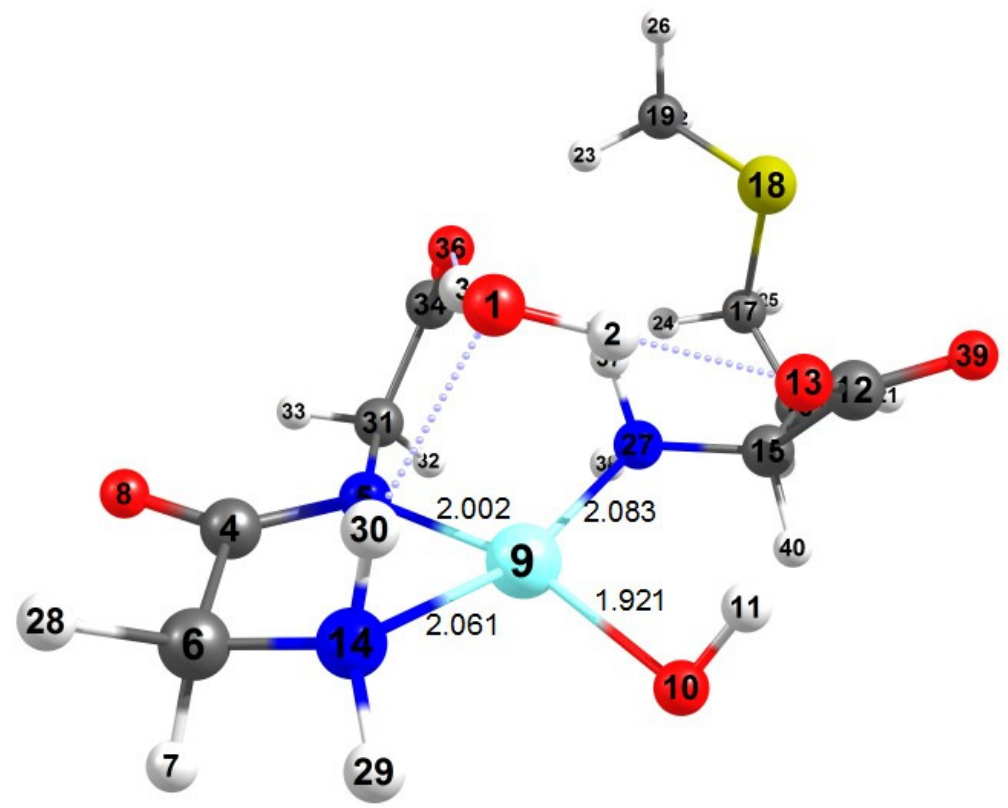

Figura 48. Estrutura otimizada da espécie ternária $\mathrm{CuL}_{1} \mathrm{~L}_{2}(\mathrm{OH})^{2-}\left(\mathrm{L}_{1}=\right.$ glicilglicina e $\mathrm{L}_{2}=$ metionina) (RI-PBE/def2-SVP/COSMO)

Tabela 23. Parâmetros estruturais da espécie ternária $\mathrm{CuL}_{1} \mathrm{~L}_{2}(\mathrm{OH})^{2-}\left(\mathrm{L}_{1}=\right.$ GlyGly e $\mathrm{L}_{2}=$ metionina) (RI-PBE/def2-SVP/COSMO)

\begin{tabular}{|c|c|c|c|c|c|c|c|c|}
\hline Átomos & $\begin{array}{l}\text { Ligações } \\
\text { (A) }\end{array}$ & CCDC & Átomos & $\begin{array}{c}\text { Ângulos } \\
\left({ }^{\circ}\right)\end{array}$ & $\mathrm{CCDC}$ & Átomos & $\begin{array}{c}\text { Diedros } \\
\left({ }^{\circ}\right)\end{array}$ & CCDC \\
\hline $\mathrm{Cu}-\mathrm{N}_{1}$ & 2,061 & - & $\mathrm{N}$ & 91,076 & - & $\mathrm{N}_{14} \mathrm{C}$ & 157,890 & - \\
\hline $\mathrm{Cu}-\mathrm{N}_{5}$ & 2,002 & - & $\mathrm{N}_{5} \mathrm{CuO}_{27}$ & 95,787 & - & $\mathrm{N}_{5} \mathrm{CuN}_{27} \mathrm{O}_{10}$ & 67,614 & - \\
\hline $\mathrm{Cu}-\mathrm{N}_{27}$ & 2,083 & - & $\mathrm{N}_{27} \mathrm{CuO}_{10}$ & 94,620 & - & $\mathrm{N}_{27} \mathrm{CuO}_{10} \mathrm{~N}_{14}$ & 158,352 & - \\
\hline $\mathrm{Cu}-\mathrm{O}_{10}$ & 1,921 & - & $\mathrm{O}_{10} \mathrm{CuN}_{14}$ & 93,109 & - & $\mathrm{O}_{10} \mathrm{CuN}_{14} \mathrm{~N}_{5}$ & 164,599 & - \\
\hline
\end{tabular}

CCDC: Cambridge Crystallographic Data Centre

A Figura 49 mostra a distribuição de densidade de spin da espécie ternária $\mathrm{CuL}_{1} \mathrm{~L}_{2}(\mathrm{OH})^{2-}\left(\mathrm{L}_{1}=\right.$ GlyGly e $\mathrm{L}_{2}=$ metionina) indicando a participação do orbital $3 d_{x^{2}-y^{2}}$ do $\mathrm{Cu}(\mathrm{II})$ e dos orbitais dos ligantes nas posições equatoriais, sugerindo uma configuração eletrônica do estado fundamental $t_{2 g}^{6} e_{g}^{3}\left(d_{z^{2}}^{2} d_{x^{2}-y^{2}}^{1}\right)$. 


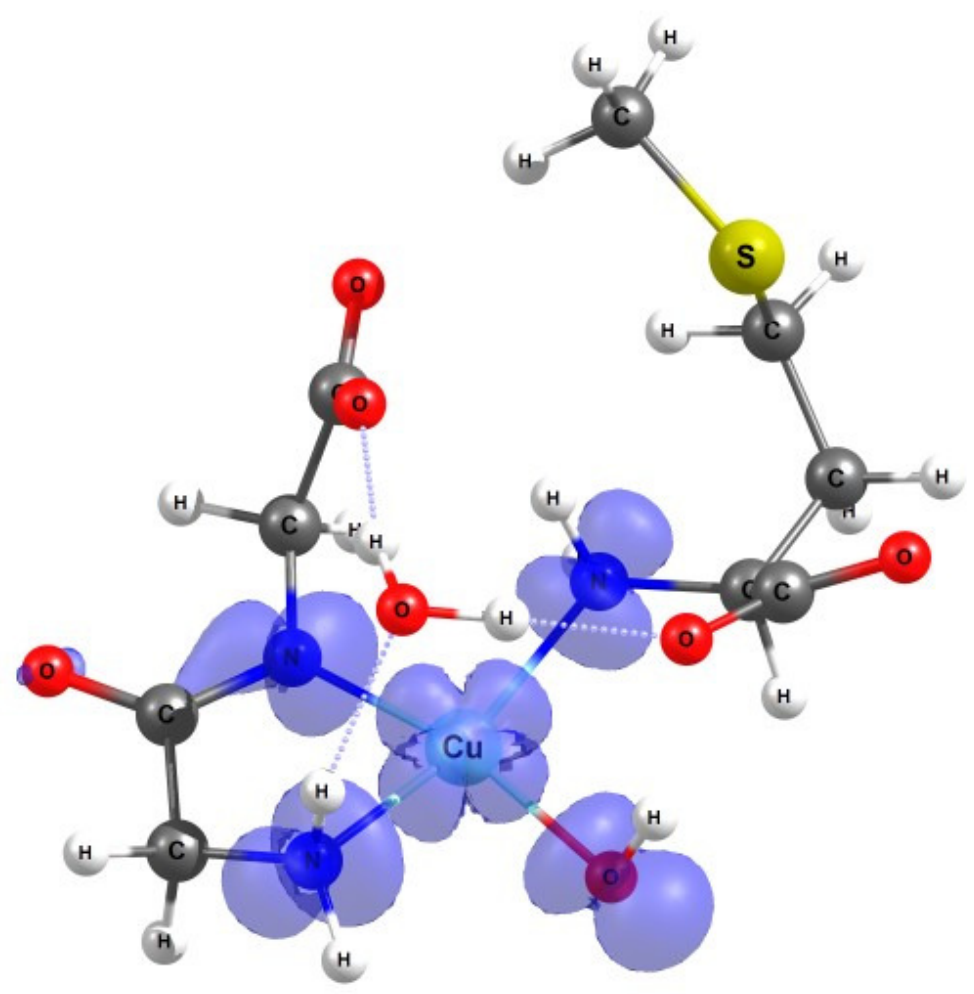

Figura 49. Distribuição de densidade de spin da espécie ternária $\mathrm{CuL}_{1} \mathrm{~L}_{2}(\mathrm{OH})^{2-}\left(\mathrm{L}_{1}=\right.$ GlyGly e $L_{2}=$ metionina) a partir de simulação B3LYP/def2-TZVP/COSMO como isosuperfície de 0,002 a.u.

As Figuras 50-52 mostram as estruturas mais estáveis, identificadas por cálculos DFT, assim como os valores de pKa`s obtidos por potenciometria para os sistemas estudados no presente trabalho.

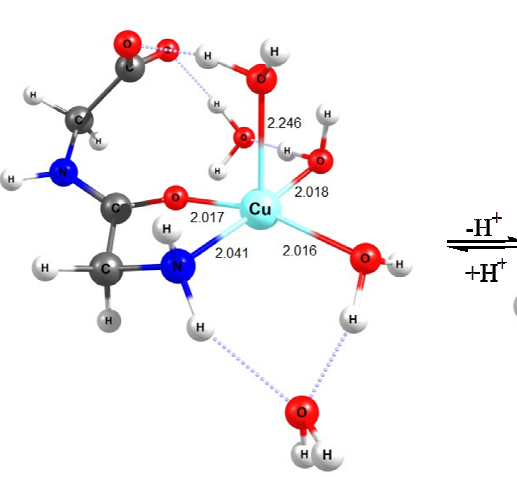

CuGlyGly

$$
\mathrm{pKa}_{1}=4,23
$$

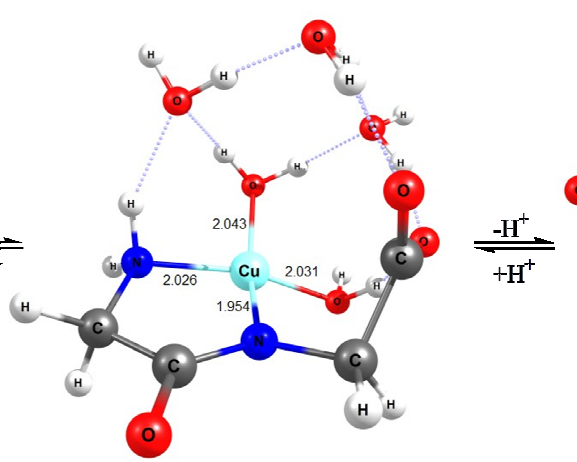

$$
\mathrm{Cu}\left(\mathrm{H}_{-1} \text { GlyGly }\right) \underset{\mathrm{pKa}_{2}=9,56}{\rightleftharpoons}
$$

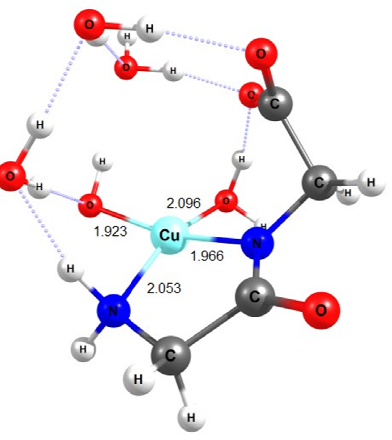

$\mathrm{Cu}\left(\mathrm{H}_{-1} \mathrm{GlyGly}\right)(\mathrm{OH})$

Figura 50. Especiação via DFT (RI-PBE/def2-SVP/COSMO) para o sistema binário Cu:GlyGly 

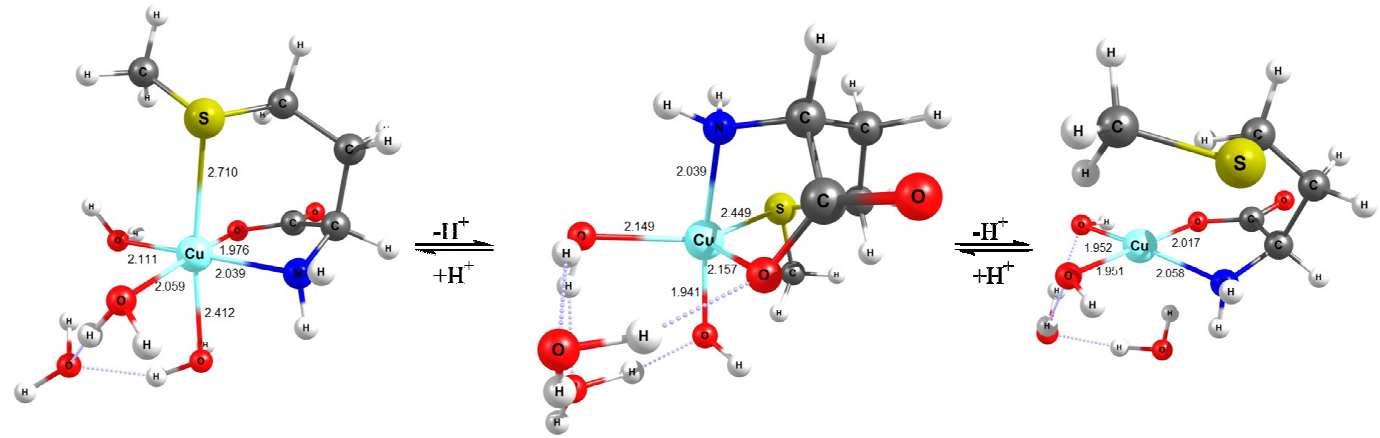

$$
\text { CuMet } \underset{\mathrm{pKa}_{1}=6,73}{\rightleftharpoons} \operatorname{CuMet}(\mathrm{OH}) \underset{\mathrm{pKa}_{2}=9,67}{=} \operatorname{CuMet}(\mathrm{OH})_{2}
$$

Figura 51. Especiação via DFT (RI-PBE/def2-SVP/COSMO) para o sistema binário Cu:Met
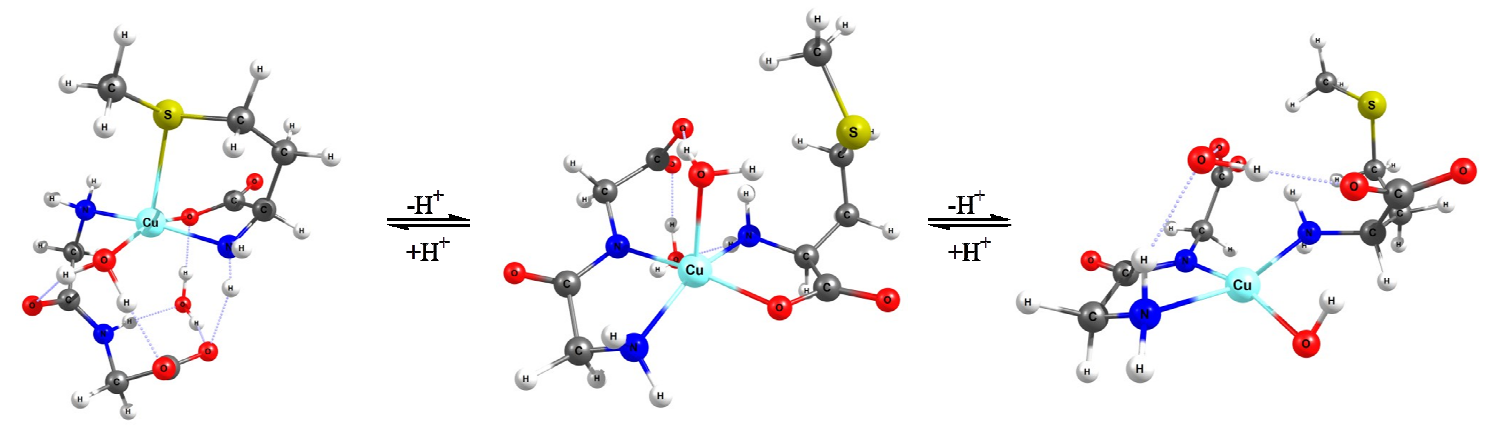

$$
\text { CuHGlyGlyMet } \quad \overline{\mathrm{pKa}_{1}=4,17}
$$

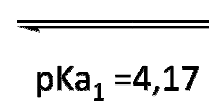

CuGlyGlyMet

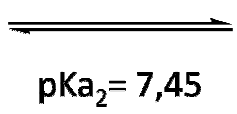

CuGlyGlyMet(OH)

Figura 52. Especiação via DFT (RI-PBE/def2-SVP/COSMO) para o sistema ternário Cu:GlyGly:Met

\section{4}

\section{Estudos termodinâmicos DFT para os complexos formados nos sistemas binários Cu:GlyGly e Cu:Met e no sistema ternário Cu:GlyGly:Met}

Primeiro, nós realizamos uma pesquisa para identificar as estruturas dos complexos mais estáveis. Após a identificação das estruturas mais estáveis, nós utilizamos a teoria do funcional de densidade DFT com os funcionais híbridos B3LYP [40] e PBE0 [155] com um conjunto de bases grande def2-TZVP [157] para determinar os parâmetros termodinâmicos para os complexos estudados e para as espécies envolvidas nas reações de desprotonação. 


\section{4 .1}

\section{Cálculos termodinâmicos e valores de pKa's dos complexos $\left[\mathrm{Cu}(\mathrm{GlyGly})\left(\mathrm{H}_{2} \mathrm{O}\right)_{5}\right]^{+}$e $\left[\mathrm{Cu}\left(\mathrm{H}_{-1} \mathrm{GlyGly}\right)\left(\mathrm{H}_{2} \mathrm{O}\right)_{5}\right]$ com os funcionais B3LYP} e PBE0 e conjunto de bases def2-TZVP

Todas as espécies mostraram uma maior estabilidade em fase aquosa do que fase gasosa $\left(\Delta \mathrm{G}_{\mathrm{solv}}^{*}<0\right)$. As espécies carregadas $\left[\mathrm{Cu}(\mathrm{GlyGly})\left(\mathrm{H}_{2} \mathrm{O}\right)_{5}\right]^{+},\left[\mathrm{Cu}\left(\mathrm{H}_{-}\right.\right.$ $\left.\left.{ }_{1} \mathrm{GlyGly}\right)\left(\mathrm{H}_{2} \mathrm{O}\right)_{4}(\mathrm{OH})\right]^{-}, \mathrm{H}_{3} \mathrm{O}^{+}$e $\mathrm{OH}^{-}$mostraram um processo bem espontâneo ao se passar para a fase aquosa (Tabela 24) comparado com as moléculas neutras.

Tabela 24. Valores de $\Delta \mathrm{G}_{\text {solv }}^{*}\left(\mathrm{kcal} \mathrm{mol}{ }^{-1}\right)$ para os complexos [Cu(GlyGly) $\left.\left(\mathrm{H}_{2} \mathrm{O}\right)_{5}\right]^{+}$, [ $\mathrm{Cu}(\mathrm{H}$. ${ }_{1}$ GlyGly $)\left(\mathrm{H}_{2} \mathrm{O}\right)_{5}$ ] e $\left[\mathrm{Cu}\left(\mathrm{H}_{-1} \text { GlyGly }\right)\left(\mathrm{H}_{2} \mathrm{O}\right)_{4}(\mathrm{OH})\right]^{-}$e para as espécies $\mathrm{H}_{2} \mathrm{O}, \mathrm{H}_{3} \mathrm{O}^{+}$e $\mathrm{OH}^{-}$a 298 $\mathrm{K}$ e $1 \mathrm{~atm}$ (B3LYP e PBE0/def2-TZVP)

\begin{tabular}{ccc}
\hline Espécies & B3LYP & PBE0 \\
& $\Delta \mathrm{G}_{\text {solv }}^{*}$ & $\Delta \mathrm{G}_{\text {solv }}^{*}$ \\
\hline$\left[\mathrm{Cu}(\mathrm{GlyGly})\left(\mathrm{H}_{2} \mathrm{O}\right)_{5}\right]^{+}$ & $-83,83$ & $-84,01$ \\
{$\left[\mathrm{Cu}\left(\mathrm{H}_{-1} \mathrm{GlyGly}\right)\left(\mathrm{H}_{2} \mathrm{O}\right)_{5}\right]$} & $-34,95$ & $-35,39$ \\
{$\left[\mathrm{Cu}\left(\mathrm{H}_{-1} \mathrm{GlyGly}\right)\left(\mathrm{H}_{2} \mathrm{O}\right)_{4}(\mathrm{OH})\right]^{-}$} & $-74,07$ & $-74,28$ \\
$\mathrm{H}_{2} \mathrm{O}$ & $-9,96$ & $-10,00$ \\
$\mathrm{H}_{3} \mathrm{O}^{+}$ & $-92,62$ & $-92,56$ \\
$\mathrm{OH}^{-}$ & $-100,99$ & $-101,18$ \\
\hline${ }^{*} \mathrm{H}_{-1} \mathrm{GlyGly}=$ dipeptídeo desprotonado no nitrogênio peptídico
\end{tabular}

Com os valores mostrados na Tabela 24 e de acordo o equilíbrio abaixo, podemos determinar o valor de pKa para o complexo $\left[\mathrm{Cu}(\mathrm{GlyGly})\left(\mathrm{H}_{2} \mathrm{O}\right)_{5}\right]^{+}$com uso das Equações 36-38 [159,160]:

$$
\begin{aligned}
& \quad\left[\mathrm{Cu}(\text { GlyGly })\left(\mathrm{H}_{2} \mathrm{O}\right)_{5}\right]^{+}+\mathrm{H}_{2} \mathrm{O} \rightleftharpoons\left[\mathrm{Cu}\left(\mathrm{H}_{-1} \text { GlyGly }\right)\left(\mathrm{H}_{2} \mathrm{O}\right)_{5}\right]+\mathrm{H}_{3} \mathrm{O}^{+} \\
& \Delta \mathrm{G}_{\text {sol }}^{*}=\Delta \mathrm{G}_{\mathrm{g}}^{*}+\Delta \Delta \mathrm{G}_{\text {solv }}^{*} \\
& \Delta \mathrm{G}_{\text {sol }}^{*}=\Delta \mathrm{G}_{\mathrm{g}}^{*}+\Delta \mathrm{G}_{\text {solv }}^{*}\left(\left[\mathrm{Cu}\left(\mathrm{H}_{-1} \mathrm{GlyGly}\right)\left(\mathrm{H}_{2} \mathrm{O}\right)_{5}\right]\right)+\Delta \mathrm{G}_{\text {solv }}^{*}\left(\mathrm{H}_{3} \mathrm{O}^{+}\right)- \\
& \Delta \mathrm{G}_{\text {solv }}^{*}\left(\left[\mathrm{Cu}(\mathrm{GlyGly})\left(\mathrm{H}_{2} \mathrm{O}\right)_{5}\right]^{+}\right)-\Delta \mathrm{G}_{\text {solv }}^{*}\left(\mathrm{H}_{2} \mathrm{O}\right)
\end{aligned}
$$$$
\mathrm{pK}_{\mathrm{a}}\left(\left[\mathrm{Cu}(\text { GlyGly })\left(\mathrm{H}_{2} \mathrm{O}\right)_{5}\right]^{+}\right)=\frac{\Delta \mathrm{G}_{\mathrm{sol}}^{*}}{(2,303) \mathrm{RT}}-1,74
$$ 
Da mesma forma, para o complexo $\left[\mathrm{Cu}\left(\mathrm{H}_{-1} \mathrm{GlyGly}\right)\left(\mathrm{H}_{2} \mathrm{O}\right)_{5}\right]$, podemos calcular o valor de pKa de acordo com equilíbrio abaixo e com o uso das Equações 39-41 (159,160):

$$
\begin{aligned}
& \quad\left[\mathrm{Cu}\left(\mathrm{H}_{-1} \text { GlyGly }\right)\left(\mathrm{H}_{2} \mathrm{O}\right)_{5}\right]+\mathrm{OH}^{-} \rightleftharpoons\left[\mathrm{Cu}\left(\mathrm{H}_{-1} \text { GlyGly }\right)(\mathrm{OH})\left(\mathrm{H}_{2} \mathrm{O}\right)_{4}\right]^{-}+\mathrm{H}_{2} \mathrm{O} \\
& \Delta \mathrm{G}_{\text {sol }}^{*}=\Delta \mathrm{G}_{\mathrm{g}}^{*}+\Delta \Delta \mathrm{G}_{\text {solv }}^{*} \\
& \Delta \mathrm{G}_{\text {sol }}^{*}=\Delta \mathrm{G}_{\mathrm{g}}^{*}+\Delta \mathrm{G}_{\text {solv }}^{*}\left(\left[\mathrm{Cu}\left(\mathrm{H}_{-1} \text { GlyGly }\right)(\mathrm{OH})\left(\mathrm{H}_{2} \mathrm{O}\right)_{4}\right]^{-}\right)+\Delta \mathrm{G}_{\text {solv }}^{*}\left(\mathrm{H}_{2} \mathrm{O}\right)- \\
& \Delta \mathrm{G}_{\text {solv }}^{*}\left(\left[\mathrm{Cu}\left(\mathrm{H}_{-1} \mathrm{GlyGly}\right)\left(\mathrm{H}_{2} \mathrm{O}\right)_{5}\right]\right)-\Delta \mathrm{G}_{\text {solv }}^{*}\left(\mathrm{OH}^{-}\right) \\
& \mathrm{pK}_{\mathrm{a}}\left(\left[\mathrm{Cu}\left(\mathrm{H}_{-1} \text { GlyGly }\right)\left(\mathrm{H}_{2} \mathrm{O}\right)_{5}\right]\right)=\frac{\Delta \mathrm{G}_{\text {sol }}^{*}}{(2,303) \mathrm{RT}}+15,74
\end{aligned}
$$

Os valores de energias livres de Gibbs $\left(\Delta \mathrm{G}_{\mathrm{g}}^{*}, \Delta \Delta \mathrm{G}_{\text {solv }}^{*}\right.$ e $\left.\Delta \mathrm{G}_{\text {sol }}^{*}\right)$ e de $\mathrm{pKa}$ para as reações de desprotonação dos complexos $\left[\mathrm{Cu}(\mathrm{GlyGly})\left(\mathrm{H}_{2} \mathrm{O}\right)_{5}\right]^{+}$e $\left[\mathrm{Cu}\left(\mathrm{H}_{-}\right.\right.$ ${ }_{1}$ GlyGly) $\left(\mathrm{H}_{2} \mathrm{O}\right)_{5}$ ] obtidos utilizando os funcionais B3LYP e PBE0 são mostrados nas Tabelas 25 e 26.

Tabela 25. Energias livres de Gibbs $\left(\mathrm{kcal} \mathrm{mol}^{-1}\right)$ e valores de pKa para as reações de desprotonação dos complexos [Cu(GlyGly) $\left.\left(\mathrm{H}_{2} \mathrm{O}\right)_{5}\right]^{+}$e $\left[\mathrm{Cu}\left(\mathrm{H}_{-1} \mathrm{GlyGly}\right)\left(\mathrm{H}_{2} \mathrm{O}\right)_{5}\right]$, em solução aquosa a $298 \mathrm{~K}$ e $1 \mathrm{~atm}$ (B3LYP/def2-TZVP)

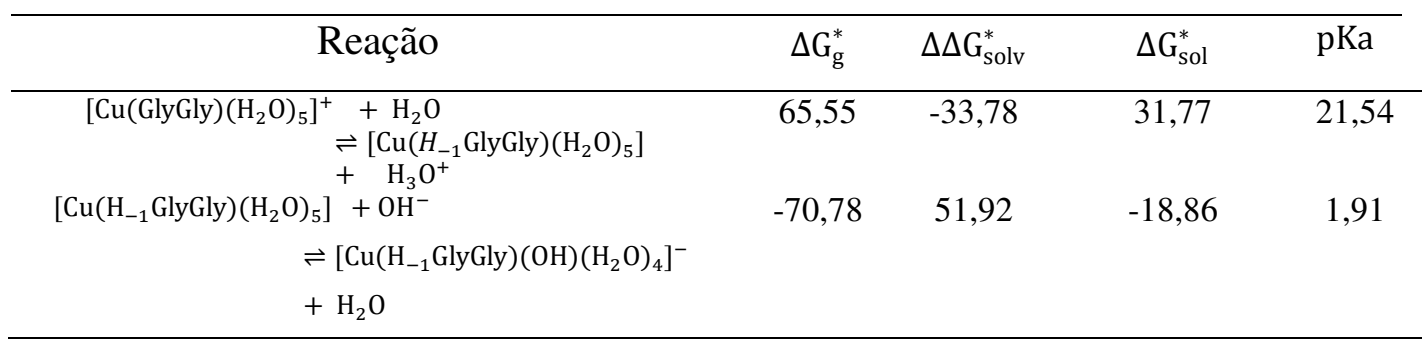

Tabela 26. Energias livres de Gibbs $\left(\mathrm{kcal} \mathrm{mol}^{-1}\right)$ e valores de pKa para as reações de desprotonação dos complexos [ $\left.\mathrm{Cu}(\mathrm{GlyGly})\left(\mathrm{H}_{2} \mathrm{O}\right)_{5}\right]^{+}$e $\left[\mathrm{Cu}\left(\mathrm{H}_{-1} \mathrm{GlyGly}\right)\left(\mathrm{H}_{2} \mathrm{O}\right)_{5}\right]$, em solução aquosa a $298 \mathrm{~K}$ e $1 \mathrm{~atm}$ (PBE0/def2-TZVP)

\begin{tabular}{ccccc}
\hline Reação & $\Delta \mathrm{G}_{\mathrm{g}}^{*}$ & $\Delta \Delta \mathrm{G}_{\text {solv }}^{*}$ & $\Delta \mathrm{G}_{\text {sol }}^{*}$ & $\mathrm{pKa}$ \\
\hline$\left[\mathrm{Cu}(\mathrm{GlyGly})\left(\mathrm{H}_{2} \mathrm{O}\right)_{5}\right]^{+}+\mathrm{H}_{2} \mathrm{O} \rightleftharpoons\left[\mathrm{Cu}\left(\mathrm{H}_{-1} \mathrm{GlyGly}\right)\left(\mathrm{H}_{2} \mathrm{O}\right)_{5}\right]+\mathrm{H}_{3} \mathrm{O}^{+}$ & 64,75 & $-33,95$ & 30,80 & 20,83 \\
{$\left[\mathrm{Cu}\left(\mathrm{H}_{-1} \mathrm{GlyGly}\right)\left(\mathrm{H}_{2} \mathrm{O}\right)_{5}\right]+\mathrm{OH}^{-}$} & $-66,77$ & 52,30 & $-14,47$ & 5,13 \\
$\rightleftharpoons\left[\mathrm{Cu}\left(\mathrm{H}_{-1} \mathrm{GlyGly}\right)(\mathrm{OH})\left(\mathrm{H}_{2} \mathrm{O}\right)_{4}\right]^{-}+\mathrm{H}_{2} \mathrm{O}$ & & & & \\
\hline
\end{tabular}




\section{4 .2}

\section{Cálculos termodinâmicos e valores de pKa's dos complexos $\left[\mathrm{Cu}(\mathrm{Met})\left(\mathrm{H}_{2} \mathrm{O}\right)_{4}\right]^{+}$e $\left[\mathrm{Cu}(\mathrm{Met})\left(\mathrm{H}_{2} \mathrm{O}\right)_{3}(\mathrm{OH})\right] \mathrm{com}$ os funcionais B3LYP e} PBEO e conjunto de bases def2-TZVP

Todos as espécies mostraram um processo espontâneo ao passar da fase gasosa para a fase condensada $\left(\Delta \mathrm{G}_{\text {solv }}^{*}<0\right)($ Tabela 27$)$. Entre os complexos, a espécie carregada $\left[\mathrm{Cu}(\mathrm{Met})\left(\mathrm{H}_{2} \mathrm{O}\right)_{4}\right]^{+}$mostrou o processo ser o mais favorável $\left(\Delta \mathrm{G}_{\text {solv }}^{\circ}=-73,85\right)$.

Tabela 27. Valores de $\Delta \mathrm{G}_{\text {solv }}^{*}\left(\mathrm{kcal} \mathrm{mol}^{-1}\right)$ para os complexos $\left[\mathrm{Cu}(\mathrm{Met})\left(\mathrm{H}_{2} \mathrm{O}\right)_{4}\right]^{+}$, $\left[\mathrm{Cu}(\mathrm{Met})\left(\mathrm{H}_{2} \mathrm{O}\right)_{3}(\mathrm{OH})\right]$ e $\left[\mathrm{Cu}(\mathrm{Met})\left(\mathrm{H}_{2} \mathrm{O}\right)_{2}(\mathrm{OH})_{2}\right]^{-}$e para as espécies $\mathrm{H}_{2} \mathrm{O}, \mathrm{H}_{3} \mathrm{O}^{+}$e $\mathrm{OH}^{-}$a 298 $\mathrm{K}$ e $1 \mathrm{~atm}$ (B3LYP e PBE0/def2-TZVP)

\begin{tabular}{ccc}
\hline Espécies & B3LYP & PBE0 \\
& $\Delta \mathrm{G}_{\text {solv }}^{*}$ & $\Delta \mathrm{G}_{\text {solv }}^{*}$ \\
\hline$\left[\mathrm{Cu}(\mathrm{Met})\left(\mathrm{H}_{2} \mathrm{O}\right)_{4}\right]^{+}$ & $-73,85$ & $-74,39$ \\
{$\left[\mathrm{Cu}(\mathrm{Met})\left(\mathrm{H}_{2} \mathrm{O}\right)_{3}(\mathrm{OH})\right]$} & $-29,71$ & $-29,73$ \\
{$\left[\mathrm{Cu}(\mathrm{Met})\left(\mathrm{H}_{2} \mathrm{O}\right)_{2}(\mathrm{OH})_{2}\right]^{-}$} & $-69,99$ & $-75,86$ \\
$\mathrm{H}_{2} \mathrm{O}$ & $-9,96$ & $-10,00$ \\
$\mathrm{H}_{3} \mathrm{O}^{+}$ & $-92,62$ & $-92,56$ \\
$\mathrm{OH}^{-}$ & $-100,99$ & $-101,18$ \\
\hline
\end{tabular}

De acordo com equilíbrio abaixo e com o uso das Equações 42-44, podemos calcular o valore de pKa para o complexo $\left[\mathrm{Cu}(\mathrm{Met})\left(\mathrm{H}_{2} \mathrm{O}\right)_{4}\right]^{+}[159,160]$ :

$$
\begin{aligned}
& \quad\left[\mathrm{Cu}(\mathrm{Met})\left(\mathrm{H}_{2} \mathrm{O}\right)_{4}\right]^{+}+\mathrm{H}_{2} \mathrm{O} \rightleftharpoons\left[\mathrm{Cu}(\mathrm{Met})(\mathrm{OH})\left(\mathrm{H}_{2} \mathrm{O}\right)_{3}\right]+\mathrm{H}_{3} \mathrm{O}^{+} \\
& \Delta \mathrm{G}_{\text {sol }}^{*}=\Delta \mathrm{G}_{\mathrm{g}}^{*}+\Delta \Delta \mathrm{G}_{\text {solv }}^{*} \\
& \Delta \mathrm{G}_{\text {sol }}^{*}=\Delta \mathrm{G}_{\mathrm{g}}^{*}+\Delta \mathrm{G}_{\text {solv }}^{*}\left(\left[\mathrm{Cu}(\mathrm{Met})(\mathrm{OH})\left(\mathrm{H}_{2} \mathrm{O}\right)_{3}\right]\right)+\Delta \mathrm{G}_{\text {solv }}^{*}\left(\mathrm{H}_{3} \mathrm{O}^{+}\right)- \\
& \Delta \mathrm{G}_{\text {solv }}^{*}\left(\left[\mathrm{Cu}(\mathrm{Met})\left(\mathrm{H}_{2} \mathrm{O}\right)_{4}\right]^{+}\right)-\Delta \mathrm{G}_{\text {solv }}^{*}\left(\mathrm{H}_{2} \mathrm{O}\right) \\
& \mathrm{pK}_{\mathrm{a}}\left(\left[\mathrm{Cu}(\mathrm{Met})\left(\mathrm{H}_{2} \mathrm{O}\right)_{4}\right]^{+}\right)=\frac{\Delta \mathrm{G}_{\text {sol }}^{*}}{(2,303) \mathrm{RT}}-1,74
\end{aligned}
$$


De acordo com o equilíbrio mostrado abaixo e com o auxílio das equações 45-47, podemos calcular o valor de pKa para o complexo $\left[\mathrm{Cu}(\mathrm{Met})(\mathrm{OH})\left(\mathrm{H}_{2} \mathrm{O}\right)_{3}\right]$ $[159,160]$ :

$$
\begin{aligned}
& {\left[\mathrm{Cu}(\mathrm{Met})(\mathrm{OH})\left(\mathrm{H}_{2} \mathrm{O}\right)_{3}\right]+\mathrm{OH}^{-} \rightleftharpoons\left[\mathrm{Cu}(\mathrm{Met})(\mathrm{OH})_{2}\left(\mathrm{H}_{2} \mathrm{O}\right)_{2}\right]^{-}+\mathrm{H}_{2} \mathrm{O}} \\
& \Delta \mathrm{G}_{\text {sol }}^{*}=\Delta \mathrm{G}_{\mathrm{g}}^{*}+\Delta \Delta \mathrm{G}_{\text {solv }}^{*} \\
& \Delta \Delta \mathrm{G}_{\text {sol }}^{*}=\Delta \mathrm{G}_{\mathrm{g}}^{*}+\Delta \mathrm{G}_{\text {solv }}^{*}\left(\left[\mathrm{Cu}(\mathrm{Met})(\mathrm{OH})_{2}\left(\mathrm{H}_{2} \mathrm{O}\right)_{2}\right]^{-}\right)+\Delta \mathrm{G}_{\text {solv }}^{*}\left(\mathrm{H}_{2} \mathrm{O}\right)- \\
& \Delta \mathrm{G}_{\text {solv }}^{*}\left(\left[\mathrm{Cu}(\mathrm{Met})(\mathrm{OH})\left(\mathrm{H}_{2} \mathrm{O}\right)_{3}\right]\right)-\Delta \mathrm{G}_{\text {solv }}^{*}\left(\mathrm{OH}^{-}\right) \\
& \mathrm{pK}_{\mathrm{a}}\left(\left[\mathrm{Cu}(\mathrm{Met})(\mathrm{OH})\left(\mathrm{H}_{2} \mathrm{O}\right)_{3}\right]\right)=\frac{\Delta \mathrm{G}_{\text {sol }}^{*}}{(2,303) \mathrm{RT}}+15,74
\end{aligned}
$$

As Tabelas 28 e 29 mostram os valores de energias livres de Gibbs $\left(\Delta \mathrm{G}_{\mathrm{g}}^{*}, \Delta \Delta \mathrm{G}_{\text {solv }}^{*}\right.$ e $\left.\Delta \mathrm{G}_{\text {sol }}^{*}\right)$ e os valores pKa para a reação de desprotonação dos complexos $\left[\mathrm{Cu}(\mathrm{Met})\left(\mathrm{H}_{2} \mathrm{O}\right)_{4}\right]^{+}$e $\left[\mathrm{Cu}(\mathrm{Met})\left(\mathrm{H}_{2} \mathrm{O}\right)_{3}(\mathrm{OH})\right]$ obtidos utilizando os funcionais B3LYP e PBE0.

Tabela 28. Energias livres de Gibbs $\left(\mathrm{kcal} \mathrm{mol}^{-1}\right)$ e valores de pKa para as reações de desprotonação dos complexos $\left[\mathrm{Cu}(\mathrm{Met})\left(\mathrm{H}_{2} \mathrm{O}\right)_{4}\right]^{+}$e $\left[\mathrm{Cu}(\mathrm{Met})\left(\mathrm{H}_{2} \mathrm{O}\right)_{3}(\mathrm{OH})\right]$, em solução aquosa, a $298 \mathrm{~K}$ e 1 atm (B3LYP/def2-TZVP)

\begin{tabular}{cccccc}
\hline Reação & & $\Delta \mathrm{G}_{\mathrm{g}}^{*}$ & $\Delta \Delta \mathrm{G}_{\text {solv }}^{*}$ & $\Delta \mathrm{G}_{\text {sol }}^{*}$ & $\mathrm{pKa}$ \\
\hline$\left[\mathrm{Cu}(\mathrm{Met})\left(\mathrm{H}_{2} \mathrm{O}\right)_{4}\right]^{+}+\mathrm{H}_{2} \mathrm{O} \rightleftharpoons\left[\mathrm{Cu}(\mathrm{Met})(\mathrm{OH})\left(\mathrm{H}_{2} \mathrm{O}\right)_{3}\right]$ & $+\mathrm{H}_{3} \mathrm{O}^{+}$ & 72,41 & $-38,52$ & 33,89 & 23,10 \\
{$\left[\mathrm{Cu}(\mathrm{Met})(\mathrm{OH})\left(\mathrm{H}_{2} \mathrm{O}\right)_{3}\right]+\mathrm{OH}^{-}$} & & $-79,41$ & 50,76 & $-28,65$ & $-5,26$ \\
$\rightleftharpoons\left[\mathrm{Cu}(\mathrm{Met})(\mathrm{OH})_{2}\left(\mathrm{H}_{2} \mathrm{O}\right)_{2}\right]^{-}+\mathrm{H}_{2} \mathrm{O}$ & & & & \\
\hline
\end{tabular}

Tabela 29. Energias livres de Gibbs $\left(\mathrm{kcal} \mathrm{mol}^{-1}\right)$ e valores de pKa para as reações de desprotonação dos complexos $\left[\mathrm{Cu}(\mathrm{Met})\left(\mathrm{H}_{2} \mathrm{O}\right)_{4}\right]^{+}$e $\left[\mathrm{Cu}(\mathrm{Met})\left(\mathrm{H}_{2} \mathrm{O}\right)_{3}(\mathrm{OH})\right]$, em solução aquosa, a $298 \mathrm{~K}$ e $1 \mathrm{~atm}$ (PBE0/def2-TZVP)

\begin{tabular}{ccccc}
\hline Reação & $\Delta \mathrm{G}_{\mathrm{g}}^{*}$ & $\Delta \Delta \mathrm{G}_{\text {solv }}^{*}$ & $\Delta \mathrm{G}_{\text {sol }}^{*}$ & pKa \\
\hline$\left[\mathrm{Cu}(\mathrm{Met})\left(\mathrm{H}_{2} \mathrm{O}\right)_{4}\right]^{+}+\stackrel{\mathrm{H}_{2} \mathrm{O}}{\rightleftharpoons}\left[\mathrm{Cu}(\mathrm{Met})(\mathrm{OH})\left(\mathrm{H}_{2} \mathrm{O}\right)_{3}\right]$ & 70,89 & $-37,90$ & 32,99 & \\
$\stackrel{+}{+} \mathrm{H}_{3} \mathrm{O}^{+}$ & & & & 22,44 \\
{$\left[\mathrm{Cu}(\mathrm{Met})(\mathrm{OH})\left(\mathrm{H}_{2} \mathrm{O}\right)_{3}\right]+\stackrel{\mathrm{OH}}{\rightleftharpoons}$} & $-74,01$ & 50,75 & $-23,27$ & $-1,31$ \\
{$\left[\mathrm{Cu}(\mathrm{Met})(\mathrm{OH})_{2}\left(\mathrm{H}_{2} \mathrm{O}\right)_{2}\right]^{-}+\mathrm{H}_{2} \mathrm{O}$} & & & & \\
\hline
\end{tabular}




\subsection{3}

Cálculos termodinâmicos e de valores de pKa's dos para os complexos [Cu(HGlyGly)(Met) $\left.\left(\mathrm{H}_{2} \mathrm{O}_{2} \text { ] e [Cu(GlyGly)(Met)( } \mathrm{H}_{2} \mathrm{O}\right)_{2}\right]^{-} \mathrm{com}$ os funcionais B3LYP e PBE0 e conjunto de bases def2-TZVP

A Tabela 30 mostra os valores de $\Delta \mathrm{G}_{\text {solv }}^{*}$ para os complexos $\left[\mathrm{Cu}(\mathrm{HGlyGly})(\mathrm{Met})\left(\mathrm{H}_{2} \mathrm{O}\right)_{2}\right], \quad\left[\mathrm{Cu}(\mathrm{GlyGly})(\mathrm{Met})\left(\mathrm{H}_{2} \mathrm{O}\right)_{2}\right]^{-} \quad$ e $\left[\mathrm{Cu}(\mathrm{GlyGly})(\mathrm{Met})\left(\mathrm{H}_{2} \mathrm{O}\right)(\mathrm{OH})\right]^{2-}$. Para todos os complexos o processo de passagem da fase gasosa para fase aquosa é espontâneo e entre os complexos a espécies carregada $\left[\mathrm{Cu}(\mathrm{GlyGly})(\mathrm{Met})\left(\mathrm{H}_{2} \mathrm{O}\right)(\mathrm{OH})\right]^{2-}$ mostrou o processo ser o mais favorável $\left(\Delta \mathrm{G}_{\text {solv }}^{\circ}=-182,27\right)$.

Tabela 30. Valores de $\Delta \mathrm{G}_{\text {solv }}^{*}\left(\mathrm{kcal} \mathrm{mol}^{-1}\right)$ para os complexos [Cu(HGlyGly)(Met) $\left(\mathrm{H}_{2} \mathrm{O}\right)_{2}$ ], [Cu(GlyGly)(Met) $\left.\left(\mathrm{H}_{2} \mathrm{O}\right)_{2}\right]^{-}$e $\left[\mathrm{Cu}(\mathrm{GlyGly})(\mathrm{Met})\left(\mathrm{H}_{2} \mathrm{O}\right)(\mathrm{OH})\right]^{2-}$ e para as espécies $\mathrm{H}_{2} \mathrm{O}, \mathrm{H}_{3} \mathrm{O}^{+}$e $\mathrm{OH}^{-}$a $298 \mathrm{~K}$ e $1 \mathrm{~atm}$ (B3LYP e PBE0/def2-TZVP)

\begin{tabular}{ccc}
\hline Espécies & B3LYP & PBE0 \\
& $\Delta \mathrm{G}_{\text {solv }}^{*}$ & $\Delta \mathrm{G}_{\text {solv }}^{*}$ \\
\hline$\left[\mathrm{Cu}(\mathrm{HGlyGly})(\mathrm{Met})\left(\mathrm{H}_{2} \mathrm{O}\right)_{2}\right]$ & $-74,39$ & $-35,61$ \\
{$\left[\mathrm{Cu}(\mathrm{GlyGly})(\mathrm{Met})\left(\mathrm{H}_{2} \mathrm{O}\right)_{2}\right]^{-}$} & $-29,73$ & $-72,41$ \\
{$\left[\mathrm{Cu}(\mathrm{GlyGly})(\mathrm{Met})\left(\mathrm{H}_{2} \mathrm{O}\right)(\mathrm{OH})\right]^{2-}$} & $-75,86$ & $-182,86$ \\
$\mathrm{H}_{2} \mathrm{O}$ & $-9,96$ & $-10,00$ \\
$\mathrm{H}_{3} \mathrm{O}^{+}$ & $-92,62$ & $-92,56$ \\
$\mathrm{OH}^{-}$ & $-100,99$ & $-101,18$ \\
\hline
\end{tabular}

De acordo com equilíbrio abaixo e com o uso das Equações 48-50, podemos calcular o valor de pKa para o complexo [Cu(HGlyGly)(Met) $\left(\mathrm{H}_{2} \mathrm{O}\right)_{2}$ ] $[159,160]$ :

$$
\begin{aligned}
& {\left[\mathrm{Cu}\left(\text { HGlyGly)(Met) }\left(\mathrm{H}_{2} \mathrm{O}\right)_{2}\right]+\mathrm{OH}^{-} \rightleftharpoons\left[\mathrm{Cu}(\mathrm{GlyGly})(\text { Met })\left(\mathrm{H}_{2} \mathrm{O}\right)_{2}\right]^{-}+\mathrm{H}_{2} \mathrm{O}\right.} \\
& \Delta \mathrm{G}_{\text {sol }}^{*}=\Delta \mathrm{G}_{\mathrm{g}}^{*}+\Delta \Delta \mathrm{G}_{\text {solv }}^{*} \\
& \Delta \mathrm{G}_{\text {sol }}^{*}=\Delta \mathrm{G}_{\mathrm{g}}^{*}+\Delta \mathrm{G}_{\text {solv }}^{*}\left(\left[\mathrm{Cu}(\text { GlyGly })(\text { Met })\left(\mathrm{H}_{2} \mathrm{O}\right)_{2}\right]^{-}\right)+\Delta \mathrm{G}_{\text {solv }}^{*}\left(\mathrm{H}_{2} \mathrm{O}\right)- \\
& \Delta \mathrm{G}_{\text {solv }}^{*}\left(\left[\mathrm{Cu}(\text { HGlyGly)(Met })\left(\mathrm{H}_{2} \mathrm{O}\right)_{2}\right]\right)-\Delta \mathrm{G}_{\text {solv }}^{*}\left(\mathrm{OH}^{-}\right)
\end{aligned}
$$


$\mathrm{pKa}=\left(\left[\mathrm{Cu}(\mathrm{HGlyGly})(\mathrm{Met})\left(\mathrm{H}_{2} \mathrm{O}\right)_{2}\right]\right) \quad=\frac{\Delta \mathrm{G}_{\mathrm{sol}}^{*}}{(2,303) \mathrm{RT}}+15,74$

De acordo com o equilíbrio mostrado abaixo e com o auxílio das Equações 51-53, podemos calcular o valor de pKa para o complexo $\left[\mathrm{Cu}(\mathrm{GlyGly})(\mathrm{Met})\left(\mathrm{H}_{2} \mathrm{O}\right)_{2}\right]^{-}[159,160]$ :

$$
\begin{aligned}
& {\left[\mathrm{Cu} \text { (GlyGly)(Met) }\left(\mathrm{H}_{2} \mathrm{O}\right)_{2}\right]^{-}+\mathrm{H}_{2} \mathrm{O}} \\
& \qquad\left[\mathrm{Cu}(\text { GlyGly })(\mathrm{Met})\left(\mathrm{H}_{2} \mathrm{O}\right)(\mathrm{OH})\right]^{2-}+\mathrm{H}_{3} \mathrm{O}^{+} \\
& \Delta \mathrm{G}_{\text {sol }}^{*}=\Delta \mathrm{G}_{\mathrm{g}}^{*}+\Delta \Delta \mathrm{G}_{\text {solv }}^{*} \\
& \Delta \mathrm{G}_{\text {sol }}^{*}=\Delta \mathrm{G}_{\mathrm{g}}^{*}+\Delta \mathrm{G}_{\text {solv }}^{*}\left(\left[\mathrm{Cu}(\mathrm{GlyGly})(\mathrm{Met})\left(\mathrm{H}_{2} \mathrm{O}\right)(\mathrm{OH})\right]^{2-}\right)+\Delta \mathrm{G}_{\text {solv }}^{*}\left(\mathrm{H}_{3} \mathrm{O}^{+}\right)- \\
& \Delta \mathrm{G}_{\text {solv }}^{*}\left(\left[\mathrm{Cu}(\text { GlyGly })(\text { Met })\left(\mathrm{H}_{2} \mathrm{O}\right)_{2}\right]^{-}\right)-\Delta \mathrm{G}_{\text {solv }}^{*}\left(\mathrm{H}_{2} \mathrm{O}\right) \\
& \left.\mathrm{pKa}=\left(\left[\mathrm{Cu}(\mathrm{GlyGly})(\mathrm{Met})\left(\mathrm{H}_{2} \mathrm{O}\right)_{2}\right]^{-}\right]\right)=\frac{\Delta \mathrm{G}_{\text {sol }}^{*}}{(2,303) \mathrm{RT}}-1,74
\end{aligned}
$$

As Tabelas 31 e 32 mostram os valores de energias livres de Gibbs

\begin{tabular}{|c|c|c|c|c|}
\hline Reação & $\Delta \mathrm{G}_{\mathrm{g}}^{*}$ & $\Delta \Delta \mathrm{G}_{\mathrm{solv}}^{*}$ & $\Delta \mathrm{G}_{\mathrm{sol}}^{*}$ & $\mathrm{pKa}$ \\
\hline $\begin{aligned} \mathrm{Cu}(\mathrm{HGlyGly})(\mathrm{Met}) & \left.\left.\left(\mathrm{H}_{2} \mathrm{O}\right)_{2}\right)\right]+\mathrm{OH}^{-} \\
& \rightleftharpoons\left[\mathrm{Cu}(\mathrm{GlyGly})(\text { Met })\left(\mathrm{H}_{2} \mathrm{O}\right)_{2}\right]^{-} \\
& +\mathrm{H}_{2} \mathrm{O}\end{aligned}$ & $-82,43$ & 54,30 & $-28,13$ & $-4,88$ \\
\hline $\begin{aligned} & {\left[\mathrm{Cu}(\mathrm{GlyGly})(\mathrm{Met})\left(\mathrm{H}_{2} \mathrm{O}\right)_{2}\right]^{-}+\mathrm{H}_{2} \mathrm{O} } \\
& \rightleftharpoons\left[\mathrm{Cu}(\mathrm{GlyGly})(\mathrm{Met})\left(\mathrm{H}_{2} \mathrm{O}\right)(\mathrm{OH})\right]^{2-} \\
&+\mathrm{H}_{3} \mathrm{O}^{+}\end{aligned}$ & 254,74 & $-192,82$ & 61,92 & 43,64 \\
\hline
\end{tabular}
$\left(\Delta \mathrm{G}_{\mathrm{g}}^{*}, \Delta \Delta \mathrm{G}_{\text {solv }}^{*}\right.$ e $\left.\Delta \mathrm{G}_{\text {sol }}^{*}\right)$ e de $\mathrm{pKa}$ dos complexos $\left[\mathrm{Cu}(\mathrm{HGlyGly})(\mathrm{Met})\left(\mathrm{H}_{2} \mathrm{O}\right)_{2}\right]$ e $\left[\mathrm{Cu}(\mathrm{GlyGly})(\mathrm{Met})\left(\mathrm{H}_{2} \mathrm{O}\right)_{2}\right]^{-}$obtidos utilizando os funcionais B3LYP e PBE0.

Tabela 31. Energias livres de Gibbs $\left(\mathrm{kcal} \mathrm{mol}^{-1}\right)$ e valores de pKa para as reações de desprotonação dos complexos [Cu(HGlyGly)(Met) $\left(\mathrm{H}_{2} \mathrm{O}\right)_{2}$ ] e $\left[\mathrm{Cu}(\mathrm{GlyGly})(\mathrm{Met})\left(\mathrm{H}_{2} \mathrm{O}\right)_{2}\right]^{-} \mathrm{em}$ solução aquosa, a $298 \mathrm{~K}$ e 1 atm (B3LYP/def2-TZVP) 
Tabela 32. Energias livres de Gibbs $\left(\mathrm{Kcal} \mathrm{mol}^{-1}\right)$ e valores de pKa para as reações de desprotonação dos complexos [Cu(HGlyGly)(Met) $\left(\mathrm{H}_{2} \mathrm{O}\right)_{2}$ ] e $\left[\mathrm{Cu}(\mathrm{GlyGly})(\mathrm{Met})\left(\mathrm{H}_{2} \mathrm{O}\right)_{2}\right]^{-} \mathrm{em}$ solução aquosa, a $298 \mathrm{~K}$ e 1 atm (PBE0/def2-TZVP)

\begin{tabular}{|c|c|c|c|c|}
\hline Reação & $\Delta \mathrm{G}_{\mathrm{g}}^{*}$ & $\Delta \Delta \mathrm{G}_{\mathrm{solv}}^{*}$ & $\Delta \mathrm{G}_{\mathrm{sol}}^{*}$ & $\mathrm{pKa}$ \\
\hline $\begin{aligned} {\left.\left[\mathrm{Cu}(\mathrm{HGlyGly})(\mathrm{Met})\left(\mathrm{H}_{2} \mathrm{O}\right)_{2}\right)\right]+\mathrm{OH}^{-} } \\
\rightleftharpoons\left[\mathrm{Cu}(\mathrm{GlyGly})(\mathrm{Met})\left(\mathrm{H}_{2} \mathrm{O}\right)_{2}\right]^{-} \\
+\mathrm{H}_{2} \mathrm{O}\end{aligned}$ & $-79,67$ & 54,45 & $-25,21$ & $-2,74$ \\
\hline $\begin{aligned} {\left[\mathrm{Cu}(\mathrm{GlyGly})(\mathrm{Met})\left(\mathrm{H}_{2} \mathrm{O}\right)_{2}\right]^{-}+\mathrm{H}_{2} \mathrm{O} } \\
\\
\rightleftharpoons\left[\mathrm{Cu}(\mathrm{GlyGly})(\mathrm{Met})\left(\mathrm{H}_{2} \mathrm{O}\right)(\mathrm{OH})\right]^{2-} \\
+\mathrm{H}_{3} \mathrm{O}^{+}\end{aligned}$ & $-165,13$ & $-193,02$ & $-358,15$ & $-264,23$ \\
\hline
\end{tabular}

\section{5}

Otimização dos clusters [Cu(GlyGly) $\left.\left(\mathrm{H}_{2} \mathrm{O}\right)_{36}\right]^{+},\left[\mathrm{Cu}\left(\mathrm{H}_{-1} \mathrm{GlyGly}\right)\left(\mathrm{H}_{2} \mathrm{O}\right)_{36}\right.$ ], [Cu( $\left.\left.\mathrm{H}_{-1} \mathrm{GlyGly}\right)(\mathrm{OH})\left(\mathrm{H}_{2} \mathrm{O}\right)_{35}\right]^{-}$, [Cu(Met) $\left.\left(\mathrm{H}_{2} \mathrm{O}\right)_{36}\right]^{+}$, [Cu(Met)(OH)( $\left.\left.\mathrm{H}_{2} \mathrm{O}\right)_{35}\right]$, [Cu(Met) $\left.(\mathrm{OH})_{2}\left(\mathrm{H}_{2} \mathrm{O}\right)_{34}\right]^{-}$, [Cu(HGlyGly)(Met) $\left(\mathrm{H}_{2} \mathrm{O}\right)_{36}$, $\left.\left[\mathrm{Cu} \text { (GlyGly)(Met)(} \mathrm{H}_{2} \mathrm{O}\right)_{36}\right]^{-}$e $\quad\left[\mathrm{Cu}(\mathrm{GlyGly})(\mathrm{Met})(\mathrm{OH})\left(\mathrm{H}_{2} \mathrm{O}\right)_{35}\right]^{2-}$ por cálculos B3LYP/def2-TZVP/COSMO

Foram realizados cálculos DFT levando em consideração não só o modelo de solvatação COSMO [149] como também uma segunda camada de solvatação. As geometria e as propriedades eletrônicas dos complexos formados foram avaliadas.

\section{- Cluster [Cu(GlyGly) $\left.\left(\mathrm{H}_{2} \mathrm{O}\right)_{36}\right]^{+}$}

Inicialmente foi feito a otimização do complexo com a presença de cinco moléculas de água na estrutura do complexo $\left[\mathrm{Cu}(\mathrm{GlyGly})\left(\mathrm{H}_{2} \mathrm{O}\right)_{5}\right]^{+}$. Nesse caso o complexo apresentou uma geometria pirâmide de base quadrada com o ligante dipeptídeo comportando-se como bidentado através do átomo de nitrogênio do grupo amino e do átomo de oxigênio peptídico (sistema coordenante $\mathrm{N}_{\text {amino }} \mathrm{O}_{\text {pept }}$ ) (ver Fig. 26).

Partimos então para a otimização do complexo apresentando uma segunda camada de solvatação, dando origem ao cluster $\left[\mathrm{Cu}(\mathrm{GlyGly})\left(\mathrm{H}_{2} \mathrm{O}\right)_{36}\right]^{+}$(Fig. 53). Nesse caso, o complexo manteve a geometria pirâmide de base quadrada, porém o ligante glicilglicina passou a atuar como ligante monodentado através do nitrogênio do grupo amino. A distância $\mathrm{Cu}-\mathrm{O}_{\text {pept }}$ de 2,573 Å, não foi considerada como uma distância de ligação ao centro metálico (ver Fig. 53). 


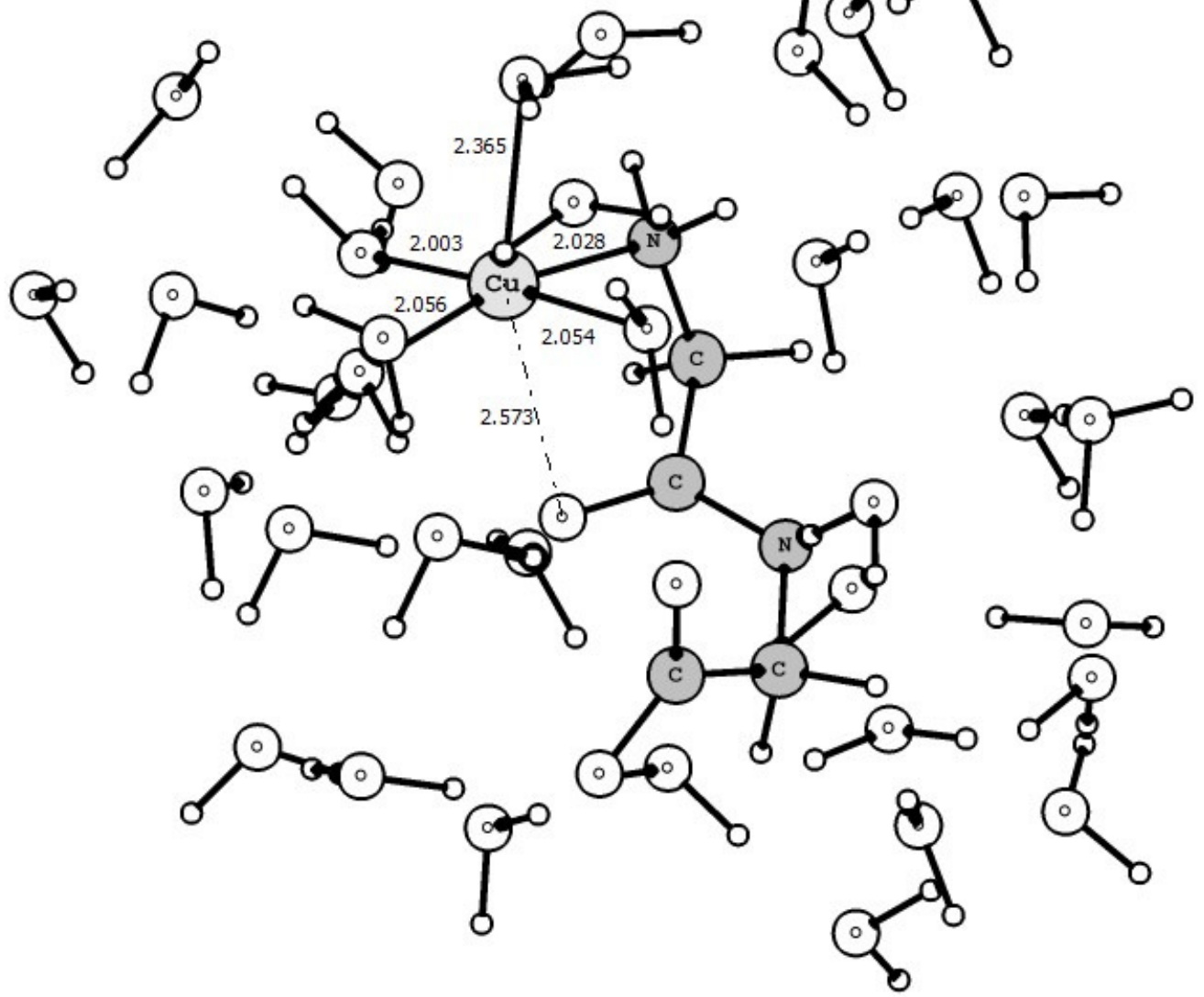

Figura 53. Geometria otimizada do cluster $\left[\mathrm{Cu}(\mathrm{GlyGly})\left(\mathrm{H}_{2} \mathrm{O}\right)_{36}\right]^{+} \quad(\mathrm{RI}-\mathrm{PBE} / \mathrm{def2}-$ SVP/COSMO)

\section{- Cluster $\left[\mathrm{Cu}\left(\mathrm{H}_{-1} \mathrm{GlyGly}\right)\left(\mathrm{H}_{2} \mathrm{O}\right)_{36}\right]$}

$\mathrm{O}$ complexo $\left[\mathrm{Cu}\left(\mathrm{H}_{-1}\right.\right.$ GlyGly $\left.)\left(\mathrm{H}_{2} \mathrm{O}\right)_{5}\right]$ apresentou uma geometria quadrado distorcido, com o ligante atuando como bidentado através do sistema coordenante $\mathrm{N}_{\text {amino }} \mathrm{N}_{\text {pept }}$ (ver Fig. 28).

Para o cluster $\left[\mathrm{Cu}\left(\mathrm{H}_{-1} \mathrm{GlyGly}\right)\left(\mathrm{H}_{2} \mathrm{O}\right)_{36}\right]$, o ligante também atuou de forma bidentada pelo sistema coordenante $\mathrm{N}_{\text {amino }} \mathrm{N}_{\text {pept }}$, porém o complexo assumiu uma geometria pirâmide de base quadrada (Fig. 54). O complexo apresentou três moléculas de água em sua estrutura, com uma das moléculas localizada na posição axial com comprimento de ligação $\mathrm{Cu}-\mathrm{O}$ de 2,359 $\AA$. 


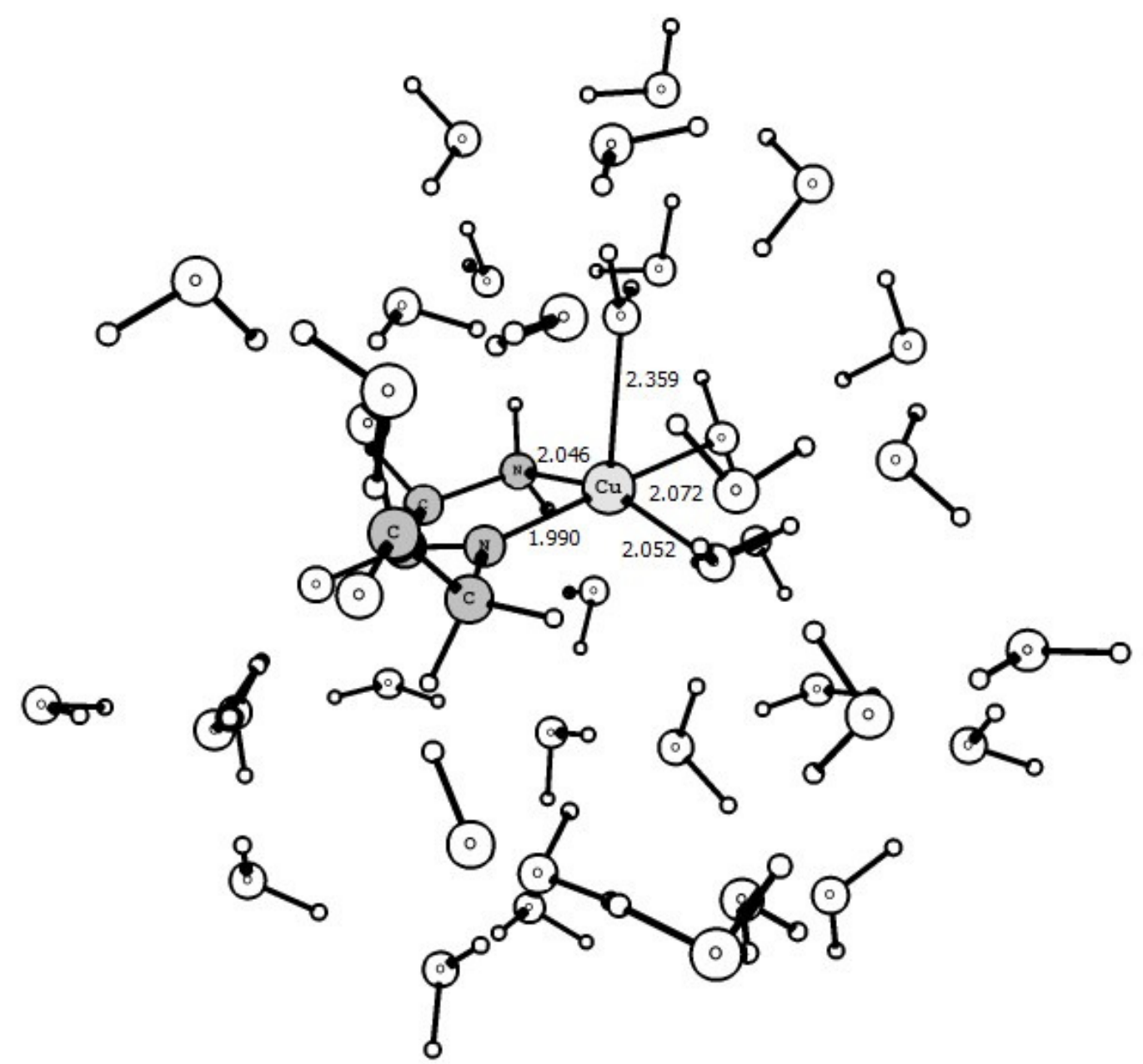

Figura 54. Geometria otimizada do cluster $\left[\mathrm{Cu}\left(\mathrm{H}_{-1} \mathrm{GlyGly}\right)\left(\mathrm{H}_{2} \mathrm{O}\right)_{36}\right]$ (RI-PBE/def2SVP/COSMO)

\section{- $\quad$ Cluster $\left[\mathrm{Cu}\left(\mathrm{H}_{-1} \mathrm{GlyGly}\right)(\mathrm{OH})\left(\mathrm{H}_{2} \mathrm{O}\right)_{35}\right]^{-}$}

$\mathrm{O}$ complexo $\left[\mathrm{Cu}\left(\mathrm{H}_{-1} \mathrm{GlyGly}\right)\left(\mathrm{H}_{2} \mathrm{O}\right)_{4}(\mathrm{OH})\right]^{-}$apresentou uma geometria quadrado distorcido com a molécula de hidroxila situada trans ao átomo de nitrogênio peptídico (ver Fig. 30). Com a presença de uma segunda camada de solvatação, o cluster $\left[\mathrm{Cu}\left(\mathrm{H}_{-1} \mathrm{GlyGly}\right)(\mathrm{OH})\left(\mathrm{H}_{2} \mathrm{O}\right)_{35}\right]^{-}$também apresentou uma geometria quadrado distorcido (Fig. 55), indicando que a presença de uma segunda camada de solvatação não afeta a geometria assumida para a espécie $\left[\mathrm{Cu}\left(\mathrm{H}_{-1} \mathrm{GlyGly}\right)\left(\mathrm{H}_{2} \mathrm{O}\right)_{4}(\mathrm{OH})\right]^{-}$. No cluster, a molécula de água mais próxima do centro metálico está localizada a uma distância de ligação $\mathrm{Cu}-\mathrm{O}$ de 2,508 Å (ver Fig. 55), não sendo considerada como uma molécula de água coordenada ao centro metálico. 


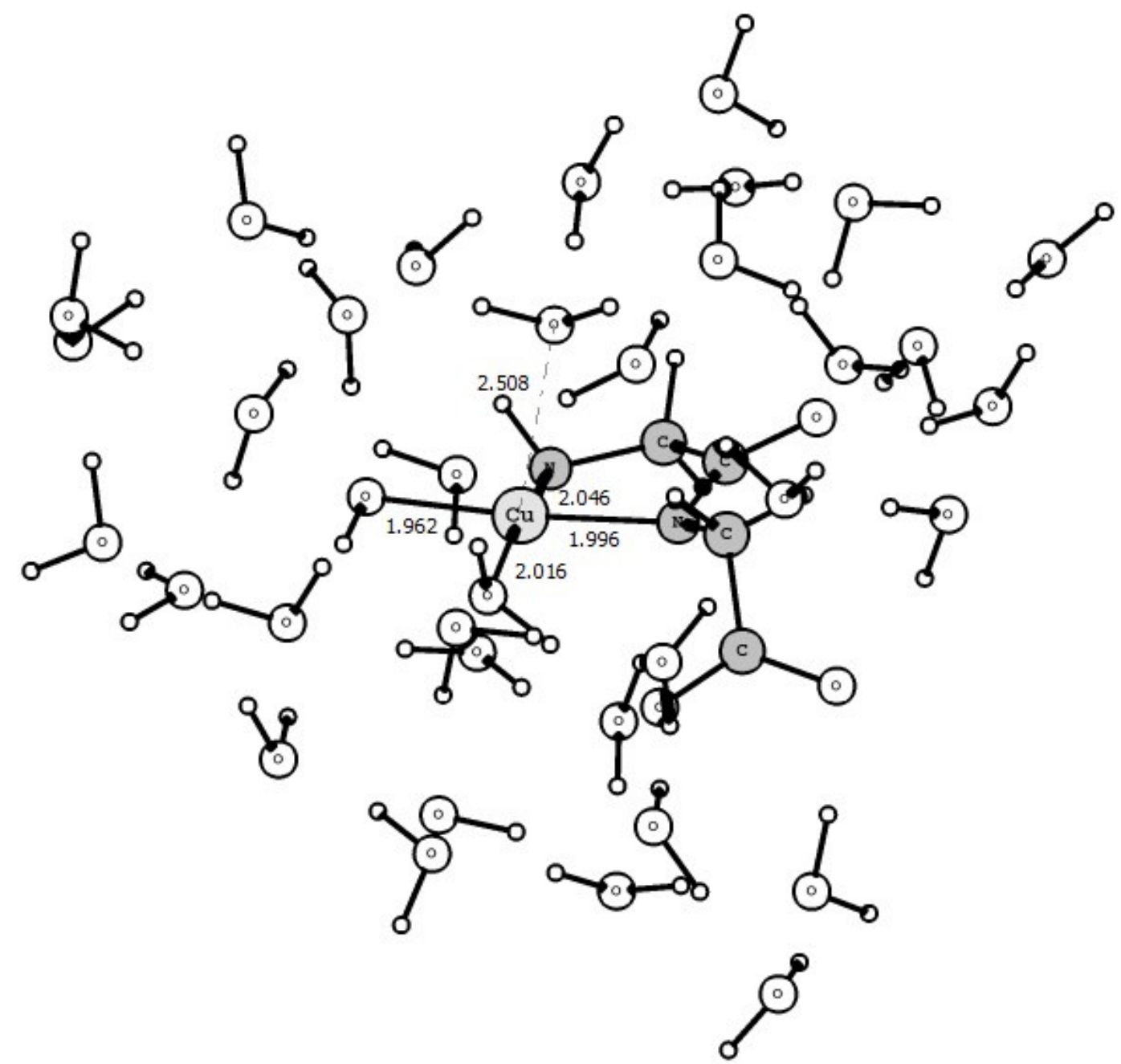

Figura 55. Geometria otimizada do cluster $\left[\mathrm{Cu}\left(\mathrm{H}_{-1} \mathrm{GlyGly}\right)(\mathrm{OH})\left(\mathrm{H}_{2} \mathrm{O}\right)_{35}\right]^{-}$(RI-PBE/def2SVP/COSMO)

As espécies $\left[\mathrm{Cu}(\mathrm{GlyGly})\left(\mathrm{H}_{2} \mathrm{O}\right)_{36}\right]^{+}$e $\quad\left[\mathrm{Cu}\left(\mathrm{H}_{-1}\right.\right.$ GlyGly $\left.)\left(\mathrm{H}_{2} \mathrm{O}\right)_{36}\right]$ apresentaram uma geometria pirâmide de base quadrada, enquanto que a espécie $\left[\mathrm{Cu}\left(\mathrm{H}_{-1} \mathrm{GlyGly}\right)(\mathrm{OH})\left(\mathrm{H}_{2} \mathrm{O}\right)_{35}\right]^{-}$mostrou uma geometria quadrado distorcido.

Após a otimização dos clusters formados entre o átomo de cobre e o ligante glicilglicina com a presença de 36 moléculas de água nas estruturas, foram geradas distribuição de densidade de spin dos complexos formados (B3LYP/def2TZVP/COSMO) (Fig. 56). Em todos os casos, a distribuição de densidade de spin encontra-se localizada em torno do cobre(II) e dos átomos que compõem a esfera de coordenação do centro metálico no plano equatorial. De acordo com a teoria do campo cristalino e a teoria do campo ligante, o complexo de $\mathrm{Cu}$ (II) em uma geometria octaédrica, tem uma configuração eletrônica do estado fundamental $t_{2 g}^{6} e_{g}^{3}$. Mas a degenerescência de $e_{g}^{3}$ é quebrada devido a distorção Jahn-Teller, na 
qual para os casos de complexos com geometrias quadrado piramidal ou quadrado planar resulta em uma configuração eletrônica do estado fundamental $t_{2 g}^{6} d_{z^{2}}^{2} d_{x^{2}-y^{2}}^{1}$. Nessa configuração, o elétron desemparelhado está localizado no orbital $d_{x^{2}-y^{2}}^{1}$ do $\mathrm{Cu}($ II) e nos orbitais sigma dos átomos coordenandos ao metal nas posições equatoriais, como observado nos clusters estudados acima: $\left[\mathrm{Cu}(\mathrm{GlyGly})\left(\mathrm{H}_{2} \mathrm{O}\right)_{36}\right]^{+},\left[\mathrm{Cu}\left(\mathrm{H}_{-1} \mathrm{GlyGly}\right)\left(\mathrm{H}_{2} \mathrm{O}\right)_{36}\right]$ e $\left[\mathrm{Cu}\left(\mathrm{H}_{-1} \text { GlyGly }\right)(\mathrm{OH})\left(\mathrm{H}_{2} \mathrm{O}\right)_{35}\right]^{-}$.
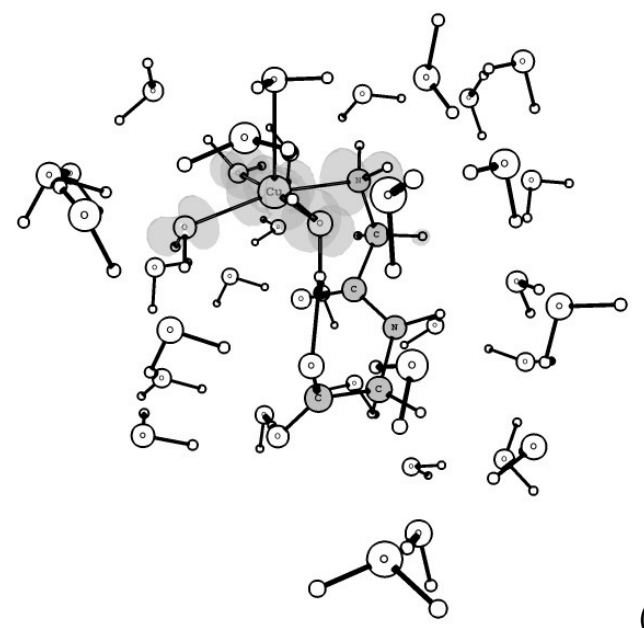

(a)

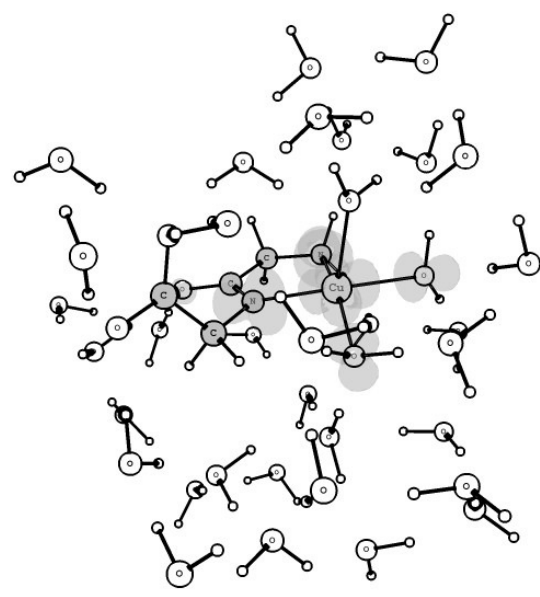

(b)

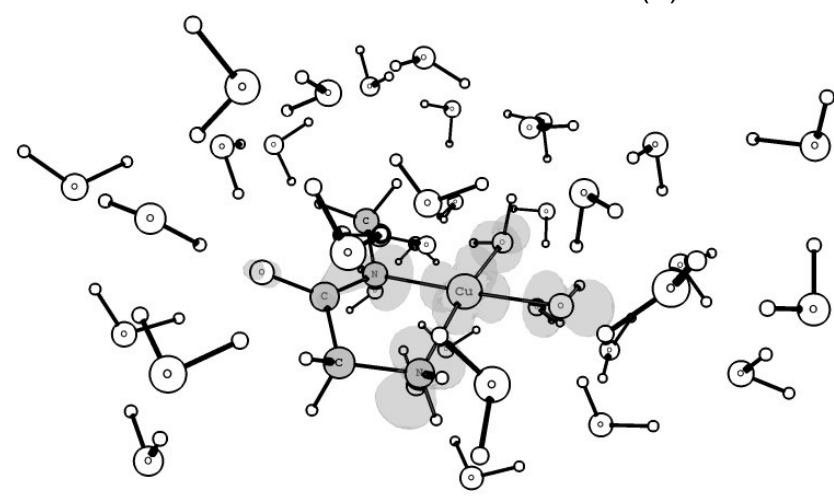

(c)

Figura 56. Densidade de spin obtida por simulação B3LYP/def2-TZVP/COSMO com isosuperfície 0,002 a.u. para os clusters: (a) $\left[\mathrm{Cu}(\mathrm{GlyGly})\left(\mathrm{H}_{2} \mathrm{O}\right)_{36}\right]^{+}, \quad$ (b) $[\mathrm{Cu}(\mathrm{H}$. ${ }_{1}$ GlyGly) $\left.\left(\mathrm{H}_{2} \mathrm{O}\right)_{36}\right]$ e (c) $\left[\mathrm{Cu}\left(\mathrm{H}_{-1} \text { GlyGly) }(\mathrm{OH})\left(\mathrm{H}_{2} \mathrm{O}\right)_{35}\right]^{-}\right.$

\section{- $\quad$ Cluster complexo $\left[\mathrm{Cu}(\mathrm{Met})\left(\mathrm{H}_{2} \mathrm{O}\right)_{36}\right]^{+}$}

A estrutura otimizada do complexo $\left[\mathrm{Cu}(\mathrm{Met})\left(\mathrm{H}_{2} \mathrm{O}\right)_{36}\right]^{+}$é mostrada na Figura 57. A metionina permaneceu comportando-se como ligante tridentado pelos átomos de oxigênio, nitrogênio e enxofre como observado no complexo contendo quatro moléculas de água em sua estrutura (ver Fig. 35). O complexo apresentando 36 moléculas de água apresentou uma geometria octaédrica, com o átomo de enxofre e uma molécula de água ocupando as posições axiais. 


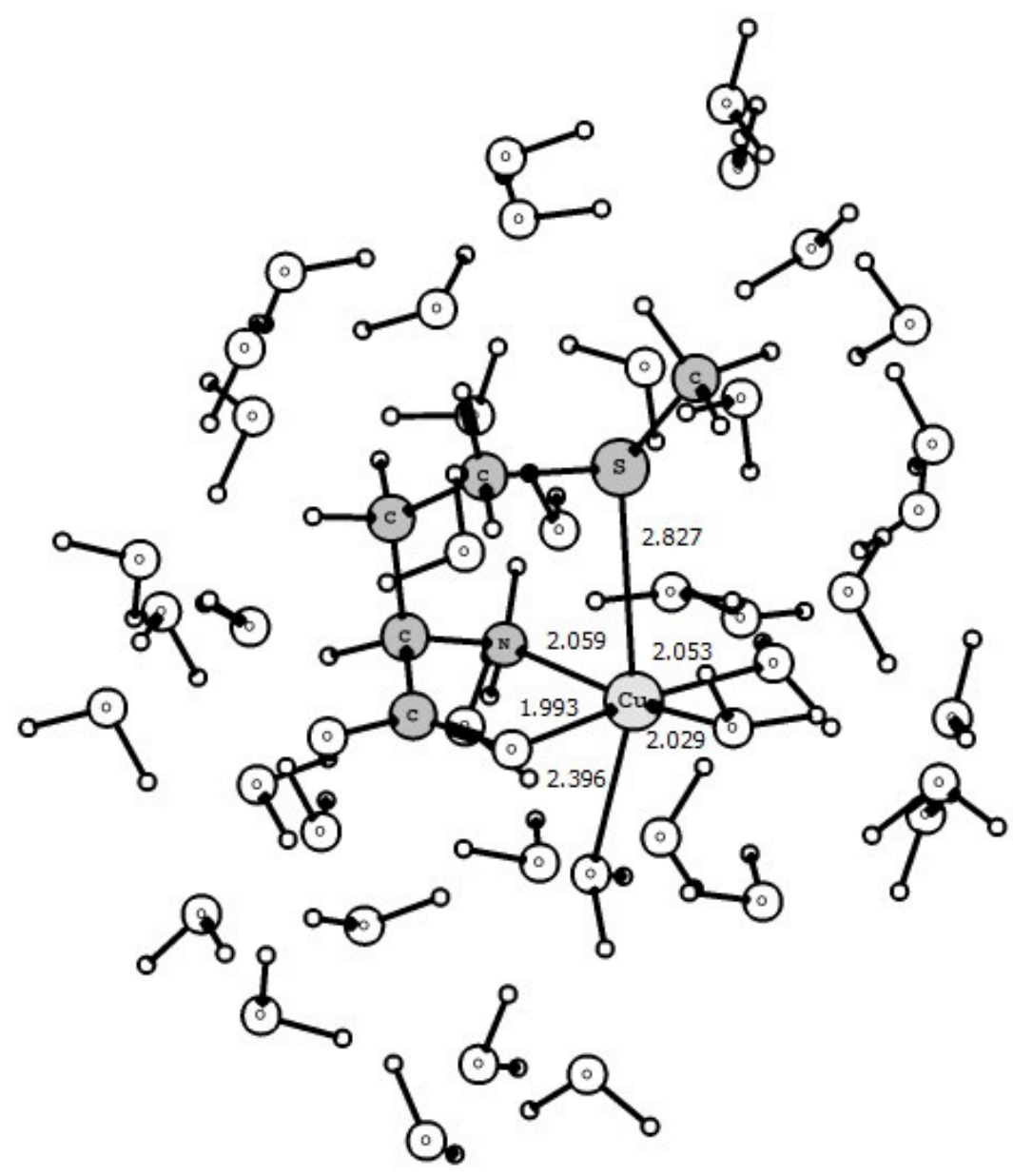

Figura 57. Geometria otimizada do cluster $\left[\mathrm{Cu}(\mathrm{Met})\left(\mathrm{H}_{2} \mathrm{O}\right)_{36}\right]^{+} \quad(\mathrm{RI}-\mathrm{PBE} /$ def2SVP/COSMO)

\section{- $\quad$ Cluster $\left[\mathrm{Cu}(\mathrm{Met})(\mathrm{OH})\left(\mathrm{H}_{2} \mathrm{O}\right)_{35}\right]$}

A estrutura otimizada do cluster $\left[\mathrm{Cu}(\mathrm{Met})(\mathrm{OH})\left(\mathrm{H}_{2} \mathrm{O}\right)_{35}\right]$ é mostrada na Figura 58. O cluster apresentou uma geometria pirâmide de base quadrada, com o átomo de oxigênio do grupo carboxílico coordenado ao metal na posição axial. A molécula de hidroxila coordenada ao metal, encontra-se no plano equatorial do complexo trans ao átomo de nitrogênio do grupo amino, com um comprimento de ligação $\mathrm{Cu}-\mathrm{O}$ de $1,970 \AA$ A. 


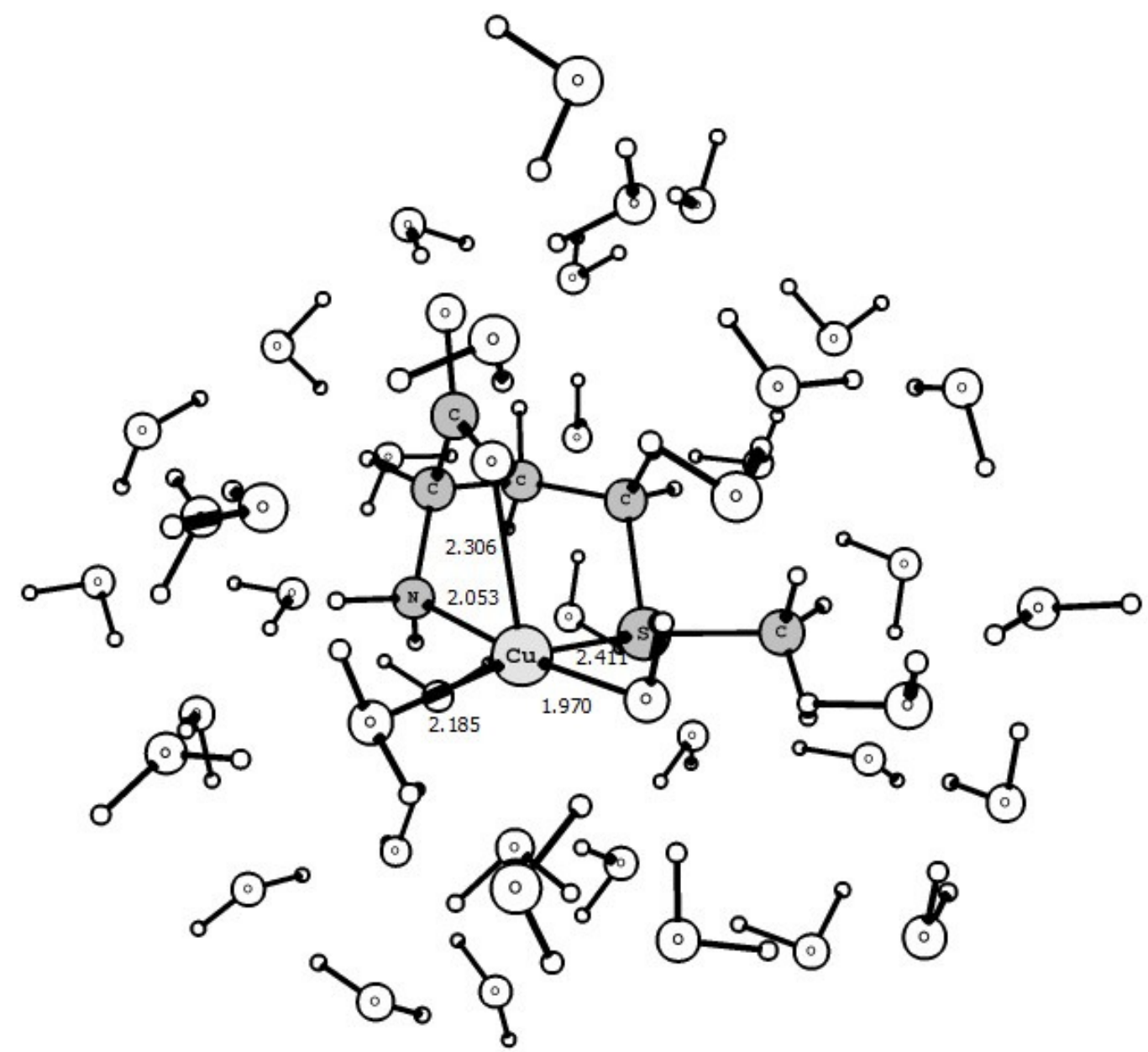

Figura 58. Geometria otimizada do cluster $\left[\mathrm{Cu}(\mathrm{Met})(\mathrm{OH})\left(\mathrm{H}_{2} \mathrm{O}\right)_{35}\right]$ (RI-PBE/def2SVP/COSMO)

\section{- $\quad$ Cluster $\left[\mathrm{Cu}(\mathrm{Met})(\mathrm{OH})_{2}\left(\mathrm{H}_{2} \mathrm{O}\right)_{34}\right]^{-}$}

A estrutura otimizada do cluster $\left[\mathrm{Cu}(\mathrm{Met})(\mathrm{OH})_{2}\left(\mathrm{H}_{2} \mathrm{O}\right)_{34}\right]^{-}$é mostrada na Figura 59. A presença de duas moléculas de hidroxila deslocou o átomo de enxofre da esfera de coordenação do centro metálico como observado no complexo $\left[\mathrm{Cu}(\mathrm{Met})(\mathrm{OH})_{2}\left(\mathrm{H}_{2} \mathrm{O}\right)_{2}\right]^{-}$. O cluster apresentou uma geometria pirâmide de base quadrada com uma molécula de água situada na posição axial, com um comprimento de ligação Cu-O de 2,342 Å. 


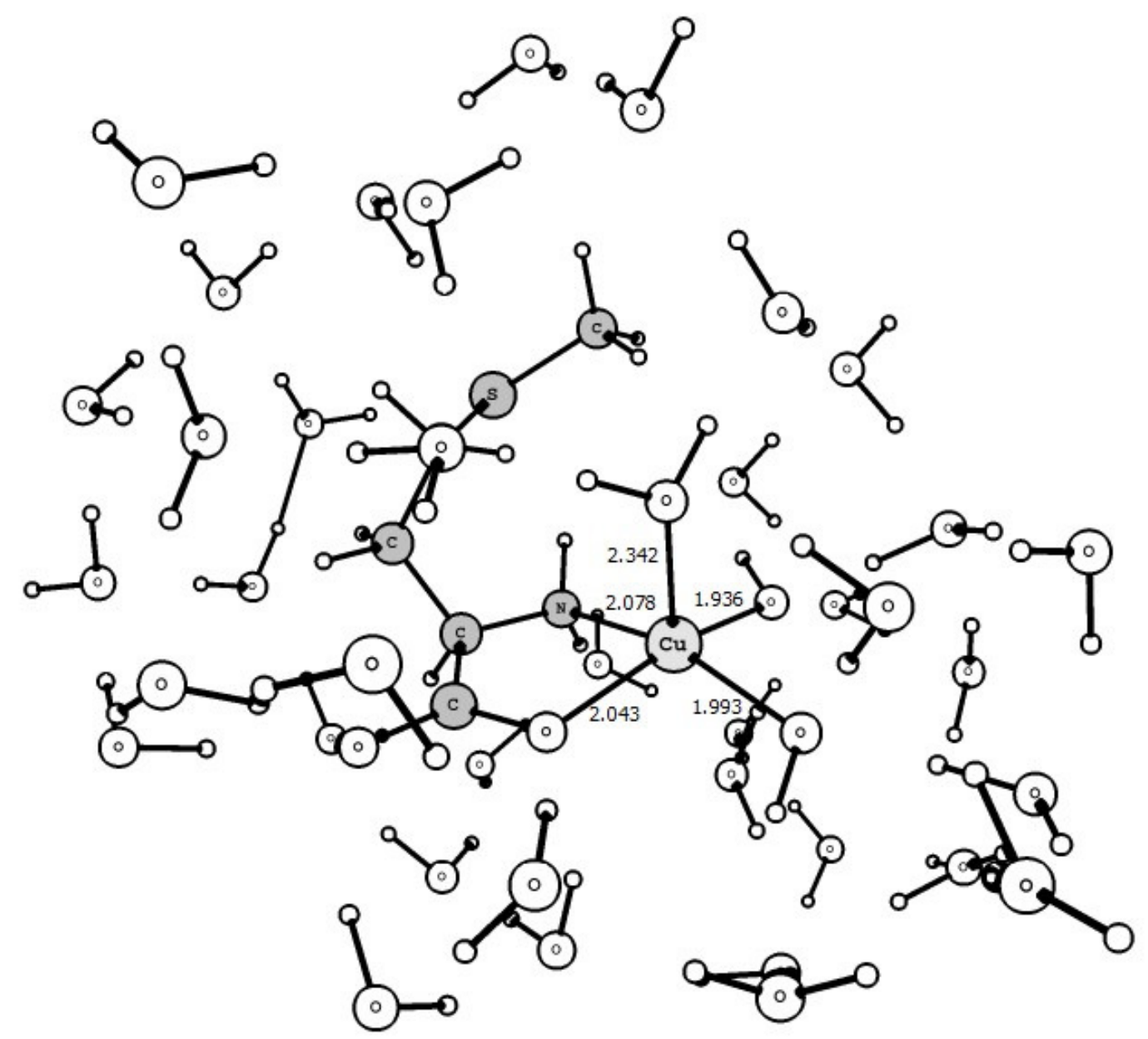

Figura 59. Geometria otimizada do cluster $\left[\mathrm{Cu}(\mathrm{Met})(\mathrm{OH})_{2}\left(\mathrm{H}_{2} \mathrm{O}\right)_{34}\right]^{-} \quad(\mathrm{RI}-\mathrm{PBE} /$ def2SVP/COSMO)

Os clusters formados entre o átomo de cobre e o ligante metionina, com a presença de uma segunda e completa camada de solvatação, apresentaram diferentes geometria. A espécie $\left[\mathrm{Cu}(\mathrm{Met})\left(\mathrm{H}_{2} \mathrm{O}\right)_{36}\right]^{+}$apresentou uma geometria octaédrica, com o átomo de enxofre e uma molécula de água coordenados ao metal nas posições axiais. A espécie $\left[\mathrm{Cu}(\mathrm{Met})(\mathrm{OH})\left(\mathrm{H}_{2} \mathrm{O}\right)_{35}\right]$ assumiu uma geometria pirâmide de base quadrada, com o átomo de enxofre em uma posição equatorial e o oxigênio do grupo carboxílico na posição axial (ver Fig. 58). Já no caso do complexo $\left[\mathrm{Cu}(\mathrm{Met})(\mathrm{OH})_{2}\left(\mathrm{H}_{2} \mathrm{O}\right)_{34}\right]^{-}$, o átomo de enxofre saiu da esfera de coordenação do metal e uma molécula de água ocupou a posição axial de uma geometria pirâmide de base quadrada.

Após otimização dos clusters foi realizado um cálculo B3LYP/def2TZVP/COSMO e foram geradas superfícies de densidade de spin (Fig. 60). O resultado mostra que a densidade de spin encontra-se localizada no plano 
equatorial, sugerindo uma configuração eletrônica para o estado fundamental $t_{2 g}^{6} d_{z^{2}}^{2} d_{x^{2}-y^{2}}^{1}$

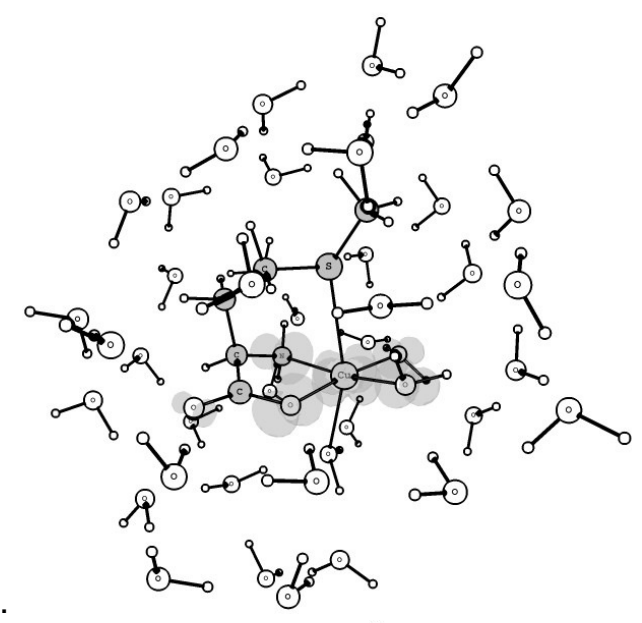

(a)
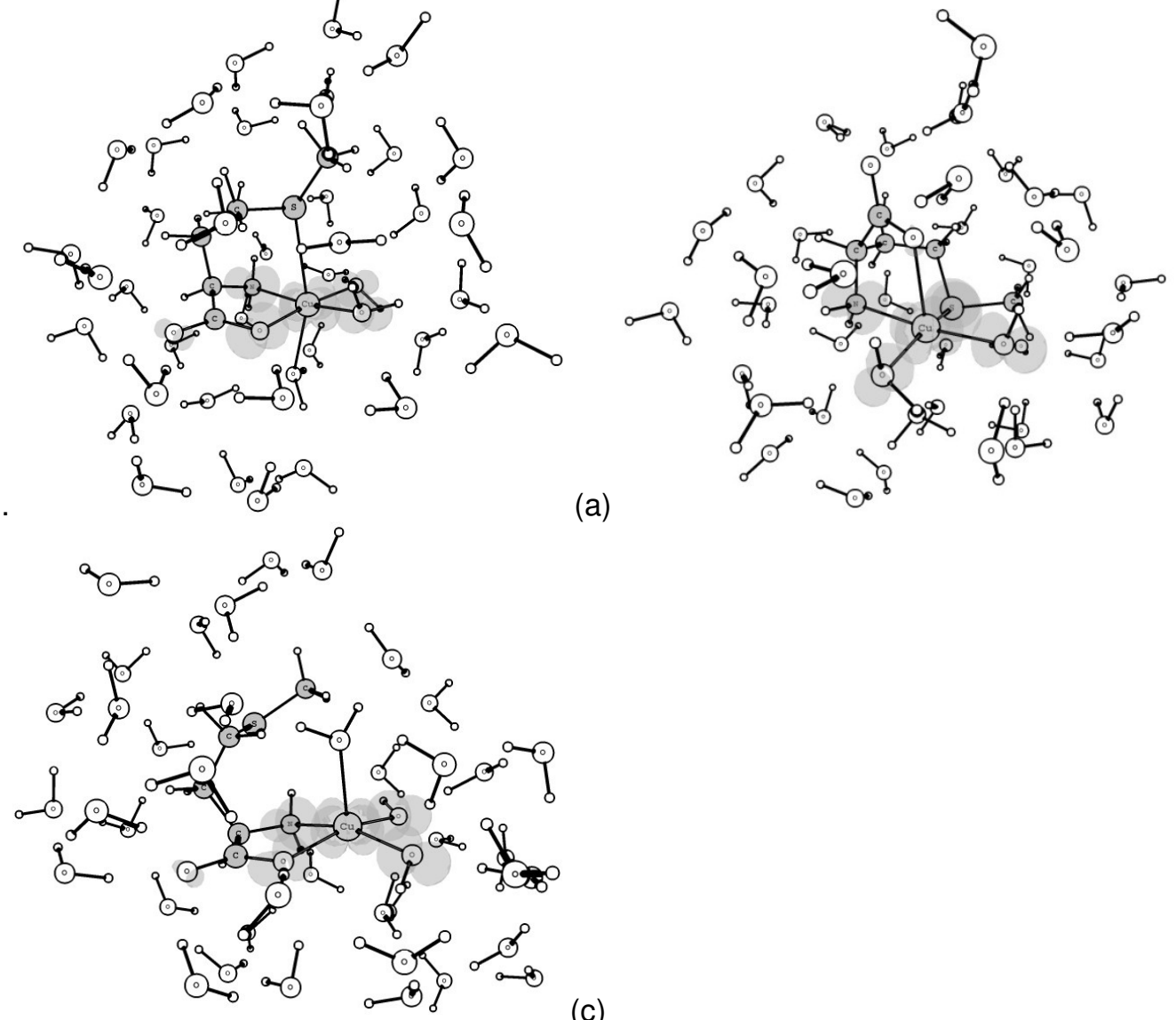

(b)

Figura 60. Densidade de spin obtida por simulação B3LYP/def2-TZVP com isosuperfície 0,002 a.u. para os clusters: (a) $\left[\mathrm{Cu}(\mathrm{Met})\left(\mathrm{H}_{2} \mathrm{O}\right)_{36}\right]^{+}$, (b) $\left[\mathrm{Cu}(\mathrm{Met})(\mathrm{OH})\left(\mathrm{H}_{2} \mathrm{O}\right)_{35}\right]$ e (c) $\left[\mathrm{Cu}(\mathrm{Met})(\mathrm{OH})_{2}\left(\mathrm{H}_{2} \mathrm{O}\right)_{34}\right]^{2}$

\section{- Cluster [Cu(HGlyGly)(Met)( $\left.\left.\mathrm{H}_{2} \mathrm{O}\right)_{36}\right]$}

A estrutura otimizada do cluster [Cu(HGlyGly)(Met) $\left.\left(\mathrm{H}_{2} \mathrm{O}\right)_{36}\right]$ é mostrada na Figura 61. Como no complexo [Cu(HGlyGly)(Met) $\left.\left(\mathrm{H}_{2} \mathrm{O}\right)_{2}\right]$, o cluster também assumiu uma geometria pirâmide de base quadrada com o átomo de enxofre ocupando a posição axial. Os comprimentos de ligação $\mathrm{Cu}-\mathrm{O}$ e $\mathrm{Cu}-\mathrm{N}$ do ligante metionina foram semelhantes aos encontrados no complexo contendo duas moléculas de água em sua estrutura, indicando que a presença de moléculas de água ao redor do complexo não interfere na geometria do complexo ternário formado. 


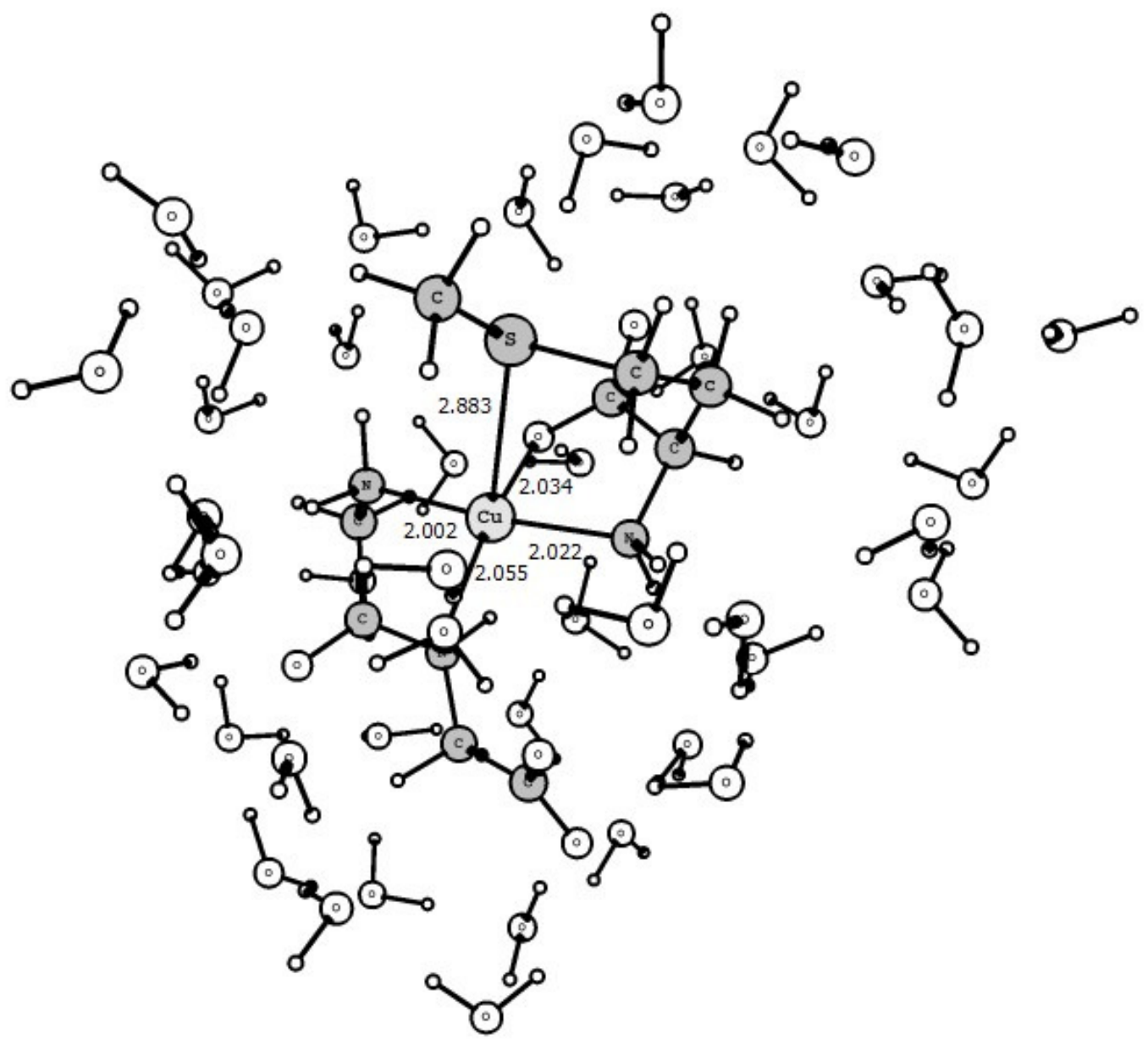

Figura 61. Geometria otimizada do cluster [Cu(HGlyGly)(Met) $\left.\left(\mathrm{H}_{2} \mathrm{O}\right)_{36}\right]$ (RI-PBE/def2SVP/COSMO)

\section{- Cluster [Cu(GlyGly)(Met)($\left.\left(\mathrm{H}_{2} \mathrm{O}\right)_{36}\right]^{-}$}

Como no complexo $\left[\mathrm{Cu}(\mathrm{GlyGly})(\mathrm{Met})\left(\mathrm{H}_{2} \mathrm{O}\right)_{2}\right]^{-}, \quad$ o cluster $\left[\mathrm{Cu}(\mathrm{GlyGly})(\mathrm{Met})\left(\mathrm{H}_{2} \mathrm{O}\right)_{36}\right]^{-}$também apresentou uma geometria pirâmide de base quadrada (Fig. 62). O comprimento de ligação $\mathrm{Cu}-\mathrm{N}_{\text {pept }}$ de 1,990 Å, indica uma maior doção de densidade eletrônica do nitrogênio peptídico ao íon $\mathrm{Cu}$ (II). A molécula de água coordenada ao metal foi localizada na posição axial com um comprimento de ligação Cu-O de 2,399 Å. 


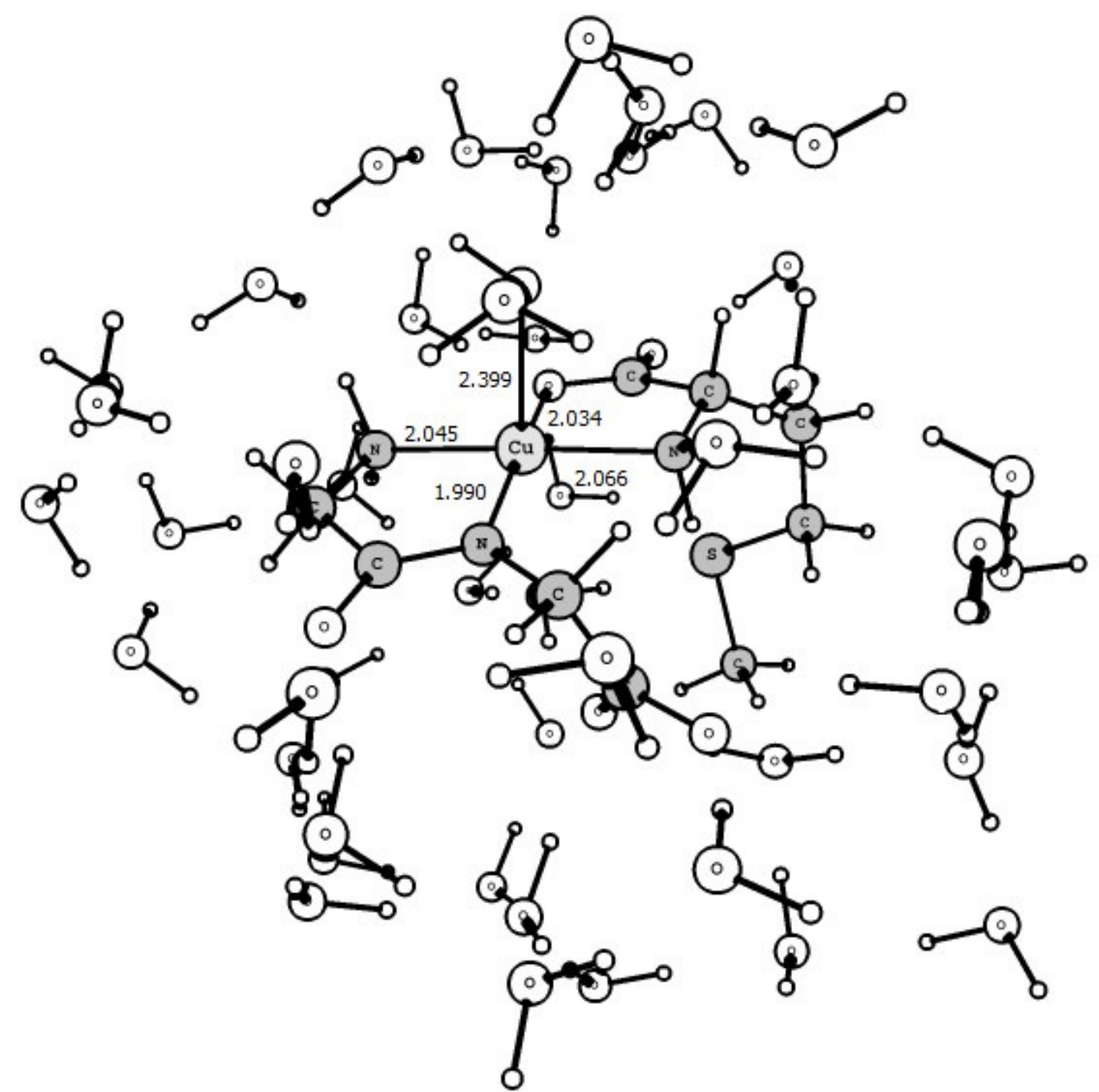

Figura 62. Geometria otimizada do cluster [Cu(GlyGly)(Met) $\left.\left(\mathrm{H}_{2} \mathrm{O}\right)_{36}\right]^{-}$(RI-PBE/def2SVP/COSMO)

\section{- Cluster $\left[\mathrm{Cu}(\mathrm{GlyGly})(\mathrm{Met})(\mathrm{OH})\left(\mathrm{H}_{2} \mathrm{O}\right)_{35}\right]^{2-}$}

A estrutura otimizada do cluster $\left[\mathrm{Cu}(\mathrm{GlyGly})(\mathrm{Met})(\mathrm{OH})\left(\mathrm{H}_{2} \mathrm{O}\right)_{35}\right]^{2-}$ é mostrada na Figura 63, e mostra uma geometria pirâmide de base quadrada com uma molécula de água ocupando a posição axial com o comprimento de ligação $\mathrm{Cu}-\mathrm{O}$ de 2,313 A. A molécula de hidroxila coordenada ao metal encontra-se na posição equatorial trans ao átomo de nitrogênio peptídico com um comprimento de ligação Cu-O de 1,997 Å. 


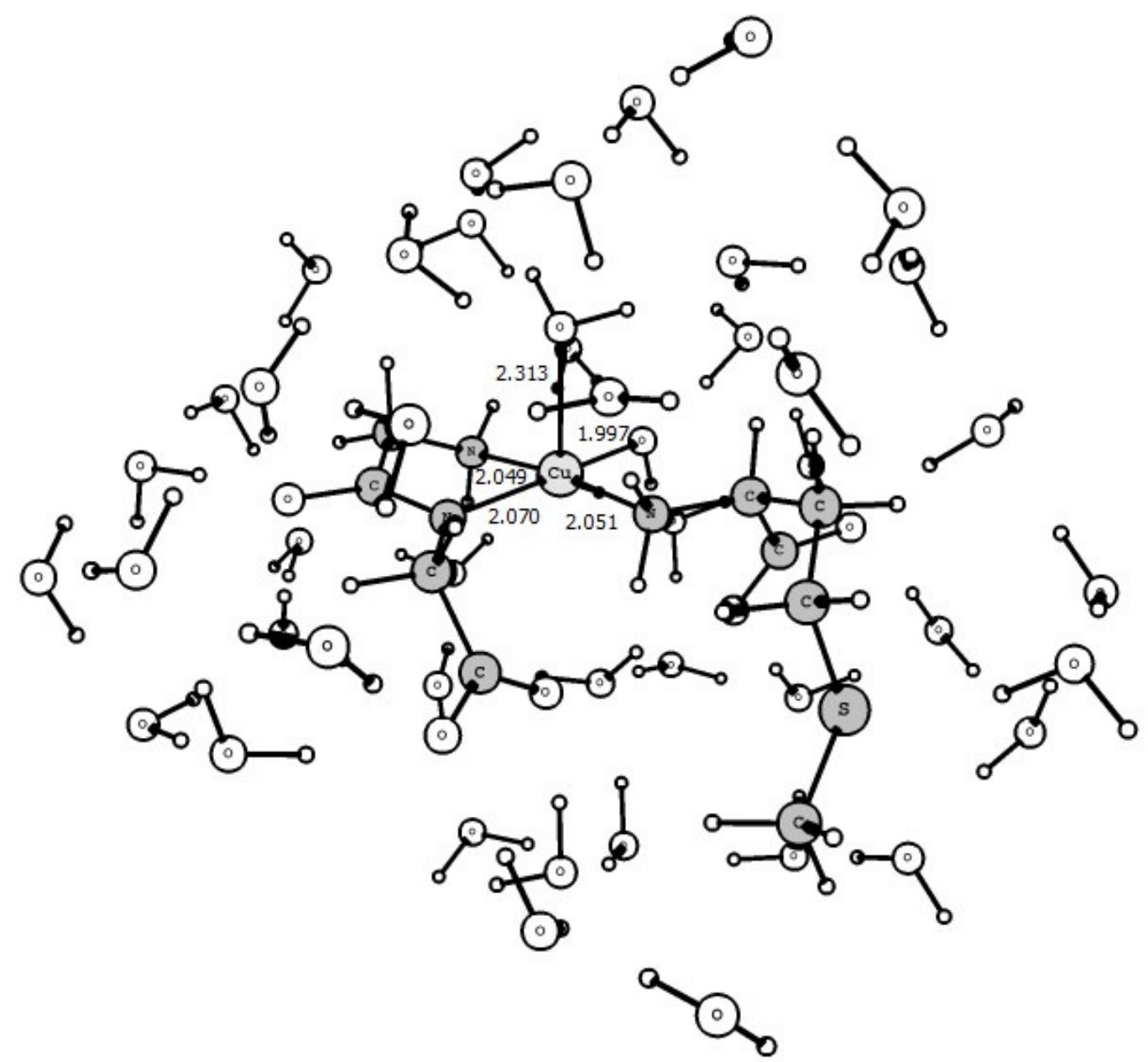

Figura 63. Geometria otimizada do cluster [Cu(GlyGly) $\left.(\mathrm{Met})(\mathrm{OH})\left(\mathrm{H}_{2} \mathrm{O}\right)_{35}\right]^{2-}(\mathrm{RI}-\mathrm{PBE} /$ def2SVP/COSMO)

Os três clusters $\left[\mathrm{Cu}(\mathrm{HGlyGly})(\mathrm{Met})\left(\mathrm{H}_{2} \mathrm{O}\right)_{36}\right], \quad[\mathrm{Cu}(\mathrm{H}$ ${ }_{1}$ GlyGly $\left.)(\mathrm{Met})\left(\mathrm{H}_{2} \mathrm{O}\right)_{36}\right]^{-}$e $\left[\mathrm{Cu}(\mathrm{GlyGly})(\mathrm{Met})(\mathrm{OH})\left(\mathrm{H}_{2} \mathrm{O}\right)_{35}\right]^{2-}$ apresentaram uma geometria pirâmide de base quadrada.

A Figura 64 mostra a distribuição de densidade de spin dos três clusters ternários e indica que o elétron desemparelhado está localizado no orbital $d_{x^{2}-y^{2}}$ do $\mathrm{Cu}(\mathrm{II})$ e nos orbitais sigma dos átomos coordenados ao centro metálico no plano equatorial. 

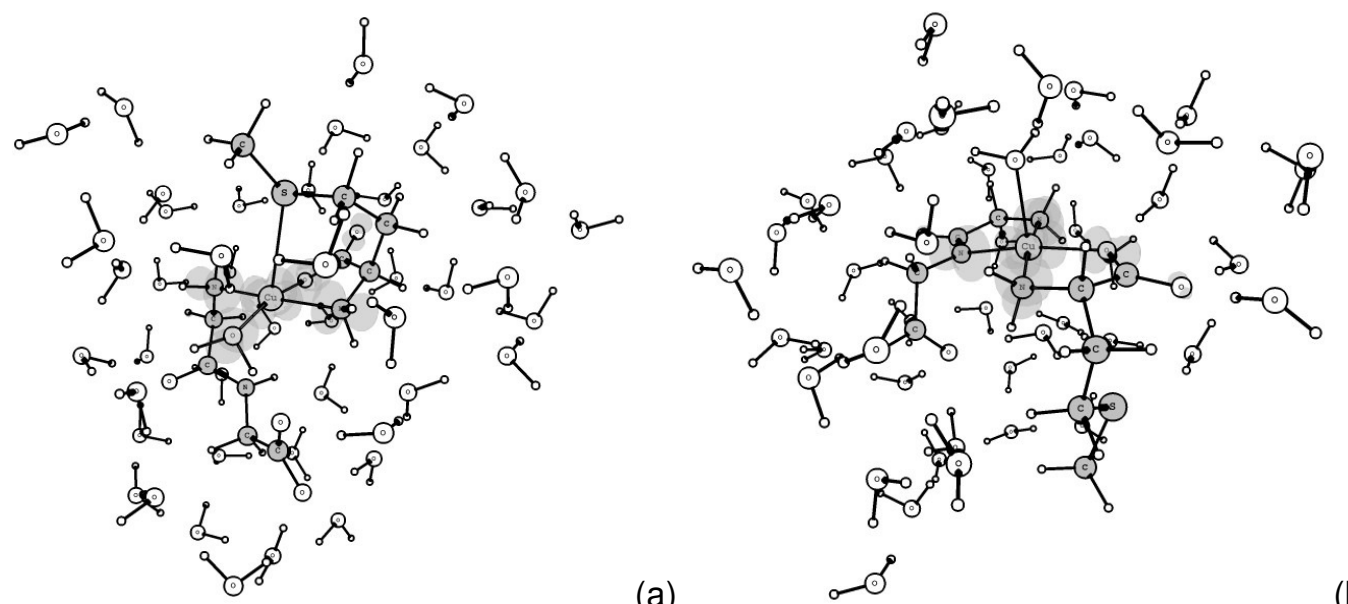

(a)

-

(b)

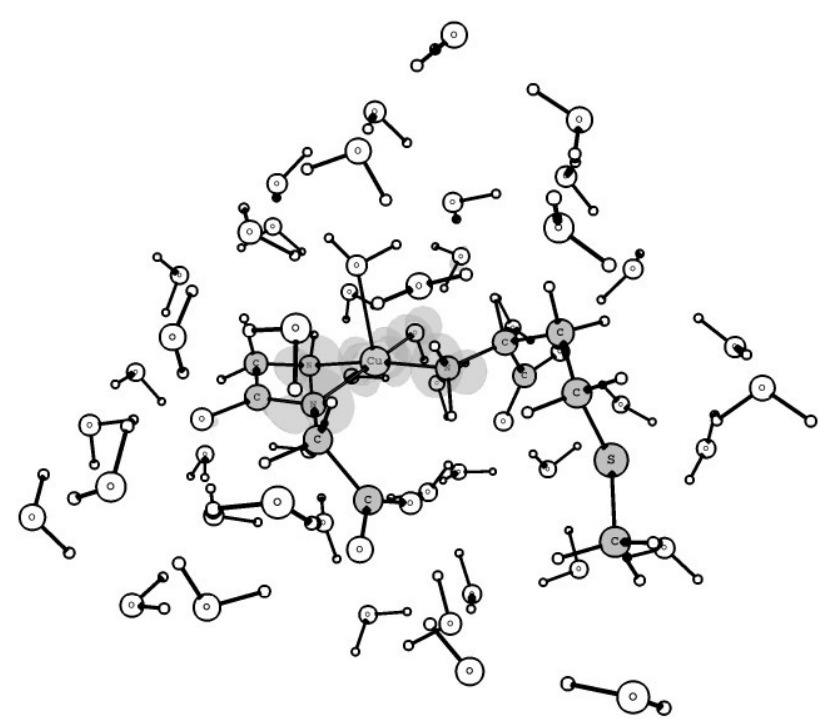

(c)

Figura 64. Densidade de spin obtida por simulação B3LYP/def2-TZVP com isosuperfície 0,002 a.u. para os clusters: (a) [Cu(HGlyGly)(Met) $\left(\mathrm{H}_{2} \mathrm{O}\right)_{36}$ ], (b) [Cu(GlyGly)(Met) $\left(\mathrm{H}_{2} \mathrm{O}\right)_{36}$ ] e (c) $\left[\mathrm{Cu}\left(\text { GlyGly) }(\mathrm{Met})(\mathrm{OH})\left(\mathrm{H}_{2} \mathrm{O}\right)_{35}\right]^{2-}\right.$ 


\section{6. \\ Conclusões}

A otimização do complexo $\left[\mathrm{Cu}(\mathrm{GlyGly})\left(\mathrm{H}_{2} \mathrm{O}\right)_{5}\right]^{+}$, que é formado na faixa de $\mathrm{pH}$ entre 2 - 4,3, confirmou que o dipeptídeo glicilglicina coordenada ao íon cobre(II) pelo átomo de nitrogênio do grupo amino e pelo átomo de oxigênio peptídico. Porém, após otimização desse complexo $\left(\left[\mathrm{Cu}(\mathrm{GlyGly})\left(\mathrm{H}_{2} \mathrm{O}\right)_{36}\right]^{+}\right)$com a inclusão da segunda camada de solvatação, foi verificado comportamento monodentado do ligante, com a coordenação ocorrendo através do nitrogênio do grupo amino sem a participação do oxigênio peptídico na esfera de coordenação do centro metálico. Portanto, cálculos teóricos levando em consideração uma segunda camada de solvatação são fundamentais para inferir tanto a geometria como os modos de coordenação dos ligantes nos diversos complexos formados em solução aquosa.

Em valores de $\mathrm{pH}$ maiores do que 4,23, ocorre à desprotonação do nitrogênio peptídico, dando origem ao complexo $\left[\mathrm{Cu}\left(\mathrm{H}_{-1} \mathrm{GlyGly}\right)\left(\mathrm{H}_{2} \mathrm{O}\right)_{5}\right]$. Nesse caso, o ligante coordena ao centro metálico através do átomo de nitrogênio do grupo amino e do átomo de nitrogênio desprotonado da ligação peptídica, sem a participação do átomo de oxigênio do grupo carboxílico na esfera de coordenação do metal. O resultado diverge dos descritos na literatura [58,151], em que se assume comportamento tridentado do ligante glicilglicina ao cobre nessa faixa de $\mathrm{pH}$. Esse comportamento foi verificado tanto no complexo contendo 5 moléculas de água quanto no complexo contendo 36 moléculas de água em sua estrutura. Para o complexo $\left[\mathrm{Cu}\left(\mathrm{H}_{-1} \mathrm{GlyGly}\right)\left(\mathrm{H}_{2} \mathrm{O}\right)_{4}(\mathrm{OH})\right]^{-}$, que é formado em valores de $\mathrm{pH}$ maiores do que 9,56, foi comprovado após cálculos teóricos que a hidrólise de uma molécula de água coordenada ao metal ocorre preferencialmente na molécula localizada na posição equatorial trans ao átomo de nitrogênio do grupo peptídico. $\mathrm{O}$ comportamento foi o mesmo para o cluster $\left[\mathrm{Cu}\left(\mathrm{H}_{-1} \mathrm{GlyGly}\right)(\mathrm{OH})\left(\mathrm{H}_{2} \mathrm{O}\right)_{35}\right]^{-}$que assumiu uma geometria quadrado distorcido. 
Para o sistema binário Cu:Met, na faixa de $\mathrm{pH}$ entre 2 - 6,73, foi verificado comportamento tridentado do ligante metionina frente ao cobre(II), formando o complexo $\left[\mathrm{Cu}(\mathrm{Met})\left(\mathrm{H}_{2} \mathrm{O}\right)_{4}\right]^{+}$em uma geometria octaédrica. O comportamento de ligante tridentado e a geometria preferencial também foi observado para o cluster $\left[\mathrm{Cu}(\mathrm{Met})\left(\mathrm{H}_{2} \mathrm{O}\right)_{36}\right]^{+}$. A partir de 6,73, começa a ocorrer às hidrólises nas moléculas de água coordenadas ao metal. A primeira hidrólise se dá, preferencialmente, em uma molécula de água situada trans ao átomo de nitrogênio do grupo amino formando o complexo $\left[\mathrm{Cu}(\mathrm{Met})\left(\mathrm{H}_{2} \mathrm{O}\right)_{3}(\mathrm{OH})\right]$. Esse complexo assumiu uma geometria bipirâmide trigonal com o átomo de enxofre ocupando uma posição equatorial. Já o cluster $\left[\mathrm{Cu}(\mathrm{Met})(\mathrm{OH})\left(\mathrm{H}_{2} \mathrm{O}\right)_{35}\right]$ mostrou uma preferência por uma geometria pirâmide de base quadrada. A partir de $\mathrm{pH}$ 9,67, o complexo formado $\left[\mathrm{Cu}(\mathrm{Met})(\mathrm{OH})_{2}\left(\mathrm{H}_{2} \mathrm{O}\right)_{2}\right]^{-}$, apresentou uma geometria quadrado distorcido sem a participação do átomo de enxofre na esfera de coordenação do metal. Porém, o cluster $\left[\mathrm{Cu}(\mathrm{Met})(\mathrm{OH})_{2}\left(\mathrm{H}_{2} \mathrm{O}\right)_{34}\right]^{-m}$ mostrou uma preferência por uma geometria pirâmide de base quadrada, com as duas moléculas de hidroxila situadas nas posições equatoriais e uma molécula de água na posição axial do complexo.

No sistema ternário formado entre o íon cobre (II) e os dois ligantes glicilglicina e metionina, verificou-se que na faixa de $\mathrm{pH}$ entre 2 - 4,17, o complexo $\left[\mathrm{Cu}(\mathrm{HGlyGly})(\mathrm{Met})\left(\mathrm{H}_{2} \mathrm{O}\right)\right]$ apresenta a glicilglicina atuando como ligante monodentado $\left(\mathrm{N}_{\text {amino }}\right)$ e a metionina como ligante tridentado $\left(\mathrm{N}_{\text {amino }} \mathrm{O}_{\text {carbox }} \mathrm{S}\right)$ em uma geometria pirâmide de base quadrada. O cluster $\left[\mathrm{Cu}(\mathrm{HGlyGly})(\mathrm{Met})\left(\mathrm{H}_{2} \mathrm{O}\right)_{36}\right]$ também apresentou a mesma esfera de coordenação e a mesma geometria assumida pelo complexo com duas moléculas de água em sua estrutura. A partir de $\mathrm{pH} 4,17$, ocorre a desprotonação do nitrogênio peptídico, dando origem ao complexo $\left[\mathrm{Cu}(\mathrm{GlyGly})(\mathrm{Met})\left(\mathrm{H}_{2} \mathrm{O}\right)_{2}\right]^{-}$. Nessa espécie, o átomo de enxofre que inicialmente encontrava-se coordenado ao metal saiu da esfera de coordenação e uma molécula de água ocupou a posição axial de uma geometria pirâmide de base quadrada. O cluster $\left[\mathrm{Cu}(\mathrm{GlyGly})(\mathrm{Met})\left(\mathrm{H}_{2} \mathrm{O}\right)_{36}\right]^{-}$mostrou o mesmo comportamento. A partir de $\mathrm{pH}$ 7,45, o complexo formado $[\mathrm{Cu}(\mathrm{GlyGly})(\mathrm{Met})(\mathrm{OH})]^{2-}$ apresentou uma molécula de hidroxila em uma posição equatorial trans ao átomo de nitrogênio do grupo peptídico, com a saída do átomo de oxigênio do grupo carboxílico do ligante metionina da esfera de coordenação do metal. O complexo assumiu uma geometria quadrado distorcido. O complexo com uma segunda camada de solvatação $\left[\mathrm{Cu}(\mathrm{GlyGly})(\mathrm{Met})(\mathrm{OH})\left(\mathrm{H}_{2} \mathrm{O}\right)_{35}\right]^{2-}$, 
mostrou uma preferência por uma geometria pirâmide de base quadrada com os modos de coordenação semelhantes ao complexo apresentando duas moléculas de água em sua estrutura.

A distribuição de densidade de spin mostrou que os complexos estudados, tanto com algumas moléculas de água quanto com a presença de uma segunda camada de solvatação (36 moléculas de água), o elétron desemparelhado está localizado no orbital $3 d_{x^{2}-y^{2}}$ do $\mathrm{Cu}(\mathrm{II})$ e nos orbitais sigma dos átomos coordenados ao metal nas posições equatoriais, sugerindo uma configuração eletrônica do estado fundamental $t_{2 g}^{6} d_{z^{2}}^{2} d_{x^{2}-y^{2}}^{1}$. Porém para o complexo $\left[\mathrm{Cu}(\mathrm{Met})(\mathrm{OH})\left(\mathrm{H}_{2} \mathrm{O}\right)_{3}\right]$, a distribuição de densidade de spin está localizada no orbital $3 d_{z^{2}}$ do $\mathrm{Cu}(\mathrm{II})$ e nos orbitais sigma dos átomos coordenados ao metal nas posições equatoriais e axiais de uma geometria bipirâmide trigonal. Nesse caso, os resultados sugeriram uma configuração eletrônica para o estado fundamental $t_{2 g}^{6} e_{g}^{3}\left(d_{x^{2}-y^{2}}^{2} d_{\mathrm{z}^{2}}^{1}\right)$

Foram determinadas as propriedades termodinâmicas dos complexos e das espécies envolvidas nas reações de desprotonação dos complexos presentes nos sistemas binários e ternário. Todas as espécies mostraram uma maior estabilidade em fase aquosa do que em fase gasosa e as espécies carregadas mostraram um aumento significativo na estabilidade nesse processo.

No presente trabalho, identificamos as possíveis espécies e os modos de coordenação do ligante glicilglicina ao íon $\mathrm{Cu}(\mathrm{II})$ em solução aquosa. Outros dipeptídeos que não possuam grupos coordenantes na cadeia lateral, possivelmente, comportam-se de maneira semelhante à glicilglicina na coordenação ao cobre(II) em solução aquosa.

Foi verificado que os complexos de cobre podem apresentar diferentes geometrias em solução aquosa. Isso se deve a pequena diferença de energia entre as possíveis estruturas que os complexos podem assumir.

A inclusão de uma segunda camada de solvatação foi fundamental para o estabelecimento dos corretos modos de coordenação dos ligantes e as geometrias dos complexos de cobre formados. Observou-se uma preferência por uma geometria pirâmide de base quadrada $\left(\left[\mathrm{Cu}(\mathrm{GlyGly})\left(\mathrm{H}_{2} \mathrm{O}\right)_{36}\right]^{+}, \quad\left[\mathrm{Cu}\left(\mathrm{H}_{-}\right.\right.\right.$ ${ }_{1}$ GlyGly $\left.)\left(\mathrm{H}_{2} \mathrm{O}\right)_{36}\right], \quad\left[\mathrm{Cu}(\mathrm{Met})(\mathrm{OH})\left(\mathrm{H}_{2} \mathrm{O}\right)_{36}\right], \quad\left[\mathrm{Cu}(\mathrm{Met})(\mathrm{OH})_{2}\left(\mathrm{H}_{2} \mathrm{O}\right)_{36}\right]^{-}$, $\left[\mathrm{Cu}(\mathrm{HGlyGly})(\mathrm{Met})\left(\mathrm{H}_{2} \mathrm{O}\right)_{36}\right], \quad\left[\mathrm{Cu}(\mathrm{GlyGly})(\mathrm{Met})\left(\mathrm{H}_{2} \mathrm{O}\right)_{36}\right]^{-} \quad \mathrm{e}$ 
$\left.\left[\mathrm{Cu}(\mathrm{GlyGly})(\mathrm{Met})(\mathrm{OH})\left(\mathrm{H}_{2} \mathrm{O}\right)_{35}\right]^{2-}\right)$ e em menor preferência as geometrias octaédrica $\left(\left[\mathrm{Cu}(\mathrm{Met})\left(\mathrm{H}_{2} \mathrm{O}\right)_{36}\right]^{+}\right)$e quadrado distorcido $\left(\left[\mathrm{Cu}(\mathrm{GlyGly})(\mathrm{OH})\left(\mathrm{H}_{2} \mathrm{O}\right)_{35}\right]^{-}\right.$ ) .

Nas desordens em que o estresse oxidativo é característico, o pH do meio é levemente acidificado. $\mathrm{O}$ cluster $\left[\mathrm{Cu}\left(\mathrm{H}_{-1} \mathrm{GlyGly}\right)(\mathrm{Met})\left(\mathrm{H}_{2} \mathrm{O}\right)_{36}\right]^{-}$, que é a espécie que predomina em $\mathrm{pH}$ em torno de 7, apresenta o átomo de enxofre livre em solução aquosa, podendo atuar como agente antioxidante em sistemas sob condições de estresse oxidativo. 


\section{7.}

\section{Referências Bibliográficas}

1. FRAÚSTO DA SILVA, J.J.R.; ARMANDO DA SILVA, J. Química Inorgânica do Cérebro - os Elementos Químicos e o Sistema Nervoso Central. Gradiva, Lisboa, 2008.

2. FRIEDEN, E. Ceruloplasmin, a link between copper and iron metabolism. Nutrition Reviews, v. 28, p. 87-91, 1970.

3. STANLEY, B.P.; PRUSINER, M.D. Neurodegenerative Diseases and Prions. New England Journal of Medicine, v. 344, p. 1516-1526, 2001.

4. GAGGELli, E. et al. Copper homeostasis and neurodegenerative disorders (Alzheimer's, prion and Parkinson's diseases and amyotrophic lateral sclerosis. Chemical Review, v. 106, p. 1995-2044, 2006.

5. SOLOMON E.I. et al. Electronic structures of metal sites in proteins and models: contributions to function in blue copper proteins. Chemical. Review, v. 104, p. 419-458, 2004.

6. ABOLA, E.E. et al. Eds. Protein Data Bank. Crystallographic DatabasesInformation Content, Software Systems and Scientific Applications. Data Commission of the International Union of Crystallography: Bonn, Germany, 1987.

7. ADMAN, E.T. Copper protein structures. Advances in Protein Chemistry. v. 42, p. 145-197, 1991.

8. PUFAHL, R.A. et al. Metal ion chaperone function of the soluble $\mathbf{C u}(\mathrm{I})$ receptor Atx1. Science, v. 278, p. 853-856, 1997.

9. CULOTTA, V.C. et al. The copper chaperone for superoxide dismutase. Journal of Biological Chemistry, v. 272, p. 23469-23472, 1997. 
10. HAZES, B. et al. Crystal structure of deoxygenated Limulus polyphemus subunit II hemocyanin at 2.18 A resolution: clues for a mechanism for allosteric regulation. Protein Science, v. 2, p. 597-619, 1993.

11. KATZ, A.K. et al. Copper-binding motifs: structural and theoretical aspects. Helvetica Chimica Acta, v. 86, n. 5, p. 1320-1338, 2003.

12. Halcrow, M.A. Interpreting and controlling the structures of sixcoordinate copper(II) centres - When is a compression really a compression? Dalton Transactions, v. 23, p. 4375-4384, 2003.

13. SABOLOVIC, J.; LIEDL, K.R. Why are copper(II) amino acid complexes not planar in their crystal structures? An ab initio and molecular mechanics study. Inorganic Chemistry, v. 38, n. 12, p. 2764-2774, 1999.

14. SABOLOVIC, J. et al. Modeling anhydrous and aqua copper(II) amino acid complexes: A new molecular mechanics force field parametrization based on quantum chemical studies and experimental crystal data. Inorganic Chemistry, v. 42, p. 2268-2279, 2003.

15. DEETH, R.J.; HEARNSHAW, L.J.A. Molecular modelling of jahn-teller distortions in $\mathrm{Cu}(\mathrm{II}) \mathrm{N}_{6}$ complexes: elongations, compressions and the pathways in between. Dalton Transactions, v. 8, p. 1092-1100, 2006.

16. CHAURIN, V.; CONSTABle, E.C.; HOUSECROFT, C.E. What is the coordination number of copper(II) in metallosupramolecular chemistry? New Journal Chemistry, v. 30, p. 1740-1744, 2006.

17. WEISS, R. et al. Crystal structure and thermochemical reactivity of an unusual copper complex that contains copper in four different coordination geometries. Dalton Transanctions, v. 15, p. 1831-1835, 2006.

18. PERSSON, I. et al. Structure of jahn-teller distorted solvated copper(II) ions in solution, and in solids with apparently regular octahedral coordination geometry. Journal of the Chemical Society, Dalton Transactions, p. 1256-1265, 2002. 
19. MAGINI, M. Coordination of copper(II). Evidence of the jahn-teller effect in aqueous perchlorate solutions. Inorganic Chemistry, v. 21. n. 4, p. 1535-1538, 1982

20. SHEALS, J.; PERSSON, P.; HEDMAN, B. IR and EXAFS spectroscopic studies of glyphosate protonationand copper(II) complexes of glyphosate in aqueous solution. Inorganic Chemistry, v. 40, n. 17, p. 4302-4309, 2001.

21. TRAN, M.L.; GAHAN, L.R.; GENTLE, I.R. Structural studies of copper(II)-amine terminated dendrimer complexes by EXAFS. Journal of Physical Chemistry B, v. 108, p. 2030-20136, 2004.

22. BENFATTO, M. et al. Evidence of distorted fivefold coordination of the $\mathrm{Cu}^{2+}$ aqua ion from an $\mathrm{X}$-ray absorption spectroscopy quantitative analysis. Physical Review B, v. 56, p. 174205.

23. FRANK, P. et al. The solution structure of $[\mathrm{Cu}(\mathrm{aq})]^{2+}$ and its implications for rack-induced bonding in blue copper protein active sites. Inorganic Chemistry, v. 44, n. 6, p. 1922-1933, 2005.

24. CHABOY, J. et al. The hydration of $\mathrm{Cu}^{2+}$ : Can the jahn-teller effect be detected in liquid solution? Journal of Chemical Physics, v. 124, n. 6, p. 64509-64517, 2006.

25. BRYANTSEV, V.S. et al. Hydration of copper(II): New insights from density functional theory and the COSMO solvation model. Journal of Physical Chemistry A, v. 112, p. 9104-9112, 2008.

26. POWELL, D.H. et al. First solvation shell of the $\mathbf{C u}(\mathrm{II})$ aqua ion: evidence for fivefold coordination. Science, v. 291, n. 5505, p. 856-859, 2001.

27. AMIRA, S.; SPANGBERG, D.; HERMASSON, K. Distorted five-fold coordination of $\mathrm{Cu}^{2+}(\mathrm{aq})$ from a car-parrinello molecular dynamics simulation. Physical Chemistry Chemical Physics, v. 5, p. 2874-2880, 2005. 
28. BLUMBERGER, J. et. al. Electronic structure and solvation of copper and silver ions: A theoretical picture of a model aqueous redox reaction. Journal of the American Chemical Society, v. 126, p. 3928-3938, 2004.

29. SCHWENK, C.F.; RODE, B.M. Influence of heteroligands on structural and dynamical properties of hydrated $\mathrm{Cu}^{2+}: \mathrm{QM} / \mathrm{MM} \mathrm{MD}$ simulations. Physical Chemistry Chemical Physics, v. 5, n. 16, p. 3418-3427, 2003.

30. SCHWENK, C.F.; RODE, B.M. New Insights into the jahn-teller effect through ab initio quantum-mechanical/molecular-mechanical molecular dynamics simulations of $\mathrm{Cu}^{\text {II }}$ in water. Chemical Physics and Physical Chemistry, v. 4, n. 9, p. 931-943, 2003.

31. SCHWENK, C.F.; RODE, B.M. Extended ab initio quantum mechanical/molecular mechanical molecular dynamics simulations of hydrated $\mathbf{C u}^{2+}$. Journal of Chemical Physics, v. 119, p. 9523-9531, 2003.

32. PASQUARELLO, A. et al. First solvation shell of the $\mathrm{Cu}$ (II) aqua ion: evidence for fivefold coordination. Science, v. 291, p. 856-859, 2001.

33. CURTISS, L.; HALLEY, J.W.; WANG, X.R. Jahn-teller effect in liquids: general principles and a molecular dynamics simulation of the cupric ion in water. Physical Review Letters, v. 69, n. 16, p. 2435-2438, 1992.

34. ALLEN, F.H. et al. The cambridge crystallographic data centre: computer-based search, retrieval, analysis and display of information. Acta Crystallographica Section B, v. 35, p. 2331-2339, 1979.

35. STACE, A.J. Metal ions in hydrogen bonded solvents: a gas phase perspective. Physical Chemistry Chemical Physics, v. 3, n. 11, p. 1935-1941, 2001 .

36. WALKER, N.R.; FIRTH, S.; STACE, A.J. $\left[\mathbf{C u}\left(\mathbf{H}_{2} \mathbf{O}\right)_{\mathbf{n}}\right]^{2+}$ clusters: the first evidence of aqueous copper(II) in the gas phase. Journal of the American Chemical Society, v. 119, p. 10239-10240, 1997. 
37. WALKER, N.R.; FIRTH. S.; STACE, A.J. Stable Cu(II) coordination complexes in the gas phase. Chemical Physics Letters, v. 292, p. 125-132, 1998.

38. BÈRCES, A. et al. Solvation of $\mathrm{Cu}^{2+}$ in water and amonia. Insight from static and dynamic density functional theory. Journal of Physical Chemistry A, v. 103, p. 9693-9701, 1999.

39. DUNCOMBE, B.J. et al. The solvation of $\mathbf{C u}^{2+}$ with gas-phase clusters of water and ammonia. Journal of Physical Chemistry, v. 111, n. 24, p. 5158$5165,2007$.

40. BECKE, A.D. Density-functional exchange-energy approximation with correct asymptotic behavior. Physical Review A, v. 38, p. 3098-3100, 1988.

41. LEE, C.T.; YANG, W.T.; PARR, R.G. Development of the colle-salvetti correlation-energy formula into a functional of the electron density. Physical Review. B, Condensed Matter, v. 37, n. 2, p. 785-789, 188.

42. PESCHKE, M.; BLADES, A.T.; KEBARLE, P. Binding energies for doubly-charged ions $\mathrm{M}^{2+}=\mathrm{Mg}^{2+}, \mathrm{Ca}^{2+}$ and $\mathrm{Zn}^{2+}$ with the ligands $\mathrm{L}=$ $\mathrm{H}_{2} \mathrm{O}$, acetone and $N$-methylacetamide in complexes $\mathrm{ML}_{\mathrm{n}}^{2+}$ for $\mathrm{n}=1$ to 7 from gas phase equilibria determinations and theoretical calculations. Journal of the American Chemical Society. v. 122, n. 42, p. 10440-10449, 2000 .

43. MARINO, T. et al. Structural and electronic characterization of the complexes obtained by interaction between bare and hydrated first row transition metal ions $\left(\mathrm{Mn}^{2+}, \mathrm{Fe}^{2+}, \mathrm{Co}^{2+}, \mathrm{Ni}^{2+}, \mathrm{Cu}^{2+}, \mathrm{Zn}^{2+}\right)$ and the glycine. Journal of Physical Chemistry B, v. 110, p. 24666-24673, 2006.

44. TUNELL, I.; LIM, C. Factors governing the metal coordination number in isolated group IA and IIA metal hydrates. Inorganic Chemistry, v. 45, n. 12, p. 4811-4819, 2006.

45. CARL, D.R.; MOISION, R.M.; ARMENTROUT, P.B. Binding energies for the inner hydration shells of $\mathrm{Ca}^{2+}$ : An experimental and theoretical 
investigation of $\mathrm{Ca}^{2+}\left(\mathrm{H}_{2} \mathrm{O}\right)_{x}$ complexes $(\mathrm{x}=5-9)$ Int. Journal of Mass Spectrometry. v. 265, p. 308-325, 2007.

46. HAY, P.J.; WADT, W.R. Ab initio effective core potentials for molecular calculations. Potentials for $\mathrm{K}$ to Au including the outermost core orbitals. Journal of Chemical Physics, v. 82, n. 1, p. 270-283, 1985.

47. Standard Reference Database 46, NIST Critically Selected Stability Constants of Metal Complexes: Version 8.0, May 2004, http://www.nist.gov/srd/nist46. htm.

48. POWELL, K.J. et al. Chemical speciation of environmentally significant metals with inorganic ligands Part 2: the $\mathrm{Cu}^{2+}-\mathrm{OH}^{-}, \mathrm{Cl}^{-}, \mathrm{CO}_{3}{ }^{2-}, \mathrm{SO}_{4}{ }^{2-}$, and $\mathrm{PO}_{4}{ }^{3-}$ systems (IUPAC Technical Report). Pure and Applied Chemistry, v. 79, n. 5, p. 895-950, 2007.

49. BLUMBERGER, J. $\mathbf{C u}(\mathbf{a q})+/ \mathbf{C u}(\mathbf{a q})^{2+}$ redox reaction exhibits strong nonlinear solvent response due to change in coordination number. Journal of the American Chemical Society, v. 130, n. 47, p. 16065-16068, 2008.

50. BLUMBERGER, J.; TAVERNELLI, I.; KLEIN, M.L. Diabatic free energy curves and coordination fluctuations for the aqueous $\mathrm{Ag}^{+} / \mathrm{Ag}^{2+}$ redox couple: A biased born-oppenheimer molecular dynamics investigation. Journal of Chemical Physics, v. 124, n. 6, p. 64507-64518.

51. O'BRIEN, J.T.; WILLIAMS, E.R. Hydration of gaseous copper dications probed by IR action spectroscopy. Journal of Physical Chemistry A, v. 112, n. 26, p. 5893-5901, 2008.

52. LI, J. et al. Calculation of redox potentials and pKa values of hydrated transition metal cations by a combined density functional and continuum dielectric theory. Inorganic Chemisty, v. 35, n. 16, p. 4694-4702, 1996.

53. MARTIN, R.L.; HAY, J.P.; PRATT, L.R. Hydrolysis of ferric ion in water and conformational equilibrium. Journal of Physical Chemistry A, v. 102, n. 20, p. 3565-3573, 1998. 
54. TSUSHIMA, S.; WAHLGREN, U.; GRENTHE, I. Quantum chemical calculations of reduction potentials of $\mathrm{AnO}_{2}^{(2+)} / \mathrm{AnO}_{2}{ }^{+}(\mathrm{An}=\mathrm{U}, \mathrm{Np}, \mathrm{Pu}$, Am) and $\mathrm{Fe}^{3+} / \mathrm{Fe}^{2+}$ couples. Journal of Physical Chemistry A, v. 110, p. 9175-9182, 2006.

55. DE ABREU, H.A.; GUIMARÃES, L.; DUARTE, H. A. DFT study of iron(III) hydrolysis in aqueous solution. Journal of Physical Chemistry A, v. 110, p. 7713-7718, 2006.

56. GUIMARÃES, L.; DE ABREU, H.A.; DUARTE, H.A. Fe(II) hydrolysis in aqueous solution: A DFT study. Chemical Physics, v. 333, n. 1, p. 10-17, 2007.

57. FREEMAN, H.C. Inorganic Biochemistry, Elsevier, New York, 1973.

58. SIGEL, H.; MARTIN, R.B. Coordinating properties of the amide bond. stability and structure of metal ion complexes of peptides and related ligands. Chemical Review, v. 82, p. 385-428, 1982.

59. KOZLOWSKI, $H$. et al. Specific structure-stability relations in metallopeptides. Coordination Chemistry Reviews, v. 184, p. 319-346, 1999.

60. WEDER, J.E. Copper complexes of non-steroidal anti-inflammatory drugs: an opportunity yet to be realized. Coordination Chemistry Reviews, v. 232, p. 95-126, 2002.

61. FACCHIN, G. et al. Structural characterization of a series of new $\mathrm{Cu}$ dipeptide complexes in solid state and in solution. Polyhedron, v. 25, p. 2597-2605, 2006.

62. FACCHIN, G. et al. Structural and spectroscopic characterization of two new $\mathbf{C u}($ II)-L-dipeptide complexes. Zeitschrift für Naturforschung. B, v. 55, p. 1157-1162, 2000.

63. FACCHIN, G. et al. Synthesis and characterization of three new $\mathrm{Cu}$ (II)dipeptide complexes. Journal of Inorganic Biochemistry, v. 89, p. 174-180, 2002. 
64. NASCIMENTO, O.R.; TABAK, M. On the interaction of $\mathrm{Cu}^{2+}$ with the heavy dipeptide Gly-Trp. Journal of Inorganic Biochemistry, v. 23, p. 1327, 1985.

65. NASCIMENTO, O.R. et al. Crystal structure and exchange pathways of the complex L-(trypthophyl-glycinato)copper(II). Inorganica Chimica Acta, v. 312, p. 133-138, 2001.

66. SUGIHARA, A. et al. The crystal structure of dipotassium bis(glycylglycinato)cuprate(II) hexahydrate, $\mathrm{K}_{2}\left[\mathrm{Cu}\left(\mathrm{NH}_{2} \mathrm{CH}_{2} \mathrm{CONCH} \mathrm{CHO}_{2}\right)_{2}\right] .6 \mathrm{H}_{2} \mathrm{O}$. Acta Crystallographica, v. B24, 203-211, 1968.

67. GLOWIAK, T.; PODGORSKA, I. Structure of tetraaqua-bis[ $\mu$ (glycylglycinato)-NOO']-dicopper(II) bis(diphenyl phosphate) dihydrate. Acta Crystallographica, v. C43, p. 53-57, 1987.

68. BLOUNT, J.F. et al. Crystallographic studies of metal peptide complexes. IV. (Glycyl-L-histidinato)copper(II) sesquihydrate. Acta Crystallographica, v. 22, p. 396-405, 1967.

69. FUSCH, G.; HILLGERIS, E. C.; LIPPERT, B. Interaction of the lysine side chain amino group with $\mathrm{CuII}$ in (glycyl-lysine) $\mathrm{Cu}$. Inorganica Chimica Acta, v. 217, n. 1-2, p. 33-38, 1994.

70. YAJIMA, T. et al. Attractive ligand-ligand interactions involving ternary copper(II) complexes with dipeptide and bidentate $\mathbf{N}$-donor ligand. Inorganica Chimica Acta, v. 339, p. 445-454, 2002.

71. GARCÍA-RASO, A. et al. Synthesis and structure of peptide-copper(II)isocytosine ternary complexes. Polyhedron, v. 21, p. 1197-1201, 2002.

72. PUSPITA, W.J.; ODANI, A.; YAMAUCHI, O. Copper(II)-dipeptide complexes containing an acid and a basic amino acid residue. Side chain effects on structures and stabilities. Journal of Inorganic Biochemistry, v. 73, p. 203-213, 1999. 
73. FACCHIN, G. et al. Cu(II) complexation with His-Gly and His-Ala. X-ray structure of $\left[\mathrm{Cu}(\mathrm{his}-\mathrm{gly})_{\mathbf{2}}\left(\mathrm{H}_{2} \mathbf{O}\right)_{2}\right] \cdot \mathbf{6} \mathrm{H}_{2} \mathrm{O}$. Inorganica Chimica Acta, v. 355, p. 408-413, 2003.

74. GARCÍA-RASO, A. et al. Reactivity of copper(II) peptide complexes with bioligands (benzimidazole and creatinine). Polyhedron, v. 22, p. 32553264, 2003.

75. FERREIRA, A.L.A.; MATSUBARA, L.S. Radicais livres: conceitos, doenças relacionadas, sistema de defesa e estresse oxidativo. Revista da Associação Médica Brasileira, v. 43, n. 1, p. 61-68, 1997.

76. HALLIWELL, B. Reactive oxygen species and the central nervous system. Journal of Neurochemistry, v. 59, n. 5, p. 1609-1623, 1992.

77. ALEXANDROVA, M.L.; BOCHEV, P.G. Oxidative stress during the chronic phase after stroke. Free Radical Biology \& Medicine, v. 39, n. 3, p. 297-316, 2005.

78. MORO, M.A. et al. Mitochondrial respiratory chain and free radical generation in stroke. Free Radical Biology and Medicine, v. 39, p. 12911304, 2005.

79. ZIMMERMANN, C. et al. Antioxidant status in acute stroke patients and patients at stroke risk. European Neurology, v. 51, n. 3, p. 157-161, 2004.

80. HOMI, H.M. et al. Changes in superoxide dismutase and catalase activities of rat brain regions during early global transient ischemia/reperfusion. Neuroscience Letters, v. 333, n. 1, p. 37-40, 2002.

81. KATI, E.; GROSSER, N.; SCHRÖDER, H. L-methionine reduces oxidant stress in endothelial cells: Role of heme oxygenase-1, ferritin, and nitric oxide. The AAPS Journal, v. 7, n. 1, p. E195-E200, 2005.

82. BAINES, A.D.; SHAIKH, N.; HO, P. Mechanisms of perfused kidney cytoprotection by alanine and glycine. American Journal of Physiology. v. 259, p. F80-F87, 1990. 
83. GARZA-QUINTERO, R. et al. Alanine protects rabbit proximal tubules against anoxic injury in vitro. American Journal of Physiology. v. 258, n. 4, p. F1075-F1083, 1990.

84. GROSSER, N. et al. Antioxidant action of L-alanine: heme oxygenase-1 and ferritin as possible mediators. Biochemical and Biophysical Research Communications. v. 314, p. 351-355, 2004.

85. ESTACION, M. et al. Blockade of maitotoxin-induced endothelial cell lysis by glycine and l-alanine. American Journal of Physiology - Cell Physiology, v. 284, n. 4, p. C1006-1020, 2003.

86. KROGER, H. et al. Protection from acetaminophen-induced liver damage by the synergistic action of low doses of the poly(ADP-ribose) polymerase-inhibitor nicotinamide and the antioxidant $\mathbf{N}$-acetylcysteine or the amino acid L-methionine. General Pharmacology, v. 28, p. 257-263, 1997.

87. PATRA, R.C.; SWARUP, D.; DWIVEDI, S.K. Antioxidant effects of $\boldsymbol{\alpha}$ tocopherol, ascorbic acid and l-methionine on lead induced oxidative stress to the liver, kidney and brain in rats. Toxicology, v. 162, n. 2, p. 81$88,2001$.

88. KOZLOWSKI, H.; BROWN, D.R.; VALEN, G. Metallochemistry of Neurodegeneration, Biological, Chemical and Genetic Aspects. RCS Publishing, UK, 2006.

89. SISODIA, S.S. et al. $\boldsymbol{\gamma}$-Secretase: never more enigmatic. Trends in Neurosciences, v. 24, n. 11, p. S2-S6, 2001.

90. BUSH, A.I. The metallobiology of Alzheimer's disease. Trends Neurosciences, v. 26, n. 4, p. 207-214, 2003.

91. SIEGEL, A.; SIEGEL, H.; SIEGEL, R.K.O. Metal ions in life sciences: Neurodegeneration Disease and Metal Ions. John Wiley \& Sons, England, 2006. 
92. GLENNER, G.G.; WONG, C.W. Alzheimer's disease: Initial report of the purification and characterization of a novel cerebrovascular amyloid protein. Biochemical and Biophysical Research Communications, v. 120, p. 885-890, 1984.

93. MASTERS, C.L. et al. Amyloid plaque core protein in Alzheimer disease and Down syndrome. Proceedings of the National Academy of Sciences USA, v. 82, p. 4245-4249, 1985.

94. KATZMAN, R.; SAITOH, T. Advances in Alzheimer's disease. FASEB Journal, v. 4, p. 278-286,1991.

95. YANKNER, B.A. et al. Neurotoxicity of a fragment of the amyloid precursor associated with Alzheimer's disease. Science, v. 245, p. 417420, 1989.

96. FRAUTSCHY, S.A.; BAIRD, A.; COLE, G.M. Effects of injected Alzheimer $\boldsymbol{\beta}$-amyloid cores in rat brain. Proceedings of the National Academy of Sciences USA, v. 88, p. 8362-8366, 1991.

97. KOWALL, N.W. et al. An in vivo model for the neurodegenerative effects of $\boldsymbol{\beta}$ amyloid and protection by substance. Proceedings of the National Academy of Sciences USA, v. 88, p. 7247-7251, 1991.

98. PIKE, C.J. et al. In vitro aging of b-amyloid protein causes peptide aggregation and neruotoxicity. Brain Research, v. 563, p. 311-314, 1991.

99. HOWLETT, D.R. et al. Aggregation state and neurotoxic properties of Alzheimer $\boldsymbol{\beta}$-amyloid peptide. Neurodegeneration, v. 4, p. 23-32, 1995.

100.HARRIS, M.E. et al. Direct evidence of oxidative injury by the Alzheimer's amyloid $\beta$ peptide in cultured hippocampal neurons. Experimental Neurology, v. 131, p. 193-202, 1995a.

101.AKSENOV, M.Y. et al. Enhancement of $\mathbf{A} \boldsymbol{\beta}(\mathbf{1 - 4 0 )}$ neurotoxicity by glutamine synthetase. Journal of Neurochemistry, v. 65, p. 1899-1902, 1995. 
102.AKSENOV, M.Y. et al. Glutamine synthetase-induced enhancement of $\boldsymbol{\beta}$ amyloid peptide $A \beta(1-40)$ neurotoxicity accompanied by abrogation of fibril formation and $\mathbf{A} \boldsymbol{\beta}$ fragmentation. Journal of Neurochemistry, v. 66, p. 2050-2056, 1996.

103.MARKESBERY, W. R. Oxidative stress hypothesis in Alzheimer disease. Free Radical Biology and Medicine, v. 23, p. 134-147, 1997.

104.MARKESBERY, W.R.; CARNEY, J.M. Oxidative alterations in Alzheimer's disease. Brain Pathology, v. 9, p. 133-146, 1999.

105.BUTTERFIELD, D.A. Alzheimer's disease: A disorder of oxidative stress. Alzheimer's Disease Review, v.1, p. 68-70, 1996.

106.BUTTERFIELD, D.A. $\boldsymbol{\beta}$-amyloid-associated free radical oxidative stress and neurotoxicity: Implications for Alzheimer's disease. Chemical Research in Toxicology, v. 10, p. 495-506, 1997.

107.HENSLEY, K. et al. Brain regional correspondence between Alzheimer's disease histopathology and biomarkers of protein oxidation. Journal of Neurochemistry, v.65, p. 2146-2156, 1995a.

108.SMITH, C.D. et al. Excess brain protein oxidation and enzyme dysfunction in normal aging and Alzheimer disease. Proceedings of the National Academy of Sciences USA, v.88, p.10540-10543, 1991.

109.LYRAS, L. et al. An assessment of oxidative damage to proteins, lipids and DNA in brains from patients with Alzheimer's disease. Journal of Neurochemistry, v. 68, p. 2061-2069, 1997.

110.MECOCCI, P. et al. Oxidative damage to mitochondrial DNA shows marked age-dependent increases in human brain. Annals of Neurology,.v. 34, p. 609-616, 1993.

111.MECOCCI, P. et al. Oxidative damage to mitochondrial DNA is increased in Alzheimer's disease. Annals of Neurology,.v.36, p.747-751, 1994. 
112.GABBITA, S.P. et al. Increased nuclear DNA oxidation in the brain in Alzheimer's disease. Journal of Neurochemistry, v. 71, p. 2034-2040, 1998.

113.HIRAI, K. et al. Vulnerable neurons in Alzheimer disease accumulate mitochondrial DNA with the common $5 \mathrm{~KB}$ deletion. Journal of Neuropathology \& Experimental Neurology, v. 57, p. 511-532, 1998.

114.PETTIGREW, J.W. et al. 31P nuclear magnetic resonance study of the brain in Alzheimer's disease. Journal of Neuropathology \& Experimental Neurology, v. 47, p. 235-248, 1988.

115.NITSCH, R.M. et al. Evidence for a membrane defect in Alzheimer disease brain. Proceedings of the National Academy of Sciences USA,.v. 89, p. $1671-1675,1992$.

116.SVENNERHOLM, L.; GOTTFRIES, C.G. Membrane lipids, selectively diminished in Alzheimer brains, suggest synapse loss as a primary event in early-onset (type I) and demyelination in late-onset form (type II). Journal of Neurochemistry, v. 62, p. 1039-1047, 1994.

117.PRASAD, M.R. et al. Regional membrane phospholipid alterations in Alzheimer's disease. Neurochemical Research, v. 23, p. 81-88, 1998.

118.SUBBARAO, K.V.; RICHARDSON, J.S.; ANG, L.C. Autopsy samples of Alzheimer's cortex show increased peroxidation in vitro. Journal of Neurochemistry, v. 55, p. 342-345, 1990.

119.MARCUS, D. L. et al. Increased peroxidation and reduced antioxidant enzyme activity in Alzheimer's disease. Experimental Neurology, v. 150, p. 40-44, 1998.

120.MCINTOSH, L.J.; TRUSH, M.A.; TRONCOSO, J.C. Increased susceptibility of Alzheimer's disease temporal cortex to oxygen free radical-mediated processes. Free Radical Biology and Medicine, v. 23, p. 183-190, 1997. 
121.LOVELL, M. A. et al. Elevated thiobarbituric acid-reactive substances and antioxidant enzyme activity in the brain in Alzheimer's disease. Neurology, v. 45, p. 1594-1601, 1995.

122.LOVELL, M.A. et al. Elevated 4-hydroxynonenal in ventricular fluid in Alzheimer's disease. Neurobiology of Aging, v. 18, p. 457-461, 1997.

123.MARKESBERY, W.R.; LOVELL, M.A. 4-Hydroxynonenal, a product of lipid peroxidation, is increased in the brain in Alzheimer's disease. Neurobiology of Aging, v. 19, p. 33-36, 1998.

124.MONTINE, T.J. et al. Cerebrospinal fluid F2 isoprostane levels are increased in Alzheimer's disease. Annals of Neurology,.v. 44, p. 410-413, 1998.

125.ROBERTS, L.J. et al. Formation of isoprostane-like compounds (neuroprostanes) in vivo from docosahexaenoic acid. Journal of Biological Chemistry, v. 22, p. 13605-13612, 1998.

126.BUTTERFIELD, D.A. et al. Amyloid $\beta$-peptide-associated free radical oxidative stress, neurotoxicity and Alzheimer's disease. Methods in Enzymology, v. 309, p. 746-768, 1999a.

127.BUTTERFIELD, D.A. et al. On methionine and Alzheimer's amyloid $\boldsymbol{\beta}$ peptide(1-42) induced oxidative stress. Neurobiology of Aging, v. 20, p. 339-342, 1999b.

128.BEHL, C. Alzheimer's disease and oxidative stress: Implications for novel therapeutic approaches. Progress in Neurobiology, v. 57, p. 301-323, 1999.

129.RETZ, W. et al. Free radicals in Alzheimer's disease. Journal of Neural Transmission-supplement. v. 54, p. 221-236, 1998.

130.BUTTERFIELD, D.A. et al. $\boldsymbol{\beta}$-Amyloid peptide free radical fragments initiate synaptosomal lipoperoxidation in a sequence-specific fashion: Implications to Alzheimer's disease. Biochemical and Biophysical Research Communications, v. 200, p. 710-715, 1994. 
131.BUTTERFIELD, D.A. $\boldsymbol{\beta}$-amyloid-associated free radical oxidative stress and neurotoxicity: Implications for Alzheimer's disease. Chemical Research in Toxicology, v. 10, p. 495-506, 1997.

132.VARADARAJAN, S. et al. Review: Alzheimer's amyloid $\boldsymbol{\beta}$-peptideassociated free radical oxidative stress and neurotoxicity. Journal of Structural Biology, v. 130, p. 184-208, 2000.

133.SELKOE, D.J. The molecular pathology of Alzheimer's disease. Neuron, v. 6, p. $487-498,1991$.

134.SELKOE, D.J. Alzheimer's disease: A central role of amyloid. Journal of Neuropathology \& Experimental Neurology, v. 53, p. 438-447, 1994.

135.CORAIN, B. et al. Alzheimer's Disease: Advances in Clinical and Basic Research. Wiley, New York, 1993.

136.BUTTERFIELD, D.A. et al. Vitamin $\mathbf{E}$ as an antioxidant/free radical scavenger against amyloid $\beta$-peptide-induced oxidative stress in neocortical synaptosomal membranes and hippocampal neurons in culture: Insights into Alzheimer's disease. Review of Neuroscience, v. 10, p. 141-149, 1999c.

137.SMITH, C.D. et al. Excess brain protein oxidation and enzyme dysfunction in normal aging and in Alzheimer disease. Proceedings of the National Academy of Sciences USA, v. 88, n. 23, p. 10540-10543, 1991.

138.CARNEY, J.M. et al. Reversal of agerelated increase in brain protein oxidation, decrease in enzyme activity, and loss in temporal and spatial memory by chronic administration of the spin-trapping compound $\mathrm{N}$ tert-butyl-a-phenylnitrone. Proceedings of the National Academy of Sciences USA, v. 9, p. 3633-3636, 1991.

139.LANSBURY, P.T. et al. Structural model for the beta-amyloid fibril based on interstrand alignment of an antiparallel-sheet comprising a Cterminal peptide. Nature structural biology, v. 2, n. 11, p. 990-998, 1995. 
140.DONG, J. et al. Metal binding and oxidation of amyloid- $\beta$ within isolated senile plaque cores: Raman microscopic evidence. Biochemistry, v. 42, n. 10, p. 2768-2773, 2003.

141.BEAUCHEMIN, D.; KISILEVSKY, R. A method based on ICP-MS for the analysis of Alzheimer's amyloid plaques. Analytical Chemistry, v. 70, n. 5, p. 1026-1029, 1998.

142.MORGAN, D.M. et al. Metal switch for amyloid formation: insight into the structure of the nucleus. Journal of the American Chemical Society, v. 124, n. 43, 12644-12655, 2002.

143.HUANG, X. et al. The A $\boldsymbol{\beta}$ peptide of alzheimer's disease directly produces hydrogen peroxide through mtal ion reduction. Biochemistry, v. $38, \mathrm{n}$. 24 , p. 7609-7616, 1999.

144.DERAEVE, C.; PITIE, M.; MEUNIER, B. Influence of chelators and iron ions on the production and degradation of $\mathrm{H}_{2} \mathrm{O}_{2}$ by beta-amyloid-copper complexes. Journal of Inorganic Biochemistry, v. 100, n. 12, p. 2117-2126, 2006.

145.DONG, J. et al. Engineering metal ion coordination to regulate amyloid fibril assembly and toxicity. Proceedings of the National Academy of Sciences. v. 104, p. 13313-13318, 2007.

146.DONG, J. Probing the role of PrP repeats in conformational conversion and amyloid assembly of chimeric yeast prions. Journal of Biological Chemistry, v. 282, p. 34204-34212, 2007.

147.CURTAIN, C.C. et al. Alzheimer's disease amyloid-beta binds copper and zinc to generate an allosterically ordered membrane-penetrating structure containing superoxide dismutase-like subunits. Journal of Biological Chemistry, v. 276, p. 20466-20473, 2001.

148.COSSI, M. et al. Energies, structures, and electronic properties of molecules in solution with the C-PCM solvation model. v. 24, p. 669-681, 2003. 
149.SCHÄFER, A. et al. COSMO implementation in TURBOMOLE: Extension of an efficient quantum chemical code towards liquid systems. Physical Chemistry Chemical Physics, v. 2, n. 10, p. 2187-2193, 2000.

150.BEN-NAIM. A. Standard thermodynamics of transfer: Uses and misuses. Journal of Physics and Chemistry, v. 82, p. 792-803, 1978.

151.KIM, M.K.; MARTELL, A.E. Copper(I1) complexes of glycylglycine. Biochemistry, v. 3, n. 8, 1964.

152.ARNIM, M.V.; AHLRICHS, R. Performance of parallel turbomole for density functional calculations. Journal of Computational Chemistry, v. 19, n. 15 , p. $1746-1757,1988$.

153.AHLRICHS, R. et al. Electronic structure calculations on workstation computers: the program system TURBOMOLE. Chemical Physics Letters, v. 162, n. 3, p. 165-169, 1989.

154.PERDEW, J.P.; BURKE, K.; ERNZERHOF, M. Generalized gradient approximation made simple. Physical Review Letters, v. 77, n. 18, p. 38653868, 1996.

155.ADAMO, C.; BARONE, V. Toward reliable density functional methods without adjustable parameters: The PBE0 model. Journal of Chemical Physics, v. 110, n. 13, p. 6158-6170, 1999.

156.EICHKORN, K. et al. Auxiliary basis sets to approximate coulomb potentials (Chem. Phys. Letters 240 (1995) 283). Chemical Physics Letters, v. 242 , p. $652-660,1995$.

157.SCHÄFER, A.; HUBER, C.; AHLRICHS, R. Fully optimized contracted gaussian basis sets of triple zeta valence quality for atoms $\mathrm{Li}$ to $\mathrm{Kr}$. Journal of Chemical Physics, v. 100, p. 5829-5835, 1994.

158.WEIGEND, F.; AHLRICHS, R. Balanced basis sets of split valence, triple zeta valence and quadruple zeta valence quality for $H$ to $R n$ : Design and 
assessment of accuracy. Physical Chemistry Chemical Physics, v. 7, p. 3297-3305, 2005.

159.PLIEGO, J.R.; RIVEROS, J.M. Theoretical calculation of pKa using the cluster-continuum model. Journal of Physical Chemistry, v. 106, p. 74347439, 2002.

160.PLIEGO, J.R.; RIVEROS, J.M. The cluster-continuum model for the calculation of the solvation free energy of ionic species. v. 105, p. 7241$7247,2005$.

161.KITTL, W.S.; RODE, B.M. ESR Determination of formation constants of copper dipeptide complexes. Journal of the Chemical Society, Dalton Transactions, . p. 409-414, 1983.

162.STOLL, S.; SCHWEIGER, A. EasySpin, a comprehensive software package for spectral simulation and analysis in EPR. Journal of Magnetic Resonance, v. 178, n. 1, p. 42-55, 2006.

163.SHOUKRY, M.M.; KHAIRY, E.M.; EL-SHERIF, A.A. Ternary complexes involving copper(II) and amino acids, peptides and DNA constituents. The kinetics of hydrolysis of $\alpha$-amino acid esters. Transition Metal Chemistry, v. 27, n. 6, p. 656-664, 2002.

164.SÓVÁGÓ, I. et al. EPR and potentiometric reinvestigation of copper(II) complexation with simple oligopeptides and related compounds. Journal of Inorganic Biochemistry, v. 63, n. 2, p. 99-117, 1996.

165.FERRAZ, K.O. et al. Copper(II) complexes with 2-pyridineformamidederived thiosemicarbazones: Spectral studies and toxicity against Artemia salina. Spectrochimica Acta Part A, v. 73, n. 1, p. 140-145, 2009.

166.MOTEKAITIS, R.J.; MARTELL, A.E. BEST-a new program for rigorous calculation of equilibrium parameters of complex multicomponent systems. Canadian Journal of Chemistry, v. 60, n. 19, p. 2403-2409, 1982. 
167.LUIZ, M.T.B. et al. Equilibrium studies and molecular recognition in the glycylglycine, dl-alanyl-dl-alanine and glycyl-l-leucine $\mathrm{Cu}$ (II)1,4,7,13,16,19-hexaaza-10,22-dioxacyclotetracosane complexes. Inorganica Chimica, v. 254, p. 345-351, 1997.

168.GOSWAMI, T.K. et al. Photoinduced DNA and protein cleavage activity of ferrocene-appended L-methionine reduced schiff base copper(II) complexes of phenanthroline bases. Organometallic, v. 28, p. 1992-1994, 2009. 
ANEXOS 
Tabela 33. Dados das curvas de titulação potenciométrica dos sistemas binários Cu:GlyGly e Cu:Met e do sistema ternário Cu:GlyGly:Met

\begin{tabular}{|c|c|c|c|}
\hline $\begin{array}{l}\text { Volume } \\
(\mathrm{mL})\end{array}$ & $\begin{array}{c}\text { pH } \\
\text { Cu:GlyGly }\end{array}$ & $\begin{array}{c}\text { pH } \\
\text { Cu:Met }\end{array}$ & $\begin{array}{c}\text { pH } \\
\text { Cu:GlyGlyMet }\end{array}$ \\
\hline 0 & 4,205 & 3,798 & 3,983 \\
\hline 0,1 & 4,324 & 3,92 & 4,047 \\
\hline 0,2 & 4,435 & 4,074 & 4,146 \\
\hline 0,3 & 4,534 & 4,232 & 4,252 \\
\hline 0,4 & 4,623 & 4,406 & 4,36 \\
\hline 0,5 & 4,702 & 4,587 & 4,466 \\
\hline 0,6 & 4,778 & 4,785 & 4,571 \\
\hline 0,7 & 4,849 & 5,007 & 4,671 \\
\hline 0,8 & 4,92 & 5,288 & 4,766 \\
\hline 0,9 & 4,994 & 5,613 & 4,857 \\
\hline 1 & 5,069 & 5,996 & 4,951 \\
\hline 1,1 & 5,145 & 6,302 & 5,043 \\
\hline 1,2 & 5,226 & 6,485 & 5,141 \\
\hline 1,3 & 5,315 & 6,611 & 5,243 \\
\hline 1,4 & 5,414 & 6,736 & 5,353 \\
\hline 1,5 & 5,525 & 6,891 & 5,478 \\
\hline 1,6 & 5,659 & 7,093 & 5,621 \\
\hline 1,7 & 5,835 & 7,373 & 5,786 \\
\hline 1,8 & 6,069 & 7,848 & 5,997 \\
\hline 1,9 & 6,491 & 8,918 & 6,269 \\
\hline 2 & 7,567 & 9,672 & 6,681 \\
\hline 2,1 & 8,519 & 10,001 & 7,226 \\
\hline 2,2 & 8,875 & 10,211 & 7,674 \\
\hline 2,3 & 9,118 & 10,363 & 8,001 \\
\hline 2,4 & 9,32 & 10,481 & 8,273 \\
\hline 2,5 & 9,494 & 10,575 & 8,522 \\
\hline 2,6 & 9,656 & 10,654 & 8,746 \\
\hline 2,7 & 9,809 & 10,721 & 8,949 \\
\hline 2,8 & 9,953 & 10,78 & 9,135 \\
\hline 2,9 & 10,089 & 10,833 & 9,3 \\
\hline 3 & 10,221 & 10,879 & 9,451 \\
\hline
\end{tabular}


Tabela 34. Dados termodinâmicos para todas as espécies discutidas no texto

\begin{tabular}{|c|c|c|c|c|}
\hline & $\begin{array}{c}\text { Energia fase } \\
\text { gasosa } \\
\text { (Hartree) } \\
\text { B3LYP/def2- } \\
\text { TZVP }\end{array}$ & $\begin{array}{c}\text { Energia fase } \\
\text { aquosa } \\
\text { (Hartree) } \\
\text { B3LYP/def2- } \\
\text { TZVP }\end{array}$ & $\begin{array}{c}\text { Energia fase } \\
\text { gasosa } \\
\text { (Hartree) } \\
\text { PBE0/def2- } \\
\text { TZVP }\end{array}$ & $\begin{array}{c}\text { Energia fase } \\
\text { gasosa } \\
\text { (Hartree) } \\
\text { PBE0/def2- } \\
\text { TZVP }\end{array}$ \\
\hline $\mathrm{H}_{2} \mathrm{O}$ & $-76,42535257$ & $-76,43820426$ & $-76,37661703$ & $-76,37661703$ \\
\hline $\mathrm{H}_{3} \mathrm{O}^{+}$ & $-76,698711$ & $-76,843285$ & $-76,65310393$ & $-76,79759256$ \\
\hline $\mathrm{OH}^{-}$ & $-75,7739878$ & $-75,9319077$ & $-75,72130033$ & $-75,8795272$ \\
\hline$\left[\mathrm{Cu}(\mathrm{GlyGly})\left(\mathrm{H}_{2} \mathrm{O}\right)_{5}\right]^{+}$ & $-2514,249194$ & $-2514,379759$ & $-2513,553427$ & $-2513,684284$ \\
\hline$\left[\mathrm{Cu}\left(\mathrm{H}_{-1} \mathrm{GlyGly}\right)\left(\mathrm{H}_{2} \mathrm{O}\right)_{5}\right]$ & $-2513,875029$ & $-2513,92771$ & $-2513,177412$ & $-2513,230794$ \\
\hline$\left[\mathrm{Cu}\left(\mathrm{H}_{-1} \mathrm{GlyGly}\right)(\mathrm{OH})\left(\mathrm{H}_{2} \mathrm{O}\right)_{4}\right]^{-}$ & $-2513,348206$ & $-2513,463218$ & $-2512,648597$ & $-2512,763952$ \\
\hline$\left[\mathrm{Cu}(\mathrm{Met})\left(\mathrm{H}_{2} \mathrm{O}\right)_{4}\right]^{+}$ & $-2745,88378$ & $-2745,998444$ & $-2745,204714$ & $-2745,320248$ \\
\hline$\left[\mathrm{Cu}(\mathrm{Met})(\mathrm{OH})\left(\mathrm{H}_{2} \mathrm{O}\right)_{3}\right]$ & $-2745,500566$ & $-2745,544897$ & $-2744,820789$ & $-2744,865149$ \\
\hline$\left[\mathrm{Cu}(\mathrm{Met})\left(\mathrm{H}_{2} \mathrm{O}\right)_{2}(\mathrm{OH})_{2}\right]^{-}$ & $-2744,963878$ & $-2745,072388$ & $-2744,279908$ & $-2744,388715$ \\
\hline$\left[\mathrm{Cu}(\mathrm{HGlyGly})(\mathrm{Met})\left(\mathrm{H}_{2} \mathrm{O}\right)_{2}\right]$ & $-3085,042676$ & $-3085,096023$ & $-3084,172094$ & $-3084,225829$ \\
\hline$\left[\mathrm{Cu}(\mathrm{GlyGly})(\mathrm{Met})\left(\mathrm{H}_{2} \mathrm{O}\right)_{2}\right]^{-}$ & $-3084,52474$ & $-3084,63663$ & $-3083,652153$ & $-3083,764527$ \\
\hline$\left[\mathrm{Cu}(\mathrm{GlyGly})(\mathrm{Met})(\mathrm{OH})\left(\mathrm{H}_{2} \mathrm{O}\right)\right]^{-2}$ & $-3083,858757$ & $-3084,146204$ & $-3082,98242$ & $-3083,27081$ \\
\hline & & & & \\
\hline
\end{tabular}


Tabela 35. Dados termodinâmicos para todas as espécies discutidas no texto

\begin{tabular}{|c|c|c|c|c|}
\hline & $\begin{array}{c}\mathrm{ZPE} \\
\left(\mathrm{KJ} \mathrm{mol}^{-1}\right)\end{array}$ & $\begin{array}{c}\mathrm{H}^{*} \\
\left(\mathrm{Kcal} \mathrm{mol}^{-1}\right)\end{array}$ & $\begin{array}{c}\mathrm{G}^{*} \\
\left(\mathrm{Kcal} \mathrm{mol}^{-1}\right)\end{array}$ & $\begin{array}{c}\mathrm{S}^{*} \\
\left(\mathrm{cal} \mathrm{mol}^{-1} \mathrm{~K}^{-1}\right)\end{array}$ \\
\hline $\mathrm{H}_{2} \mathrm{O}$ & 53,69 & $-47912,43992$ & $-47923,86297$ & 38,31311798 \\
\hline $\mathrm{H}_{3} \mathrm{O}^{+}$ & 90,82 & $-48077,05184$ & $-48088,99115$ & 40,04463707 \\
\hline $\mathrm{OH}^{-}$ & 20,91 & $-47509,35583$ & $-47519,18471$ & 32,96625118 \\
\hline$\left[\mathrm{Cu}(\mathrm{GlyGly})\left(\mathrm{H}_{2} \mathrm{O}\right)_{5}\right]^{+}$ & 647,6 & $-1577715,698$ & $-1577588,955$ & $-425,0981431$ \\
\hline$\left[\mathrm{Cu}\left(\mathrm{H}_{-1} \mathrm{GlyGly}\right)\left(\mathrm{H}_{2} \mathrm{O}\right)_{5}\right]$ & 617,5 & $-1577320,386$ & $-1577360,237$ & 133,6588958 \\
\hline$\left[\mathrm{Cu}\left(\mathrm{H}_{-1} \mathrm{GlyGly}\right)(\mathrm{OH})\left(\mathrm{H}_{2} \mathrm{O}\right)_{4}\right]^{-}$ & 585,2 & $-1576997,541$ & $-1577037,425$ & 133,7711238 \\
\hline$\left[\mathrm{Cu}(\mathrm{Met})\left(\mathrm{H}_{2} \mathrm{O}\right)_{4}\right]^{+}$ & 655,5 & $-1722897,615$ & $-1722941,084$ & 145,7955619 \\
\hline$\left[\mathrm{Cu}(\mathrm{Met})(\mathrm{OH})\left(\mathrm{H}_{2} \mathrm{O}\right)_{3}\right]$ & 626,5 & $-1722665,457$ & $-1722705,511$ & 134,3402806 \\
\hline$\left[\mathrm{Cu}(\mathrm{Met})\left(\mathrm{H}_{2} \mathrm{O}\right)_{2}(\mathrm{OH})_{2}\right]^{-}$ & 593,3 & $-1722336,633$ & $-1722377,477$ & 136,9936732 \\
\hline$\left[\mathrm{Cu}(\mathrm{HGlyGly})(\mathrm{Met})\left(\mathrm{H}_{2} \mathrm{O}\right)_{2}\right]$ & 852,2 & $-1935127,726$ & $-1935175,349$ & 159,7278775 \\
\hline$\left[\mathrm{Cu}(\mathrm{GlyGly})(\mathrm{Met})\left(\mathrm{H}_{2} \mathrm{O}\right)_{2}\right]^{-}$ & 815,2 & $-1934809,904$ & $-1934859,198$ & 165,3312657 \\
\hline $\left.\mathrm{Cu}(\mathrm{GlyGly})(\mathrm{Met})(\mathrm{OH})\left(\mathrm{H}_{2} \mathrm{O}\right)\right]^{2-}$ & 782 & $-1934397,89$ & $-1934446,56$ & 163,263062 \\
\hline
\end{tabular}

